\title{
Online Dispute Resolution for Consumers in the European Union
}

\section{Pablo Cortés}

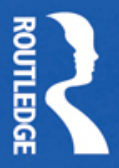

Routledge Research in IT and E-Commerce Law 


\section{Online Dispute Resolution for Consumers in the European Union}

E-commerce offers immense challenges to traditional dispute resolution methods, as it entails parties often located in different parts of the world making contracts with each other at the click of a mouse. The use of traditional litigation for disputes arising in this forum is often inconvenient, impractical, timeconsuming and expensive owing to the low value of the transactions and the physical distance between the parties. Thus modern legal systems face a crucial choice: either to adopt traditional dispute resolution methods that have served the legal systems well for hundreds of years or to find new methods which are better suited to a world not anchored in territorial borders.

Online Dispute Resolution (ODR), originally an off-shoot of Alternative Dispute Resolution (ADR), takes advantage of the speed and convenience of the internet, becoming the best, and often the only option for enhancing consumers' redress and strengthening their trust in e-commerce. This book provides an in-depth account of the potential of ODR for European consumers, offering a comprehensive and up to date analysis of the development of ODR. It considers the current expansion of ODR and evaluates the challenges posed in its growth. The book proposes the creation of legal standards to close the gap between the potential of ODR services and their actual use, arguing that ODR, if it is to realise its full potential in the resolution of e-commerce disputes and in the enforcement of consumer rights, must be grounded firmly on a European regulatory model.

Pablo Cortés is the CSET Lecturer in Civil Justice at the School of Law, University of Leicester, UK. 


\section{Routledge Research in IT and E-Commerce Law}

Titles in the series:

Law of Electronic Commercial Transactions

Contemporary issues in the EU, US and China

Faye Fangfei Wang

The Current State of Domain Name Regulation

Domain names as second class citizens in a mark-dominated world

Konstantinos Komaitis 


\title{
Online Dispute Resolution for Consumers in the European Union
}

\author{
Pablo Cortés
}


First published 2011

by Routledge

2 Park Square, Milton Park, Abingdon, Oxon, OX14 4RN

Simultaneously published in the USA and Canada

by Routledge

270 Madison Avenue, New York, NY 10016

Routledge is an imprint of the Taylor E Francis Group, an informa business

This edition published in the Taylor \& Francis e-Library, 2010.

To purchase your own copy of this or any of Taylor \& Francis or Routledge's collection of thousands of eBooks please go to www.eBookstore.tandf.co.uk.

\section{(C) 2011 Pablo Cortés}

The right of Pablo Cortés to be identified as author of this work has been asserted by him in accordance with sections 77 and 78 of the Copyright, Designs and Patents Act 1988.

All rights reserved. No part of this book may be reprinted or reproduced or utilised in any form or by any electronic, mechanical, or other means, now known or hereafter invented, including photocopying and recording, or in any information storage or retrieval system, without permission in writing from the publishers.

British Library Cataloguing in Publication Data

A catalogue record for this book is available from the British Library

Library of Congress Cataloging-in-Publication Data

Cortés, Pablo.

Online dispute resolution for consumers in the European Union /

Pablo Cortés.

p. $\mathrm{cm}$.

Includes bibliographical references.

1. Arbitration and award-European Union countries-Data processing. 2. Dispute resolution (Law)_European Union countries-Data processing. 3. Electronic commerce-Law and legislation-European Union countries-Data processing.

I. Title.

KJE4169.C67 2010

347.24'09-dc22

2010001340

ISBN 0-203-84775-X Master e-book ISBN

ISBN 10: 0-415-56207-4 (hbk)

ISBN 10: 0-203-84775-X (ebk)

ISBN 13: 978-0-415-56207-2 (hbk)

ISBN 13: 978-0-203-84775-6 (ebk) 
To Anne-Marie 



\section{Contents}

Table of cases $\quad$ xi

List of ODR providers $\quad \mathrm{xv}$

Acknowledgements xvii

Foreword xix

Introduction 1

Background 1

Electronic commerce in the European Union 1

The need for online dispute resolution (ODR) 2

Setting the tone 3

Summary of contents 4

Methodology 5

Location and contribution of the book in the existing academic debate 6

Notes

1 Consumer protection and access to justice in the era of electronic commerce: A European perspective 9

1.1 Introduction 9

1.2 Consumer protection policy in the online market 10

1.2.1 The legal definition of consumer 10

$\begin{array}{ll}1.2 .2 \text { Consumer protection } & 11\end{array}$

1.2.3 Consumer protection in the field of e-commerce 12

$\begin{array}{ll}1.3 \text { Consumer access to justice: Small claims procedures } & 17\end{array}$

$\begin{array}{lll}1.3 .1 & \text { Introduction } & 17\end{array}$

1.3.2 Small claims procedure in Ireland 18

1.3.3 Small claims in England and Wales 20

1.3.4 Small claims court in Spain $\quad 22$

1.3.5 Assessment 22 
1.4 Conflict of laws

1.4.1 Introduction 24

1.4.2 Choice of law 25

$\begin{array}{lll}1.4 .3 & \text { Forum selection } & 28\end{array}$

1.4.4 Assessment 33

1.5 Enforcement 35

1.5.1 Introduction 35

1.5.2 Judicial enforcement in the EU 35

1.5.3 Administrative enforcement 40

1.5.4 Assessment 42

1.6 Conclusion 43

Notes 44

2 Online dispute resolution: An emerging option for consumer redress 51

2.1 Introduction 51

2.2 Definition and growth of ODR 52

2.2.1 Defining ODR 52

2.2.2 A brief history of ODR $\quad 54$

2.2.3 Advantages and difficulties in using ODR 56

2.2.4 Dispute avoidance 59

2.2.5 Dispute resolution 64

2.2.6 European initiatives promoting the use of

$\begin{array}{ll}2.3 \text { ODR challenges } & 75\end{array}$

2.3.1 Challenges to ODR $\quad 75$

2.3.2 Funding $\quad 75$

$\begin{array}{ll}\text { 2.3.3 Directing disputants to ODR services } & 77\end{array}$

2.3.4 Fairness and due process $\quad 79$

$\begin{array}{lll}2.3 .5 & \text { Enforcement } & 82\end{array}$

2.3.6 The role of technology $\quad 83$

2.4 Conclusion 85

$\begin{array}{ll}\text { Notes } & 87\end{array}$

3 Consumer adjudicative processes supported by technology:

Court processes and arbitration $\quad 94$

3.1 Introduction 94

3.2 Online judicial processes 95

3.2.1 Domestic disputes: The incorporation of technology into the judicial process 
3.2.2 Cross-border disputes: European small claims procedure

3.3 Online arbitration $\quad 106$

3.3.1 Introduction 106

3.3.2 Obstacles to the online arbitral process 107

3.3.3 Domestic arbitral procedures: The Spanish

Consumer Arbitration Boards

3.3.4 The UDRP: An international adjudicative process similar to arbitration 114

3.4 Conclusion

Notes

4 Online mediation for consumers: The way forward 144

4.1 Introduction 144

4.2 From offline mediation to online mediation 145

4.2.1 The difference between online and offline mediation 145

4.2.2 Types of mediation $\quad 146$

4.2.3 Two ODR examples: SmartSettle and SquareTrade

4.2.4 Benefits and limitations in using online mediation

4.2.5 Appropriate cases for online mediation 151

4.2.6 Building trust in online mediation 152

4.2.7 Dynamics of computer mediated communications

4.3 Self-regulation and soft law: Procedural aspects of mediation

4.3.1 Flexibility, legal certainty, confidentiality and transparency

4.3.2 Independence, fairness and protection of the weaker party

$\begin{array}{ll}\text { 4.3.3 The mediator's status } & 157\end{array}$

4.3.4 Accountability 158

4.4 Regulatory approach in the EU: The Mediation

Directive

4.4.1 The purpose of regulating mediation in the EU

4.4.2 Mandatory mediation 161

4.4.3 Enforcement of settlements 163

4.4.4 Suspension of limitation periods 164 
4.5 Regulatory approach at the domestic level, particularly in England and Wales

4.5.1 Mediation under national law

4.5.2 The approach to mandatory mediation in England and Wales

4.5.3 The way forward

4.6 Conclusion

Notes

5 A legal framework to develop consumer ODR in the EU:

A proposal

5.1 Introduction

5.2 The need for a regulatory balance in the field of ODR

5.2.1 Increasing access to justice through ODR

5.2.2 Failed expectations in ODR

5.2.3 Creating a balance between regulation and self-regulation

5.2.4 Risks of self-regulation

5.2.5 The objective of regulating ODR

5.2.6 International initiatives

5.2.7 Regional regulatory initiatives

5.3 Proposal for a regulation in the field of ODR

5.3.1 The purpose of regulating ODR at the EU level

5.3.2 The need to increase awareness of ODR

5.3.3 Mandatory ODR clauses

5.3.4 Procedural legal standards for accredited ODR 200

5.3.5 Enforcement of ODR decisions 204

5.4 Conclusion 206

$\begin{array}{ll}\text { Notes } & 207\end{array}$

Conclusion 213

Summary 213

Findings $\quad 214$

Tiered ODR systems $\quad 221$

Future dynamics and recommendations for ODR 222

Notes 223 


\section{Table of cases}

\section{European Union}

Alassini and Others $v$ Telecom Italia C-317/08, 18 March 2010

179,180

Di Pinto, C-361/89, 14 March 1991

Case Francesco Benincasa/Dentalkit, C-269/95, 3 July 1995

Océano Grupo Editorial SA and Salvat Editores SA C-240/98,

27 June 2000

Deweer v Belgium (1980) 2 EHRR 439

\section{United Kingdom}

Aird and Aird v Prime Meridian Ltd [2006]

EWCA (Civ) 1866

Bowman v Fels [2005] EWCA (Civ) 226

176

Burchell v Bullard [2005] EWCA (Civ) 358

Cable \& Wireless v IBM United Kingdom Ltd [2002] EWHC

(Comm Ct) 2059.

166,178

Campbell v MGN Ltd [2005] UKHL 61; [2002] EWCA (Civ) 1373 49, 167

Dunnett v Railtrack plc [2002] 2 ALL ER 850

Egan v Motor Services (Bath) [2007] EWCA (Civ) 1002

Flowers Inc v Phonenames Ltd [2001] EWCA (Civ) 721

Halsey $v$ Milton Keynes General NHS Trust [2004]
EWCA (Civ) 576
$8,137,156,167,176,177,178,210$

Hickman v Blake Lapthorn [2006] EWHC (QB) 12

169,179

Hurst v Leeming [2001] EWHC (Ch) 1051; [2003] 1 Lloyds Rep $379 \quad 178$

Max Mosley v News Group Newspaper Limited [2008]

EWHC (QB) 1777

Multiplex Constructions (UK) Ltd $v$ Cleveland Bridge UK Ltd

and another (No 7) [2008] EWHC 2280

Palfrey $v$ Wilson [2007] EWCA (Civ) 94

P4 Ltd v Unite Integrated Solutions plc [2006] EWHC (TCC) 2924

$R$ (Cowel) v Plymouth City Council [2001] EWCA (Civ) 1935, [2002] 1 WLR 803 
xii Table of cases

Rowallan Group Ltd v Edgebill Portfolio No. 1 [2007] EWCA (Ch) 32

\section{France}

French Union of Jewish Students v Yahoo! Inc. Tribunal de Grande

Instance de Paris. Interim Court Order (20 November 2000)

Sté V 2000 and Sté XJ 220 Ltd c M. Meglio and M. Renault Cass Civ Ire

(21 May 1997).

Union Fédérale des Consommateurs-Que Choisir (UFC) v AOL R. F. N.

02/03156 Tribunal de Grande Instance, Nanterre

(2 June 2004)

\section{Australia}

De Rose v State of South Australia [2003] FCAFC 286

97,136

\section{United States}

Advanced Bodycare Solutions, LLC v Thione International,

Inc., No. 07-12309 (11th Cir. 21 April 2008)

Allied-Bruce Terminix Cos. v Dobson (1995) 513 U.S. 265

Brower $v$ Gateaway 2000 Inc 676 N.Y.S. 2d 569, 572 (1998)

$138,165,178$

109,138

Calder v Jones 465 U.S. 783, 788 (1984)

110,138

Carnival Cruise Lines, Inc. v Shute, 499 U.S. 585 (1991)

Caspi v Microsoft Network, L.L.C. 732 A.2d 528 (N.J. 1999)

30,48 30

Comb and Toher $v$ Paypal, Inc (US District Court, ND Cal, San José Div 2002)

Dale v Comcast Corp. 998 F3rd (11th Circuit 2007).

Decker v Circus Hotel 49 F. Supp. 2d 743 (D.N.J. 1999)

Euromarket Designs, Inc v Crate \& Barrel Ltde 96 F Supp 2d

824 (NDIll 2000)

110,138

138

48

French Union of Jewish Students $v$ Yahoo! Inc 379 F.3rd (2000)

Green Tree Financial Corp. v Bazzle, 123 S. Ct. 2402 (2003)

Green Tree Fin. Corp.-Ala. v Randolph 513 U.S. 79 (2000)

Helicopteros Nacionales de Colombia, S.A. v Hall 466

U.S. 408 (1984)

Hill $v$ Gateaway 2000, Inc., 105 F.3d 1147 (7th Cir. 1977)

Hy Cite Corp. v Badbusinessbureau.com, 297 F. Supp. 2d 1154,

1160 (W.D. Wis. 2004)

International Shoe Co. $v$ Washington, 326 U.S. 310 (1945)

Parisi v NetLearning, Inc., 139 F. Supp. 2d 745 (2001)

Perkins v Benguet Consolidated Mining Co. 342 U.S. 437 (1952)

Ross v Bank of America F.3d. 2008 WL 1836640 (Cir.2d. N.Y.) 
Yahoo!, Inc. v La Ligue Contre Le Racisme Et L'Antisemitisme

169 F.Supp. 2d 1181 (N.D. Cal. 2001)

World-Wide Volkswagen Corp. v Woodson, 444 U.S. 286, 291 (1980)

Zippo Manufacturing Company v Zippo Dot Com. Inc., 952

F.Supp. 1119 (W.D. Penn. 1997)

\section{Ireland}

Harrison v Ennis 1967 IR 286

Superwood Holdings plc. v Alliance (unreported, SC 12 April 2002)

\section{ODR Service Providers}

Amazon.com, Inc. v Steven Newman alkla Jill Wasserstein alkla Pluto

Newman, WIPO/D2006-0517

America Online, Inc. v Johuathan Investments, Inc., and Aollnews.com

WIPO/D2001-0918

Arthur Guinness Son E Co. (Dublin) Limited v Dejan Macesic

WIPO/D2000-1698

ATET Corp. v Amjad Kausar WIPO/D2003-0327

Bloomberg L.P. v Secaucus Group, NAF/FA97077

Bridgestone Firestone, Inc., Bridgestone/Firestone Research, Inc., and

Bridgestone Corporation v Jack Myers WIPO/D2000-0190

CBS Broadcasting, Inc. v Gaddoor Saidi WIPO/D2000-0243

Chivas USA Enterprises, LLC, et al v Cesar Carbajal WIPO/D20060551

Consorzio del Prosciutto de Parma v Mattew Gasse, Hanslmeier

Fleischwarenfabrik WIPO/D2003-0474

Control Techniques Limited v Lektronix Ltd WIPO/D2006-1052

141

Daniel J. Quirk v Michael J. Maccini NAF/FA94964

David Gilmour, David Gilmour Music Limited and David Gilmour Music

Overseas Limited v Ermanno Cenicolla WIPO/D2000-1459

Dr. Michael Crichton v In Stealth Mode WIPO/D2002-0874

Dreamgirls.com v Dreamgirls Entertainment WIPO/D2006-0609

Excelentísimo Ayuntamiento de Barcelona v Barcelona.com Inc.

WIPO/D2000-0505

Gobierno de Asturias v Diego Miras Silva WIPO/D2007-1392

His Holiness Phakchok Rinpoche v Kim Joe WIPO/D2006-0328

Jazeera Space Channel TV station v AJ Publishing WIPO/D2005-0309 140

Jerome Stevens Pharmaceuticals, Inc. $v$ Watson Pharmaceuticals

WIPO/D2004-1029

John Ode dba ODE and ODE - Optimum Digital Enterprises $v$ Intership

Limited WIPO/D2001-0074 
xiv Table of cases

Justice for Children v R Neetso / Robert W. O'Steen WIPO D2004-0175 141

L'Oreal S.A. v Munbyunja WIPO/D2003-0585

Ladner $v$ Wetmore NAF/FA 305190

LifePlan $v$ Life Plan clo Relational Dynamics, Inc., NAF/ FA0005000094826

Lockheed Martin Corporation v Dan Parisi WIPO/D2000-1015

Mobile Communications Services, Inc. v WebReg RN WIPO/D2005-1304 142

National Dial a Word Resgistry Pty Ltd and others $v 13000$

Directory Pty Ltd WIPO/D 2008-0020

PC Mall, Inc. v Pygmy Computer Systems, Inc. WIPO/D2004-0437

Playboy Enterprises International, Inc. v Joao Melancia WIPO/D20061106

Proto Software, Inc. v Vertical Axis Inc/PROTO.COM WIPO/D20060905

Royal Bank of Scotland Group and NatWest Bank v Personal and Pedro Lopez WIPO/D2003-0166

Société Air France v Virtual Dates, Inc. WIPO/D2005-0168

Sormac BV v Domains by Proxy, Inc. and James McCrory, WIPO/D20071338

Telstra Corporation Limited v Nuclear Marshmallows WIPO/D2000-0003 142 The Royal Bank of Scotland Group v Personal and Pedro Lopez WIPO/

D2003-0166

Tom Cruise v Network Operations Center/Alberta Hot Rods WIPO/

D2006-0560

Wal-Mart Stores, Inc. and Mrs. Helen Walton v Bestinfo/David Webb 


\section{ODR providers}

\section{List of ODR providers}

All American Dispute Resolutions Online (AADROL) available at http://www.medi84u.com

American Arbitration Association (AAA) available at http://www.adr.org Asian Domain Name Dispute Resolution Centre available at http://www.adndrc.org Appellex Bargaining Solutions available at http://www.appellex.com Better Business Bureau Online available at http://www.bbbonline.org Camera Arbitrale di Milano available at http://www.camera-arbitrale.com Chartered Institute of Arbitrators available at http://www.arbitrators.org Centre for Effective Dispute Resolution available at http://www.cedr.co.uk Cibertribunal Peruano available at http://www.cibertribunalperuano.org Conflict Resolution.com available at http://www.conflictresolution.com Concilia Online available at http://www.conciliaonline.net Confianza Online available at http://www.confianzaonline.org CPR Institute for Dispute Resolution available at http://www.cpradr.org CyberSettle available at http://www.cybersettle.com

Czech Arbitration Court available at http://www.adreu.eurid.eu Dispute Manager available at http://www.disputemanager.com eBay Community Court available at http://www.ebaycourt.com Electronic Consumer Dispute Resolution available at http://www.ecodir.org Electronic Courthouse available at http://www.electroniccourthouse.com Freiwilligen Selbstkontrolle Multimedia available at http://www.fsm.de European Institute for Conflict Management available at http://www.eucon-institute.com

Fair Shake available at http://www.fairshakeodr.com Hong Kong International Arbitration Centre available at http://www.hkiac.org

iCourthouse available at http://www.icourthouse.com

International Chamber of Commerce available at http://www.iccwbo.org The Internet Ombudsman available at http://www.theinternetombudsman.com 
Der Internet Ombudsman available at http://www.ombudsmann.at JAMS available at http://www.jamsadr.com Juripax available at http://www.juripax.com Mediate.com available at http://www.mediate.com Mediation Arbitration Resolution Services available at http://www.resolvemydispute.com

Médiateur du Net available at http://www.foruminternet.org

Mediation Now available at http://www.mediationnow.com

The Mediation Room available at http://www.themediationroom.com

The National Arbitration Forum available at http://www.arb-forum.com

ODRWorld available at http://www.odrworld.com

PayPal/eBay Resolution Center available at http://www.paypal.com

Risolvi Online available at http://www.risolvionline.it

SettleToday available at http://www.settletoday.com

SmartSettle available at http://www.smartsettle.com

Telecommunications Industry Ombudsman available at http://www.tio.com.au

TRUSTe available at http://www.truste.org

Web Assured available at http://www.webassured.com

World Intellectual Property Organization available at http://www.arbiter.wipo.int/domains 


\section{Acknowledgements}

This book is based on the research that I undertook while writing a $\mathrm{PhD}$ thesis, which I successfully submitted to the Faculty of Law, University College Cork, in October 2008. Thanks are first due to the Irish Council for Humanities and Social Sciences, whose financial support was essential in the writing of the thesis.

Many thanks go to my doctoral supervisor Professor Steve Hedley, who has been instrumental in completion of the first version of this research. $\mathrm{He}$ wisely guided me from start to finish with the foresight of an experienced supervisor. I am also grateful to Professor John Mee, who gave me invaluable advice and helped to resolve all types of challenges.

In the past years I have discussed my ideas with judges, lawyers, academics and students. It is a long list of people and thus it would be difficult to name all to whom I am indebted. A special mention, however, must include Professor Dermot Walsh, to whom I am grateful for his kind assistance at the start of my research career. I would also like to thank Judge David O'Riordan as well as the Faculty of Law at University College Cork. A special word of thanks needs to be said to my fellows of the National Centre for Technology and Dispute Resolution, especially to Professor Ethan Katsh, Colin Rule and many other ODR experts such as Dr Thomas Schultz, Dr Julia Hörnle and Professor Arno Lodder from whom, as noted in this book, I have learned so much.

Many thanks go to my friends and colleagues, Dr Olufemi Amao and Dr Patrick McCarthy, whose understanding, advice and support were paramount in the completion of this book. I wish to thank John McNally for kindly reading a first draft of this book and spotting typos and inconsistencies. He ensured a more readable version of this book.

Without family and friends writing would be intolerable. For moral support I would like to thank my wonderful family: my loving mother, my inspiring late grandmother and my dear brothers and sisters whose love I treasure. I have been particularly fortunate to benefit from the guidance of my sister Myriam and her husband Norberto; without their initial support it would not have been possible for me to pursue a research career.

Finally, I owe my greatest debt of thanks to my fiancée, Anne-Marie 
xviii Acknowledgements

Murphy. I could not have concluded this book without her continued love, support and generous help.

Leicester, May 2010

Pablo Cortés

School of Law

University of Leicester 


\section{Foreword}

It was during the April 2007 UN forum on Online Dispute Resolution (ODR) hosted by Graham Ross in Liverpool that I met Pablo Cortés for the first time. He was telling with great enthusiasm about the research he was conducting on norms for ODR. He clearly believed in the benefits of ODR, and his aim was to stimulate the use of ODR by designing an appropriate, coherent legal framework for the European Union. As you can find out when reading this book, he successfully accomplished his mission.

One and a half years later we encountered again in Cork, in a very different setting, namely during his Viva (the confidential oral examination for Ph.D candidates) in University College Cork, Ireland. His defence of Developing Online Dispute Resolution for Consumers in the European Union ${ }^{1}$ started October 3 , 2008, at 13:30. Fully in line with the topic of the thesis I logged into Skype that morning in the hotel, and when I did an alert popped up. It appeared to be the birthday of our mutual friend and colleague, Colin Rule. So during the Viva I started with asking him whether he had congratulated Colin. This was obviously not the type of question he expected, but I explained the question was not referring to benefiting from Colin's groundbreaking work in ODR (as we all do), but because it was Colin's birthday. This first 'question' remained the only one he did not answer accurately, I quote from the Viva rapport: ${ }^{2}$

The candidate started with a clear presentation of the topic of the thesis. He dealt with the questions in a very accurate way, addressing the necessary issues fluently and demonstrated a very good understanding of the domain.

October 2008 was in fact a fruitful month for norms on Online Dispute Resolution. Co-incidentally the same month Susan Schiavetta defended her remarkable doctoral dissertation entitled Electronic Alternative Dispute Resolution - Increasing Access To Justice Via Procedural Protections at the University of Oslo (Norway) on October 23 and 24, 2008. ${ }^{3}$ But back to Pablo; he did not only write on ODR, but has been an active participant of the standardisation of ODR project by the EU/CEN as well: ${ }^{4}$ he has provided feedback 
and attended the first meeting in Brussels in 2008. Furthermore even before this book was published, his work has been read by a large group of students. I used excerpts from his thesis in an ODR module of an international LL.M in business law course on E-commerce Law in spring 2009. The students did highly appreciate this part of the course, and considered the writing by Pablo Cortés really valuable. Also a group of Dutch students in my Master course on Internet Law, both in 2008 and 2009, learned many things from an early version of a chapter of this book which was part of mandatory reading.

In September 2009, in Barcelona, on his home ground, Pablo Cortés presented during an ODR event and he then asked me if I would be willing to write this foreword. I immediately accepted, and am very glad to be in the position of recommending this work.

As said, this book is well suited for students, but also for both academics and practitioners interested in norms on ODR. Before the Viva I had read the manuscript of the Ph.D-thesis that the present book is based upon with great pleasure. I quote once more from the rapport:

The candidate has written a solid work with thorough considerations of the issues, and good use of the literature. He supplemented his literature review with several interviews with stakeholders in the field of ODR. He developed along the lines of existing recommendations the idea of drafting a Directive $e^{5}$ to harmonise necessary elements of building trust in ODR. His proposal is nuanced, sophisticated, and mature. The candidate writes in a pleasant style, synthesises and analyses the material very well.

This is indeed a great book, by a talented scholar of whom I expect we will hear much more. As the foreword reveals I met Pablo in Liverpool, Cork, Brussels, and Barcelona, so maybe it would be a good idea if he presents me the print of the book in person, in Amsterdam. On the other hand, we live in the information society, so an e-book or a hard copy via normal post is fine too. Maybe most fitted to the topic of the book is if he informs me online, using Skype, an ODR platform, or with our avatars in a virtual world. One way or the other, I am sure I will re-read the book, and highly recommend its reading.

Amsterdam, January 2010

Arno R. Lodder Computer/Law Institute, VU University Amsterdam Centre for Electronic Dispute Resolution

1 In the initial invitation entitled Developing Online Dispute Resolution in Europe for Electronic Contracts. 
2 By Professor Steven Hedley (supervisor), Dr. Darius Whelan, and I.

3 Supervisors were Professors Ola Mestad and Lee Bygrave. The adjudication committee consisted of Professors Hans Jacob Bull, Elizabeth Thornburg, and I.

4 Final CEN Workshop Agreement (CWA) was published in September 2009, the members of the project team were Andrea Borri (Firenze Tecnologia, Italy), Jacques Gouimenou (TIGA technologies, France), Brian Hutchinson (University College of Dublin, Ireland), Arno R. Lodder and Vincent Tilman (Eurochambres)

5 It must be noted that the thesis recommended the drafting of a Directive; conversely this book recommends the drafting of a Regulation as a more appropriate legislative instrument for the harmonisation of ODR standards. 



\section{Introduction}

The notion that most people want black-robed judges, well-dressed lawyers, and fine panelled courtrooms as the setting to resolve their dispute is not correct. People with problems, like people with pains, want relief, and they want it as quickly and inexpensively as possible. ${ }^{1}$

\section{Background}

\section{Electronic commerce in the European Union}

Electronic commerce (e-commerce) is the largest and fastest growing market in the world. It offers online consumers a vast selection of products and businesses with an enormous potential customer base. The increasing number of internet users in the European Union (EU), with more than half of its citizens using the internet regularly, has impacted on the growth of business to consumer (B2C) e-commerce. As a result, e-commerce is the most common form of cross-border shopping in the EU, where one-third of EU citizens used the internet in 2008 to buy something online. ${ }^{2}$ According to the European Commissioner for Consumer Protection, consumer spending represents 58 per cent of the EU gross domestic product (GDP). ${ }^{3}$ However, only 29 per cent of EU small and medium sized enterprises are currently involved in cross-border transactions, even when 48 per cent stated that they would be prepared to sell to online consumers in other Member States.

Amidst the difficulties facing the expansion of e-commerce within the EU, a significant barrier is created by the potential problems in resolving complaints. ${ }^{4}$ Indeed, cross-border trade is being slowed down not because there is a lack of regulation but because there is no means to enforce the existing law; in other words, there is no effective method of resolving disputes. This is very apparent for small value claims which cannot usually be resolved in courts since the cost of obtaining a remedy in court will frequently be greater than the amount claimed. Consequently, consumers often do not even try to assert their rights and statistics continue to record ad nauseam how EU consumers often distrust e-commerce. ${ }^{5}$ 
If the EU is to benefit fully from the economic potential of its internal market, a proactive policy approach is needed to stimulate favourable market developments in online consumer protection. ${ }^{6}$ It will also be necessary to develop tailored mechanisms to ensure the enforcement of consumers' rights, which adequately reflect the requirements of cyberspace. If this is done effectively, by providing consumers and businesses with trust and consistency in the resolution of disputes, it will facilitate the growth of e-commerce. ${ }^{7}$

\section{The need for online dispute resolution (ODR)}

In relation to the resolution of online consumer disputes, our legal system faces a crucial choice: either to adopt traditional dispute resolution methods that have served our legal systems well for hundreds of years or to find a new method which is better suited to a world not anchored in jurisdiction and identity. In the borderless online marketplace, parties located in different parts of the world make contracts with each other at the click of a mouse. In this virtual environment, where activities take place amongst strangers, the potential for misunderstanding, mistake and fraud is augmented. However, litigation for these disputes arising out of e-commerce is often inconvenient, time-consuming and expensive owing to the low value of the transactions and the physical distance between the parties. ${ }^{8}$ Furthermore, courts may lack the resources and the expertise to keep up with the growth in cross-border disputes arising out of an ever emerging e-commerce. ${ }^{9}$

The resolution of disputes is enhanced when assisted by Information and Communications Technology (ICT), because when distance communications are utilised there is no need to travel, which in turn reduces costs and increases access to justice. Online Dispute Resolution (ODR) mainly involves Alternative Dispute Resolution (ADR) processes, largely assisted by the speed and convenience of ICT and the internet, which are eminently suited to the needs of e-commerce. ODR creates the opportunity for the resolution of lesser-value and cross-border disputes which could not simply be resolved otherwise. In addition, ODR in the B2C context has the role of increasing consumer trust, essential in the development of sustainable e-commerce; if that is not provided, consumers will certainly prefer to shop at the local store. ${ }^{10}$

There are some misconceptions about ODR, such as the idea that ODR is only valid for small claims, or that ODR exclusively relies on automated technology, or that ODR can only deal with online disputes. As a matter of fact, ODR has proven successful in resolving offline and large value disputes, eg CyberSettle, ${ }^{11}$ and it generally incorporates neutral third parties, eg Domain Name Dispute Resolution Policy (UDRP). Today, ADR is mainly used in relation to employment disputes, family disputes and commercial disputes, including those with cross-border elements. ADR is, however, largely untested with B2C disputes. Moreover, there is no clear evidence that ADR mechanisms correlate to a feeling of consumer safety, any more than 
evidence demonstrating that ADR contributes to consumer satisfaction in dispute resolution. ${ }^{12}$ However, when ADR is complemented with distance communications it is unquestionable that it increases access to justice for many e-commerce players. ODR services, such as PayPal online mediation (as well as the service that was provided to eBay users by SquareTrade until May 2008) are frequently the only processes available for addressing e-commerce disputes.

In order to achieve valuable legal protection for online consumers, it is necessary to develop dispute resolution mechanisms that respond to the needs of the parties, as disputes arising online have different needs to those arising offline. The United Nations Conference on Trade and Development observed that '[i]n the online environment, loss of time often causes loss of opportunities, and people involved in e-commerce will want to resolve problems in the fastest possible way'. ${ }^{13}$ The closer our legal system is to meet this goal, the more it will boost consumers' confidence in e-commerce.

\section{Setting the tone}

\section{Aim of this book}

This book examines how ADR when complemented with ICT can assist in resolving consumer disputes that arise from e-commerce. ADR laws and principles as well as flexible judicial processes, such as the small claims process, will be evaluated as most of these principles also apply to ODR processes. Most of the discussion in this book is limited to only a few ODR methods, namely online mediation, online arbitration and online small claims processes, since these methods are the most common and have the greatest potential for resolving consumer disputes. Furthermore, these are the methods proposed in the last chapter of this book in a model for designing an EU legal framework in the field of ODR. However, the types of ODR methods are much wider and some references to them will be made throughout the book.

The aim of this book is to give an overview of the current use and potential of ODR in the B2C context and to identify obstacles to a more widespread use of ODR for consumer transactions. In this context, the role of the law would be to respond to the need of directing disputants to use cost-effective ODR services, while also ensuring compliance with due process principles. Online disputes are often of a global nature; hence, national and regional laws may constrain rather than aid the resolution of cross-border disputes. The final objective will be to identify the legal responses required in the EU to accelerate the expansion of ODR in the resolution of $\mathrm{B} 2 \mathrm{C}$ disputes.

This book will focus first and foremost on ODR but it will also examine, where necessary, broader areas such as consumer protection, ADR, civil procedure and conflicts of law. The types of disputes considered in this book will be national as well as cross-border consumer contractual disputes arising out 
of the online marketplace, where parties do not have equal bargaining power (ie B2C). In so doing, this book will primarily be focusing on those disputes which appear to be most suitable for ODR, namely those concerned with the entitlement to material benefits rather than those concerned with fundamental rights. This includes civil and economic disputes, for instance disputes related to violation of trademarks, sales, exclusion clauses, unfair terms, deliveries, payments, and so forth.

This book seeks to examine the policy making and regulatory challenges of ODR with the aim of identifying a new approach to the resolution of online consumer disputes, which may assist in redressing grievances, strengthening consumer trust and making e-commerce more secure. Legal provisions for ODR seem to be the best option for resolving these challenges. The ultimate objective of this book is to assess the need for designing a new EU regulatory model in order to improve the enforcement of online consumers' rights. This book will therefore evaluate the proposition that ODR, if it is to realise its full potential in the resolution of e-commerce disputes and to facilitate the enforcement of ODR decisions, must be grounded firmly on an EU regulatory basis.

\section{Summary of contents}

Chapter 1 considers consumer protection and access to justice from an EU perspective. This chapter intends first to examine the consumer protection law in the EU and the means to enforce consumers' legitimate rights. When litigation for the resolution of disputes arising out of online transactions becomes necessary, parties must answer questions related to the establishment of the legal forum, the determination of the applicable law and the enforcement of judgments. The general objective of Chapter 1 is to evaluate whether the judicial system offers a helpful tool to enforce consumers' rights adequately and whether alternative methods of dispute resolution are necessary.

Chapter 2 introduces ODR as a consumer redress option. This chapter discusses the current development of ODR and evaluates the challenges posed by ODR, such as how it can be impartially funded, how to direct parties to take advantage of ODR, how to ensure enforcement and due process standards and, finally, to define the role played by technology in the dispute resolution process.

Chapter 3 deals with consumer adjudicative processes supported with ICT, ie cybercourts and online arbitration. With regard to cybercourts, this chapter examines first how national judicial authorities are incorporating ICT into their processes but its focus lays mainly on the Regulation for a European Small Claims Procedure, ${ }^{14}$ which in order to be cost-effective will need to rely heavily on ICT. This chapter also addresses online arbitration and the principal legal obstacles that face its implementation. Particular attention is given to an international adjudicative process akin to arbitration, the Uniform 
Domain Name Dispute Resolution Policy (UDRP), examining in detail how it works, identifying its main advantages and pitfalls, and to what extent this ODR model could be applied to resolve mainstream B2C disputes through online arbitration.

Chapter 4 examines online mediation for e-consumers. The main challenge for online mediation is to attract the parties in dispute to a consensual ODR process. To achieve this, it is necessary to educate the parties and for the legislature and the judiciary to promote mediation as a matter of public policy. The Directive on Mediation, which is due to be implemented in all EU Member States by May 2011, encourages mediation and assures the direct recognition and enforcement of cross-border settlements. ${ }^{15}$ In addition, English courts offer litigants an incentive to consider ADR, advising that an unreasonable refusal to mediate will result in an order to pay all the legal costs. ${ }^{16}$ This chapter tests the application of the above regulation and case law to consumer online mediation. It also considers whether mandatory online mediation may be implemented successfully.

Chapter 5 evaluates the critical question of whether a legal framework is needed in the EU to develop consumer ODR. This chapter explores the efficiency and sufficiency of the existing regulatory mechanisms and the need for designing a European legal framework in the field of ODR. It puts forward a proposal for taking co-ordinated action within the EU to ensure that those ODR services that meet the required legal standards could be rewarded with a higher level of legal recognition.

\section{Methodology}

A comparative analysis between the United States (US) and the EU jurisdictions seems appropriate since both jurisdictions are committed to working closely together on ADR and ODR. ${ }^{17}$ However, the focus of this research is on the EU jurisdiction, with specific reference to Ireland, Spain and the UK. The choice of jurisdictions takes into account both my language skills and the benefit of using and contrasting common law and civil law approaches to dispute resolution. This book intends to evaluate the introduction of ICT mechanisms in the above jurisdictions to resolve consumer disputes through the use of litigation and ADR methods. Thus, this book evaluates national initiatives, such as the Irish online small claims procedure, the Spanish online consumer arbitration and the decisions from the English courts persuading litigants to use ADR mechanisms.

The methodology of this book reaches beyond an analysis of primary legal material and extends into a consideration of experts and political discourse on the measures introduced to deal with ADR, ICT and ODR. For instance, this book discusses reports from the European Commission, the Organisation for Economic Co-operation and Development (OECD) and European Consumer Centres (ECC). Furthermore, the previous work of ODR experts (such as Ethan Katsh, Colin Rule, Lucille Ponte, Thomas Schultz, Julia Hörnle, 
Arno Lodder and Orna Rabinovich-Einy) has contributed to the design and theoretical underpinnings of this book.

Finally, it must be mentioned that there are some limitations to this research because it is difficult accurately to assess ODR development when statistical analysis is scarce. In order to measure properly the effectiveness of ODR more information on outcomes, processes and users' comments is needed. The most important statistical analysis to date has been carried out by Melissa Conley Tyler in 2004. ${ }^{18}$ Previously, in 2001, Consumers International carried out another survey study specifically on B2C ODR. ${ }^{19}$ At the EU level the only study on ODR is the Workshop Agreement on Standardisation of Online Dispute Resolution Tools. ${ }^{20}$ This study has had as its objective the improvement of the interoperability of ODR services in the EU and beyond; in so doing it has focused on delivering a taxonomy through the classification of existing ODR methods as a basis for building an ontology. Yet, this agreement does not include any statistical data. Along the same lines, it has been decided to restrict this book to a theoretical and normative approach rather than to carry out empirical research given the time constraints for this book. Further, given the confidential nature of most ODR processes, save with some exceptions, eg UDRP, it has proven to be very difficult to obtain statistical data from most ODR providers.

\section{Location and contribution of the book in the existing academic debate}

Although the study on the application of ODR to B2C disputes is not new, most of the legal writing emanates from the US. ${ }^{21}$ To date, there has been comparatively little published on this issue in the EU. There is evidence that ODR is still emerging in the EU where it is facing additional hurdles, such as different languages and legal cultures. With the advance of new technologies, there is an increasing interest from the European Commission in the promotion of ODR to boost and accelerate the growth of e-commerce within the European single market. ${ }^{22}$ This book evaluates ODR methods by examining the progress of ODR in the European legal context. It considers what can be taken from the ODR legal academic writing in various jurisdictions and to apply this information in an EU context, which aims to create a secure online internal market that will promote adequate consumer redress and encourage corporate competition.

The focus on the EU market is owed to a number of reasons. Most of the literature comes from the US, leaving a current gap in the EU legal literature. It is obvious that there are vast differences between both jurisdictions: both in current legal structures and in the online environment, as well as the behaviour and expectations of EU and US consumers. The EU has a different legal culture from the US, putting far more emphasis on the protection of consumers and regulation of the marketplace. In the EU there is an 
increasingly harmonised regime of consumer protection law, which includes distance selling, unfair terms and consumer credit regulations. EU consumers have arguably greater expectations of protection in the marketplace than US consumers. A common plan, therefore, to enforce those rights could be developed in the EU.

The European Commission has shown interest in creating a regulatory model, which has been indicated by preparatory acts, such as the two Green Papers on access to consumer justice and ADR. ${ }^{23}$ The second of the papers is of particular importance because it opened the debate on cross-border ADR and promoted 'ADR and ODR [as] a political priority'. ${ }^{24}$ Nonetheless, very few concrete initiatives have emerged from the EU to date. The most likely reason for this is that the EU is awaiting the development of ODR within the industry. In this book, I have considered how the EU could intervene to further the development of ODR.

EU interest has also been evident through the financial support granted for ODR initiatives and projects. Among these initiatives is the Electronic Consumer Dispute Resolution scheme (ECODIR) and the Euro-Label trustmark, projects which aimed to set up systems devoted to the electronic resolution of internet disputes arising between consumers and merchants in Member States. These projects, however, did not achieve a successful market implementation; consequently, their study will help us to examine the difficulties currently faced by ODR initiatives. This book will therefore analyze the main hurdles for ODR projects in obtaining successful market implementation and will propose solutions to overcome current obstacles. It will also examine the role of other European initiatives such as the ECC-Net, which informs consumers of their rights when they find themselves in a dispute in another Member State. As far as possible, I have tried to state the law as I see it at Easter 2010.

\section{Notes}

1 WE Burger (former Chief Justice, United States Supreme Court) 'Our Vicious Spiral' (1977) 22.

2 Commission Staff Working Document 'Preparing Europe's Digital Future i2010 Mid-Term Review' (14 April 2008) COM(2008) 199 final. European Commission, Special Eurobarometer 298 'Consumer Protection in the Internal Market' (October 2008).

3 M Kuneva (Commissioner for Consumer Protection) (2007a) 'Consumer Strategy 2007-2013’ Press Conference Brussels (13 March 2007).

4 Eurobarometer (October 2008) 'SME Retailers Take to E-commerce but It's Strictly National' European Commission Press Release (8 February 2007) available at http://www.europa.eu (unless otherwise stated, all websites were last accessed on 1 January 2010).

5 Organisation for Economic Co-operation and Development (OECD) Report on 'Consumer Dispute Resolution and Redress in the Global Marketplace' (11 April 2006) available at http://www.oecd.org/dataoecd/26/61/36456184.pdf.

6 Communication from the Commission to the Council, European Parliament, 
the European Economic and Social Committee and the Committee of the Regions 'i2010 - A European Information Society for growth and employment' (COM(2005) 229 final) 4.

7 OECD Conference on Empowering E-consumers 'Strengthening Consumer Protection in the Internet Economy' Background Report DSTI/CP(2009)20/final Washington D.C. (8-10 December 2009) 29; European Commission 'EU Consumer Policy Strategy 2007-2013’ (COM(2007) 99 final) 11.

8 Crawford (2001) 389.

9 Ponte (2001) 55.

10 Rule (2002) 120.

11 http://www.cybersettle.com.

12 Edwards \& Theunissen (2007).

13 United Nations Conference on Trade and Development, E-Commerce and Development Report 2003 'Online Dispute Resolution: E-Commerce and Beyond' ch 7 at 197.

14 Regulation (EC) 861/2007 of the European Parliament and of the Council of 11 July 2007 establishing a European Small Claims Procedure [2007] OJ L199/1.

15 Directive 2008/52/EC of the European Parliament and of the Council of 21 May 2008 on Certain Aspects of Mediation in Civil and Commercial Matters art 6 [2008] OJ L136/3.

16 Halsey $v$ Milton [2004] EWCA Civ 576.

17 Federal Trade Commission and US Department of Commerce 'Summary of Public Workshop: Alternative Dispute Resolution for Consumers Transactions in the Borderless Online Marketplace' (6-7 June 2000).

18 Conley Tyler \& Bretherton 'Seventy-Six and Counting: An Analysis of ODR Sites' (2003/04) Report of Research Conducted for the Department of Justice, Victoria, Australia available at http://www.odr.info/unece2003/pdf/Tyler.pdf.

19 Consumers International 'Disputes in Cyberspace 2001: Update of Online Dispute Resolution for Consumers in Cross-Border Disputes' Consumers International Office for Developed and Transition Economies (November 2001).

$20 \mathrm{CEN} / \mathrm{ISS}$ Workshop Agreement on Standardization of Online Dispute Resolution Tools prCWA XXX (20 October 2009).

21 Conley Tyler \& Allen 'Online Dispute Resolution Library Index' available at http://www.odr.info.

22 Green Paper of the European Commission of 19 April 2002 of Access to Consumer Justice and Alternative Dispute Resolution in Civil and Commercial Law (COM(2002) 196 final).

23 Green Paper of the European Commission of 16 November 1993 on Access of Consumers to Justice and the Settlement of Consumer Disputes in the Single Market (COM(1993) 576 final).

24 Ibid. 


\title{
1 Consumer protection and access to justice in the era of electronic commerce
}

\author{
A European perspective
}

Access to the courts may be open in principle. In practice, however, most people find their legal rights severely compromised by the cost of legal services, the baffling complications of existing rules and procedures, and the long, frustrating delays involved in bringing proceedings to a conclusion. There is far too much law for those who can afford it and far too little for those who cannot. ${ }^{1}$

\subsection{Introduction}

The aim of this chapter is to evaluate whether European consumers are provided with adequate protection when they participate in e-commerce. To that end, this chapter considers not only the substantive law provided to encourage consumer participation in e-commerce but also the adequacy of existing judicial tools to enforce these rights effectively.

This chapter is divided into four sections. The first section (1.2) sets out the current European consumer protection regulation affecting e-commerce. The European Union (EU) is developing and harmonising consumer protection law with the aim of achieving a truly integrated internal market. This has been manifested in the area of e-commerce through many legal initiatives discussed in this chapter, such as the E-Commerce Directive and the Distance Selling Directive, soon to be part of the Directive on Consumers Rights. The European regulation is examined in the global context by contrasting its tendency towards codification against the more hands off regulatory approach of the US. This section considers whether there is a need to pursue greater legal harmonisation at regional and international levels in order to encourage the development of e-commerce.

The second section (1.3) considers consumer access to judicial redress in a European context within the EU by examining the small claims procedures of Ireland, Spain and the UK. It assesses these national judicial procedures and tests their accessibility for consumers by considering such critical questions as whether the existing small claim procedures are effective to deal with (i) low cost disputes or (ii) those with cross-border elements, such as those disputes arising out of e-commerce transactions. 
The third section (1.4) addresses the conflict of laws. The development of e-commerce has led to an increase in the number of cross-border disputes. The Brussels Regulation and the Rome Regulation are contrasted with US case law on choice of law and forum selection in order to compare the legal treatment in both jurisdictions for business to consumer (B2C) disputes. At the international level it is apparent that the question of conflict of laws is still quite unsettled, but at a regional level there is greater legal uniformity. In addition to the above, this section also examines the efforts at an international level to reach legal harmonisation of the principles of conflict of laws through the Hague Conference.

Finally, section 1.5 discusses the enforcement of consumers' rights under the EU legislation. First, it considers judicial enforcement and the procedural requirements for applications to enforce judgments and other judicial decisions. It examines how consumers may seek redress independently or as a group of affected individuals, either by collective actions, or from the representations of consumer organisations and government consumer agencies. It also discusses enforcement when this is carried out by governmental organisations that monitor and enforce consumer rights.

\subsection{Consumer protection policy in the online market}

\subsubsection{The legal definition of consumer}

A consumer is considered to be anyone acting for personal purposes and in a non-commercial capacity. From a legal perspective a consumer is an individual that needs legal protection when dealing with a business owing to his perceived lack of knowledge and weak position in the course of entering into a transaction. According to the Proposal for a Directive on Consumer Rights a 'consumer means any natural person who [. . .] is acting for purposes which are outside his trade, business, craft or profession'. ${ }^{2}$ As opposed to this, the trader is considered to be a natural or legal person who, for the transaction in question, is acting in a commercial or professional capacity.

The European Court of Justice (ECJ) deliberated over the definition of consumer a number of times in order to clarify its scope. In France $v$ Di Pinto the defendant (Di Pinto) offered professionals who wanted to sell their businesses an opportunity to advertise their offers in his magazine. ${ }^{3}$ The question referred to the ECJ was whether professionals in the process of selling their businesses could be treated as consumers owing to their lack of experience in these transactions. The ECJ did not accept this subjective notion of consumers and rejected the above argument. This definition of consumer was reinforced in the case of Francesco Benincasa $v$ Dentalkit. ${ }^{4}$ In this case the parties had entered into a franchising agreement for the defendant to open a business, which was never completed. The question raised in this case was whether the defendant could be considered as a consumer under Article 13(1) of the Brussels Convention of 27 September 1968. This Article defined consumer as 
a party acting for a purpose which may be considered as outside his professional activities. The resulting question was formulated: is this qualification then applicable to parties who have not yet entered into a commercial activity? The ECJ stated that a consumer, in the light of the Convention, should be interpreted as a private end-consumer, and in no way engaged in commercial or professional activity. Hence, following this interpretation of the ECJ, consumers should be understood in a strict sense, that is, individuals whose activities are exclusively guided by private and household purposes without any connections to professional or commercial activities. ${ }^{5}$

Despite this unmistakable interpretation of the law there will always be border-line cases, eg a solicitor who buys a car for personal and business purposes. It seems that in this type of border-line cases consumer protection law will normally apply as long as the professional interest is not higher than the personal one. ${ }^{6}$

\subsubsection{Consumer protection}

The notion of consumer protection first appeared to challenge the doctrine of freedom of contract in the 1970s. This new concept questioned whether it was fair to allow a business to decide freely on the terms and conditions of a contract when dealing with consumers who are not technical experts and have neither the bargaining power nor the knowledge to negotiate fairly the terms of the contract. Under these circumstances the notion of freedom is truly applicable to one of the parties. At this point, the doctrine of freedom of contract stopped being absolute and began to be seen as a doctrine with some limitations. In order to balance the inequality of contractual power between businesses and consumers, the legislature decided to intervene by enacting laws to protect consumers when entering in contractual relations with businesses.

To achieve adequate consumer protection, the law of contract must balance two of its functions. The first one is the 'facilitative function' that states that parties must have the freedom to do what they want to do (if both really want the same once they are ad idem), which is the idea underlying the doctrine of freedom of contract. The second one is the 'protective function', which aims to prevent abuse from the stronger party over the weaker party when negotiating the terms and conditions of consumer contracts. To obtain this double objective Girot suggests that the consumer law should 'be enlightened by "the notion of the parties' reasonable expectations" '? This notion contributes to find a balance between, in words of Adams and Brownsword, marketindividualism and consumer welfarism. ${ }^{8}$

The idea that 'weak businesses' must have legal protection when dealing with stronger parties is based on the same legal principle supporting consumer protection, ie the imbalance of power may allow abuses from the stronger party. In this context, the European Commission consulted in the Revision of the Consumer Acquis whether weak businesses or businesses 
that have a double capacity (eg buying something for personal as well as for professional use) should receive the same level of protection as consumers. The case law of the ECJ and the Revision of the Consumer Acquis implies that the inclusion of non-consumers under the protection of the consumer regulation is undesirable. ${ }^{9}$ The reason behind this restriction is that the best method for recognising consumers is distinguishing them from those acting in a professional capacity. Furthermore, accepting commercial parties within the meaning of consumer protection might increase the risk of legal disharmony when national courts construe this new category.

Nevertheless, removing professionals from consumer protection regulation should not exclude them from legal protection because small businesses are often in similar circumstances to those experienced by consumers. Businesses can still be protected by general rules of contract law, such as those related to the valid formation of contracts, which are applied to both businesses and consumers. ${ }^{10}$

\subsubsection{Consumer protection in the field of e-commerce}

\subsubsection{EU regulation}

At the time of writing, in the context of information and communications technology (ICT) there are two main directives which aim to protect consumers when buying online. These are the Distance Selling Directive and the E-Commerce Directive, ${ }^{11}$ which aim not just to grant minimum rights for consumers but also to harmonise the Member States' legislation in order to facilitate and boost the internal market.

Under the Electronic Commerce Directive, EU Member States must ensure that their legal systems allow the formation, completion and enforcement of electronic contracts. ${ }^{12}$ The requirements to create a valid electronic contract are similar to those relating to traditional paper contracts. On the one hand, common law legal systems require the concurrence of at least three elements: (i) an agreement ad idem (offer and acceptance); (ii) consideration (the acquisition of something of value in return for what one gives or promises, usually an agreed sum of money); and (iii) the intention to create legal relations. On the other hand, civil law countries do not see consideration as a compulsory element. In addition to the requisites to enter into traditional contracts, consumer electronic contracts must fulfil extra legal requirements. First, consumers must be informed about the technical steps required to conclude the e-contract. Secondly, the terms and conditions must be available in a manner that allows their storage and reproduction. ${ }^{13}$ Finally, the directive introduces a new element required for the formation of an e-contract, namely the confirmation, which requires the service provider to acknowledge the receipt of a consumer's order. ${ }^{14}$

One of the challenges of e-contracts is the difficulty in verifying the identity of the parties. This obstacle is partly overcome through the use of 
electronic signatures. In this regard, the European Commission has adopted a directive guaranteeing EU-wide legal recognition of electronic signatures. ${ }^{15}$ However, this directive provides for some exceptions such as contracts relating to land transactions, where, even though the preparatory acts were carried out online, the final signature must be of the established accepted paper based type. Although the directive intends to be technological neutral, it establishes two types of e-signatures, simple and advanced signatures. The latter type of signature has cryptographic assurance of the sender's identity, and the integrity of the text to which is attached. This differentiation has attracted many criticisms for being biased in favour of advanced technologies, ie smart cards. ${ }^{16}$ The directive has been criticised for being over-regulatory to the point that it has restricted the development of ICT in this area. However, it can be argued that the market needs to know when an e-signature is legally binding; yet the need for legal certainty must be balanced with the risk of creating technological restrictions and barriers to the development of e-signatures.

Consumer protection in the EU is still developing. The Directive on Unfair Commercial Practice outlines ‘sharp practices' such as pressure selling, pyramid schemes, misleading marketing and unfair advertising. ${ }^{17}$ It is important to point out that this directive, unlike the Directive on Consumer Rights (but in the same way as most EU directives in the field of consumer protection), only provides minimum harmonisation. In order words, the Directive on Unfair Consumer Practice has set minimum standards to contribute to the harmonisation of consumer protection law between the Member States, but allowing Member States to expand consumers' rights further. Additionally, this directive obliges businesses not to mislead consumers with misinformation through acts or omissions. ${ }^{18}$ Through this directive consumers are given the same protection against aggressive or misleading marketing whether they buy locally or from other Member States. It also provides additional protections for vulnerable consumers who are often the target of unscrupulous traders, such as rules regulating advertising that targets children.

The most significant European regulation in relation to e-commerce is the Directive on the Protection of Consumers in Respect of Distance Contracts, commonly referred to as the Distance Selling Directive. ${ }^{19}$ This directive, along with three others - Unfair Contract Terms, Sales and Guarantees and Distance Selling - are presently being merged into the Directive on Consumer Rights, which harmonises and updates the law of the EU Member States for consumer contracts for goods and services. ${ }^{20}$ The new text is more in line with the e-commerce environment and introduces full harmonisation in its provisions, restricting EU Member States from introducing more or less stringent provisions when implementing it into their domestic legislations. ${ }^{21}$

The proposed Directive on Consumer Rights recognises a number of rights to consumers which cannot be waived in the terms of a B2C contract. These are: 
(i) Right to information: Consumers must be provided with certain information, such as the name and address of the supplier; main characteristics of goods and services; price inclusive of taxes; arrangements for payment; existence of right of withdrawal, where applicable; information on after-sales; and guarantees etc. ${ }^{22}$

(ii) Consumer protection against the fraudulent use of credit cards.

(iii) Cooling off period for distance and off-premises contracts, eg online contracts. Consumers can withdraw from transactions if they are not satisfied, without any justification. To invocate this right, a consumer must communicate his or her decision in writing to the business within 14 calendar days. ${ }^{23}$ This period increases to a maximum of an extra three months where the supplier had not provided the relevant information. ${ }^{24}$ The supplier must return any money received from the consumer (less the cost of returning the goods, except when the goods are defective) within 30 days, counting from the day the supplier had received the returned goods. ${ }^{25}$ The right to cancel does not require any particular form, but consumers may use a standard form included in the Annex I of the directive. This right has some exceptions under which the consumer will not be entitled to cancel the contract: in case of goods made to the consumer's specifications; audio, video recording or computer software where the consumer has broken the seal; newspapers, periodicals or magazines; contracts for gaming, betting or lottery services etc. ${ }^{26}$ Surprisingly, the directive omits the exclusion of goods which cannot be returned for health, safety and/or hygiene reasons, such as lipsticks and underwear.

(iv) Prohibiting certain activities by the supplier such as inertia selling, which is the practice of sending products to people who have not asked for them, and then demanding payment. ${ }^{27}$ It also restricts the use of automated calling systems without human intervention.

The directive imposes an obligation on all Member States to observe this common set of rules for consumer protection and to implement them with the assistance of an efficient means of enforcement. In addition, it imposes the obligation of actively informing consumers and businesses about these rules. ${ }^{28}$

\subsubsection{Electronic commerce in the global context: $E U$ and US comparison}

In order to consider consumer law in an international context it is first necessary to make a comparison between the two largest world economies where, on the one hand, the United States has a greater economic and legal integration owing to the fact that it has been operating a single market economy since its constitutional foundation and, on the other hand, the more recent formation of the EU results in a more fragmented market, despite its increasing integration. However, in terms of consumer regulation, the EU has achieved a 
higher level of legal integration and legal codification than that obtained in the US. In the US, consumer protection focuses on false advertising, particularly when directed at minors and deceptive business practices, such as coercing consumers into unfair contracts. In contrast to the EU, the US has not enacted new legislation to protect consumers who contract online ${ }^{29}$ and it has taken an approach of 'favoring business efficiency, flexibility, and practicalities'. ${ }^{30}$ The Federal Trade Commission (FTC) strategy for protecting consumers is basically enforcing the existing regulations applicable to contract law, as well as educating consumers and businesses on how to participate in e-commerce. ${ }^{31}$

The effectiveness of these diverse policies in protecting consumers is arguable; in fact, both policies have contributed to the growth of e-commerce. The EU approach supports heavy consumer protection, taking a 'precautionary' approach with the aim of promoting a sustainable growth of competitive e-commerce within the internal market. The US view, in contrast, suggests that excessive consumer protection, such as that of the pro-consumer European regulation, may be detrimental to the evolution of e-commerce by restricting innovation. ${ }^{32}$ The US 'hands off regulatory approach is based on liberal ideas which support the premise that small and medium sized firms will not be economically viable if they have to comply with high consumer protection policies.

Notwithstanding the different approaches, many requirements in online contract formation are common in both jurisdictions. For instance, one peculiarity of electronic agreements is that these e-contracts are usually dealt with faster than some paper-based contracts. As a result, when contracting online, it is more likely that errors will be made, particularly at the time of the consumer's acceptance. ${ }^{33}$ In these cases, service providers in both jurisdictions must make technical means available allowing customers to identify and correct input errors prior to the placing of the order. ${ }^{34}$ Additionally, the US FTC has statutorily prohibited unfair acts and advertising that are likely to cause substantial consumer injury. With the same purpose in mind, the EU has created the Directive on Misleading Advertising. ${ }^{35}$ Also the Unfair Terms Directive (soon to be the Directive on Consumer Rights) has some similarities with the US Restatement (Second) Conflict of Laws, whereby any term included in the contract will be invalid if one party believes that the other party would not consent if that party was aware of the inclusion of such a term. ${ }^{36}$

There are still many European provisions in relation to consumer protection that differ widely from the US 'hands off approach. Among them, the most significant are the absence of the 'cooling off period' in the US regulation; the US provisions that allow an easier enforcement of standard form contract terms; and the validation of post-payment disclosure of material terms in consumer transactions. ${ }^{37}$ This approach is in direct conflict with that taken in the EU, where generally the law limits the enforcement of standard form contract terms; it recognises a consumer's right to withdraw and it 
requires the full disclosure of terms prior to the formation of the contract and payment by the consumer. ${ }^{38}$

Overall, it is difficult to say which of these policies is more effective for encouraging market development. Ramsay notes that there is very little empirical data on whether central policies such as the cooling-off period actually have any impact on the market. ${ }^{39}$ It seems clearer, however, that legal harmonisation will benefit the cross-border market since consumers' expectations will be more easily fulfilled.

\subsubsection{The need for harmonisation}

The base for harmonisation of national legislation in the EU is grounded in Article 114 of the Treaty on the Functioning of the EU, which stresses the need for a high level of protection for consumers. ${ }^{40}$ From a consumer's point of view there still appears to be a lack of confidence in e-commerce; consumers do not yet feel well protected when engaging in cross-border transactions. The main reason given by consumers' surveys is the difficulty of resolving after-sales problems (88 per cent) and the problems of initiating legal action in the courts (83 per cent). ${ }^{41}$ However, as Vogenauer and Weatherill pointed out, these difficulties are not only caused by the lack of uniformity in the legislation but also stem from problems arising from the different languages and cultures involved in cross-border transactions. According to them, it is not surprising that nearly eight in ten consumers would propose, as a solution to the cross-border barriers, the unification of the law and the introduction of the possibility of suing in their own countries. $^{42}$

From the business owners' point of view, the difficulties of cross-border transactions derive from the need to comply with disparate domestic regulations, in particular with consumer protection laws and fiscal regulations. In the same survey businesses also propose, as a solution to these cross-border difficulties, the harmonisation of laws as well as the establishment of ADR services to resolve disputes. ${ }^{43}$ In many cases small and medium enterprises (SMEs) and consumers do not know the law and procedure of the other Members States, which accordingly makes them uncomfortable in engaging in cross-border transactions, even between Member States where the law is quite similar. A European harmonisation in contract law may encourage cross-border trade by giving the perception to SMEs and consumers that their expectations will be fulfilled at the national and also at the regional level. In addition, the harmonisation of international private law rules at an international level would contribute to facilitating a greater access to justice. ${ }^{44}$

However, European legal harmonisation in respect of consumer protection differs from the US policy. This is because the EU is drafting a new consumer regulation from scratch, whereas the US is taking a different legal strategy by trusting market self-balance more and thus avoiding the introduction of consumer laws that could hinder the growth of the market. ${ }^{45}$ 
Taking these divergent policy approaches into account, a higher degree of harmonisation in substantive law cannot be reached in the short term; it will be more practical to seek a higher degree of harmonisation in the enforcement of national and cross-border remedies. ${ }^{46}$ The continued evolution of e-commerce depends to a large extent on the trust and confidence of the stakeholders and that can only be obtained by fulfilling their legitimate legal expectations.

\subsection{Consumer access to justice: Small claims procedures}

\subsubsection{Introduction}

This section explores the access of individual consumers to the courts within the EU with a focus on the small claims procedure in Ireland, Spain and the UK. ${ }^{47}$ In so doing, it considers whether national courts can presently offer an effective mechanism to resolve small value disputes. This section also addresses whether national procedures can be used effectively by online consumers to resolve cross-border disputes arising out of e-commerce. Hence, this section examines exclusively national judicial processes for resolving small value disputes as they are intended to be a suitable mechanism to deal with B2C disputes. The European Small Claims Procedure, however, will be later discussed in Chapter 3.

When a consumer is dissatisfied with a transaction, the first logical step is an attempt to resolve the dispute by negotiating directly with the business. If a solution cannot be reached, consumers will generally become disappointed and frustrated with the transaction, although they will be unlikely to seek redress. Exceptionally, when the amount of money involved is significant, consumers may consider the option of going to court. In these cases, it is expected that the consumer will send a letter threatening proceedings, if the grievance is not settled. ${ }^{48}$

Several legal systems offer an expeditious judicial process, often called a Small Claims Procedure (SCP) or Small Claims Court, to resolve small value claims without the need for legal representation. The SCP is generally available as an additional judicial procedure to the ordinary civil procedure. The aim of the SCP is to provide a means of dispute resolution where the expense and the time involved are proportionate to the value of the claim. As a result, judges in the SCPs take a more interventionist role, particularly by assisting unrepresented parties with procedural issues. With the publication of a European Green Paper, the Commission distributed a questionnaire to the Member States with the intention of promoting public awareness about the creation of a European Small Claims Procedure and to obtain a better understanding of the existing SCPs. ${ }^{49}$ The result of this questionnaire showed that at the time of its publication only a few Member States had a SCP, namely Ireland, the UK, Spain and Sweden. Furthermore, other legal systems offered summary ordinary procedures applicable to small claims. Arguably, these 
procedural simplifications can also be considered a SCP, as in practice very similar results may be achieved.

Baldwin identifies five main features of the SCP that distinguish it from the ordinary civil procedure. ${ }^{50}$ First, the SCP is a more informal and simplified procedure. Secondly, legal representation of litigants is generally discouraged. Accordingly, claimants do not have the obligation to make any legal arguments to support their claims. Thirdly, judges play a more interventionist role at oral hearings by assisting the unrepresented litigants in relation to procedural matters. Fourthly, procedural rules are more relaxed for litigants and judges, giving litigants more flexibility in presenting their evidence and judges greater discretion in reaching their decisions. Finally, litigants often pay for their own legal costs; therefore, the claimant does not run the risk of having to pay the defendant's costs (including the fees for legal representation) if the claimant is unsuccessful.

\subsubsection{Small claims procedure in Ireland}

Under Irish law, the district court is competent to hear small claims on the basis of the District Court (Small Claims Procedure) Rules 1997 and 1999. ${ }^{51}$ Only consumers are eligible for this procedure where they have bought goods or contracted services for private use from someone selling them in the course of their business. ${ }^{52}$ Claims related to minor damage to property (eg torts) and non-return of rent deposits in relation to holiday premises may also be addressed under the SCP. ${ }^{53}$ However, personal injuries, ${ }^{54}$ hire-purchase agreements, breach of leasing agreements and debts are excluded from the SCP. The maximum amount of a claim is $€ 2000$; claims over this limit fall under the ordinary civil procedure of the district court. The Irish SCP is designed to allow consumers with small value disputes to obtain redress in court at a low cost without the need for legal representation. This is reinforced by a prohibition on the district court awarding legal costs to any of the litigants. The SCP commences when the claimant submits a claim with the corresponding fee of $€ 15$ in the small claims office at the district court. Since December 2006 the online version allows lodgment of a claim and the fee online. The new online service has proven to be very popular because not only does it allow a claim to be lodged, but also it allows the claimant to monitor the progress of his claim. ${ }^{55}$

To lodge a claim online, a consumer-claimant must click the Small Claims Procedure box on the website http://www.courts.ie. Once there, the site explains the competence of the SCP and the option of filing an online standard claim application. Consumers are expected to read simple, brief guidelines and a checklist before they fill in the application in the secure website. A district court clerk, called the registrar, will receive the claim and will consider whether the claim is appropriate for the SCP and if so, the claim would be admitted and processed. If the registrar rejects the claim, an e-mail will be sent to the claimant informing him of the reasons for the rejection. If the 
court registrar admits the claim, a notification will be sent to the claimant with the corresponding case number and a pin number which allows the claimant to follow the case online. A copy of the claim coupled with all the documentary evidence and a 'notice of dispute' will be sent to the respondent (the business) by registered post. ${ }^{56}$

The main advantage of the online initiative is that it makes the SCP accessible to consumers who can now file and monitor their cases from a computer, 24 hours a day, 7 days a week. If the respondent accepts the claim, or if he does not reply to it within 15 days, the district court will make an order in the claimant's favour for the amount claimed. ${ }^{57}$ This must be paid in a short period of time by a cheque which will be sent by post to the claimant without the need for attending court. In time, these payments may be effected online through bank transfers, instead of using the current traditional mail systems. This online project has shown that the SCP is easily adaptable to the use of ICT. ${ }^{58}$

The respondent may ignore or contest the claim. First, if the respondent does not reply to the claim within 15 days, the claim will be automatically treated as undisputed. The registrar at this stage will ask the claimant to swear an affidavit, and then the district court will make an order in favour of the claimant. The district court will order the respondent to pay the liquidated amount requested in the claim, which in any case must be limited to the claimant's financial loss, excluding any additional compensation. ${ }^{59}$ Secondly, in the event that the respondent contests the claim, the registrar may interview and negotiate with both litigants separately with the intention of reaching a pre-trial settlement. ${ }^{60}$ The registrar may propose solutions when requested by the litigants. ${ }^{61}$ Over half of the cases are settled with the aid of the registrar, without the need for an oral hearing in court. In this context, some of the competences of registrars are very similar to those of a mediator. For instance, they explain the procedure to the parties and encourage them to reach a settlement.

The role of the registrar helps to reduce the number of disputes that go before the judge, facilitating a quicker procedure for those cases which are more complicated and that are not ripe for an early negotiable agreement. When the matter cannot be settled, the claim will be brought before the district court judge for a public oral hearing. On the day of the hearing, litigants are expected to explain the facts and give evidence under oath. They are also allowed to bring their own solicitors, experts and witnesses, but each party must bear his own costs. ${ }^{62}$ The 'no costs' rule is a powerful disincentive to the use of solicitors and encourages the development of a cost-effective SCP. ${ }^{63}$

Overall, the main limitation of the Irish SCP is the stringent criteria to be met to become a claimant. This has promoted the development of new alternatives to resolve small claims disputes where litigants do not fall within the criteria set by the Irish SCP. As a result, the Irish Bar Council has developed a small claims arbitration procedure which deals with claims of up to $€ 7500$ 
where fees are limited to $€ 750 .{ }^{64}$ Unlike a SCP, this is a voluntary procedure whereby parties must enter into a contract that subjects all disputes to the arbitration. It is a fast track, which uses standard forms in plain English. Arbitral awards are delivered within 14 days after the oral hearing. The awards are final and legally binding. ${ }^{65}$

\subsubsection{Small claims in England and Wales}

The present SCP in England and Wales was introduced following the review on access to justice by Lord Woolf. ${ }^{66}$ The Civil Procedure Rules (CPR) 2001 distinguish three tracks: the small claims track (SCP) for low valued claims; fast track for moderate value claims (over $£ 5000$ but not exceeding $£ 25,000$ ); and the multi-track for high value (over $£ 25,000$ ), complex or important issues. The SCP dominates the civil procedure, reaching over 70 per cent of the claims brought before the county court. ${ }^{67}$ Under this procedure the current monetary limit is $£ 5000$ but it maintains a number of exceptions, such as personal injuries and housing repairs where the limit is $£ 1000$.

The majority of claims are related to debts, compensation for faulty services or goods and disputes between landlords and tenants. The SCP is not only limited to consumers, but also allows businesses to initiate legal actions. The procedure starts when the claimant submits a claim with the fee in the county court. ${ }^{68}$ Additionally, in England and Wales, certain claims for a fixed amount of money (less than $£ 100,000$ ) can also be submitted online through the Money Claim Online service. ${ }^{69}$ The English SCP is designed in a userfriendly manner in order to enable litigants to participate without legal representation. Nevertheless, this has not been fully achieved; the National Audit Office has stated that since judges make decisions based on legal provisions, legally unrepresented parties against represented litigants tend to do less well. ${ }^{70}$ This imbalance probably happens in many other jurisdictions where legal representation is also discouraged for SCPs. In fact, the National Consumer Council advised against allowing parties to use lawyers since this makes the SCP longer and more legalistic. Litigants without legal representation can however be accompanied at the oral hearing by a lay representative who will be able to speak on his or her behalf.

In making an overall analysis of the small claims system in England and Wales, Baldwin and Lord Woolf recommended the need for giving preliminary legal advice to lay litigants in order to assess the probability of bringing successful claims to a court of law. ${ }^{71}$ This advice is currently restricted by procedural rules whereby court staff are not allowed to provide information about the possible difficulties of enforcement or to indicate the likelihood of the litigants' success. The district judge may act as a mediator or conciliator at the start of the hearing, but normally time restrictions prevent this from being meaningful and either there is a settlement on the court doorstep or the judge hears and tries the case. ${ }^{72}$ 
This situation, however, may change in the near future. In December 2006 the Department of Constitutional Affairs (DCA) published four reports with the results of three pilot schemes offering mediation for small claims disputes in Exeter, Manchester and Reading county courts. ${ }^{73}$ In brief, the Exeter pilot project consisted of a number of qualified solicitors who acted as mediators; in Manchester, a full-time mediator officer was available in court to give information about the SCP and free voluntary mediation services; similarly, the Reading pilot project facilitated settlement negotiations and it provided information to unrepresented litigants explaining the SCP. From all the above schemes, the one in Manchester with the in-house mediator was considered the most satisfactory and cost-effective. This model is currently being extended to other courts across England and Wales.

The overall experience was regarded as very positive for both the litigants and the judiciary, but it raised a number of concerns derived from the lack of experience in using these new services. For instance, some participants expressed disappointment at what they perceived as low settlements or high settlements given that they felt under pressure to settle. ${ }^{74}$ The main reason for this was the lack of understanding of the process of mediation where some of the parties expected it to be an adversarial procedure; and the lack of training and experience of the mediators. Although the use of mediation as a complement to the SCP has proven to be positive, in order to offer a fair mediation service, more resources should be put in place to inform parties about the procedure as well as in training staff. Indeed, this may increase the cost of the mediation to the extent that it may end up being a more valuable but expensive alternative to the small claims procedure. ${ }^{75}$ Further research on this area is needed in order to assess the appropriateness of high quality mediation for small claims.

The three pilot projects have also shown that distance communication, in particular mediation taking place by phone calls, is very effective. In this regard, Wood raises interesting questions in relation to telephone mediations: ${ }^{76}$

When parties are telephoned by 'the court' and asked to discuss resolving the case, are they fully aware that they do not have to settle? Are they fully aware of the mediator's role and the nature of the process? Are they truly aware that the Judge is not involved in the discussion and will know nothing about the negotiations? [...] 'does this new approach work?' The Manchester success rates seem to speak for themselves. They may ask, 'would you rather these cases went to trial?'

Parties are likely to receive some pressure from the registrar or mediator to settle their disputes; yet this should not justify reaching a settlement through coercion, or allowing the misrepresentation of mediators by making parties believe that the judge wants a settlement, to the extent that if one party refuses to reach a settlement, the judge will be inclined to rule against that 
party. ${ }^{77}$ This could be avoided by warning the parties that they cannot be coerced to settle and that if this occurs they may report such coercion to the relevant authority. ${ }^{78}$

\subsubsection{Small claims court in Spain}

The Spanish Civil Procedure Act regulates two different civil procedures: the Ordinary Procedure (Juicio Ordinario) and the Oral Procedure (Juicio Verbal). ${ }^{79}$ The Court of First Instance (Tribunal de Primera Instancia) must use the oral procedure for claims up to $€ 3005$. This procedure, however, cannot be considered as a genuine SCP because it is mandatory for litigants to be legally represented. ${ }^{80}$ When claims fall under the threshold of $€ 900$ litigants can use standardised claim forms and are allowed to attend courts without the assistance of legal practitioners. ${ }^{81}$ It is only the latter claims which might accurately be referred as SCP because the possibility of participating in the court unrepresented is one of the core features of the SCP.

The Spanish SCP commences when a claimant submits a claim, which is done by filing standard forms that can be downloaded from the website of the General Council for the Judiciary. ${ }^{82}$ The filing of the claim is generally done physically in the competent court. ${ }^{83}$ The law allows for the use of distance filing when technical means are available, although it is not widespread yet. ${ }^{84}$ Similarly to the English SCP, at the oral hearing the judge may attempt to conciliate the parties, but this is a rather formalistic attempt that does not have a persuasive nature. ${ }^{85}$ During the hearing, the judge may aid unrepresented litigants in presenting their cases, and 10 days after the hearing the judge must deliver a judgment. In spite of this deadline there can be delays from the court in producing their judgments, which may vary from one court to another depending on their caseload. The decisions of the Court of First Instance can be appealed within five days to the Provincial Court (Audiencia Provincial). ${ }^{86}$

When litigants, without being compelled by the law, decide to seek the assistance of lawyers in the SCP they will have to bear their own costs. ${ }^{87}$ There are two exceptions to this rule. The first is when the judge considers that the claimant commenced the legal action on frivolous grounds; and, secondly, when the court is located in a different town to the defendant's home town. In the above situations the judge has discretion when deciding whether the claimant must pay the defendant's legal costs or not, but in any event the legal expenses cannot be more than one-third of the total amount claimed.

\subsubsection{Assessment}

The resolution of small value disputes faces a number of obstacles. First of all, when there is little money involved litigants will usually not seek redress because the cost of such redress is generally more than that of a positive 
outcome, particularly when taking into account not only legal and court costs but also loss of earnings in attending the court and the stress of litigation. ${ }^{88}$ Lord Woolfs reports analysing the civil process in the UK found that high costs were the main obstacle, and argued that in order to obtain effective civil litigation 'we must seek to achieve a more proportionate but workable system, not one which is theoretically impeccable but unaffordable' ${ }^{89}$ Lord Woolfs reports effected deep reforms within the UK, which in turn inspired reforms across the EU, particularly in the Irish civil justice, with the aim of achieving legal procedures that are proportionate and accessible for small value disputes. Online procedures, such as the Online Money Claim in England and the Online Small Claims Procedure in Ireland contribute to lower cost barriers to litigants. Despite this, significant barriers still remain in national procedures.

The main limitation of the Irish SCP, as mentioned above, is the stringent criteria required to become a claimant. The rationale behind this policy seems to be the preservation of the SCP from the monopolisation of scarce resources. Businesses, unlike consumers, can often become repeat-players in the SCP, which give them the advantage of achieving economies of scale..$^{90}$ This has promoted the development of new alternatives to resolve small claims disputes for small businesses that do not fall within the scheme of the SCP, such as the Bar Council arbitral small claims scheme.

The Consumer Strategy Group recommended in 2005 that the limit of the maximum award in the small claims procedure in the district court should be increased to $€ 3000 .^{91}$ A positive aspect of the Irish procedure is the assistance of the registrar who plays a key role as a conciliator during the first stages of the proceedings. Hence, this figure could be replicated in the other national SCPs. In fact, the English courts are currently implementing a similar system, providing a full time mediator, following the pilot project carried out in Manchester.

The main constraint in the Spanish SCP is the low monetary limit of the procedure $(€ 900)$ and the need of legal representation of all the claims that go over this limit. ${ }^{92}$ According to Duggan the civil procedure must balance the risks and advantages of expeditious procedures by proportionality measures. He observes:

The absence of lawyers combined with the exclusion of rules of evidence and procedure and the prohibition of appeals increases the risk of wrong decisions. This is a cost of the systems. However, the cost of not having the system must also be taken into account $[. .$.$] Imperfect justice [. .$.$] is$ better than no justice $\left[.\right.$. ] at all. ${ }^{93}$

Another main obstacle affecting all national SCP is the difficulty in dealing with cross-border disputes, which increasingly appear amongst internet users. ${ }^{94}$ In July 2007 the OECD Committee on Consumer Policy produced a recommendation in which it stressed that today's procedures for small claims 
were designed to deal with low costs disputes at a national level; consequently, resolving cross-border disputes has proven, thus far, to be quite inefficient. ${ }^{95}$ This is noted in the current Irish and English SCPs, which are not completely accessible for non-residents. Despite the fact that the law allows claimants who are non-residents to initiate legal actions, significant burdens are imposed. For instance, litigants have to be physically present during the court oral hearing, and if one of the parties decides not to attend the hearing, it would cause an obvious imbalance. As a result, litigants living abroad would have to pay travel and accommodation expenses which, in most cases, cannot be recovered.

Furthermore, the current mediation programmes are not feasible for crossborder disputes since they rely mainly on face-to-face discussions. Although some of these obstacles have started to be addressed with the new regulation on the European Small Claims Procedure, it is regrettable that the new pan-European procedure does not provide enough tools for encouraging settlements. ${ }^{96}$

The European Commission has stressed three difficulties that individual consumers have in accessing justice. ${ }^{97}$ Those are the high cost of litigation, the length of time taken in resolving the disputes and the complexity of the existing legal procedures. It highlighted that the lack of redress is particularly acute in the cross-border arena. To overcome these difficulties the Commission suggested three formulas. First, it proposed the simplification and improvement of the judicial procedures. Secondly, the Commission remarked on the importance of improving the methods of communication between consumers and businesses in order to avoid unnecessary disputes. Lastly, the Commission encouraged the use of consumer ADR and ODR methods.

\subsection{Conflict of laws}

\subsubsection{Introduction}

Conflict of law rules determine which countries' laws and jurisdiction are applied in a particular case. Courts first decide on their own competence to try a case and subsequently the applicable law for the particular case. To know this in advance is essential in electronic commerce because often more than one jurisdiction is involved in one transaction, where traders and consumers may have different obligations. In order to obtain legal certainty online businesses will generally include choice of law and jurisdiction clauses in their contracts. However, the rules deciding the applicable law, the competent jurisdiction and the validity of contractual clauses are not the same in every country. Furthermore, there is no international convention that resolves all conflict of laws between different jurisdictions in B2C transactions. For the purpose of this section I will focus on the law of the two largest world economies, the EU and the US. 


\subsubsection{Choice of law}

\subsubsection{Choice of law for private sales}

When two consumers (C2C or private sales) become involved in a dispute, for instance through the e-Bay auction house, the applicable rules are those used in business transactions (B2B). In practice, consumers in these cases are unlikely to look for redress in the courts, unless there is a large amount of money involved, eg someone who sells his own car through an online auction, and the buyer purchases the car with some mechanical problems unknown to the seller.

The law of every country gives parties bargaining on an equal footing $(\mathrm{C} 2 \mathrm{C}$ and $\mathrm{B} 2 \mathrm{~B}$ ) complete freedom to determine the choice of law as long as the legal system chosen by the parties has some connection with the parties or the subject matter of the contract. However, when consumers deal with other consumers they would probably not write a contract, so they will be exposed to the default legal rules. Under these circumstances, in the (unlikely) event that the parties start a legal action, it will be the courts themselves which will decide about their competence. In making this decision courts will probably look at where the contract was made and where the execution of the contract occurred; in the former example it would be upon the delivery of the car. If the delivery was done in the seller's country, then the forum and the law of the seller's country will probably be applicable. By contrast, if the delivery was done in the buyer's country, then country and national law of the buyer will be applicable.

\subsubsection{Choice of law under the EU Regulation}

The main instrument governing the choice of law within the European Union since 17 December 2009 is the Regulation on the Applicable Law to Contractual Obligations (Rome I), which provides for uniform choice of law rules in contract for all Member States (except Denmark). ${ }^{98}$ The new regulation has the aim of adapting the text to the growth of cross-border shopping, particularly on the internet.

\subsection{ROME I REGULATION}

The Rome Regulation makes a distinction between those contracts with a choice of law clause and those where there is no such clause.

Choice of law clause Most electronic contracts will contain a choice of law clause. Article 6 of the Rome Regulation provides that consumer contracts may have a valid choice of law clause but this clause may not deprive the consumer of the protection afforded by the mandatory rules of the country of his habitual residence if the business pursues or directs its commercial activity in the consumer's Member State. 
This provision distinguishes between active and passive consumers. The former would be those consumers who look for the business actively, and the latter would be those consumers who are approached by the business. The regulation gives special protection to passive consumers. This begs the question of whether an internet website constitutes advertising in the Member State of the consumer's domicile. It seems that businesses advertising with a website directly in a Member State (eg by e-mail or through a website directed to the consumer's country, ie using the consumer's language, currency etc) may not override the mandatory consumer protection laws of the consumer's country. ${ }^{99}$ Therefore, if a choice of law clause limits the rights recognised to consumers in their countries under the above circumstances, such clauses shall be voided and the mandatory rules of the consumer's habitual residence will be applied instead. ${ }^{100}$

No choice of law clause The lack of a choice of law clause is rare but it may happen in relation to e-mail transactions without standard terms or it can be used for some businesses as a marketing option having a short terms and conditions contract. The Rome Regulation states that in those cases the applicable law will be the law of the country where the consumer is habitually resident, when the contract is entered into according to the form listed above in Article 6, that is, with a specific invitation to buy. Furthermore, in some cases national laws have given consumers the presumption that the contract, unless proved otherwise, was formed in their habitual country of residence. $^{101}$

When the conditions of Article 6 are not fulfilled, the law of the country in which the seller is located will be applied. ${ }^{102}$ In this regard, the E-Commerce Directive and the European Court of Justice consider that the seller's location on the internet is the service provider's nation of establishment, ie the Member State where the business is physically located, regardless of the location of the technology that hosts the website. ${ }^{103}$

The regulation has been received with disappointment amongst businesses' representatives, who fear that the new regulation may curb the growth of online sales. They argue that businesses (mainly SMEs) that sell products across borders will have to deal with consumer complaints under the legal systems of each Member State. Although consumer protection laws are governed by EU law, in most cases it only establishes minimum standards, leaving it to the Member States to develop further consumer protection laws. Conversely, consumer organisations welcome the new regulation, noting that increasing consumer protection will favour consumer trust in e-commerce, boosting consumer participation in the online market.

\subsubsection{Choice of law in the US}

The policy behind US law is the doctrine of freedom of contracts where the parties, including $\mathrm{B} 2 \mathrm{C}$ transactions, have the autonomy of choosing their 
applicable law. Hence, the US legal approach is not as sensitive and interventionist as the EU towards the inequality of bargaining powers between consumers and businesses.

Choice of law clause The main difficulty with the US law is the large number of state laws that are potentially applicable. ${ }^{104}$ The most relevant regulations in the US are the Second Restatement of Conflict of Laws, the Uniform Electronic Transaction Act (UETA), the Uniform Commercial Code (UCC) and the Uniform Computer Information Transactions Act (UCITA).

The US Second Restatement of Conflict of Laws is a compilation of legal rules, which, in spite of being quite influential, are not binding, unless parties contract them in expressly. It essentially provides that the law chosen by the parties will be applied in all cases, except under two circumstances: first, when the chosen state has no substantial relationship to the parties or the transaction; and, secondly, when the application of the chosen law would be contrary to a fundamental policy of a state, which has a greater interest in the issue, but only when that state would be the chosen one if there was not a contractual clause.

UETA is the first comprehensive effort to prepare state law for the e-commerce era. It is a proposed law of procedural rules which recognises the validity of electronic contracts and e-signatures. It also covers only those aspects of the electronic transactions that the parties did not agree in their contract. This Act has been implemented in the majority of the US, strengthening the enforceability of online transactions. ${ }^{105}$ Nonetheless, UETA will only be applied to electronic transactions when the contracts are not governed by the UCITA and UCC statutes.

The latest revision of the UCC was made in 2001 by the American Law Institute and the National Conference of Commissioners on Uniform State Laws. In this revision the proposed law gives even more autonomy to the parties in deciding the applicable law, eliminating the former condition that the chosen law had to have a reasonable relationship with the contract. ${ }^{106} \mathrm{It}$ must be noted that this new proposal is not applicable to $\mathrm{B} 2 \mathrm{C}$ contracts.

The UCITA, originally intended to be part of the UCC, is a controversial regulation that has been created to deal with electronic information transactions. It was promulgated in 1999 but has only been implemented in two states, namely Virginia and Maryland. Currently, there is substantial doubt about the UCITA gaining more acceptances among other states' parliaments. ${ }^{107}$ The UCITA has been criticised for disadvantaging consumers, despite still providing a certain level of consumer protection. The Act states that "parties in their agreement may choose the applicable law. However, the choice is not enforceable in a consumer contract to the extent it would vary a rule that may not be varied' under that law of the jurisdiction applicable in the absence of that agreement. ${ }^{108}$ This policy has driven the UCITA to move away from the current version of the UCC, where a court is permitted to invalidate a choice of law provision if the chosen law does not bear a 
'reasonable relationship' to the transaction. ${ }^{109}$ The drafters of the UCITA considered that this court control of the choice of law imposed undue costs and uncertainty on e-commerce. Under the UCC, as well as under the UCITA, parties may opt out of it, save with some exceptions, such as those related to consumer protection.

No choice of law clause The Second Restatement provides that in the event that the parties have not chosen the applicable law, the law governing the electronic contract will usually be that of where the consumer is domiciled, that is, the location from where the acceptance was transmitted and to where the goods were delivered. The UCITA automatically selects the law of the licensor's principal place of business if product delivery is accomplished online or by electronic delivery, ie downloads of software. ${ }^{110}$ The location of the licensor does not depend on the location of the computer that contains the information, but on the place of establishment. This rule mirrors the E-Commerce Directive's place of establishment provision. By contrast, when the delivery is carried out through a tangible medium, most states rely on the UCC, which, akin to the Rome Regulation, states that the governing law will be that of the consumer's location. ${ }^{111}$

Overall, in fact US courts and legislators tend to recognise choice of law clauses even when those favour businesses, but only as long as there is a reasonable relationship between the parties, the transaction and the chosen law. The reasoning behind this is that respecting choice of law clauses and favouring businesses is believed to result in lower prices for consumers. Although there is consumer protection in the US, it must be taken into account that a significant proportion of legal protection for consumers stems from the state law, where the governments of the states appear reluctant to relinquish domestic control over the consumer protection to the federation. By contrast, in the EU it is European law which directs the consumer protection policy, imposing greater limitations on the choice of law clauses. Finally, it must be noted that since the competent law is chosen after deciding on the competent forum, the latter will have significant influence over the applicable law; not surprisingly, judges are often unwilling to apply foreign laws.

\subsubsection{Forum selection}

The forum selection determines which courts of law can try a particular case. The basic rule is that defendants may be sued in their own jurisdiction, yet consumer contracts constitute a significant exception.

\subsubsection{European law}

The Brussels Regulation (also known as Brussels I) establishes the forum selection in all of the EU Member States with the exception of Denmark, which continues to apply the Brussels Convention. ${ }^{112}$ In the context of 
electronic consumer contracts, the most important provision is Article 15.1(c), which limits businesses to bring actions only in the consumers' domicile, while giving consumers the choice of suing businesses in their own domicile or at the businesses' domicile. ${ }^{113}$ This rule, similarly to Rome I, will only be applied whenever a business pursues commercial activities in the consumer's state; for instance, when the online businesses are giving information to consumers in their languages, currencies and deliver the goods in the consumers' country. ${ }^{114}$ In other words, those websites with one language and a single currency (eg in English and accepting only pounds sterling) will be considered as not pursuing commercial activities in other Member States. ${ }^{115}$ Consumers, however, are no longer required to complete contracts in their Member States of domicile for their forum to apply. ${ }^{116}$

There are a number of exceptions to these rules. The first exception is when an individual buys property: the applicable law and the competent forum in these cases will be that where the property is located. Secondly, another exception is those cases related to intellectual property rights (IPRs): the country where the IPRs are registered will decide on the applicable law and the forum. Thirdly, insurance companies may be sued in the forum of the claimant or where the damage had occurred. Finally, if the defendant (consumer or not) appears in a particular court, such court may become automatically competent because it is understood that the defendant implicitly recognised such jurisdiction.

\subsection{APPLICATION OF FORUM SELECTION RULES BY THE EU MEMBER STATES}

As mentioned above, under the Brussels Regulation, the use of the language or the currency of the consumer's Member State is prima facie evidence of the business's interest in directing his activities to the particular country; hence consumers will have the option of claiming in their domicile. The British courts, however, seem to interpret this rule cautiously. ${ }^{117}$ In Crate \& Barrel the consumer's jurisdiction was not recognised because the judge held that the design of the website was exclusively directed to the Irish market despite the fact that the site was accessible to UK consumers. ${ }^{118}$ The judge followed an early decision in which it was held that 'the mere fact that Web sites can be accessed anywhere in the world does not mean ... that the law should regard them as being used everywhere in the world'. ${ }^{119}$

This decision nevertheless contrasts with that of the French courts in the Yahoo! Case, whereby the French courts had made orders against a US based website on the basis that it infringed French anti-incitement laws for selling Nazi memorabilia, despite the fact that the website was in English and Yahoo! had filters in place to block users with French IP addresses. ${ }^{120}$ In this case Yahoo! France had to comply with the decision of the French court, while Yahoo! Inc (the US corporation) did not comply with the decision of the French court because its activity was held lawful by the US court (under the protection of the First Amendment of the US Constitution). ${ }^{121}$ According to 
Colón-Fung: 'this case illustrates the difficulty of enforcing laws designed to protect consumer's domicile where the law [of the consumer's domicile and the law] of the seller's domicile conflict. ${ }^{122}$ Also in UFC $v$ AOL the Tribunal de Grande Instance of Nanterre (Paris) found in 2004 that 31 of the 36 terms used in the AOL e-contracts were unfair and void. ${ }^{123}$ It appears that French law, although complying with the Brussels Regulation, gives French courts jurisdiction over almost any case in which a French national is a party. ${ }^{124}$

\subsubsection{Jurisdiction rules in the US}

Albeit that the highest number of websites offering to supply goods and services are based in the US, the jurisdiction rules here are different. In the US the choice of forum is based on several legal precedents that evaluate the defendant's contact with the plaintiff s state to determine if jurisdiction is appropriate. The choice of forum is generally referred to by US courts as 'personal jurisdiction'. This concept includes 'general' and 'specific jurisdiction'. The former occurs when disputes do not arise from the defendant's contacts with the forum. ${ }^{125}$ By contrast, the specific jurisdiction is the exercise of jurisdiction when disputes arise out of the defendant's contacts with the forum. The Due Process Clause of the 14th Amendment limits the power of a state court to try only those cases that have sufficient connections with that state. ${ }^{126}$ In order to determine the reasonability of the forum, US courts will use the so-called 'minimum contacts' test. Minimum contacts must exist between the parties, the transaction and the forum. This test was first designed by the US Supreme Court in International Shoe Co. $v$ Washington. ${ }^{127}$

Contractual clause As a general rule US courts respect contractual clauses in consumer contracts, unless of course such clauses contain an unreasonable and unfair choice of jurisdiction. The leading case is Carnival Cruise Lines, Inc. $v$ Shute. ${ }^{128}$ This case involved a Washington State couple who purchased two tickets from Carnival, a Florida based cruise line. In the contract there was a clause whereby any dispute arising must be resolved in the courts of Florida. During the cruise trip on Mexican waters Ms Shute slipped on a deck mat and suffered a number of injuries. The case commenced with a dispute on the competent jurisdiction. The US Supreme Court (SC) held that a forum selection clause in a consumer contract was reasonable because it was (i) freely bargained for; (ii) it was entered into in exchange for reduced fares; and (iii) it did not unduly burden the plaintiffs.

More recent cases have extended the reasoning of Carnival to consumer online contracts. The New Jersey SC applied this reasoning in Caspi $v$ Microsoft Network, LLC, holding a forum selection clause placed online by Microsoft to be valid. ${ }^{129}$ In that case the court ruled in favour of the clause because the plaintiff failed to prove any of the following three circumstances: 
(i) that the clause is the result of fraud or excessive bargaining power; (ii) that the enforcement would violate public policy; or (iii) that it would create a seriously inconvenient trial. The same rule was applied to arbitration clauses. In Hill v Gateway 2000, Inc., the US Court of Appeals for the 7th Circuit held valid an online arbitration clause. ${ }^{130}$

Overall, US courts will generally uphold these agreements unless it can be shown that they are unfairly oppressive, unconscionable or outside the reasonable expectations of the consumer. It must be noted that the expectations of consumers in the US, where clauses are generally enforced, would differ significantly from those of consumers in the EU.

Non-contractual clause In those situations where there are no contractual clauses or the extant ones are deemed unreasonable, the seminal case for internet transactions is Zippo Manufacturing Company v Zippo Dot Com, Inc., which delivered an approach that aimed to determine personal jurisdiction in all cases related to e-commerce. ${ }^{131}$ The case involved trademark claims by Zippo Manufacturing (the maker of Zippo lighters based in Pennsylvania) against Zippo Dot Com (a news-website based in California). Zippo Manufacturing filed a suit in the Western District of Pennsylvania and Zippo Dot Com argued lack of personal jurisdiction because it did not have its premises or staff in that jurisdiction but only a website which was accessible from there. Since the dispute was about the domain name, the plaintiff alleged specific (as opposed to general) jurisdiction. The court found that Zippo Dot Com was an 'active website' with a significant number of users subscribed in Pennsylvania and therefore upheld its jurisdiction.

The Zippo court also set a sliding scale test which classifies the likelihood that personal jurisdiction could be exercised on businesses, based in another jurisdiction, in proportion to the nature of the commercial activity conducted by their website on the plaintiff s jurisdiction. This classification was done on three different levels:

(i) Active websites: Those that clearly look for contractual parties in other jurisdictions. Under this test personal jurisdiction is always considered proper.

(ii) Passive websites: When somebody posts information online that is not interactive but merely informative. In these cases online users, consumers or not, cannot exercise their personal jurisdiction.

(iii) Mixed websites: They are a combination of the former two, where the user can exchange information with the host computer, even though the website is not particularly targeting those users. In these cases, courts will analyse the level of interactivity and the commercial nature of the exchange of the particular information. In consumer contracts the general tendency of the US courts has been to favour consumers' jurisdiction, but when the interactivity of the parties is low, courts might find it difficult to recognise their jurisdiction. 
This test focuses its attention on whether the defendant conducts his activity intentionally and directly to the consumer's forum. The analysis is nevertheless quite awkward when using the sliding scale approach and it is being considered increasingly vague and inappropriate by both scholars and courts. ${ }^{132}$ Awoyemi argues that the 1997 Zippo doctrine is outdated because many websites are increasingly falling into the mixed websites category, thus emptying the predictive value of the Zippo test and opening the floodgates to different judicial interpretations. ${ }^{133}$ The Zippo sliding scale test is still often mentioned by the US courts, but as this test aims to fit all cases into this approach to internet jurisdiction, it is now becoming too simplistic and even inconsistent with the Supreme Court's personal jurisdiction case law. Consequently, courts are now increasingly dropping the sliding scale test in their reasoning when deciding the competent jurisdiction. Unfortunately, as a result, US courts are producing a confusing and incoherent body of case law where some courts still rely on the sliding scale Zippo case, others apply it exclusively to specific jurisdiction cases (and not to general jurisdiction cases) and still others use it as a combination with the conventional minimum contacts test. ${ }^{134}$

Overall, under the US ad hoc analysis, the act of regularly sending goods into the consumer's forum will likely fulfil the requisite of minimum contacts; true also when a consumer buys goods or services as a result of a direct marketing scheme. These transactions cannot be sporadic but must be continuous, systematic and substantial to recognise a general jurisdiction for consumers' disputes. In the event of a specific jurisdiction in connection to the consumer's forum, unless there is clause stating otherwise, the competent court will be the one sitting in the consumer's domicile. ${ }^{135}$

\subsubsection{The US and the EU compared}

The determination of forum differs substantially between the EU and the US. The EU follows the civil law approach, looking at the connection between the dispute and the forum based on legislation, while the US follows the common law approach, looking at a number of judicial precedents making an ad hoc analysis and evaluating the connection between the defendant and the plaintiffs forum, that is without considering the connection between the dispute and the forum. ${ }^{136}$ In those cases where there are forum selection clauses, as noted above, the Brussels Regulation is quite restrictive in regard to consumer contracts while the US is not. Nonetheless, it would be easier to argue on a case by case basis at a US court unreasonableness of a forum selection clause in a B2C contract than in a B2B contract. When a US court applies the country of origin approach using the minimum contact test, it checks if a website is purposely availing itself to the plaintiffs forum. Conversely, the EU follows the country of destination approach, which is generally easier to determine. 


\subsubsection{Jurisdiction under the Hague Conference}

Outside the EU there are no multilateral agreements to ensure the mutual recognition and enforcement of judgments. The most important attempt to reach a global agreement was the Hague Conference on Private International Law, where the conflicting views of the EU and US in relation to consumer disputes have been one of the main issues of discussion. The principal disagreement is that the EU was supporting the adoption of the country of destination rule while the US was backing the seller's country of origin rule. An area where an agreement could be more easily reached is in relation to those disputes where the seller does not have notice about the location of the buyer; in those cases the country of origin rule should be applied. ${ }^{137}$

The Conference adopted a Preliminary Draft Convention on Jurisdiction and Foreign Judgments in Civil and Commercial Matters. ${ }^{138}$ In this draft, the most debated provision is Article 7 , which provides that consumers can initiate an action in their habitual residence, when contracts had been concluded or directed to the consumers' state. However, this Article has three alternatives: $:^{139}$

(i) The above rule would be used as a default rule when the parties have not entered a contractual clause selecting a forum.

(ii) The states may enter a reservation that would allow them to respect a jurisdiction agreement only when it has been agreed after the dispute arises.

(iii) The second alternative will be implemented in all states, in other words, Article 7 applies unless a jurisdiction agreement was entered into after the dispute arose.

The EU supports options (iii) and (ii), which are reflected in the Brussels Regulation and the US supports option (i). ${ }^{140}$ In order to make this proposal workable it has been suggested to narrow the scope of the Convention by excluding its applicability to consumers and e-commerce; however, this suggestion raises another difficulty, ie the definition of new boundaries to limit the scope. ${ }^{141}$ The Hague Conference was partly abandoned by scaling back to cover only enforcement of judgments resulting from choice of court agreements in B2B contracts. ${ }^{142}$ Therefore, with the breakdown of the negotiations on consumer cases, conflicts of laws are likely to continue in the current climate of legal uncertainty.

\subsubsection{Assessment}

It is ironic and unfortunate that parties are forced to spend time and money in litigating on where to litigate. ${ }^{143}$ There are two obvious methods to limit conflicts of laws. First, it is the use of forum selection and choice 
of law clauses but, as pointed out above, these contractual clauses have different weights in the US and the EU. Secondly, it is the improvement of legal harmonisation. This option seems unlikely to occur in the near future where the alternatives cannot satisfy either businesses or consumers, nor the US and the EU. ${ }^{144}$ The main attempt to create uniform rules was during the Hague Conference, which has been largely regarded as unsuccessful. ${ }^{145}$

In practice, however, only large corporations are concerned about the conflict of laws because they are the likely ones to be involved in these disputes. B2C transactions on the internet are usually low cost transactions. Realistically, no-one is going to pursue a lawsuit for a small amount of money, even when the competent forum is his own jurisdiction. ${ }^{146}$ If a lawsuit is initiated in one country for a small amount of money, a default judgment is likely to result since it is doubtful that a defendant would spend money to defend himself in the plaintiff s forum. Hence, conflict of laws rules would be applicable only to consumer disputes where a large amount of money is involved, eg in some personal injuries cases. For the remaining disputes a more suitable method to resolve conflicts should be sought.

Presently, the current regulation in the global market raises too many legal questions on the applicable law and jurisdiction. Furthermore, rule-based adjudication systems are often difficult to sustain in environments where jurisdictions overlap and enforcement can be extremely difficult. Within the EU, businesses can restrict the geographical scope of their offers by using technology or using disclaimers or by setting a website in a manner that is clearly directed exclusively to specific jurisdictions. On the other hand, this approach limits competition and consumer choice, one of the main advantages of online commerce.

The Global Business Dialogue on Electronic Commerce states that 'extrajudicial procedures for settling disputes can be an effective alternative to the cumbersome and expensive resort to courts'. ${ }^{147}$ Consensual ADR does not follow jurisdictional rules or national laws, eliminating the uncertainty of the law applicable in different jurisdictions. Litigation for online disputes is typically disproportionate to what are often low value transactions. ADR systems when complemented by ICT, ie ODR, are systems best suited for transnational disputes because these methods are generally less lengthy and do not require the physical presence of the parties. Consequently, ODR has the potential to be less costly than litigation and thus more suitable for consumer disputes. These systems will be evaluated in the next chapter.

Nonetheless, court proceedings are the only way of resolving disputes when parties do not agree to the use of ADR, or when the decisions of ADR bodies are contested by one of the parties. Therefore, questions of jurisdiction and applicable law must be dealt with urgently if the law aims to encourage both business investment and consumer trust in e-commerce. ${ }^{148}$ 


\subsection{Enforcement}

\subsubsection{Introduction}

The success of courts as a means of providing effective consumer redress is contingent on the ability of the winning party to enforce the court's decision. In the legal context, enforcement refers to the execution of the law carried out by the competent authority. Public enforcement can be performed by a governmental body or by the judiciary. This section is divided into two parts. The first part considers judicial enforcement, and the second part considers how governmental organisations monitor and enforce consumer rights.

\subsubsection{Judicial enforcement in the $\mathrm{EU}$}

Consumer protection in e-commerce is meaningless unless effective enforcement mechanisms are provided. Thomson suggested that the "[l]aw will not be generally observed unless there is enforcement machinery to use against the occasional violator'. ${ }^{149}$ Judicial enforcement is carried out by a court sanctioning an action that compels one party to comply with a former court order (the judgment). This part has been divided into two sections. First, it commences by considering the procedural requirements of enforcement when it is initiated by consumers. It continues, discussing when such an application is carried out by groups or entities that act on the consumer's behalf.

\subsubsection{Procedural requirements}

The procedural law to enforce judicial decisions has different requirements depending on whether the judgments are foreign or domestic.

\subsection{FOREIGN JUDGMENTS}

In order to enforce a judgment in another country it would be necessary to check first if there is a bilateral agreement between the country whose court has delivered the judgment and the country where that judgment is sought to be enforced. Where there is no agreement, judgments will be enforced on the basis of the enforcing country's private international rules, which generally follow the principle of reciprocity, ie both states recognise their judicial decisions as mutually binding and enforceable. In addition, common requirements for enforcing foreign judgments include the judgment to be final and binding and the rendering court to have proper jurisdiction over the matter and the parties. This last requirement often raises difficulties since many countries (outside the EU) have different rules for jurisdiction and applicable law. ${ }^{150}$

Within the EU, enforcement rules have been unified through the Brussels Regulation, which provides that anyone with a sufficient interest in a judgment may apply for its enforcement (ie locus standi). ${ }^{151}$ The application 
is made to the court that has territorial jurisdiction on the basis of the domicile of the party against whom enforcement is sought or of the place of enforcement. ${ }^{152}$ The declaration of enforceability (ie exequatur) must be issued after certain formalities have been completed and must be served on the other party, who may challenge it. It is possible to refuse the recognition of a foreign judgment under specific circumstances, such as public policy, being irreconcilable with an earlier judgment etc.

The European Council observed that the intermediate measures for the enforcement of judgments were still too restrictive. ${ }^{153}$ Consequently, the EU decided gradually to remove all existing intermediate measures for the enforcement of judicial decisions. Two major initiatives were taken. The first step towards this aim was the removal of the exequatur procedure for uncontested monetary claims with the creation of the European Enforcement Order (EEO). ${ }^{154}$ The EEO dispenses uncontested pecuniary claims from all intermediary measures under certain conditions, mainly related to the service of documents in the case of judgments by default. A second major initiative was the Regulation of the European Small Claims Procedure (ESCP) which removes the exequatur procedure when enforcing ESCP judgments in another Member State. ${ }^{155}$

\subsection{DOMESTIC JUDGMENTS}

The application procedure of enforcement is similar in all EU Member States since they follow the Brussels Regulation. This section briefly considers how consumers may use this procedure in three Member States, namely Ireland, England and Spain.

Ireland Although it is not necessary for an applicant to be legally represented, a legal practitioner will generally write the application of enforcement. Applications must be made in person, together with the fee, in the competent court (district, circuit or High Court depending on the amount claimed), which will be later passed to the other party. There are a number of ways for enforcing a judgment: execution, registration, affidavit, instalment orders, attachment of earnings etc. The other party may oppose the enforcement with an appeal, which is allowed not against the enforcement measure itself, but only against the substantive judgment (or against the order upon which the enforcement is grounded).

England and Wales Similar to Ireland, in England and Wales there is a choice of enforcement methods which may be used. Applications must also be made in person in the competent court, except for the Money Claim Online, where a request can also be made online. For the application it is not necessary to have the assistance of a legal professional, but professional advice on the procedure by a solicitor or the Citizens' Advice Bureau is recommended because the procedure may be very complicated for a lay person to understand. Consumer 
claims are mainly enforced by the county court but when the amount is more than $£ 50,000$ the application must be transferred to the High Court.

Spain Enforcement applications need to be made with the assistance of a lawyer except when the application is submitted to the First Instance Court for amounts of less than $€ 900 .{ }^{156}$ Spanish courts proceed, as most courts, by accepting first a judicial decision as in rem which precludes the re-litigation of a claim on the same facts on the ground of res judicata. Unlike Ireland, appeals in England and Wales are not possible for decisions granting enforcement, but the debtor may oppose the adoption of specific measures. However, the initiation of an appeal proceeding does not suspend the enforcement of the measures granted by the court.

\subsubsection{Legal enforcement on behalf of consumers}

There are instances where a breach of consumer protection legislation affects a number of consumers in a similar way. Sometimes these consumers are unlikely to pursue damages individually owing to the high legal fees and complexities of the legal system compared to the relatively low value of their individual losses. In some countries consumers, besides being able to enforce their rights individually, may also find redress by bringing cases as a group of affected parties. According to the OECD this type of enforcement plays a key 'role in regulating the marketplace, depriving defendants of ill-gotten gains and deterring future wrongful or irresponsible commercial behaviour'. ${ }^{157}$ There are three different categories in which consumers may be represented in court: by class actions, by consumer organisations and by governmental consumer agencies.

\subsection{BY CLASS OR COLLECTIVE ACTIONS}

Class action procedures commence when the claimants file a case on behalf of themselves or of a group who have suffered the same loss in similar circumstances. It can be against a company or a public entity, although they are frequently against large corporations that provide services to a large number of customers; for instance, an electricity supplier that overcharges its customers.

Generally speaking, there are broadly two types of class action procedures: the opt-out model and the opt-in model. The opt-out model automatically includes all consumers in similar circumstances, who will be bound by the final decision, unless they expressly exclude themselves. ${ }^{158}$ By contrast, the opt-in model only includes those consumers who have expressly joined the claimant and agreed to be bound by the final decision. ${ }^{159}$

Class actions were originally created in the US in order to compensate for the lack of governmental support in enforcing consumer laws. In the EU, 13 Member States currently allow them under their domestic laws, although with certain restrictions. ${ }^{160}$ The European Commission has highlighted the 
need for creating a communitarian instrument to address collective redress mechanisms at EU level with cross-border disputes. ${ }^{161}$ As mentioned above, the consumer protection policy in the EU is based on the intervention of the public authorities to stop market abuses, while in the US the public policy encourages attorneys to take more initiative in upholding consumer rights and correcting market abuses. One reason for this is that US attorneys may charge contingent fees, with the approval of the court. Contingent fees consist of a fee charged on certain amounts over the final judgment (normally from one-third to 50 per cent). These fees allow consumers to access courts without paying lawyers in advance. Critics of consumer class actions contend that such fees benefit plaintiffs' lawyers more than consumers themselves. $^{162}$

According to Emmons and Garoupa, in the EU contingent fees are strictly prohibited by the ethical code of the European Association of Lawyers; however, recent legislative changes in some Member States (eg the UK) tend to change the approach towards the US model by permitting the charging of conditional fees which allow lawyers not to charge when they lose a case and to obtain an upscale premium (up to 100 per cent of the original fee) if the case is won. ${ }^{163}$ Further, the UK is currently considering the introduction of contingency fees. ${ }^{164}$

An additional difference between the US and EU fee model is that in the US the rule is that litigants bear their own costs, while within the EU the costs follow the event; thus a party using a conditional fee will usually take out an insurance policy in the event that such party had to cover the winner's legal fees. In some Member States such as in the UK, the winner may also require the losing party to pay all the legal fees, including the conditional fee agreement and the insurance premium. ${ }^{165}$ According to Duggan, conditional fees give the claimants' lawyer an incentive either to settle the case quickly and cheaply or to drag the case out so that the lawyer's costs are increased. ${ }^{166}$ In reality, lawyers will not generally act on a conditional fee basis unless the prospects of success are abnormally high, eg above 80 per cent, so significant limitations remain. ${ }^{167}$ Notwithstanding this, the conditional fee has an important advantage, since it removes the need for the state to provide plaintiffs with legal aid in these cases.

A significant difficulty in these procedures is the resources needed to reach and communicate with all the claimants. These types of disputes are good options to be managed through the use of ICT tools, particularly with the increase of e-commerce, where the number of disputes augments across borders. ${ }^{168}$ Hence, the use of technology to negotiate and resolve these disputes may help to overcome difficulties related to the use of litigation in various jurisdictions and it will ease communications among the many consumer claimants. 


\subsection{BY CONSUMER ORGANISATIONS}

Many European directives allow Member States to provide consumer organisations with the right to take legal action to ensure compliance with consumer protection laws. ${ }^{169}$ As a result, most Member States have given this right to certain consumer organisations in different manners. ${ }^{170}$ There are several types of legal action, but the main three are the following: ${ }^{171}$

(i) Actions in the collective interest of consumers: where a consumer organisation takes a legal action in its own name on behalf of the collective interest of consumers. These legal actions are particularly useful when the consumer harm is widespread. In order to initiate this action, it is not necessary to show an actual harm to individual consumers. In most cases the only remedies available to consumer organisations are conduct remedies, eg injunctions. In the EU, the Injunction Directive has set a uniform procedure which can be used by some qualified bodies (such as certain consumer organisations approved by their Member States) to take injunctive actions against traders in another Member State in order to protect collective interests of consumers in case of infringements of national provisions transposing the EU directives, eg infringements concerning misleading advertisements, consumer credit, package travel, unfair contract terms, distance selling contracts, sale of consumer goods and guarantees. ${ }^{172}$ Its application, however, has been very limited, with only two cases in the last decade. ${ }^{173}$

(ii) Joint representative actions: where a consumer organisation represents a particular group of consumers. There are some concerns about this practice. Although it is important to increase consumer access to justice it is necessary to avoid 'exposing business to spurious or vexatious claims or unwittingly creating a compensation culture'. ${ }^{174}$ With the aim of avoiding the above damage or abuse a number of safeguards can be introduced, such as allowing legal actions only from bodies approved by the government, exclusively on behalf of named consumers and subject to pre-trial approval from the court. ${ }^{175}$

(iii) Partie civile: in the majority of the Member States that come from the civil law tradition, consumers and consumer organisations may join as a civil party to a criminal prosecution of a defendant, requesting exclusively a civil remedy. In these cases it is possible not only to obtain conduct remedies for consumers as with the Injunctions Directive, but also compensation.

\subsection{BY GOVERNMENTAL CONSUMER AGENCIES}

In some cases, neither consumers nor consumer agencies have the resources to seek judicial redress, in particular when such redress is sought overseas. Domestic laws in many countries allow government officials to bring legal actions to protect consumers, eg in Ireland the National Consumer Agency and 
in the UK the Office of Fair Trading. Furthermore, other bodies are created to address more specific problems, such as the Spanish National Centre for the Response to Information Technology Attacks, which specialises in fraud issues related to IT. These are public entities that monitor market infractions and stop them, either directly or via the courts. In most countries government agencies have the authority to seek redress on behalf of their consumers, including sometimes on behalf of foreign consumers. ${ }^{176}$

\subsubsection{Administrative enforcement}

Administrative authorities also ensure compliance with consumer regulation using their own enforcement mechanisms. This is particularly cost-effective in stopping market abuses when it affects a large group of consumers who do not have the initiative in seeking redress in courts. This may happen for a number of reasons: consumers are not aware of their rights, or they do not detect abuses, or they do not have economic resources. ${ }^{177}$

\subsubsection{EU dimension}

The European Commission considers that one of the main problems of e-commerce is the lack of consumer confidence in internet transactions, which may come from genuine disputes with businesses that act in good faith or from rogue traders that take advantage of consumers. ${ }^{178}$ It appears that the latter is the main reason that hampers consumer confidence in e-commerce. Common examples of these activities that often simultaneously affect consumers in different countries are deceptive prize draws, e-mail scams, premium rate phone calls, misleading advertising, online banking cons (ie phishing), timeshare and holiday club rogue traders, and so on. ${ }^{179}$

Within the EU rogue online businesses often move to different Member States in order to avoid being stopped by the national authorities. This is encouraged by the legal restrictions of national authorities in sharing information with the national authorities of other countries. Currently, this practice is hoped to be mitigated by the recent Regulation on Consumer Protection Cooperation, which removes existing barriers to information exchange and cooperation between national enforcement agencies. ${ }^{180}$ The objective of this regulation is to link up national enforcement authorities to stop rogue traders from taking advantage of the internal market by deceiving consumers. The regulation requires that each Member State designates a single public enforcement authority to be part of the mutual assistance network. ${ }^{181}$ Each of these authorities can call on other members of the network for assistance in investigating a possible cross-border breach of consumer EU laws and ultimately to stop rogue traders. The regulation is also complemented by the Injunctions Directive, which allows these bodies to apply for an injunction in any court of the EU against a rogue online business. ${ }^{182}$

The regulation imposes an obligation on the assigned national authorities 
of exchanging relevant information, even without request from the interested authority. ${ }^{183}$ However, in some circumstances limited by the regulation, an enforcement authority may deny the requested information, eg if there is a final judgment on the matter. ${ }^{184}$ In case of disagreement between two of the national authorities, the European Commission will issue an opinion resolving the disagreement. All the designated enforcement authorities will have common investigating and enforcement powers, such as access to any relevant document related to an infringement of intra-communitarian law, competence to carry out website inspections, to request the ceasing of an infraction etc. ${ }^{185}$ It also sets a number of competences that can be developed by the Member States, such as the authority to impose fines or to seek consumer monetary redress. In order to protect honest traders all the information collected by the competent authorities is gathered in a confidential database controlled by the European Commission. ${ }^{186}$ All communications are carried out online using the national language agreed by the parties and, in case of disagreement, each country would use its own official language. ${ }^{187}$

This type of cooperation will not be completed until it is extended at international level, given the lack of barriers to e-commerce and its global nature. In this regard, the regulation allows Member States to cooperate through their link agencies with third countries in accordance with their bilateral agreements, but any information obtained from another Member State needs first the approval from such Member State. ${ }^{188}$ Clearly, the cooperation and centralisation of the enforcement at the EU level is a further step towards consumer confidence and success in the fight against rogue traders and scams. An additional positive side effect of this regulation is that it is expected to contribute to improving the quality and the consistency in enforcing EU law. ${ }^{189}$ This regulation also shows clear intentions from the EU to cooperate and negotiate on these issues with third countries at the same time that they reassure respect for personal data. ${ }^{190}$

\subsubsection{International dimension}

At an international level there have been some efforts to increase cooperation in this area. As has already been discussed, the Hague Conference on Private International Law negotiated issues on competent jurisdiction. ${ }^{191}$ In addition, the International Consumer Protection and Enforcement Network is an organisation that compiles bodies involved with trade practices and law enforcement. Its function is to share information about cross-border commercial activities that may affect consumer interests and to encourage international cooperation among law enforcement agencies. ${ }^{192}$

The OECD set Cross-Border Fraud Guidelines with principles for international cooperation among enforcement agencies that protect consumers against cross-border fraudulent and deceptive practices. ${ }^{193}$ The main purpose of these guidelines is to promote international cooperation to stop harmful practices which originated abroad, as this is the only way fully to protect their 
consumers at home. In doing so, it calls for the sharing of non-confidential information between relevant bodies to tackle harmful consumer practices. The guidelines do not call as yet for government enforcement agencies to seek consumer redress in another country, but they encourage joint research on this possibility. ${ }^{194}$ This is quite a challenge because in those cases where a national authority may have the power to find redress for foreign consumers, it may not be able to prioritise the expenditure of limited resources to protect them. In addition, from a logistic perspective, a case involving a large number of consumers living abroad will be difficult to deal with. ${ }^{195}$ In this regard, ICT development and cooperation between national agencies are essential.

The Global Business Dialogue on Electronic Commerce (GBDe) recommended governments to 'encourage enforcement agencies to adopt a more aggressive interpretation, application and enforcement of existing criminal and consumer protection laws' ${ }^{196}$ To foster optimum efficiency the GBDe suggested that sharing information among private and public entities as well as agreement on an international procedure for cross-border fraud are of key importance in order to stop illegal activities on the internet. ${ }^{197}$

\subsubsection{Assessment}

It has been shown that there are several methods to enforce consumers' rights and that many of them complement each other. In the EU all these methods are combined to deliver the enforcement of consumer law. Recapitulating, first, individual legal action by consumers can be sufficient to resolve disputes in courts when the amount at stake is significant and the parties are in the same jurisdiction and located near each other. Secondly, actions on behalf of consumers are more suited when a significant number of consumers suffered similar losses caused by the same defendant. Lastly, in the EU, governments and consumer protection agencies will be the best approach for seeking redress in cases of fraudulent practices where private action is slow and ineffective. ${ }^{198}$ By contrast, in the US, regulatory agencies play a lesser role than the courts. Individual litigation and class actions are used more frequently for correcting market abuses. ${ }^{199}$

The major hindrance is that most of the existing procedures were developed to address domestic cases and they are generally not adequate to provide consumers with remedies across borders, where costs and practical difficulties are beyond the reach of most consumers with low value disputes. It is widely believed that ICT has an important role to play in assisting the resolution of many cross-border disputes. Thus, other options (that will be discussed in the next chapter) such as the use of Online Dispute Resolution methods (ODR) may prove to be more suited to certain disputes, such as a one-off dispute of low value with a legitimate business arising out of an e-commerce transaction. 


\subsection{Conclusion}

European consumer regulation is evolving with the aim of obtaining a higher level of uniformity across the Member States. By contrast, the US has adopted a hands-off-approach towards consumer protection, ie trusting the market to self-correct. In order to gain more integrated e-commerce what is needed is greater legal harmonisation at regional and international levels. Nonetheless, international harmonisation in substantive and procedural law, in spite of being theoretically ideal, is quite challenging and impractical given the significant legal disparities still present among different countries, as has been shown by the Hague Conference.

From a substantive law perspective it appears that consumers within the EU are more protected when buying online than in the physical world, but this protection may be to a large extent fictitious because consumers find it difficult to enforce their rights when these are not respected, particularly across borders. If a consumer dispute arises in a bricks and mortar shop, the consumer may return to the shop and discuss it with the owner and, if that is not sufficient, the consumer may go to the small claims court. Presently, small claim procedures are designed to deal (with greater or lesser efficiency) with low cost disputes at a national level. Thus, cross-border litigation does not seem to be effective for consumer disputes, even when favouring consumers' forums and laws, particularly when the enforcement has to be carried out in a different forum. The costs of cross-border litigation are likely to deter all but the highest value consumer claims from pursuing this option. Clearly, traditional consumer enforcement mechanisms are unsuitable for the internet age.

It is necessary to question the need of having consumer protection laws in the EU if there are no effective ways of enforcing these laws. At present the resolutions of small value disputes with cross-border elements, such as those arising from e-commerce, are untouched under the domestic judicial procedures. A potentially more suitable judicial process for resolving e-commerce disputes, the European Small Claims Procedure, was implemented in January 2009. This cross-border procedure is discussed in Chapter 3.

There is an urgent need to provide an easy-to-utilise venue for consumers to resolve their disputes. In other words, it is necessary to develop an efficient system to enforce consumers' rights. It is not suggested that courts are not necessary; in fact, courts cannot be substituted by private dispute resolution bodies when dealing with certain cases, such as those that involve criminal wrongdoing. But for a large number of cases that arise online, where the value under dispute is less than likely legal bills and where both parties truly participated in the transaction in good faith, different alternatives are needed. An efficient mechanism for the resolution of online consumer disputes might assist in redressing grievances and strengthening consumer trust, thereby making e-commerce more reliable. The best options are those of ICT, ADR and the synergy of these two elements (ODR), which is discussed in the following chapter. 
In this chapter the existence of European legislation on consumer protection has been analysed. That analysis indicates that the European approach acknowledges that the internal market of itself does not and will not result in effective consumer protection and, for this reason, the EU is developing consumer protection laws, both substantive and procedural provisions. Accordingly, a consistent application of that European view of the market seems to require an analysis of the need to regulate ODR. The remainder of this book will evaluate whether that view of the market is applied consistently to ODR, and it will suggest what legal framework will be the most consistent with it.

\section{Notes}

1 Bok (1983).

2 Proposal for a Directive of the European Parliament and of the Council on Consumer Rights, COM(2008) 614 final.

3 Case C-361/89 France v Di Pinto [1991] ECR I-1189 (1st Chamber - Conclusions of Mischo AG) (12 December 1990).

4 Case C-269/95 Francesco Benincasa v Dentalkit Srl [1997] ECR I-3767.

5 Girot (2001) 75-78.

6 Ibid.

7 Ibid 32.

8 Adams \& Brownsword (2007) 192.

9 Girot (2001) 78; Commission Staff Working Paper Report on the Outcome of the Public Consultation on the Green Paper on the Review of the Consumer Acquis. See also DG Health and Consumer Protection, Preparatory Work for the Impact Assessment on the Review of the Consumer Acquis (6 November 2007).

10 Girot (2001) 98.

11 Directives 97/7EC, 2000/3/EC.

12 Directive 2000/3/EC art 9. It must be noted that the implementation of this Article may include some exceptions, eg under s 19(1) of the Irish E-Commerce Act 2000 electronic contracts can not be discriminated on the sole grounds of being electronic but s 10 states a number of exceptions: court procedures, wills, trusts, affidavits and transfer of property (not the contract but just the deeds) etc.

13 Ibid art 10.

14 Ibid art 11.

15 Directive 1999/93/EC of the European Parliament and of the Council of 13 December 1999 on a Community Framework for Electronic Signatures OJ L13.

16 Mason (2008).

17 Directive 2005/29/EC.

18 Ibid arts 6, 7.

19 Directive $1997 / 7 /$ EC.

20 Proposal for a Directive of the European Parliament and of the Council on Consumer Rights $\operatorname{COM}(2008) 614$ Final.

21 Ibid art 4.

22 Ibid art 5.

23 Ibid art 12.

24 Ibid art 13.

25 Ibid arts $16,17$.

26 Ibid art 12.

27 Ibid art 45. 
28 Ibid art 44.

29 Naylor \& Ritter (2005) 887.

30 Colón-Fung (2007) 237.

31 Spindler \& Borner (2002).

32 Winn \& Webber (2006) 4.

33 Hultmark Ramberg (2001) 429.

34 UCITA \& E-Commerce Directive art 11(2).

35 Directive 97/55/EC of European Parliament and of the Council of 6 October 1997.

36 Directive 13/93 EC and Restatement (Second): Conflict of Laws (1971) para 211(3).

37 UCITA ss 112, 209.

38 Directive on Consumer Rights.

39 Ramsay (2006) 26.

40 Treaty on the Functioning of the European Union as Amended by the Treaty of Lisbon [2008] OJ C115/13.

41 Flash Eurobarometer (14 November 2002) 39-40. Cf. Eurobarometer (March 2010).

42 Vogenauer and Weatherill (2005) 827.

43 Ibid 128.

44 Gilles (2006) 359.

45 World Wide Web Consortium 'A Framework for Global Electronic Commerce' (1997) available at http://www.w3.org/TR/NOTE-framework-970706.html.

46 Swire (2005) 1987.

47 An earlier version of some of the ideas expressed in this section were previously published in Cortés (2008a) 83-88.

48 White (1999) 296.

49 Green Paper on the European Order for Payment Procedure and the Measures to Simplify and Speed up Small Claims Litigation of 20 December 2002 (COM(2002) 746 final).

50 Baldwin (2003) 317-18.

51 SI 1999/191.

52 SCP (1999) r 1.

53 Actions relating to rent deposits for places of residence must be brought to the Private Residential Tenancies Board available at http://www.prtb.ie/.

54 Personal injuries, when liability is not at stake, are often resolved through an institutional ADR process, the Personal Assessment Injuries Board (PIAB). See PIAB (Amendment 2007) Act 2003.

55 During the first year of operation of the Online Small Claims 41.5 per cent of all cases were received through the online system. See Court Service Annual Report (2007) 25 available at http://www.courts.ie.

56 SCP (1999) r 5.

57 SCP (1999) r 6(1).

58 Courts Service News (2007) 'Online Small Claims is Here'.

59 SCP (1999) r 11(1).

$60 \operatorname{SCP}(1999)$ rr $4,8(1)$.

61 The registrar from the District Court of Cork City informed the author that normally this negotiation is carried out through telephone calls. An interview was carried out with the registrar, Desmond McCarthy by the author in the District Court of Cork on 26 May 2006.

$62 \operatorname{SCP}(1999)$ rr 10, 13.

63 European Commission, SANCO, The Study Centre for Consumer Law, Centre for European Economic Law Katholieke Universiteit Leuven, Belgium 'An Analysis and Evaluation of Alternative Means of Consumer Redress other than Redress 
through Ordinary Judicial Proceedings' Leuven (January 2007) (Irish National Report) 3, 14 available at http://ec.europa.eu/consumers/redress/reports_studies/ index_en.htm.

64 The Bar Council of Ireland, Small Claims Arbitration Rules Bar, 'Council Launches Small Business Scheme' RTE News (19 October 2005).

65 Arbitration Acts 1954-98. See also Arbitration Bill 2008.

66 Lord Woolf produced two reports: 'Access to Justice: Interim Report to the Lord Chancellor on the Civil Justice System in England and Wales' (London: Lord Chancellor's Department, 1995) and 'Access to Justice: Final Report to the Lord Chancellor on the Civil Justice System in England and Wales' (London: Lord Chancellor's Department, 1996).

67 Lord Chancellor's Department Judicial Statistics: Annual Report 2004 at 48. Note that this percentage is probably higher because 14 per cent of claims had not been specified.

68 Claim forms are available from local courts and from Her Majesty's Courts Service website at http://www.hmcourts-service.gov.uk.

69 http://www.moneyclaim.gov.uk. For more information see also ch 3.

70 National Audit Office (1995-96) 21.

71 Baldwin (2003) 332.

72 United Kingdom National Report, University of Leuven (November 2006) 9.

73 For Exeter, see Enterkin \& Sefton (September 2006) DCA Research Series and Prince \& Belcher (2006) Small Claims Dispute Resolution Pilot Project at Exeter County Court. For Manchester, see Doyle (September 2006) Evaluation of the Small Claims Mediation Service at Manchester. For Reading see Craiforth (September 2006) Evaluation of the Small Claims Support Service Pilot.

74 Advice Service Alliance (January 2007) 3.

75 Reid (March 2007) 12.

76 Wood (2007) 313.

77 McEwen \& Maiman (1981) 237.

78 Anonymous (1990) 1098.

79 The primary sources of the Spanish civil procedure: Ley de Enjuiciamiento Civil (hereinafter, Spanish Civil Procedural Rules or CPRs) of 8 January 2000 and Ley Organica del Poder Judicial (LOPJ) developed by the Ley 38/1988 de Demarcación y Planta Judicial and the RD 122/1989. Also note that 'Peace Courts' (Juzgados de Paz), similarly to the magistrates' courts in England, are competent to try small claims under $€ 90$.

80 With regard to representation it must be noted that the Spanish legal systems has two different legal figures that work together to assist the litigants in a lawsuit, they are called procuradores and abogados. In short, the role of procuradores is to represent the parties, while abogados are entrusted with the defence of the parties.

81 Spanish CPRs art 31.2.1. Consumers in Spain have also another voluntary procedure aside from the courts, which is the Consumer Arbitration System (Arbitraje de Consumo). See ch 3.

82 Spanish CPRs arts 437.2, 814.1. See the website of the Consejo General del Poder Judicial available at http://www.poderjudicial.es/eversuite/GetRecords? Template $=$ cgpj/cgpj/principal.htm.

83 Spanish CPRs art 273.

84 Spanish CPRs art 162. A recent regulation introduced the LEXNET system whereby attorneys may communicate with the court online if they are registered in the system and have acquired a digital signature. See Huguet Tous (17 July 2007) 3-5.

85 Spanish CPRs arts 414, 415.

86 Spanish CPRs art 455.2.2.

87 Spanish CPRs art 241.1.1. 
88 White (1999) 293.

89 Lord Woolf produced two reports: 'Access to Justice: Interim Report to the Lord Chancellor on the Civil Justice System in England and Wales' (London: Lord Chancellor's Department, 1995) 354 and 'Access to Justice: Final Report to the Lord Chancellor on the Civil Justice System in England and Wales' (London: Lord Chancellor's Department, 1996) 106.

90 Duggan (2006) 59.

91 Consumer Strategy Group (April 2005).

92 The same can be said about other civil law jurisdictions such as France.

93 Duggan (2006) 59.

94 European Consumer Centre Clearing House Dublin (June 2004).

95 OECD Recommendation on Consumer Dispute Resolution and Redress (July 2007) 6.

96 Regulation 861/2007/EC of the European Parliament and of the Council of 11 July 2007 establishing a European Small Claims Procedure OJ L199/1. See ch 3.

97 European Commission Communication of 30 March 1998 on the Out-ofCourt Settlement of Consumer Disputes COM(1998)198 final.

98 Regulation 593/2008 of the European Parliament and of the Council of 17 June 2008 on the Law Applicable to Contractual Obligations (Rome I). Denmark is still under the Rome Convention 1980.

99 Dickie (1999) 86.

100 There are a number of exceptions in art 6.4, such as services supplied outside the consumer's country of residence, some contracts of carriage and certain contracts related to immovable property.

101 See eg Spanish Ley 34/2002 art 29.

102 Zaremba (2003) 479.

103 Directive 2000/3/EC art 2.3, recital 9.

104 Poggi (2000) 224.

105 At the time of writing 46 states have enacted UETA. See http://www.ncsl.org/ default.aspx? tabid $=13484$.

106 The reviewed UCC is experimenting amendments in this regard all around the country. See Graves (2005) 59.

107 Some states even enacted legislation blocking the application of the UCITA provisions. The main controversy regards click-wrap licences in market sales and certain cancellation rights. See Ackerman 'E-Commerce Law Update UETA \& UCITA' available at http://www.peterackerman.com/article.html.

108 UCITA 109 (a) is inspired on the Restatement Second of Conflict of Laws.

109 UCC $1-105$.

110 UCITA 109 (b).

111 Zaremba (2003) 13.

112 Council Regulation 44/2001 of 22 December on Jurisdiction and the Recognition and Enforcement of Judgements in Civil and Commercial Matters [2000] OJ L12/1 at 1-23.

113 Brussels Regulation art 16.

114 Ibid art 15.1(c).

115 UK Department of Trade and Industry 'Cross Border Consumer Contractual Disputes: Guidance of the Rules of Jurisdiction and Applicable Law available at http://www.dti.gov.uk/ccp/topics1/guide/jurisdiction_rome.htm.

116 St Oren (2003) 671-85.

117 The Brussels Regulation was implemented by the Civil Jurisdiction and Judgments Order 2001 SI 2001/3929.

118 Unreported (25 July 2000).

119 Flowers Inc v Phonenames Ltd [2000] ETMR 1025; [2001] FSR 20 (ChD). 
120 French Union of Jewish Students $v$ Yahoo!, Inc. Tribunal de Grande Instance de Paris, Interim Court Order (20 November 2000). In this case the auction website allowed Mein Kampf to be sold all over the world, including France where its anti-genocide law did not approve such sale. See Ware III (2006) 307.

121 Yahoo!, Inc. v La Ligue Contre le Racisme et L'Antisemitisme 169 F. Supp. 2d 1181 (N.D. Cal. 2001). See also Environment Designs v Peters [2001] FSR 288.

122 Colón-Fung (2007) 240.

123 Union Fédérale des Consommateurs-Que Choisir (UFC) v AOL RFN 02/03156 Tribunal de grande instance Nanterre (2 June 2004).

124 French Civil Code art 14.

125 The Supreme Court major's general jurisdiction cases are Perkins v Benguet Consolidated Mining Co. 342 U.S. 437 (1952) and Helicopteros Nacionales de Colombia, S.A. v Hall 466 U.S. 408 (1984). The Supreme Court recognised general jurisdiction only in the first case.

126 See Asahi 480 U.S. at 108; see also Calder v Jones 465 U.S. 783, 788 (1984); World-Wide Volkswagen Corp. $v$ Woodson 444 U.S. 286, 291 (1980).

127 International Shoe Co. $v$ Washington 326 U.S. 310 (1945).

128 Carnival Cruise Lines, Inc. v Shute 499 U.S. 585 (1991).

129732 A.2d 528 (N.J. 1999); Decker v Circus Hotel 49 F. Supp. 2d 743 (D.N.J. 1999). See Thompson v Handa-Lopez, Inc. 998 F. Supp. 738 (W.D. Tex. 1998) (refusing to enforce a forum selection clause that was unclear). See also Cordera (2001) 321.

130 Hill v Gateaway 2000, Inc. 105 F.3d 1147 (7th Cir. 1997). See also ch 3.

131 Zippo Manufacturing Company v Zippo Dot Com. Inc. 952 F.Supp. 1119 (W.D. Penn. 1997).

132 See eg Hy Cite Corp. v Badbusinessbureau.com 297 F. Supp. 2d 1154, 1160 (W.D. Wis. 2004). Hawkins (2006) 2371.

133 Awoyemi (2005) 62.

134 Hawkins (2006) 2391.

135 Kidd \& Daughtrey (2000) 215.

136 O’Brian (2003) 496.

137 Swire (2005) 1990.

138 Preliminary Draft Convention on Jurisdiction and Foreign Judgments in Civil and Commercial Matters (Hague Convention) October 1999 and its revision June 2001.

139 The full text is available at http://www.hcch.net/upload/wop/jdgmpd11.pdf.

140 Convention on Choice of Court Agreements (concluded 30 June 2005); however, this convention excludes its application to consumer contracts. The full text is available at http://www.hcch.net/index_en.php?act=conventions. text\&cid $=98 \&$ zoek $=$ consumer.

141 O’Brian (2003) 507.

142 Convention on Choice of Court Agreements.

143 O’Brian (2003) 497.

144 Agreement by Consumers International and the Global Business Dialogue on Electronic Commerce, Alternative Dispute Resolution Guidelines (May 2003).

145 OECD (11 April 2006) 51.

146 Commission Green Paper of 9 February 'Legal Aid in Civil Matters: The Problems Confronting the Cross-Border Litigant' COM(2000) 51 final.

147 GBDe New York Recommendations (2003) 55.

148 Ibid 60.

149 Thompson (1964) 19.

150 OECD (11 April 2006) 42. With the exception of Denmark which is still governed by the Brussels Convention. 
151 Council Regulation 44/2001 of 22 December 2000 on Jurisdiction and the Recognition and Enforcement of Judgments in Civil and Commercial Matters OJ L12.

152 In the case of Ireland the competent court is always the High Court. See SI 648/ 2005.

153 Tampere European Council (October 1999).

154 Regulation 805/2004 of 21 April 2004 creating a European Enforcement Order for Uncontested Claims [2004] OJ L143/15.

155 See ch 3.

156 Ley de Enjuiciamiento Civil 1/2000 of 7 January 2000 art 545.

157 OECD (11 April 2006) 30.

158 The opt-out model is used by US, Canada, Australia, Portugal etc; OECD (11 April 2006) 31.

159 The opt-in model is used by Germany, Japan, Sweden etc; OECD (11 April 2006) 31.

160 Civil Consulting and Oxford Economics, European Commission, DG SANCO, 'Evaluation of the Effectiveness and Efficiency of Collective Redress Mechanisms in the European Union' Final Report (26 August 2008) 6.

161 Currently, 10 per cent of all collective claims have a cross-border element. See European Commission, Green Paper on Consumer Collective Redress (27 November 2008) (COM(2008) 794 final).

162 US National Report, Leuven Report 2.

163 Emos \& Garoupa (2006) 379.

164 Jackson (2010) 94.

165 See eg in England and Wales the Access to Justice Act 1999. This provision is designated to ensure that the damaged party is entitled to recover for all the damage caused to him or her. See Campbell v MGN Ltd [2005] UKHL 61. Yet, this provision is currently under review. See Jackson (2010) 94.

166 Duggan (2006) 54.

167 Lightman 'Mediation: An Approximation to Justice' (SJ Berwin 28 June 2007) 2. See also Lightman 'Breaking Down the Barriers' (Times Online 31 July 2007) available at http://business.timesonline.co.uk/tol/business/law/article2166092.

168 Rabinovich-Einy (2003) 1; Rule (2002) 216.

169 Directive 97/55/EC on Misleading Advertising; Directive 93/13/EEC 97/7EC on Unfair Contract Terms; Directive 97/7EC on Distance Selling. See also Proposal for a Directive on Consumer Rights 2008/0196.

170 OECD (11 April 2006) 32.

171 This classification is taken from OECD (11 April 2006) $33 \mathrm{ff}$.

172 Directive 1998/27/EC of 19 May on Injunctions for the Protection of Consumers' Interests 1998 OJ (L166) 51.

173 Report from the Commission concerning the Application of the Injunctions Directive available at http://ec.europa.eu/consumers/enforcement/docs/report_ inj_en.pdf.

174 The UK Department of Trade and Industry (DTI) Consultation: Representative actions in consumer protection cases (12 July 2006) 6.

175 Ibid 7.

176 OECD (11 April 2006) 37.

177 Ibid 7.

178 Rapid Press Note 'No Hiding Place for Rogue Traders: Commission Proposes EU-wide Network of National Watchdogs' (22 July 2003).

179 ECC Dublin Newsletter (January 2007).

180 Regulation 2006/2004 has been fully in force since 29 December 2006. See art 22.

181 Ibid art 4. 
182 Directive 1998/27/EC of 19 May on Injunctions for the Protection of Consumers' Interests [1998] OJ L166/51; Office of Fair Trading (13 December 2006) 13.

183 Regulation 2006/2004 art 7.

184 Ibid art 15.

185 Ibid art 4.6.

186 Ibid arts $10,13$.

187 Ibid art $12.3,12.4$.

188 Ibid art 14.

189 See Proposal for a regulation on consumer protection cooperation (18 July 2003) (COM(2003) 443 final) Explanatory Memorandum para 19.

190 Ibid art 18, preamble para 10.

191 Preliminary Draft Convention on Jurisdiction and Foreign Judgments in Civil and Commercial Matters (Hague Convention) October 1999 and its revision June 2001.

192 See http://www.icpen.org/.

193 OECD 'Guidelines for Protecting Consumers from Fraudulent and Deceptive Commercial Practices Across Borders' Recommendation of the OECD Council (11 June 2003).

194 OECD ibid s VI.

195 OECD (11 April 2006) 38.

196 GBDe (2003) 51.

197 Ibid 52.

198 OECD (11 April 2006) 44; Duggan (2006) 67.

199 Winn \& Webber (2006) 5. 


\section{Online dispute resolution An emerging option for consumer redress}

[T] he shortcomings of the online market became clear. The second wave of e-commerce will build the services buyers and sellers need to sustain their involvement in online marketplaces, dispute resolution first of all. Only after users of online marketplaces can obtain redress will the real potential of e-commerce be achieved. ${ }^{1}$

\subsection{Introduction}

The internet's relatively low economic entry barrier invites global participation in e-commerce even for those who cannot afford direct participation in the offline market arena. ${ }^{2}$ Consumers and businesses from different countries can now easily enter into international transactions. This new global commerce is producing a knock-on effect on the volume of international disputes. However, the resolution in court of these disputes is often impractical because it is necessary to participate in complicated, expensive and lengthy offline procedures. This constraint contributes to the lack of trust that deters many potential consumers from purchasing online, as the judicial forum for enforcing their legal entitlements is unreachable. Consequently, the ability of the internet to support and expand international commerce may be curtailed to some extent by the lack of effective methods for resolving international disputes in a simple manner, quickly and at low cost.

Accordingly, it is believed that efficient mechanisms to resolve online disputes will impact on the development of e-commerce. The tools with potential for achieving this are ADR and ICT. This book focuses specifically on consumer ODR and considers its potential for resolving the disputes that arise between businesses and consumers when engaging in e-commerce. While the application of ODR is not limited to disputes arising out of $\mathrm{B} 2 \mathrm{C}$ online transactions, it seems to be particularly apt for these disputes, since it is logical to use the same medium (the internet) for the resolution of e-commerce disputes when parties are frequently located far from one another. ${ }^{3}$ This chapter follows the previous analyses made by ODR experts such as Katsh, Ponte, Schultz and Rule; special attention will be given to the 
last author and arguments contained in his book, Online Dispute Resolution for Business. ${ }^{4}$

The aim of this chapter is to examine the current state of consumer ODR from a European perspective; on such account it evaluates the potential of ODR in assisting online consumers and businesses to resolve e-commerce disputes. This chapter will provide some suggestions about how ICT and ADR can facilitate the resolution of disputes and which models are the most appropriate for resolving B2C disputes arising out of e-commerce.

The chapter focuses in particular on the practical and technical difficulties for the development of consumer ODR; the following chapters will focus on the legal impediments. The chapter is divided into two main sections. The first section (2.2) considers the state of the current development of ODR. It begins by defining ODR and related concepts, such as ADR and online ADR. Secondly, it looks to the brief history of ODR. Thirdly, it examines the main advantages and difficulties of ODR for resolving consumer disputes. Fourthly, it continues by discussing the various mechanisms used for avoiding disputes, such as legal audits, internal complaint procedures, escrows, online payment providers, reputation systems and trustmarks. Fifthly, it will consider the major dispute resolution methods to deal with consumer disputes, ie automated negotiation, assisted negotiation, mediation, arbitration and small claims court processes. Finally, it looks at the most significant European initiatives aiming to promote the use of consumer ODR, namely, the Consumer Complaint Form, ECODIR and ECC-NET.

The second section (2.3) evaluates the challenges posed by ODR. It addresses how current ODR projects are being funded and the possible risks to impartiality that may arise. Another major challenge to consumer ODR is directing parties to utilise it; several strategies to achieve this will be considered, such as promoting awareness, increasing confidence in e-commerce by using trustmarks and by providing public ODR services etc. Due process issues are at stake when a power imbalance exists; in this regard, key aspects, such as the need for impartiality, the selection of neutral third partiess, legal representations and exerting control over ODR providers will be discussed. Judicial enforcement and self-enforcement mechanisms are also considered as of paramount importance for the development of ODR. Finally, the role of technology in ODR processes is analysed by looking at the strengths and weaknesses of the different ICT techniques, the security issues, and the potential of the fourth party in assisting individuals to resolve their disputes.

\subsection{Definition and growth of ODR}

\subsubsection{Defining ODR}

Dispute resolution techniques range from methods where parties have full control of the procedure to methods where a third party is in control of both 
the process and the outcome. ${ }^{5}$ The following diagram illustrates the main dispute resolution methods and the parties' control over the resolution of the dispute. ${ }^{6}$

Initially, there was a resistance to using ICT and ADR, by both parties and lawyers alike. In the last few years ADR has gained greater acceptance amongst the general public and the legal profession. In fact, some courts now require parties to resort to ADR, typically mediation, before allowing them to engage in litigation. ${ }^{7}$ The rising popularity of ADR can be explained by the ever-increasing caseload of the traditional courts, the potential cost benefits of ADR over litigation and a preference for confidentiality.

Dispute resolution methods may be complemented with ICT. The process is referred to as ODR when it is conducted mainly online. This may include the initial filing, the neutral appointment, the evidentiary processes, oral hearings, discussions, and even the rendering of binding decisions. ODR is simply a different medium to resolve disputes, from beginning to end, while still respecting due process principles. ${ }^{8}$

ODR emerged from the synergy between ADR and ICT as a method of resolving disputes arising online and for which the traditional means of dispute resolution were inefficient or unavailable. ${ }^{9}$ The introduction of ICT into dispute resolution is currently growing to the extent that the difference between offline dispute resolution and ODR is blurred. Hörnle has observed

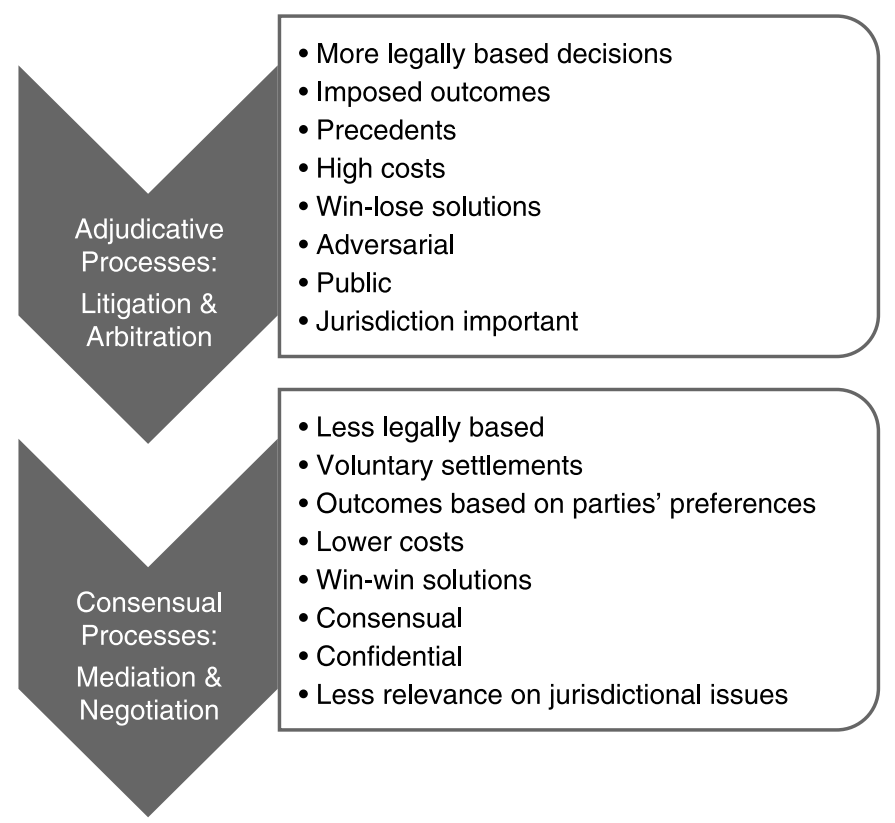

Figure 2.1 Chart adapted from the United Nations Conference on Trade and Development (UNCTAD), E-Commerce and Development Report 2003, Chapter 7, Online Dispute Resolution: E-Commerce and Beyond, 178. 
that it is only possible to distinguish between proceedings that rely heavily on online technology and proceedings that do not. ${ }^{10}$

Some commentators have defined ODR exclusively as the use of ADR assisted principally with ICT tools, although part of the doctrine incorporates a broader approach including online litigation and other sui generis forms of dispute resolution when they are assisted largely by ICT tools designed ad hoc. ${ }^{11}$ The latter definition seems more appropriate as it incorporates all methods used to resolve disputes that are conducted on the internet through a tailored online platform. Moreover, this approach is more consistent with the fact that ODR term was created out of the conceptual distinction with offline dispute resolution processes. ${ }^{12}$

The concept of online ADR is used for referring to those methods involving primarily ADR methods assisted largely by ICT. Similar to ODR, the boundaries of ADR are a debatable concept. In England and Wales ADR is considered as covering all methods for resolving disputes other than litigation. By contrast, in the United States ADR is generally referred to as 'non-adjudicative' dispute resolution, excluding arbitration and other adversarial proceedings. ${ }^{13}$ In this book it has been decided to use the former approach while employing the term of consensual ODR when referring to non-adjudicative ODR methods.

The nature of ODR, like ADR, may derive from public or private sectors depending on the source of the provider. In Spain, for instance, the most widespread consumer ADR method is the Consumer Arbitration Boards, which are of a local origin as they are controlled and funded by the local authorities. ${ }^{14}$ In England and Wales Her Majesty's Court Service has implemented an ODR service within the courts with the introduction of the Online Money Claim. Other types of ADR and ODR methods may have a corporative nature, such as the ombudsman for banks and insurance companies. Finally, ADR and ODR can also be provided by private online start up initiatives such as CyberSettle and Paypal. ODR is therefore not a fixed concept, but one that is evolving, to include any procedure that relies mainly on ICT to resolve disputes. ${ }^{15}$

\subsubsection{A brief bistory of $O D R$}

The first ODR scheme ever launched was the Virtual Magistrate (VM) located in Villanova University (Philadelphia, USA) and founded by the National Centre for Automated Information Research in 1995. The VM was a voluntary online arbitration procedure aimed to resolve disputes between Internet Service Providers (ISPs) and users. At that time, it was not clear whether the ISPs could be held responsible for the activities of their users, so there was a concern that ISPs could be sued quite often on basis of these activities. ${ }^{16}$ The VM had competence to deal with disputes arising from defamation, intellectual property, fraud and illegal appropriation of commercial secrets etc. This project rendered only one decision, Tierney $v$ Email America, ${ }^{17}$ which, 
incidentally, was not a very popular one. The decision ordered America Online (AOL) to remove a commercial notice posted on its website advertising the availability of millions of e-mail addresses that could be used for bulk e-mailing.

Benyekhlef and Gélinas believe that this project was unsuccessful for three reasons. ${ }^{18}$ The first was because of the exclusion of all commercial transactions, including those where arbitration seemed to be an appropriate method. Moreover, in their view, for some of the competencies given to the VM, mediation might have been more appropriate. The second reason was on account of the primitive software used, which relied mainly on non-secure e-mail. Finally, they claimed that the contractual arbitration used by this project could not effectively enforce arbitral awards. It appears that this scheme was ahead of its time. In addition to the above reasons, Katsh and Rifkin maintained that the main difficulty that the scheme encountered was to persuade respondents to participate in arbitration. ${ }^{19}$ Initially AOL, the largest ISP at the time, had informally agreed to refer disputes to the VM, but as AOL had the authority to terminate their contract for almost any reason, it decided not to risk its power and independence by outsourcing these decisions. The VM did not succeed in persuading other ISPs to participate in the scheme. Katsh and Rifkin observed that the lesson learnt was that "whoever has the economic power in a dispute is unlikely to be eager to surrender that power to a third party decision-maker'. ${ }^{20}$ Indeed, this is a difficulty faced in the resolution of $\mathrm{B} 2 \mathrm{C}$ disputes.

Shortly afterwards the Online Ombudsman Office was launched in 1996. It offered mediation services for all internet disputes. ${ }^{21}$ This project showed that working within a particular marketplace is very useful for attracting users. ${ }^{22}$ CyberTribunal also appeared in 1996. It was a ground-breaking service in dispute resolution combining mediation and arbitration. The service ended in 1999, when the founders set up a new project eResolution. All these ODR schemes were experimental in nature and aimed at creating a viable ODR system. Looking back at the short history of ODR, it is possible to divide the emergence of ODR into four different phases:

(i) Hobbyist phase: It is understood that this phase was from the creation of the internet until 1995, when ODR did not exist. During this time the first disputes arose from the internet and informal ODR mechanisms were used. Ideas started appearing in the different methods as to how these disputes could be solved in an effective manner.

(ii) Experimental phase: from 1995 to 1998, when more disputes started to appear and the first ODR initiatives were used by not-for-profit organisations, eg VM.

(iii) Entrepreneurial phase: from 1998 to 2002, when the ODR industry started to emerge and commercial enterprises had successful initiatives, eg SquareTrade and CyberSettle. ${ }^{23}$

(iv) Institutional phase: This phase was initiated in 2002 and continues to the 
present. It refers to the adoption of ODR programmes by public bodies, eg Online Money Claim in England and Wales and the Online Small Claims in Ireland.

According to Conley Tyler, as of March 2006, at least 149 ODR services have been launched worldwide, ${ }^{24}$ although many of them have since closed down or appear to be dormant, without significant activity. The reasons contributing to hinder the development of ODR services are analysed throughout this book.

\subsubsection{Advantages and difficulties in using $O D R$}

The use of ICT to resolve disputes changes the dynamics by which parties interact. There are pros and cons when using ICT. According to Rule, the aim is to design ODR platforms that maximise the pros and minimise the cons. ${ }^{25}$

\subsubsection{Advantages}

\subsection{TIME SAVINGS}

The use of the internet to resolve disputes can speed up the procedure since parties have more flexibility when using ODR asynchronous communications. This is because ODR allows parties to work at any convenient time $24 / 7$, ie not just during court hours or with scheduled meetings. ${ }^{26}$

\subsection{CONVENIENCE OF THE PROCEDURE}

The use of asynchronous communications allows the parties to be prepared to produce their best response without being easily intimidated or bullied. ${ }^{27}$ Moreover, some scholars consider that asynchronous communications allow parties to think more thoroughly than in verbal exchanges before actually sending their messages. ${ }^{28}$ It also opens lines of communication that are not used in the more formal offline legal procedures. Ponte and Cavenagh maintain that ODR often uses confidential procedures which encourage parties to be more honest in a trusting environment that fosters settlement. ${ }^{29}$ ODR facilitates the parties to start working on the resolution of their disputes immediately. It also allows neutral third parties to continue assisting the parties after key communications. ${ }^{30}$

\subsection{COSTS SAVINGS}

ODR offers a lower cost than offline procedures because there are no travel and accommodation expenses, which in international consumer disputes are frequently higher than the value of the dispute. The use of informal means of ODR facilitates self-representation and fast settlements resulting in cost and 
time savings. Lower expenses expand the possibility of using ODR in low value disputes, increasing consumer access to justice.

\subsection{LITIGATION}

ADR has significant advantages when compared with litigation, which can be added to ODR services. The most significant advantage is that the parties have greater control over the processes and the decision. For instance, in consensual ODR the parties create their own agreement without having it imposed on them by a third party. As a result, there may not always be strict winners and losers. ${ }^{31}$ In addition, the parties may select the most convenient neutral third party and process. Neutral third parties are experts on the particular area of the dispute, which can remove the need for lawyers and expert witnesses. ${ }^{32}$ By contrast, judges are compelled to follow existing procedures and precedents. When consensual ODR methods are used the rules of evidence do not apply; hence procedures are more flexible and the parties need not be represented by a legal practitioner.

\subsection{CONTROL OVER OUTCOMES}

Consensual ODR gives the parties more control over the outcomes, increasing conflict resolution options and encouraging enforcement. Parties can reach agreements without the limitations imposed by the law. Additionally, when parties voluntarily agree upon a decision there is a better chance of voluntary compliance than when the decision is imposed by a judge, since in the latter case one party will often feel unsatisfied with the decision. Furthermore, judicial enforcement is complicated, slow and expensive, particularly when enforcing cross-border decisions.

\subsection{APPROPRIATENESS}

ODR seems to be the most appropriate tool to address online disputes. Ponte and Cavenagh observe that ' $[t]$ he online community is looking for conflict resolution options that mirror the speed and efficiency of the Web'. ${ }^{33}$ However, it would be foolish to see ODR as a panacea for consumer disputes; ${ }^{34}$ in fact, ODR is facing many difficulties in its implementation.

\subsubsection{Difficulties}

\subsection{LACK OF FACE-TO-FACE CONTACT}

Body language, tone of voice and facial expressions are important components of communications. The absence of non-verbal cues may facilitate misrepresentation of identity ${ }^{35}$ and lead to miscommunication. Videoconferencing and other online technologies may help to compensate for the 
lack of face-to-face contact ${ }^{36}$ but they will not be able completely to substitute it. Neutral third parties and technology have an important role in delivering meaningful communications and building trust. This requires different training for neutral third parties. The interpretation of written communications, although different from physical communications, is also possible. It has been argued that face-to-face communications tend to favour those who are physically attractive and more articulate, and it can create possible bias in terms of religion, sex, nationality or physical appearance. ${ }^{37}$ In this context, the internet enables parties to self-represent, thus removing prejudices. $^{38}$

\subsection{TECHNOLOGICAL PROBLEMS}

The argument that ODR favours those who are familiar with computers is losing ground as the number of people using computers on a regular basis is increasing; however, parties may have different levels of knowledge and skills. In addition, there are no equal technical standards, ie technology advances differ in every country. Presently, within the EU many people still use dial-up as well as broadband connections.

\subsection{LANGUAGE BARRIERS}

Currently most existing ODR services use only the English language, which can be another difficulty in expressing accurate information and avoiding miscommunications. This can be a barrier not just for those parties who do not speak the language but also for those parties who use it as a second or third language.

\subsection{LEGAL DIFFICULTIES}

The absence of clear legal standards for ODR creates many difficulties, particularly if the need of public enforcement arises.

\subsection{NEED FOR PARTY CONSENT}

Litigation is an adversarial procedure familiar to those who use it regularly. For those who refuse to participate in court proceedings, the latter may summon them with subpoenas and fines. But how can online ADR procedures summon the parties, especially when the EU prevents the application of ODR (or ADR generally) if it impedes consumers' access to court? ${ }^{39}$

\subsection{LOSS OF PUBLIC ACCESS AND PRESSURE}

ODR generally applies confidential procedures which may cover up important information about defective products, poor customer service, discriminatory 
practices and other unethical business conduct that, if publicly known, would impact on consumer purchasing choices. On the other hand, it can be argued that the role of the public authorities is to police these abuses, while ODR can be used as an effective mechanism to obtain fast and fair redress for consumers.

The above issues have been listed as ODR difficulties instead of ODR disadvantages, as most of them can be overcome or mitigated with appropriate practice, technologies and law. It must be noted that some of the advantages and difficulties perceived above are arguable since they are based on certain assumptions that would need reliable empirical data to be categorically confirmed. ${ }^{40}$

\subsubsection{Dispute avoidance}

ODR can be divided into dispute avoidance and dispute resolution. ${ }^{41}$ The first refers to the use of ICT to impede the occurrence of disputes between the parties and the resolution of disputes at an early stage without requiring the disputants to become fully engaged in a dispute resolution process. The second refers to ICT as applied in the settlement of disputes. This book focuses on dispute resolution mechanisms, although it is necessary at least briefly to refer to the several dispute avoidance mechanisms as they contribute to a better understanding of the potential of ICT for resolving disputes. An effective use of these mechanisms can help businesses and consumers to alleviate the need for external resolution procedures, saving the parties valuable time and money. There are many types of dispute avoidance mechanisms, and those referred to below are the main ones currently in use.

\subsubsection{Internal complaint procedures}

These are also called internal dispute settlements, in-house customer satisfaction systems, call centres, complaint services etc. Internal complaint procedures are the most popular and preferred method to impede the appearance of B2C disputes. ${ }^{42}$ The Organisation for Economic Co-operation and Development (OECD) issued the E-Commerce Guidelines for Consumer Protection, where it highlighted in 2007 the need to use these in-house processes effectively, ${ }^{43}$ because it is a beneficial strategy for providing consumers and businesses with quick and inexpensive solutions. ${ }^{44}$ In this regard it has suggested that merchants should improve their complaint handling procedures before investing in external ODR procedures. ${ }^{45}$ The Global Business Dialogue on E-Commerce (GBDe) also considers that in most cases the use of these mechanisms is recommended prior the use of external ODR. ${ }^{46}$

Direct negotiations between businesses and consumers are of paramount importance as most disputes can be solved by this method if it is used appropriately. ${ }^{47}$ Internal complaint procedures can be made more convenient when complemented with ICT. For instance, the use of ODR software may 
assure that consumers include all critical information needed for the resolution of disputes, thus providing effective case management tools. The potential downside of this is that ODR software may open the floodgates for frivolous, vexatious or non-meritorious claims.

\subsubsection{Escrows and online payment providers}

Another dispute avoidance system is the escrow service, which is an online payment option that, for a small fee, maintains accounts for online buyers who want to make deposits via electronic money transfers. The money is transferred to the seller once the buyer receives and approves the purchased item, after an agreed inspection period. ${ }^{48}$ This method helps to avoid the problem of fraudulent sellers. ${ }^{49}$

Escrow services are not commonly used by online consumers, perhaps because they cost money and complicate the otherwise quick buying process. In addition, consumers who use credit cards or other payment services to make online purchases may already be protected to a similar degree through the credit card's chargeback policy.

Online payment providers, such as Paypal.com, first recommend the parties to work through the dispute together. Paypal.com has launched a dispute resolution centre which facilitates communications between the buyer and seller. According to Colin Rule, since launching the centre, buyers' claims against sellers decreased by 50 per cent, and seller losses on Paypal.com owing to chargebacks decreased by 20 per cent. ${ }^{50}$ If the negotiation between the parties fails to produce a satisfactory result, the buyer may escalate the dispute into a claim; in this case Paypal.com will temporarily retain the money paid by a buyer when the latter makes a complaint within 45 days after the payment. Paypal.com holds the money until the dispute is settled, but only in those cases where the merchandise did not arrive, or the description of the product was 'significantly different' to the product itself. ${ }^{51}$ In these circumstances Paypal.com acts as an online arbitrator which will first examine the documentary evidence provided by the parties, and then will resolve the dispute, providing the parties with an instant and effective enforcement. However, in circumstances where the seller withdraws the money from his account before the buyer makes the claim, Paypal.com will not be responsible for the buyer's loss. Both eBay and PayPal offer members comprehensive programmes that provide protection against loss from non-delivery or misrepresentation for most purchases up to a certain value. ${ }^{52}$

\subsubsection{Online shopping assistants}

Online shopping assistants fulfil a similar role as trustmarks as they inform consumers about the sellers in order help them avoid disputes, particularly those related to fraudulent issues. An interesting example of dispute avoidance is a software tool created by the European Consumer Centre (ECC) in 
Denmark called the Howard Shopping Assistant. ${ }^{53}$ It is simple to use. The consumer only has to type the domain name of the business and the software will deliver the following information:

- when the website was registered/updated

- the results of an archive.org search, which shows the images of the website of the online business during the last few years

- official company register information

- the results of a Google search excluding the website of the online business

- the adherence of the online business to a trustmark scheme

- the existing trustmarks in the country where the online business is based

- the general limitation period, eg a minimum of two years

- the general cancellation period, ie 14 days

- examples of website comparison in the country of the online business

- contact information of the national ECC.

The Howard Shopping Assistant is therefore a website that helps consumers to check whether an online business is reliable or not. This software is a very useful initiative that promotes consumer empowerment and dispute avoidance.

\subsubsection{Feedback systems}

The aim of a reputation or feedback system is to increase the users' confidence by giving them the information and experience of former users. Feedback systems are particularly popular among online auction houses because they occur to some extent on a 'blind basis', that is between unknown sellers and buyers, where the buyer cannot always adequately assess the seller and the goods. ${ }^{54}$ As a consequence, there is a large potential for lack of consumers' confidence. In order to minimise this, online auction houses such as eBay, which hosts around 16 million online auctions a day, have developed rating systems that show comments from former buyers in previous transactions.

The eBay feedback rating system is a prime example of a database readily available to buyers and sellers alike. Every eBay seller is ranked in each transaction with positive, negative and neutral feedback by the buyer. Before purchasing anything on eBay a buyer will first check the reliability of the seller, and will decide whether or not to do business with that seller, taking into account the result of the seller's previous transactions. The better reputation a seller has, the more trust that seller will inspire in future buyers. This allows sellers with good reputations to charge higher prices than other competitors. This system encourages a sustainable market competence that is impossible to replicate in the offline world. Katsh and Rifkin observe that 'online auctions, even though they have an innately distrustful atmosphere, have succeeded because of software that makes the auction a 
convenient multiparty negotiation space and that integrates devices for building trust. ${ }^{55}$

\subsubsection{Trustmarks}

Trustmarks were designed with the aim of distinguishing reputable sellers, particularly SMEs without widely recognised brands. Trustmarks assure consumers that trustmark carriers comply with quality standards and that they pledge to participate in an ODR system should a dispute arise between the seller and the buyer. For instance, SquareTrade claimed that their trustmark users increase their sales by over 15 per cent after joining SquareTrade. ${ }^{56}$ Trustmarks, trustseals and certification programs are different words to designate protocols or standards of good practice for privacy, dispute resolution and e-commerce. Independent trustmark providers are trust enablers, which supply their seals or slogans to their member websites as long as they comply with the standards of good practice. ${ }^{57}$ In order to do so, trustmark providers generally require a number of requisites, such as that businesses trade in the online market for a certain period of time, eg a year before they can qualify to apply for the seal or trustmark. ${ }^{58}$ If the online business does not comply with the required standards, the seal may be removed by the trustmark provider.

According to Rule there are some websites that are reluctant to post trustmarks on their homepage for a number of reasons: it may not fit the design of the site, it may look like advertisement or a bit defensive, it may take a user away from the site etc. ${ }^{59}$ To minimise these negative effects some merchants have decided to place their trustmark logo outside the home page.

In order to be effective, a trustmark needs to create a popular brand that reaches a critical mass. Most trustmarks are mainly national and intended for particular markets. ${ }^{60}$ At European level the two largest schemes are Trusted Shops and Euro-Label but they have not yet obtained a significant market share. ${ }^{61}$ Despite this, the European Parliament continues to push for the expansion of a European trustmark for SMEs. ${ }^{62}$ Outside the EU only a few have achieved a successful penetration in e-commerce. This is the case of the Better Business Bureau (BBB) and TRUSTe. ${ }^{63}$

To date, the most well known trustmark provider is TRUSTe. This is a notfor-profit organisation which aims to ensure that its members disclose how personal information obtained by them is handled. ${ }^{64}$ It certifies website privacy and e-mail policies, monitors practices and resolves consumer disputes related to privacy violations. TRUSTe Watchdog is the name of the ODR program. In order to use this mechanism, TRUSTe first asks claimants to attempt to resolve their disputes directly with the seal holder through direct negotiation. When parties cannot reach an agreement TRUSTe Watchdog studies the claim and produces a decision. In its decision TRUSTe Watchdog can ask a seal holder to have certain information corrected or deleted; it can request a website to change its policy on privacy, but it cannot require 
a seal holder to pay monetary damages. ${ }^{65}$ Appeals can be submitted to TRUSTe within 10 days of the initial decision. If the seal holder refuses to comply with the decision, TRUSTe may revoke their seal and communicate, if appropriate, the matter to the national regulator or the courts.

The reliability of TRUSTe has been widely criticised because, despite having handled thousands of disputes, to date TRUSTe has never revoked a single seal. One of the most controversial cases involved a claim against Yahoo!'s decision to change its personal information policy, which affected information collected prior to the change of its policy.

The main problem of trustmarks is that their proliferation has brought confusion and a lack of harmonisation to the standards for consumer protection. The creation of European minimum standards for trustmarks linking them to the ECC-Net might help to maintain a minimum criterion. ${ }^{66}$ In the EU most e-commerce participants are in favour of creating a European trustmark but the main hurdle is the financing of this project. It is debatable whether self-regulation and private funding in this area are efficient and fair, particularly when this is supported exclusively by the businesses. Thus, it may be more appropriate if these trustmark providers are backed by a governmental or regional authority, consumer associations and industry groups. By contrast, if trustmarks are left without any control it may create a false appearance of protection that is to the detriment of many consumers. This would result in the opposite effect than the one for which they were created, ie that of increasing the confidence and protection of consumers. ${ }^{67}$ Furthermore, empirical evidence suggests that certified businesses are more likely to breach the code of conduct than those that are not certified. ${ }^{68}$

The US Better Business Bureau (BBB), in a joint venture with the Federation of European Direct Marketing, Eurochambers and many other organisations that encourage consumer trust in e-commerce, embarked in the development of an international trustmark and ODR cross-border standards. ${ }^{69}$ The minimum standards are based on the self-regulation efforts carried out by the OECD and the GBDe. ${ }^{70}$ This ongoing project is called the Global Trustmark Alliance (GTA) and it aims to launch an international trustmark, co-branding it with the existing national schemes, as well as to provide a transatlantic system for handling B2C disputes. A similar initiative related to the GTA was a cross-border complaint project provided by BBB, TrustUK and WebTraderUK. ${ }^{71}$ Unfortunately these projects currently seem to be at a standstill.

On the one hand, the major advantage of trustmarks is that they reduce fraud by making it more difficult for rogue traders to operate. On the other hand the major challenge is to attain brand recognition of the trustmark and to obtain a sustainable financial model. This will be best achieved with the assistance of a public regional coordination and an effective awareness strategy showing businesses that a trustmark could increase their market share, increasing consumers' trust and reducing the chances of court actions when the trustmark program is complemented with ODR services. If this is done 
effectively it will contribute significantly to increasing consumer confidence in e-commerce.

\subsubsection{A proposal: Trustmark complemented with a feedback system}

One of the main objectives of consumer ODR is to promote consumer confidence in legitimate businesses. This has already been largely obtained by companies such as eBay, which has achieved the trust of millions of customers by using a very successful feedback system. However, there has not been success in replicating a feedback system for the global e-commerce market. Often, when we find a new website selling something, we generally have concerns that the supplier may be a fraudster or that the product is not as good as advertised. In order to enhance trust in potential consumers, businesses could adhere to feedback ratings designed by ODR providers and trustmark schemes. ${ }^{72}$

The first likely obstacle to this is that many businesses would probably not want to participate in a trustmark scheme that could give them negative feedback. Much of the reticence in business to participate in a public forum for voicing customer dissatisfaction is the fear of negative commentary which might be unfair or exaggerated. This is particularly problematic on the internet, which moves so fast and allows people to rant, castigate and condemn so easily. However, if the trustmark scheme is a reputable one (ie one with public backing, such as the BBB Online and the ECC-Net) and the business is a small enterprise that does not have anything to lose by opening its product to the global market, it might be worth it for the business to join. Perhaps, something along these lines would only be appealing for small businesses; that alone would be a small step forward to improve the trust of the online community as well as the competence in the global electronic market, which is still dominated by large corporations, where brand recognition remains vitally important.

\subsubsection{Dispute resolution}

\subsubsection{Automated negotiation: CyberSettle case study}

Automated negotiation is carried out exclusively by an ODR platform without the intervention of a neutral third party. It usually involves a 'blind bidding' negotiation process designed to determine economic settlements for claims in which liability is not challenged. It occurs when one party invites the other to negotiate the amount of money in dispute. If the other party agrees, they start a blind bidding process whereby both parties make secret offers, which will only be disclosed if both offers match certain standards. They can usually submit up to three offers and if the difference between them is less than a percentage (usually ranging from 30 down to 5 per cent) or a given amount of money, then the settlement will be the mid-point of the two offers. Although it is a simple method, it effectively encourages the parties to 
settle, splitting the difference when the amounts are close. This method has proven to be particularly successful with insurance compensations and commercial activities. It is also a valuable tool for disputants because they can use it without revealing their bottom line settlements (unless an agreement is reached) and, more importantly, without waiving their right to access the court, in the case that the negotiation turns out to be unsuccessful.

Currently, the main provider is CyberSettle, which has been working online since 1998 settling over 200,000 disputes for more than US\$1.6 billion, where US $\$ 12.5$ million was its largest online settlement. ${ }^{73}$ There are approximately 150,000 attorneys registered with CyberSettle, of whom 30,000 have already used CyberSettle to facilitate the settlement of their clients' disputes. CyberSettle commenced resolving insurance disputes but it has now expanded its services to other claims. For instance, CyberSettle entered into a contract with the City of New York to assist the city and its citizens in settling claims related to sidewalks, city property, traffic devices, motor vehicles, personal injury etc. ${ }^{74}$ This shows how ODR is useful for resolving bricks and mortar disputes that arise with businesses, insurance companies and municipalities.

CyberSettle has also developed a system called RapidFunds to provide settlement funds in less than 72 hours. ${ }^{75}$ CyberSettle entered into a strategic alliance with the American Arbitration Association (AAA) allowing its clients to use both companies' ADR and ODR services. ${ }^{76}$ Clients are initially able to use automated negotiation from CyberSettle and, if they cannot settle their dispute, they will be directed to use the conciliation, mediation or arbitration services with the AAA. Similarly, blind bidding can be considered in those cases where initially a number of issues are at a stake but after the use of mediation, for example, the only remaining issue in dispute is the amount of money. CyberSettle now offers optional telephone facilitation for unresolved disputes.

CyberSettle has been subject to a number of criticisms. According to Weiss the fairness of CyberSettle is doubtful owing to the fact that repeat users can 'cheat' through their capacity to aggregate bid histories and outcomes in a manner that a one-time user cannot. ${ }^{77}$ In addition, he argues that the system fails to provide trade offs. Deffains and Gabuthy contend that CyberSettle creates a situation similar to the 'prisoner's dilemma' (game theory) in which the aggressiveness of the parties leads them to use a strategic approach that produces suboptimal results. ${ }^{78}$ They further maintain that the success of CyberSettle rests on the protection of their patent and its subsequent lack of competition. This argument may be contested since there were other ODR providers, such as The Mediation Room and SmartSettle One, which provided similar services. $^{79}$

It is worthwhile noting that the blind bidding system works very well in the US with CyberSettle, but it did not succeed in the UK. The reason for this is owing to the way lawyers get paid in both countries. ${ }^{80}$ In the US, lawyers in certain claims, such as personal injury claims, may get paid a proportion of the money recovered (ie contingency fee), while in the EU the system is 
different. In the UK, for instance, solicitors may charge an additional fee when they win their cases (ie conditional fees), although fees are always related to the number of billable hours. Therefore, there is a strong economic incentive to drag disputes out as long as possible. ${ }^{81}$ However, the system in the UK may soon change if fixed fees are implemented and contingency fees allowed. ${ }^{82}$ If this happens, lawyers will be interested in settling as soon as possible, thus encouraging the use of systems such as blind bidding.

Objectively, the achievements of CyberSettle are undeniable. CyberSettle has developed successful software that contributed to the settlement of over 100,000 disputes. This was attained by targeting particular industry sectors, such as insurance companies, and providing a fast and highly automated ODR tool that deals with simple monetary claims. The main advantage of automated negotiation is that it has the potential for saving money and years of litigation for both parties. The main disadvantage is that it deals only with monetary disputes where liability is not at stake. Therefore, in order to reach its full potential automatic negotiation must be used as a complement to other ODR processes.

\subsubsection{Assisted negotiation, online mediation and online conciliation:}

Square'Trade case study

Mediators use information management skills encouraging parties to reach an amicable agreement; in doing so, they enable parties to communicate more effectively through the rephrasing of their arguments. Conciliation is similar to mediation but, in addition, the conciliator can propose solutions for the parties to consider before an agreement is reached. Also, assisted negotiation procedures are designed to improve parties' communications through the assistance of a third party or software. In fact, some commentators argue that assisted negotiation, conciliation, and even facilitation, are just different words for mediation. ${ }^{83}$ The major advantages of these processes, when used online, are their informality, simplicity and consumer friendliness. ${ }^{84}$

The leading ODR provider for consumer mediation was until recently SquareTrade. However, following changes in the eBay feedback system in May 2008, SquareTrade decided to stop resolving eBay feedback disputes from June 2008. ${ }^{85}$ It seems that SquareTrade continues to provide services to eBay users, such as warranty services and the trustmark program. This section will pay particular attention to SquareTrade as it operated successfully for a number of years and created a model that furthered the development of ODR. Currently, the ODR services provided by SquareTrade have been taken over by eBay and PayPal dispute resolution services, but results on these services are still scarce. For these reasons, it is still relevant to discuss the functioning of SquareTrade, which was contracted by a number of market places, the largest of which was eBay.

SquareTrade did not handle disputes between users and eBay; it handled only those between sellers and buyers on eBay. SquareTrade offered two levels 
of dispute resolution: assisted negotiation and mediation, but it was only used after eBay's own consumer satisfaction process. eBay limits its assistance by first 'identifying the key information that needs to be exchanged between parties and implementing a procedure that guarantees the exchange of these data. ${ }^{86}$ By contrast, SquareTrade's automatic negotiation software matches solutions to problems. During its existence, SquareTrade boasted of having resolved over 2 million disputes across 120 countries in five different languages. ${ }^{87}$ SquareTrade resolved small value disputes using a process in which a mediator assists disputants through asynchronous e-mail and web communications with the parties. SquareTrade employed around 200 mediators from over 15 different countries. ${ }^{88}$ At present, more detailed statistics on the negotiation and mediation schemes are not publicly available. ${ }^{89}$

The advantage of dealing with large numbers of disputes is that the same issues arise many times and thus it is possible to divide the disputes into different sections. The SquareTrade process started when a buyer or a seller filed a complaint. To do so, the claimant was asked to fill out a web-based standard claim form that identified the type of dispute and presented a list of common solutions, from which the claimant selected the ones that he agreed to. ${ }^{90}$ The other party was contacted by e-mail where he was informed about the SquareTrade process, and asked whether he wished to participate. The parties were often keen on participating because this was the only manner by which the buyer could get redress and the seller positive feedback. The other party filed the response, selecting the resolutions. If both parties agreed on the same resolution, the dispute was resolved. When an agreement could not be reached, parties were put into a negotiation environment. A web interface was used to shape communications into a constructive and polite negotiation. This was achieved with software tools that limited the free text space, encouraged the proposition of agreements, set deadlines and even shaped the tone of exchanges.

This software was the key element of the process because it took over some of the expertise of the third party. This process could be defined as 'mediated negotiation'. According to Rabinovich-Einy, SquareTrade technology

... [i]ntervenes in the negotiations between the parties and, by allowing parties to formulate and reformulate the problem and the solution, performs some of what would be associated with a mediator's role, moving the parties from a problem mode to a solution stance. ${ }^{91}$

Most disputes (over 80 per cent) were resolved during the first two stages, which was an impressive success rate given that, in the majority of cases, the parties had already been involved in some type of failed direct negotiation before engaging with SquareTrade. ${ }^{92}$ In the rest of the cases a mediator could be requested for a nominal fee, acting as an expert evaluator or conciliator that made settlement proposals to the parties. ${ }^{93}$ This second stage involved the payment of a US\$29.95 fee. According to SquareTrade, '[a] sophisticated case 
management technology enables mediators to handle lower to medium-value consumer disputes in an efficient cost effective manner' ${ }^{94}$ The appointed mediator proposed solutions, if required by the parties to do so. Agreements were always kept confidential by SquareTrade, and became binding as contracts.

SquareTrade has proven that processes such as online negotiation and online mediation can be efficient tools to resolve consumer disputes. One of the key issues for the success of SquareTrade was the simplicity and convenience of this service. In addition, SquareTrade services to eBay were concentrated on a reduced number of issues, such as delays, bad descriptions and negative feedback. This made possible the development of an efficient automatic process that enhanced online negotiation. The success of consensual and automated processes depends on the nature of the dispute, the accuracy of information provided and the capability of the software or the neutral third party in assessing and evaluating the facts and evidence. SquareTrade was particularly effective because it introduced incentives that encouraged parties' participation; in other words, both parties wished to resolve their dispute: sellers wanted to obtain positive feedback and buyers wanted redress.

\subsubsection{Online arbitration}

Arbitration is a process where a neutral third party (arbitrator) delivers a decision which is final and binding on both parties. It can be defined as a quasi-judicial procedure because the award replaces a judicial decision. ${ }^{95}$ In an arbitration procedure, however, parties can usually choose the arbitrator and the basis on which the arbitrator makes the decision, ie the applicable law. Furthermore, it is less formal than litigation, although more so than any other consensual procedure. It is often used to resolve businesses' disputes because this procedure is noted for being private and faster than litigation. Once the process is initiated, the parties cannot abandon it. Another feature of arbitration is that the award is enforceable in most countries owing to the wide adoption of the 1958 New York Convention on the Recognition and Enforcement of Foreign Arbitral Awards. ${ }^{96}$ Moreover, arbitral awards frequently prove easier to enforce than court decisions from overseas.

Arbitration is far easier to conduct online than mediation processes because neutral third parties do not have to engage with the disputants in such an intense manner. Despite this, arbitration is probably the least popular ODR method for the resolution of consumer disputes, especially at an international level. The reason for this is that it is difficult to secure the other party's consent once the dispute has arisen. In fact, EU law and consumer groups have traditionally disfavoured the use of arbitration for fear that arbitration would impede consumers from enforcing their full procedural and substantive rights in the courts. ${ }^{97}$ Nevertheless, presently some consumer groups are taking a more supportive approach given the existing difficulties in applying domestic laws to cross-border disputes, as well as the increase of consumer arbitration services managed by reputable providers. ${ }^{98}$ 
The majority of legal studies on online arbitration agree that neither law nor arbitral principles prevent arbitration from taking place online. ${ }^{99}$ Although online arbitration seems admissible under the New York Convention and the E-Commerce Directive, this is to some extent an assumption by most commentators, rather than a legal statement. ${ }^{100}$ Currently, most ODR providers allow parties to carry out part of the arbitration process online, eg parties may download claim-forms, the submission of documents through standard e-mail or secure web interface, the use of telephone hearings etc. ${ }^{101}$

The main challenge for online arbitration is that if judicial enforcement is required then it partly defeats the purpose of having an online process. For this reason, some dispute resolution processes have developed self-enforcement mechanisms such as technical enforcements, black lists and trustmarks. Nonetheless, this is not always feasible; in order to develop online arbitration there is a need to amend the New York Convention allowing the validity of arbitral awards arising from ODR processes. This could also be done through an EC regulatory instrument that would establish the requirements for the validity of online arbitral awards. However, to ensure that online arbitral awards of consumer disputes will be enforced, it will be necessary to set strict legal standards.

\subsubsection{Sui Generis arbitration: UDRP and chargebacks}

Traditionally, arbitration resolves disputes by delivering a decision that will be legally binding, ie enforceable by the courts. Non-legally binding arbitration processes may also be effective when using ODR tools because they encourage settlements by injecting a dose of reality and objectivity. ${ }^{102}$ Self-enforcement measures may reinforce the efficacy of non-binding processes. The most significant example is the Uniform Domain Names Dispute Resolution Policy (UDRP) created by the Internet Corporation for Assigned Names and Numbers (ICANN). Some commentators have referred to the UDRP as an administrative process. In any case, the UDRP has developed a transparent global ODR process that allows trade mark owners to fight cybersquatting successfully. ${ }^{103}$ The UDRP is used for resolving disputes between trade mark owners and those who allegedly have registered a domain name in bad faith for the purpose of reselling it for a profit, or taking advantage of the reputation of a trademark. This ODR process will be examined in detail in the next chapter.

One of the main focuses of e-commerce to date has been related to secure payment systems. Chargeback is a remedy used to reverse transactions made with credit or debit cards when fraudulent usage has occurred, or when there is a violation of the contract terms. In the UK consumers have the right to claim damages from the credit card issuer when the purchase value is within the range of $£ 100-£ 30,000 .{ }^{104}$ This would also apply when an UK consumer deals with a foreign business, which eliminates the need for the consumer to initiate a legal action in a foreign jurisdiction. ${ }^{105}$ This method is very popular among 
consumers since this is the main method used to transfer money online and consumers are not required to give evidence to cancel a payment. The seller has the burden of proving that the merchandise or service was given according to the contract terms. Once this is proven, the bank makes the payment to the seller. Exceptionally, when a particular seller has several chargebacks, the bank may deny the seller the use of credit card facilities for his transactions.

Chargebacks are largely used around the world for banks and the main credit card suppliers, such as Visa and American Express. However, the coverage of debit and credit cards varies considerably among different countries. For this reason one of the weaknesses is the fact that chargebacks are not always extended internationally, thus limiting the scope of the remedy's application in e-commerce. ${ }^{106}$ Commonly, debit card holders have fewer protections than credit card holders, but these also vary depending on the jurisdiction. In the UK, for instance, credit card holders have more protections than debit card holders, while in Ireland the protections afforded to consumers are the same. ${ }^{107}$ This disharmony occurs even though the same European directives are applicable to both Member States; this is due to the fact that most of these services do not depend exclusively on the regulations, but also on self-regulatory provisions. ${ }^{108}$

This remedy intends to balance the inequality of power between consumers and businesses, encouraging the latter to be fair when dealing with consumers. It is regarded as a very efficient dispute resolution method for consumers because of the speed, accessibility and lack of charge for this service to their clients, who would simply have to notify their banks to cancel a transaction. Edwards and Wilson, however, pointed out that there is a lack of awareness among consumers as to their rights under European law in the event of a credit card transaction going wrong. ${ }^{109}$

Conversely, the existing systems are considered largely inefficient for businesses since the credit card company acts as an arbitrator without engaging in an adversarial hearing process, which prima facie tends to favour consumers as the burden of proof is on the business. ${ }^{110}$ Moreover, businesses are aware that repeated chargeback claims against them will jeopardise their card privileges and are therefore likely to be cooperative. Rule correctly observes that the financial market is a good source for the resolution of disputes online because disputes appear often, it has the means to enforce decisions (as it holds the money) and there is ample money to finance it. ${ }^{111}$ The main limitation is that the financial market is heavily regulated and many transactions are of a low value.

\subsubsection{Online small claims courts}

Small claims procedures provide a middle ground between formal litigation and ADR, where disputes involving small value claims can be resolved faster, cheaply and less formally. The main limitation of small claims procedures is that they are restricted to particular jurisdictions. In order to overcome 
this limitation the European Commission has created the Regulation for a European Small Claims Procedure (ESCP), which implementation took place in January 2009. ${ }^{12}$ The ESCP is predominantly a written procedure that deals with claims under $€ 2000$ arising in cross-border disputes. Its main advantage is that it provides for the enforcement of decisions in any of the Member States without the present need to go through the formal mutual recognition of judgments, ie exequatur.

The introduction of the ESCP will need to rely on ICT if it is to realise the efficient enforcement of the rights of European consumers. Member States will decide about the use of ICT for the ESCP; but since the ESCP is a written procedure which deals with small value disputes between individuals located in different countries, it will necessarily have to use ICT in order to make the legal procedure cost effective. However, consumers might still prefer to use other ODR methods if providers offer better systems, with cheaper and quicker resolutions.

It must also be taken into account that ESCP is only applicable to EU Member States, which may persuade businesses with a market outside the EU to opt for creating a contractual clause referring all disputes to an ODR provider capable of being equally applicable to EU citizens and to those from overseas. It must be noted that exclusionary contractual clauses may be considered unfair under the forthcoming Directive on Consumer Rights for limiting consumers' access to justice, unless the agreement of consumers takes place after the dispute arises. Consumers will only agree to use an ODR process if it is cheaper and faster than the ESCP.

\subsubsection{Other ODR techniques}

\subsection{MED-ARB}

Med-Arb allows parties to use a tiered process in which the parties are given the chance to negotiate on their own or with the assistance of a mediator. If the parties are incapable of reaching an agreement, then they may ask the online mediator to act as an arbitrator and to render a decision on the unresolved issues, which can be binding or not binding, as the case may be. ${ }^{113}$

\subsection{NEUTRAL EVALUATION}

Here, similarly to arbitration, a neutral third party makes a decision on the basis of the written submissions and evidence provided by the parties. However, in the case of evaluation this decision takes the form of a non-binding recommendation. This feature may make participation more attractive for the parties, but it cannot ensure the resolution of the dispute. Kaufmann-Kohler and Schultz believe that there is clear potential for the development of neutral evaluation. ${ }^{114}$ In fact, SquareTrade offered these types of services when the mediator suggested settlements. 


\subsection{OMBUDSMEN}

These are independent bodies which carry out investigations on the failure of services, when a consumer lodges a complaint. Most schemes are controlled by professional sectors, such as the ombudsman in insurance and finances. Ombudsman's proceedings generally use mediation and conciliation techniques. These services are free of charge for consumers and decisions are only binding towards the professionals involved in the particular sector. ${ }^{115}$ An example is the European Ombudsman, which investigates complaints (which may be filed online) about maladministration in the institutions and bodies of the European Union. ${ }^{116}$

\subsection{MOCK JURIES}

These are ODR processes whereby a jury of voluntary peers makes nonbinding decisions of the issues in dispute via a web-based platform, eg eBay Community Court and iCourthouse. ${ }^{117}$ The lack of deliberation at some websites makes the experience seem closer to an online opinion poll than to a traditional jury trial. According to Marder, these cyberjuries are evolving from online opinion polls to online mock juries, where lawyers test cases in cyberspace before presenting them to a jury in a court room. ${ }^{118}$ Perhaps, the next step will be online juries.

\subsubsection{European initiatives promoting the use of consumer ODR}

The European Commission has funded several initiatives with the aim of strengthening the internal market. Among these initiatives there are several projects related to ODR which are intended to increase consumers' confidence in the European market. This section discusses three of the most relevant European projects: Consumer Complaint Form, ECODIR and ECC-Net. ${ }^{119}$

\subsubsection{Internal complaint handling: The consumer complaint form}

The initial project was launched by the European Commission in 1999 and was known as the CCform, which stands for consumer complaint form. ${ }^{120}$ The CCform was designed to help European consumers to file complaints and businesses to process them through the use of a consumer friendly form with standardised questions based on a multiple tick approach. The CCform could be translated into 11 languages, with the exception of the free comments area.

This initiative allowed consumers to file free online complaints to those SMEs which had been registered under the CCform programme. ${ }^{121} \mathrm{Com}-$ plaints could also be sent to non-registered merchants. In these cases, the CCform platform first approached the merchant to confirm its registration. Businesses that joined the CCform project were joined into the contract of the CCform Code of Conduct and were required to display its logo on their websites as a trustmark. A serious breach of the Code of Conduct would result 
in sanctions, such as financial penalties, public censure, or temporary or permanent cancellation of CCform membership.

The CCform was turned into what is now called the 'consumer complaint form', which provides a standard complaint form for European consumers. ${ }^{122}$ The new complaint form is also available in 11 languages on the websites of the European Commission and the European Consumer Centres Network (ECC-Net). The form consists of four pages, together with a User's Guide. It can be used for national and cross-border disputes regardless of the amount involved. The European Commission intends to launch a pilot project in the near future, in order to assess the form's relevance and effectiveness. ${ }^{123}$ It appears from the limited existing empirical studies that it is still relatively unknown among most consumers and businesses. ${ }^{124}$

\subsubsection{Dispute resolution providers: ECODIR}

At the European level, the first and most developed ODR project to resolve cross-border consumer disputes is ECODIR (Electronic Consumer Dispute Resolution). This project came as a result of the intention of the European Commission to improve European consumers' access to justice through the use of ICT and ADR. ${ }^{125}$ ECODIR was funded by the European Commission and two research centres, from University College Dublin and the University of Namur. The programming support came from the Canadian project eResolution. ECODIR was designed to resolve small value consumer disputes through a tiered procedure that included, first, negotiation, then mediation and, finally, recommendation. ECODIR provides a mechanism similar to SquareTrade, and allows the filing of complaints in two languages, namely English and French. ${ }^{126}$ During the pilot phase ECODIR allowed the parties voluntarily to file their disputes free of charge. The limited experience of ECODIR has revealed that most cases were resolved during the mediation phase. $^{127}$

ECODIR was intended to be launched on the market as a not-for-profit organisation in 2003. However, this was frustrated largely to two main hurdles: first, the lack of awareness from businesses and consumers; and, secondly, the withdrawal of public funding. ${ }^{128}$ ECODIR's rights were sold to the National Arbitration Forum (NAF). Cruquenaire, ECODIR coordinator, observed that a lesson learnt from ECODIR was that it failed to engage the parties, suggesting that trustmarks and convincing businesses to seek legal advice through their lawyers might have been a more effective approach. ${ }^{129}$ Hutchinson, supervisor of ECODIR, also pointed out that the main difficulty was to persuade businesses to participate. ${ }^{130}$ Seemingly, this occurred partially because of misinterpretation of ECODIR, which was often identified as a consumer watchdog and as an investigatory authority, instead of a neutral and secure environment for consumer dispute settlement.

ECODIR experience proves that the promotion of awareness is a central issue that requires the cooperation of the parties' representatives, consumer 
groups and professional associations. Before online businesses decide to join in any ODR scheme, they must understand clearly its value in practical terms. Awareness must be communicated in an appropriate manner and with the necessary incentives, for instance in the form of reputation (eg trustmarks) and cost savings (eg online proceedings as opposed to offline complaint handling proceedings).

\subsubsection{Clearing houses: The ECC-NET}

The European Consumer Centres Network (ECC-Net) is an EU-wide network that includes all the Member States as well as Norway and Iceland. Its primary function is to promote consumer confidence within the European market by informing consumers about their rights and remedies in crossborder transactions. The network is co-financed by the Health and Consumer Protection Directorate General of the European Commission and each of the national governments. The secondary functions of the ECC are to provide feedback to the European Commission on consumers' disputes and to co-ordinate the operation of approved national ADR and ODR schemes. The list of approved ADR and ODR providers is available online with the links of those that comply with EU Recommendations 1998/257/EC and 2001/310/ EC. ${ }^{131}$ For instance, in Ireland, a dispute resolution provider may apply to the Department of Enterprise, Trade and Employment (DETE) to be approved by completing an online form. Both DETE and ECC-Ireland must review the application and, once it is agreed that the applicant satisfies all the requirements established in the recommendations, the provider will be added to the database of ADR providers.

It is worth noting that, even though almost half of the complaints concern e-commerce transactions, ${ }^{132}$ only a small number of the approved ADR schemes also offer ODR services. The lack of a formal monitoring system makes one wonder whether the existing ODR services comply on an ongoing basis with the minimum legal requirements established by European law. A recent independent report for the European Commission has remarked that not all of the approved national ADR and ODR service providers comply with the recommendations. ${ }^{133}$

Consumers' queries are directed to the national ECC. The habitual methods of communication are by e-mail or telephone, although it is possible to post letters or visit the offices. ${ }^{134}$ The website has information related to consumers' rights and frequently received complaints. When consumers contact the ECC staff directly, they will be advised on their rights and, if necessary, the ECC may recommend approaching the trader to seek an amicable solution. If that fails, the ECC may contact the trader directly or recommend the use of the approved ADR or ODR providers. However, given that this works on a voluntary basis, if traders refuse to cooperate the only option left to enforce consumers' rights is through litigation. According to the ECCIreland, this option has never been recommended in cross-border disputes 
because it was considered unfeasible, at least up until the implementation of the European small claims procedure. ${ }^{135}$

\subsection{ODR challenges}

\subsubsection{Challenges to ODR}

Despite the fact that the performance of national litigation with online disputes has been impractical and expensive, ODR has not yet achieved widespread market implementation. Indeed, ODR is still emerging. Successful providers are used for specific subject matters (eg UDRP for domain names) or for specific market places (eg PayPal for eBay) where the 'demand is very high and competitors perform quite badly'. ${ }^{136}$ A report from the OECD concluded that one of the reasons why ODR has not reached its full efficiency is because it has not yet been able to achieve the desire of cost effective services appropriate for the resolution of mainstream e-commerce disputes, ie small value disputes. ${ }^{137}$

This section examines the main challenges posed to consumer ODR service providers for achieving effective market implementation. It starts by considering how present ODR projects are being funded and the perils of impartiality that this may cause. Directing parties to ODR is another major challenge, which needs to be overcome by promoting awareness, using contractual clauses referring to ODR, providing the right balance between confidentiality and transparency and using trustmarks. Due process issues are at stake when a power imbalance exists; in this regard, this section examines key aspects such as the selection of neutral third parties, review panels, reasoned decisions, legal representations and the exertion of control over ODR providers. Enforcement can be difficult in voluntary ODR procedures; thus, public and private strategies are examined. Finally, the role of technology as the fourth party assisting individuals to resolve their disputes is evaluated. The key to delivering better expertise to the parties appears to be in designing ODR systems that focus on certain types of disputes. ${ }^{138}$

\subsubsection{Funding}

\subsubsection{Public funding}

ODR models may be promoted as matter of public policy by governments since efficient ODR can contribute to the sustainable growth of e-commerce. In fact, to date most B2C ODR projects have obtained some funding from public bodies. The Better Business Bureau (BBB) has suggested that the expense of effective systems will require a partnership amongst governments, not-for-profit foundations, academic institutions and the private sector, in order to ensure that, at the least, the technological infrastructure is created. ${ }^{139}$ The American Bar Association (ABA) Task Force has also supported the idea 
of government subsidies. ${ }^{140}$ The ABA maintains that if disputes are resolved using ODR, courts' expenses may be reduced. Although it has to be acknowledged that most online disputes are of low value, they would not have ended up in court if ODR services had not been provided.

The assistance of ICT is being introduced to court procedures as well as to ADR services. The funding for court processes, such as the Online Money Claim in the UK, and the Online Small Claims in Ireland, are the same as in the offline world: co-funded between the state and the litigants. This is true for most ADR services. For instance, the Dutch Foundation of ADR Committees for Consumer Affairs, an independent organisation offering ADR services, in addition to the users' fees, has received financial support from the Ministry of Justice. ${ }^{141}$ Also, the Danish Consumer Complaints Board is funded by public funds and fees paid by businesses and consumers. The fee is refunded when parties either settle or win the claim. Similarly, the UK Chartered Institute of Arbitration charges claimants a low registration fee that will be refunded if they succeed with their claim. In other cases, such as the Arbitration Scheme in Spain, participation is free for consumers. ${ }^{142}$

\subsubsection{Private funding}

Ponte observes that insurance policies might cover ODR expenses instead of legal expenses, though such policies will be more costly as the number of claims with ODR services will increase. ${ }^{143}$ Insurance companies can calculate the risk of bad transactions among all participants and cover those transactions that go awry. Rule points out that this may be an incentive for sellers to engage in fraud knowing that the insurance company will cover buyers' losses ${ }^{144}$ however, insurance premiums could increase accordingly.

Private funding to secure sufficient income may jeopardise the independence of an ODR service provider, especially in B2C transactions where a unilateral fees model, from the business, seems to be the most common way to encourage consumers' participation. In order to avoid a perception of bias Katsh and Rifkin note that the ODR provider should publish if there is any funding given by the business. ${ }^{145}$ Transparency should be complemented with additional mechanisms to ensure impartiality, such as systems to handle complaints when procedures were not followed. ${ }^{146}$

The only available survey on ODR funding sources found that user fees have been the predominant funding mechanism for ODR providers. ${ }^{147}$ This has taken many forms, including a filing fee, an hourly rate for neutral third parties, a standard fee or a percentage of settlement reached.

Most ethical rules for dispute resolution practice state that the fee for dispute resolution process cannot be contingent on the outcome of the case. For instance, actions of the mediator can be easily affected by such conditional compensation, allowing an inequitable settlement or lowering the expectations of one party. ${ }^{148}$ Even though, economic incentives may create problems in the neutrality of human managed ADR processes; it may not 
cause problems in an ODR process where automated processes are used, eg CyberSettle.com.

If the market considers that the use of ODR is necessary for its development it will subsidise it. This was the case of eBay which funded SquareTrade in order to promote trust in its online auctions. Consumers International recommends the participation in ODR free of charge thus encouraging its use; alternatively, it has been suggested that a moderate charge would make the process more valuable and would discourage frivolous claims. ${ }^{149}$ Costs could also follow the event if the parties agree to that, but the full payment of the fee must be made in advance to ensure an expeditious enforcement.

It appears, however, that funding is not the only challenge or difficulty for the implementation of ODR. Conley Tyler observes that for "providers that have not attracted business, the fees charged do not appear to be the problem: their fees are not notably more than for successful enterprises' ${ }^{150}$ Evidence of the truth of this was through the ODR providers who failed to attract parties despite offering free services during their initial pilot phase, such as the VM funded by the University of Villanova and ECODIR funded by the European Commission. Since public funding is not the only requirement for creating efficient consumer ODR, governments could fund ODR services in a more effective way to ensure market implementation. Different strategies could be adopted, such as giving funding to those ODR programmes which have achieved market implementation, subsidising e-businesses in creating effective in-house customer services, providing some type of tax incentives for those businesses that adhere to ODR service providers etc.

\subsubsection{Directing disputants to ODR services}

\subsubsection{Awareness}

Greater awareness and understanding of ADR concepts and processes are needed for ODR to flourish. ${ }^{151}$ ODR is futile if consumers are unaware of its availability and where to find it. ${ }^{152}$ Even in the event that an individual has submitted a complaint to an ODR service that is not linked to the other party (generally the business), the real challenge will be to convince the party to participate. This is particularly difficult when there is an imbalance of power between the parties. Participation may vary depending on the chosen ODR process. In the case of arbitration it would be easier to engage when parties have agreed before the dispute arises. This, however, may present legal problems within the EU, unless it is a non-binding arbitration, or binding only on the business. In the case of mediation it would be easier to obtain the parties' participation, particularly when there is no significant imbalance of power between them, where there is an interest in maintaining the relationship and when the dispute is not highly confrontational.

Katsh and Rifkin maintain that businesses may be reluctant to offer ODR 
in case their customers might think that disputes were a frequent occurrence. They suggest that consumers must be informed not just about their rights, but assuring them that they also have remedies which can be enforced. ${ }^{153}$ ODR can build trust, but it needs to be advertised appropriately. Intermediaries such as lawyers, consumer organisations and chambers of commerce, may influence the type of remedies available to the parties. ${ }^{154}$ In addition, ODR is frequently offered in the context of affiliation programmes, ie trustmarks. Traders generally affiliate to these schemes on a voluntary basis to enhance consumer confidence. In this context, the goal of ODR is not just to settle disputes but also to enhance consumer confidence in e-commerce. ${ }^{155}$

In order to obtain the parties' confidence in ODR it is necessary to attain the right balance between transparency and confidentiality. ${ }^{156}$ However, approaches to transparency and confidentiality may vary depending on the ODR process in question. For instance, online arbitration systems need to be more open with decisions than consensual methods, such as mediation, because precedents, concerns about bias and conflicts of interest are more pronounced.

\subsubsection{Transparency and informing parties}

In order to enhance trust in ODR providers, some relevant information must be given to the parties, particularly when the ODR provider offers an alternative forum for resolving rights that consumers may have recognised in a legal process. All ODR providers should be subject to mandatory disclosure requirements, including: ${ }^{157}$

- the type of ODR procedure and its main features, eg languages

- restrictions of the procedure, eg monetary threshold etc

- requirements that consumers must meet, eg the previous attempt to obtain redress through the business internal complaint system

- governing structure

- criteria for becoming a neutral third party

- costs, including fees and possible extra costs when decisions need to be enforced

- rules that serve as the basis for the body's decisions, eg legal provisions, considerations of equity, codes of conduct etc

- $\quad$ security measures to keep private data confidential

- enforceability of decisions and agreements

- an annual report evaluating the functioning of the provider.

Of particular importance is the publication of reasoned decisions, which is necessary in order to create a degree of transparency and legal certainty, essential to increasing trust in ODR. This is indispensable in adversarial procedures, especially when resolving B2C disputes with a clear disparity. In addition, it would allow the users, consumers' organisations and governments 
to participate in the evaluation of ODR services, thereby improving their accountability. ${ }^{158}$ On the other hand, the publication of decisions may hamper confidentiality, one of the main attractions of ADR. In the B2C context, businesses do not want publicity for their wrongs, and many users are keen to maintain their privacy. Therefore, a certain balance between these two basic elements, confidentiality and transparency, must be met in order to develop an effective system. ${ }^{159}$ Gaitenby suggests that the names of the parties may be kept confidential; however, this is compatible with maintaining a transparent online process where the decision is published as well as the name and profile of the neutral third party. ${ }^{160}$ Other solutions would be the use of impersonal statistical data, sample cases, selective publication of decisions etc. ${ }^{161}$

\subsubsection{Trust}

ODR seeks to provide trust in online commercial contexts but there still is a considerable lack of trust in ODR itself. ${ }^{162}$ This distrust is augmented by the impotence of a newly acquired distrust derived from the number of disputes arising out of e-commerce. ${ }^{163}$

There are several ways by which ODR providers can enhance confidence in their services; for example by providing press articles and contact information (including e-mail addresses, telephone numbers, real addresses and data protection rules); ${ }^{164}$ supplying simple information about the process and third neutrals; the use of trustmarks; and providing feedback mechanisms. Feedback is a major advantage that ODR has over ADR. ${ }^{165}$ Parties should be allowed to provide feedback regardless of whether their process was successful or not. According to Rule, the best insights on how to improve ODR will be given by the users. ${ }^{166}$ Therefore an effective feedback system can be invaluable.

\subsubsection{Fairness and due process}

There is a concern about the imbalance of power between businesses and consumers. A consumer may use ODR once or twice a year, while a business as repeated players may be using it for dozens of cases at any given time. This increases the imbalance where businesses are likely to make more informed choices than consumers. For this reason, it is important that outside bodies set standards ensuring procedural fairness in B2C processes. ${ }^{167}$ Due process rights need to be respected, but that is not sufficient, consumers need to perceive that their rights are being respected too. ${ }^{168}$

\subsubsection{Impartiality}

Third parties must be aware of the jurisdiction and the cultural background of the disputants, who may perceive impartiality in different manners. Public institutions may also take an important role ensuring and monitoring impartiality. ${ }^{169}$ 
The extent of neutrality can be questioned when it reaches a point where the mediator refuses to intervene in a decision, even when the parties reach a poor decision. It is arguable whether mediators can suggest outcomes or whether this could conflict with the facilitative role of the mediator. ${ }^{170}$ In cases where the mediator shifts to other roles during the process, eg med-arb, this cannot be considered unethical when parties expressly agree or the code of conduct provides for this possibility. ${ }^{171}$ Although, it should require that the mediator offer the parties the option of selecting another third party. Rule observes that computers are less concerned with perceptions of bias, eg ODR providers, such as SquareTrade (and now PayPal), automatically display a list of common resolutions depending on the type of dispute. ${ }^{172}$

ODR providers must be very scrupulous about preventing any conflict of interests because credibility is essential to gain the trust of disputants and once damaged it is very difficult to re-establish. ${ }^{173}$ Codes of conduct generally ask mediators to acknowledge and withdraw on grounds of independence where there is a conflict of interest, unless all parties agree to retain the mediator. ${ }^{174}$ Conflict of interests would include family ties, business relationships, intimate relationships, former legal representation, etc. In the ODR field there is a concern that the majority of providers do not disclose information on which their major shareholders are, and this is very important in order to avoid conflicts of interest.

\subsubsection{Selection of neutral third parties}

Neutral third parties should have the necessary training to obtain the appropriate skills for assisting in the resolution of online disputes in a fair and satisfactory manner. A higher degree of knowledge of the subject matter will be expected from arbitrors than from mediators, in order to ensure competent and fair awards. In addition, most of the literature considers that special training for ODR services is necessary, but law degrees should not be always required. ${ }^{175}$ The suitability of lawyers as neutral third parties is arguable; for instance, it is generally understood that lawyers are more prepared for dealing with IP disputes, while family disputes can be better dealt with by counsellors and social workers. Furthermore, it can be argued that lawyers with insufficient training might not always be good mediators, particularly if they are unable to depart from their roles as advocates in the judicial process, instead of focusing on assisting the parties to reach a suitable solution amicably.

Online neutral third parties generally have training and experience in the offline world. Gaitenby suggested the transposition of third party training standards and experienced neutral third parties from the ADR field to the ODR field until ODR has achieved enough experience to supply its own training standards and third parties. ${ }^{176}$ Syme points out that '[d]ifferent criteria may be needed for selecting on-line practitioners. For example, written communication skills and typing speed may become more important than oral communication skills and body language'. ${ }^{177}$ For this reason, neutral 
third parties must adapt their communication skills to interact with computers, since there is not a direct correlation between ADR skills and the ability to use ODR efficiently. ${ }^{178}$ Training is needed to teach neutral third parties how to use an ODR platform, answer technical questions from the parties (avoiding the participation of technicians), send efficient and frequent communications with the parties, the use of concurrent caucusing and so on. ${ }^{179}$ The use of ICT facilitates screening of the performance of neutral third parties and identifying mistakes and excluding those who do not work appropriately. This, however, requires substantial investment. ${ }^{180}$

ODR has the advantage of providing a pool of neutral third parties that is not geographically limited, which facilitates the selection of neutral third parties in accordance with the characteristics of the disputes, including technical knowledge, cultural differences, languages, gender and ethnicity. ${ }^{181}$ Nevertheless, the most appropriate neutral third party may be too expensive because the greater the skill and competence of neutral third parties, the greater the amount they charge for their services. Consequently, an inherent risk in dealing with low value disputes is that neutral third parties may come from less experienced staff, which in turn might affect the fairness of the procedure. In order to avoid this Bygrave proposes the merging of similar claims when possible. ${ }^{182}$

\subsubsection{Legal representation}

The manner in which lawyers manage and deliver information is compatible with the use of ICT. ODR must allow legal representation when it is needed since ODR aims to promote and accelerate fair resolutions and not to reduce them. Whenever legal representation takes place, it must be disclosed to the other parties. There are, however, some concerns that may arise from the use of legal representation in ODR procedures. First, the parties might not feel comfortable when their legal representatives or the neutral third parties are less skilful in using ICT. This can be reduced by appropriate training. Secondly, it would be more difficult to monitor licences and the quality of legal representation by bar associations from different countries. These issues may be overcome in time, particularly at a regional level. Thirdly, the downside of legal representation is that it increases the cost of dispute resolution procedures and it adds the risk of making procedures lengthier. ${ }^{183}$ Thus, in a low value dispute parties should avoid obtaining legal representation whenever possible. This can be achieved by using consensual processes and ODR platforms that are user friendly.

Legal representation is not always necessary. For instance, some inquisitorial processes facilitate self-representation, eg the ombudsman. However, legal representation will be more necessary in adversarial processes, assisting disputants in understanding the procedure, the rules and the best manner in presenting their cases. ${ }^{184}$ Under the domestic law of every country there is a possibility of applying for free legal aid in cases where a party lacks sufficient 
resources. In many cases, it can be used for litigation as well as extrajudicial processes. For instance, the AAA in the US, which is the largest not-for-profit ADR organisation, has a fee waiver scheme in favour of consumers without sufficient economic means. ${ }^{185}$

In the EU, since May 2006 a European directive has unified the free legal aid provisions for cross-border disputes. ${ }^{186}$ Legal aid may be used to encourage extrajudicial dispute resolution methods. Notwithstanding this, legal aid has some limitations, because in order to qualify for it, applicants must demonstrate that they have reasonable grounds to initiate proceedings. According to Duggan, reasonable grounds means that the applicant must have a good probability of winning the case and that there is a substantial amount at stake. ${ }^{187}$

Finally, it is important to keep in mind that due process is not the only challenge to ODR. Indeed, according to Edwards and Wilson, even non-biased providers of ODR services such as ECODIR indicate that although due process is a prominent issue in the literature, in reality it neither particularly prevents nor impedes e-commerce consumers to go to ODR'. ${ }^{188}$

\subsubsection{Enforcement}

Most experts agree that another reason which may hamper the development of ODR is the legal uncertainty regarding ODR enforcement. Thornburg considers that governments must ensure that ODR providers comply with minimum standards of due process because they perform public functions, which may ultimately require courts to enforce the outcome. ${ }^{189}$ When parties voluntarily agree upon a decision, compliance may be expected, but it cannot be always assured. In these cases a national court may have to intervene in order to enforce a contractual settlement, which if it is not done efficiently, might empty the utility of the previous ODR service. Presently, there is no clear case law on how courts enforce online agreements. The first ODR enforceable decisions will come from public institutions, such as the Spanish Online Consumer Arbitration Boards, whose decisions are directly enforceable in courts. However, at the time of writing most of the existing initiatives are not delivering online decisions; although that day may not be far off.

In order to avoid enforcement from the judiciary, some ODR services have designed efficient self-enforcement mechanisms. ICANN, for example, requires domain name registrars to enforce UDRP decisions within 10 days of the decisions' publication. There is only one exception, if a legal proceeding is initiated, then enforcement will not take place until the judicial proceeding concludes. ${ }^{190}$ In practice, however, court actions are extremely rare. This may be for a number of reasons: (i) the high cost of litigation; (ii) the fact that cybersquatters may consider their chances for redress very low or; (iii) the 10 day period to bring a court action may be too restrictive etc. As a result, the vast majority of UDRP decisions are final and enforceable. ${ }^{191}$

Trustmarks could also require business members to contribute to a fund 
out of which consumers are compensated when business members fail to honour ODR decisions or agreements. Also blacklists may be effective. The Consumer Complaint Board in Denmark states that 80 per cent of its decisions are voluntarily complied with by the businesses. The remaining decisions are published in a blacklist of defaulters on the consumer agency's website. This strategy of 'naming and shaming' has led to eventual compliance with an additional 30 per cent of the remaining decisions. ${ }^{192}$ Furthermore, the publication of these decisions makes consumers and businesses aware of the importance of buying from a business that has adhered to a dispute resolution scheme and this, in turn, leads businesses to join these schemes. ${ }^{193}$

\subsubsection{The role of technology}

\subsubsection{ICT tools used in ODR}

When comparing ODR with ADR, the main difference is ODR's lack of faceto-face (F2F) interaction between the parties, which is a pillar of ADR. Early writers, such as Eisen, even maintained that the lack of F2F communications would not allow the development of ODR. ${ }^{194}$ Although this assumption has been proven wrong by successful ODR providers, such as the UDRP and CyberSettle, the lack of F2F contact brings new challenges. Certainly, the use of ICT cannot and should not always substitute F2F interactions, although ICT may complement F2F interactions when this benefits the parties. In some circumstances there are reasons for not using F2F communications, because F2F interaction is neither always essential nor superior to ICT communications and, most importantly, F2F communication is not always feasible to resolve e-commerce disputes. ${ }^{195}$

Studies in the field of ODR have revealed that in some cases the lack of physical interaction may benefit the resolution of disputes, for example by cooling down the nerves of the meeting and by compensating those who are not particularly articulate, or who do not have a pleasing physical appearance. In addition, the development of ICT, as well as the rapid increase of broadband users, makes the use of F2F substitutes more accessible, such as videoconferencing and other telecommunications tools like emoticons, helping parties in representing their feelings and emotions.

The first challenge confronting ODR platform designers and neutral third parties is choosing among the different types of online communications. Each online communication technique has its strengths and weaknesses. Hence, ODR providers and neutral third parties must evaluate them in deciding which process is the most appropriate for the needs of a particular dispute. ${ }^{196}$

A difficulty in the growth of ODR is to devise technology which would be compatible between different users and providers. This is important when ODR users may need to store and exchange evidence and other documents. To 
such end there are ongoing efforts to develop ODR-XML (Exchange Markup Language), which is a variant of XML that enables information exchange among ODR systems, providing a standardised system. ${ }^{197}$

ODR will change at the same rate as new online tools and resources are developed. ${ }^{198}$ According to Katsh and Wing, ICT advance is occurring exponentially because ICT expansion increases with the passage of time. ${ }^{199}$ This is clearly seen with the advances in computers and internet connections over the last decade. ${ }^{200}$ The European Commission predicts: 'ICT will become smarter, smaller, safer, faster, always connected and easier to use, with content moving to three-dimensional multimedia formats' ${ }^{201}$ Colin Rule, probably the world's best ODR visionary foresees that:

If wireless access becomes the norm, people may have the ability to engage in dispute resolution procedures on their handheld devices or cellular phones. If artificial intelligence advances rapidly, we may witness a growth in the use of non-human mediators and arbitrators. Translation technology may eventually allow for seamless interactions between people who do not speak the same language. All of these what-ifs may sound like science fiction, but their development will play a crucial role in determining the future of ODR. The only sure thing is that technology will continue to evolve, and in a few years our current tools and techniques will look primitive. ${ }^{202}$

\subsubsection{Security issues}

Security issues are important, in particular when sensitive issues are involved. When using ODR, the parties need to be assured that their communications are protected from external parties to encourage open participation. Security mechanisms are improving with the innovation of technology. Initially, ODR platforms relied on e-mails, where the level of privacy has been compared by Schultz as that of a postcard. ${ }^{203}$ As with due process, the level of security must be in proportion to the amount of money involved in a dispute.

ODR websites are also at risk of virus infections, intrusions or computer or networking crashes. Firewalls, back-up policies and antivirus systems are the standard mechanisms to reduce these risks. ${ }^{204}$ Larson observed that ' $[w] e$ are fighting our way through computer viruses and worms that lead us to question the value and reliability of the online environment'. ${ }^{205}$ Yet, as Hörnle noted, there is no communication method that is absolutely secure; even paper documents can be intercepted, copied or otherwise compromised. ${ }^{206}$

In the online sphere, the most common procedure to encode information is the use of Hyper Text Transfer Protocol [http] plus Secure Socket Layer [SSL]) which is indicated by a domain name preceded by 'https' and displaying a lock symbol in the corner of the user's screen. An additional secure method is the Public Key Infrastructure (PKI) encryption system, which is comprised of 
a public key (held by the client and server) and a private key (held exclusively by the client). Only clients can decode the information using both keys. ${ }^{207}$

\subsubsection{Technology as the fourth party}

In ODR, the information management is not only carried out by physical persons but also by computers and software. The assistance of ICT has been named by Katsh as the 'fourth party' because ODR is seen as an independent input to the management of the dispute. ${ }^{208}$ In addition to the two disputants and the neutral third party, the labelling of technology as the fourth party is a clear metaphor which stresses how the use of technology can be as powerful as changing the traditional three sided model. The fourth party embodies a range of capabilities in the same manner that the third party does. While the fourth party may at times take the place of the third party, ie automated or assisted negotiation, it will frequently be used by the third party as a tool for assisting the process. ${ }^{209}$

The fourth party may do many things, such as organise information, send automatic responses, shape writing communications in a more polite and constructive manner, eg blocking foul language. Furthermore, it can monitor performance, schedule meetings, clarify interests and priorities and so on. ${ }^{210}$ The level of assistance by the fourth party increases the more technological advances, hence reducing the role of the neutral third party.

In offline settings, arguably, the features of the place where parties meet are not important, but when parties meet online the role of cyberspace is of paramount importance, because the fourth party shapes the way expertise is delivered and the way communications take place. ${ }^{211}$ In online negotiation and online mediation the use of the software (fourth party) helps the parties in reaching an agreement by taking on part of the role of the third party.

\subsection{Conclusion}

ODR is understood to be any dispute resolution process which is mainly carried out with the assistance of the internet and ICT. Clearly, ODR has several advantages, but the most significant one is that ODR allows communication at a distance, eliminating the need for travelling and reducing costs. It also allows the use of asynchronous communications delivering a more convenient and flexible option for resolving disputes. As a result, ODR has important potential to increase consumer access to justice. In this regard, ODR may be an alternative to lack of access to justice, rather than an alternative to courts. However, ODR also has a number of pitfalls, such as the lack of face-to-face communications, technological burdens, legal restrictions and so on. In order to release the full potential of ODR, a system must be designed in the best possible manner so as to reduce the number of difficulties and exploit all the advantages of ODR.

ODR can work at two levels. First, ODR can be employed as a dispute 
avoidance mechanism, which aims to limit disputes arising out of $\mathrm{B} 2 \mathrm{C}$ transactions. The most significant methods are internal complaints procedures, escrows, trustmarks and feedbacks. Governments may promote the development of these mechanisms, in particular by providing financial support and monitoring their efficiency. Secondly, many disputes need to be dealt with through neutral third parties using dispute resolution mechanisms. The most significant online methods for resolving consumer disputes are automated negotiation, assisted negotiation, mediation, arbitration and small claims court procedures. Most of the existing data and statistics on cases resolved and other issues relating to ODR providers are not publicly available, which makes it rather difficult to draw more specific conclusions as to the efficacy of the majority of existing ODR providers. Depending on the dispute, the jurisdiction and the participants involved, it may be more appropriate to use one ODR method over another. Within the EU there are some initiatives promoting the use of ODR but they have not achieved a large scale market implementation.

It appears clear that in order to develop efficient ODR services that can achieve market implementation, it will be necessary to overcome a number of challenges as previously identified in this chapter. First, ODR services need to obtain funding from public or private sources while maintaining their independence. Currently, the majority of ODR services in the EU are being co-funded between governments, businesses and consumers, but private funding is not always as transparent as it is required to be for effective and fair ODR in B2C disputes. Greater public financial support would contribute to overcoming the existing lack of awareness and trust. Secondly, another key aspect is to assure that the parties participate, which has been achieved in part by using trustmarks and market referrals (eg SquareTrade) and targeting a particular industry (eg CyberSettle). Another method that still has not been fully explored is the reference of the disputants by clearing houses that monitor and recognise efficient ODR services (eg ECC-NET). Participation in ODR can be strengthened by promoting awareness, increasing users' trust, putting transparent procedures in place and fostering public recognition of the efficient ODR services.

Thirdly, full due process principles are important when there is a power imbalance between the parties, in particular, when the funding and time available for the resolution of disputes is limited. Yet it may be impossible to deliver a full coverage of procedural rights, since it is difficult to deliver the rule of law without the cost of due process requirements. The objective is to balance the value of disputes with the level of due process that assures impartiality, transparency and legal representation when necessary. Fourthly, effective enforcement mechanisms have to be assured. On the one hand, these mechanisms may come from judicial enforcement, although it is not clear yet whether existing regulations allow for the enforcement of ODR agreements. On the other hand, private self-enforcement mechanisms have proven effective, such as blacklistings, feedback mechanisms and technical control (eg ICANN). 
Finally, since ICT plays a central part in ODR, the role of technology as the fourth party is of key importance. The fourth party must be intuitive and the ODR interface must be user friendly. ODR methods and security issues need to take into account the needs of the disputants, which at a minimum should incorporate private and public spaces. If ODR tools are ineffectively used they can be a burden on the dispute resolution process. By contrast, when appropriate ODR technology is effectively utilised, it can be a great contribution to the dispute resolution process. Parties, in particular trained neutral third parties, should clearly understand the weaknesses and strengths of the ICT tools used.

With many existing ODR providers worldwide, ODR is no longer 'science fiction'; it has the potential to become a major part of dispute resolution practice. The future outlook for ODR development seems positive. There are two reasons for this: e-commerce is growing as well as users' confidence and ability in interacting online. ODR is still at an early stage and, as it was conceived online, its growth will depend upon the expansion of cyberspace, the progression of e-commerce, the evolution of technology and the userfriendliness of ODR software. ODR, however, does not depend exclusively on ICT development; it also depends on other issues, such as creating adequate legal standards with the backing of the courts and the legal community. This last aspect will be closely examined in the following chapters, which consider how regulation may contribute to the development of consumer ODR.

In particular, the following chapters deal with specific ODR methods (online small claims courts, arbitration and non-adjudicative methods, especially online mediation) and will examine their potential for efficiently resolving consumer disputes. Governments have an important role in promoting awareness of ODR and in supervising ODR to ensure its compliance with due process concerns. To that end it is necessary to examine if the existing law allows the effective use of consumer ODR, or if new laws need to be created to promote the development of effective and fair ODR services.

\section{Notes}

1 Rule (2002) 89.

2 Some of the ideas expressed in this chapter have been previously published in Cortés (2009) 90-100.

3 Bygrave (7 May 2002) 2. Katsh \& Rifkin (2001).

4 Rule (2002). Colin Rule is the director of dispute resolution for eBay and PayPal.

5 Rule (2002) 37.

6 United Nations Conference on Trade and Development (UNCTAD), E-Commerce and Development Report 2003 'Online Dispute Resolution: E-Commerce and Beyond' ch 7 at 178 .

7 See ch 4 .

8 García Álvaro (2003) 180.

9 Katsh \& Rifkin (2001) 9.

10 Hörnle (2003a) 27. 
11 Kaufmann-Kohler \& Schultz (2004) 5.

12 Schultz (2003a) 6.

13 Michaelson \& Maples (2005) 725.

14 See ch 3.

15 Katsh \& Rifkin (2001) 117; Hörnle (2004) 2.

16 UNCTAD (2003) 203.

17 VM Docket No 96-0001 (8 May 1996).

18 Benyekhlef \& Gélinas (2005) available at http://www.lex-electronica.org/articles/ v10-2/Benyekhlef_Gelinas.pdf.

19 Katsh \& Rifkin (2001) 56.

20 Ibid 107.

21 http://www.ombuds.org/center/ombuds.html.

22 Katsh \& Rifkin (2001) 56.

23 Ibid 47-70.

24 Conley Tyler 'Evaluating Recent Developments in Online Dispute Resolution' Presentation on 22 March 2006 to the Fourth International Forum on ODR, Cairo.

25 Rule (2002) 85.

26 Ross (2004) 2.

27 Rule (2002) 62.

28 Kaufmann-Kohler \& Schultz (2004) 23; Shah (2004) 20; Baumann (2002) 1233; Rule (2002) 63-64; Wahab (2004a) 130.

29 Ponte \& Cavenagh (2005) 24.

30 Rule (2002) 62.

31 Wissler (1995) 324.

32 Ponte \& Cavenagh (2005) 26.

33 Ibid 28.

34 Hörnle (2002).

35 Conley Tyler \& McPherson (2006) 11.

36 Clark, Cho \& Hoyle (2003) 14.

37 Gibbons, Kennedy \& Gibbs (2002) 44.

38 Rule (2002) 68.

39 Council Directive 93/13/ECC Unfair Terms Directive Annex 1 [q] OJ L095 (21 April 1993).

40 Gillieron (2008) 319.

41 Different names are used by other commentators, eg Edwards \& Wilson refer to hard or traditional ODR and soft ODR. See Edwards \& Wilson 'Redress and Alternative Dispute Resolution in Cross-Border E-Commerce Transactions' DG Internal Policies of the Union, Policy Department Economic and Scientific Policy, Briefing Note (IP/A/IMCO/IC/2006-206) 1; Edwards \& Wilson (2007) 328.

42 European Commission, Health and Consumer Protection Directorate-General Directorate B Consumer Affairs prepared by The Study Centre for Consumer Law, Centre for European Economic Law Katholieke Universiteit Leuven, Belgium 'An analysis and evaluation of alternative means of consumer redress other than redress through ordinary judicial proceedings' (17 January 2007) 9 (Leuven Report).

43 OECD E-commerce Guidelines 1999 and OECD Recommendation on Consumer Dispute Resolution and Redress (July 2007) 8.

44 Andrews (19 April 2005) 9 and OECD (11 April 2006) 10.

45 Ramasastry (2004) 164.

46 GBDe New York Recommendations (2003) 56.

47 OECD (July 2007) 67 estimates between 60-80 per cent of consumer disputes can be resolved by using direct negotiation. 
48 http://www.escrow.com.

49 Rule (2002) 102.

50 Interview with Colin Rule, PayPal's Director of Online Dispute Resolution, Practical eCommerce 'Quick Query: PayPal Exec on Payment Disputes' (7 April 2008).

51 Buyer and Seller Protection Policies in www.paypal.com (last modified 7 June 2007).

52 http://pages.ebay.com/help/tp/questions/protection-program.html.

53 http://www.theshoppingassistant.com; European Consumer Centre Denmark http://www.consumereurope.dk; see also European Consumer Centres' Network 'The European Online Marketplace, Consumer Complaints 2007' (May 2008) 31.

54 Tadic-Colic (2005) 251.

55 Katsh \& Rifkin (2001) 38-39.

56 Abernethy 'Building Large-Scale Online Dispute Resolution and Trustmark Systems' Proceedings of the UNECE Forum on ODR (2003) available at http:// www.odr.info/unece2003.

57 http://www.truste.com; http://www.squaretrade.com.

58 http://www.bbbonline.org; Haloush (2007) 84.

59 Rule (2002) 107.

60 Trzaskowski 'Which Trustmarks Schemes Exist Today? Key Findings from a Report on European E-Commerce Trustmark Schemes' ECC-Net Conference 'Trustmarks in the EU' Denmark (10 November 2006).

61 http://www.euro-label.com; http://www.trustedshops.com/.

62 European Parliament Article 'Online Shopping a Domestic Affair?' (26 June 2007).

63 Rule (2002) 107.

64 TRUSTe seals are in well known websites such as Microsoft, Yahoo, AOL and Amazon. Balboni (2009) 36.

65 Consumer Privacy Guide 'What is TRUSTe and how does it work to protect my privacy' available at http://www.consumerprivacyguide.org/faq/truste. shtml\#steps.

66 van den Heuvel 'Online Dispute Resolution as a Solution to Cross-Border E-Disputes: An Introduction to ODR' 21-25 available at http://www.oecd.org/ dataoecd/63/57/1878940.pdf. See also ch 5 of this book.

67 Balboni (2009).

68 Edelman 'Coupons.com and TRUSTe: Lots of Talk, Too Little Action' (18 March 2008) available at http://www.benedelman.org/news/031808-1.html.

69 The Organising Committee is mainly comprised of existent trustmark organisations: BBBOnline, Eurochambres, FEDMA, eCom (Japan), KIEC (Korea), Santiago Chamber of Commerce (Chile), Taiwan Secure Shopping Association, CommerceNet Singapore, TrustUK (now closed), Ecom Trust (EU).

70 http://www.globaltrustmarkalliance.org/index.asp; see also GBDe (2004) Recommendation 4.

71 'BBB, TrustUK and WebTraderUK Create a New Safety Net to Support Cross-Border Ecommerce' available at http://www.crossborderadr.org.

72 Thornburg (2001) 47; Mommers (2006) 182-86.

73 http://www.cybersettle.com; see also Krause (October 2007).

74 Plains "New York City to "CyberSettle" More Cases Online (30 July 2007) available at http://www.cybersettle.com/info/news/pressreleases.aspx? id=36.

75 Zissu 'Cybersettle ${ }^{\circledR}$ RapidFunds ${ }^{\circledR}$ System to Provide Attorney/Claimant Settlement Funds in Less Than 72 Hours' (18 October 2004) available at http:// www.cybersettle.com.

76 Plains 'The American Arbitration Association and CyberSettle Join Forces' (25 September 2006) available at http://www.cybersettle.com. 
77 Weiss (2006) 89.

78 Deffains \& Gabuthy (2005) 205.

79 http://www.smartsettle.com/.

80 Colin Rule interview with Graham Ross (CEO of The Mediation Room) Cyberweek (2007) available at http://www.themediationroom.com/.

81 Duggan (2006).

82 Jackson (8 May 2009).

83 Jacobs 'Mediation Now and Then' in Barbee (ed) Mediation, International Bar Association Legal Practice Division (July 2007) 14.

84 Motion (2005) 145.

85 SquareTrade 'ODR Is No Longer Offered by SquareTrade' available at http:// www.squaretrade.com/pages/odr-discontinued.

86 Rabinovich-Einy (2006) 284; see also Raines, Summer \& Conley Tyler 'From e-Bay to Eternity: Advances in Online Dispute Resolution' (5 April 2006).

87 Katsh \& Wing (2006) 26; Abernethy 'Building Large-Scale Online Dispute Resolution and Trustmark Systems' Proceedings of the UNECE Forum on ODR 2003 available at http://www.odr.info/unece2003.

88 Rabinovich-Einy (2006) 258.

89 E-mail from Steve Abernethy, President \& CEO SquareTrade, to author (10 January 2008) (on file with author) stating that SquareTrade does not publish statistics on its negotiation and mediation program.

90 Rule (2002) 103.

91 Rabinovich-Einy (2006) 258.

92 Katsh \& Rifkin (2001) 142. Abernethy (2003) 2.

93 Rule (2002) 104.

94 Abernethy (2003) available at http://www.odr.info/unece2003 at 2.

95 Green Paper of 19 April 2002 on Alternative Dispute Resolution in Civil and Commercial Law, COM(2002) 196 final.

96 The New York Convention has currently more than 150 signatories. See http:// www.uncitral.org/uncitral/en/uncitral_texts/arbitration.html.

97 eg Council Directive 93/13/ECC Unfair Terms Directive Annex 1 [q] OJ L095 (21 April 1993).

98 Colón-Fung (2007) 243.

99 Hill (1999) 2; Wahab (2004a) 123; Vreeswijk \& Lodder (2006); Katsh \& Rifkin (2001) 138; Kierkegaard (2004) 180.

100 Morek (2006) 165.

101 Ponte \& Cavenagh (2005) 84; Leuven Report (17 January 2007) United States National Report 7. Currently the AAA provides Webfile and Neutrals' eCentre web-based platform to parties and neutrals for the management of the procedures. See http://www.adr.org; see also Davis (2006) 2.

102 Stipanowich 'The Arbitration Penumbra: Arbitration Law and the Rapidly Changing Landscape of Dispute Resolution' Legal Studies Working Paper Series, Paper Number 2008/1.

103 See Internet Corporation for Assigned Names and Numbers (ICANN) and UDRP Policy and Rules.

104 Consumer Credit Act 1974 s 75(3)(b).

105 Ibid s 75(1); Office of Fair Trading v Lloyds TSB [2007] QB 1 at 29 (CA); Hörnle (2009) 38-42.

106 Shannon Martin (2002) 153.

107 OECD (July 2007) 14.

108 OECD (July 2007) 12, 15.

109 Edwards \& Wilson (2007) 17.

110 Consumers International 'Disputes in Cyberspace Report' (2000) available at http://www.consumersinternational.org. 
111 Rule 'ODR in the Financial Sector' paper presented at the 5th ODR Forum Liverpool (19 April 2007).

112 Regulation 861/2007/EC of the European Parliament and of the Council of 11 July 2007 establishing a European Small Claims Procedure OJ L199 1.

113 Ponte \& Cavenagh (2005) 98.

114 Kaufmann-Kohler \& Schultz (2004) 9.

115 See eg the British Banking Ombudsman Scheme available at http:// www.financial-ombudsman.org.uk or the Ombudsman for Pensions in Ireland http://www.pensionsombudsman.ie/.

116 http://www.ombudsman.europa.eu/.

117 For eBay Community Court see http://ccourt.ebaydevelopment.co.uk/ jurypreview and for iCourtHouse see http://www.i-courthouse.com/ main.taf?\&redir $=0$.

118 Marder (2006) 239.

119 EURID is another major EU project which is discussed in ch 3 together with the UDRP. Other ODR providers in the EU are Juripax, Mars, Mediateur du net, Resolvi Online and The Mediation Room.

120 Communication on the out-of-court settlement of consumer disputes of 30 March 1998 (SEC(1998) 576 final) containing a European consumer complaint form.

121 http://ccform.interbyte.be/.

122 The consumer complaint form is available at http://ec.europa.eu/consumers/ redress/compl/cons_compl/acce_just03_en.pdf.

123 A survey from Eurobarometer showed that only 5 per cent of EU citizens knew about the consumer complaint form, European Union Citizens and Access to Justice (October 2004).

124 Evaluation of the pilot project on use of the European consumer complaint form, available at http://ec.europa.eu/consumers/redress/compl/cons_compl/ acce_just13_en.pdf.

125 http://www.ecodir.org.

126 Lodder \& Zeleznikow (2005) 299.

127 During the pilot phase 62 cases were filed with ECODIR. Of these 27 were genuine disputes and the other 35 were test cases. See Kaufmann-Kohler \& Schultz (2004) 338.

128 Interview with Alexandre Cruquenaire in Kaufmann-Kohler \& Schultz (2004) 346.

129 Kaufmann-Kohler \& Schultz (2004) 346.

130 Ibid 339.

131 Recommendations 98/257/CE and 2001/310/CE. See also the database of all approved ADR and ODR bodies at http://ec.europa.eu/consumers/redress/ out_of_court/adrdb_en.htm.

132 ECC-Net Annual Report 2008 (3 August 2009) 15.

133 Leuven Report 11.

134 ECC-Net Annual Report 2008 (3 August 2009) 9.

135 The ECC reported that it is not aware of a single dispute where litigation was advised by a national ECC centre. See ECC-Net Annual Report 2005 (June 2006) 29.

136 Calliess (2003) 651.

137 OECD (July 2007) 23; Gawith (2006) 115.

138 Rule (2002) 255.

139 Leuven Report 97.

140 Thornburg (2001) 57.

141 OECD 'Best Practices for Consumer Policy: Report on the Effectiveness of Enforcement Regimes' (20 December 2006) 34. 
142 Leuven Report (17 January 2007) Spanish National Report.

143 Ponte (2002) 472.

144 Rule (2002) 108.

145 Katsh \& Rifkin (2001) 41.

146 Consumers International (2000) 17.

147 Conley \& Bretherton 'Seventy-Six and Counting: An Analysis of ODR Sites' Proceedings of the UNECE Forum on ODR 2003 at 12.

148 Rule (2002) 58.

149 UNCTAD (2003) 190; Rule (2002) 119.

150 Conley \& Bretherton 'Seventy-Six and Counting: An Analysis of ODR Sites' Proceedings of the UNECE Forum on ODR 2003 at 12.

151 UNCTAD (2003) 195.

152 Kierkegaard (2004) 206.

153 GBDe Recommendations (2003) 53.

154 Ramsay (2006) 34.

155 Nadler (2001) 333.

156 Ramasastry (2004) 166.

157 GBDe Recommendations (2003) 58, and principle of transparency (II) Recommendation 98/257/EC.

158 Rabinovich-Einy (2003/04) 17.

159 Hörnle (2009) 145. She argues that the current balance between confidentiality and transparency is not appropriate.

160 Gaitenby (2004).

161 Rule (2002) 269.

162 Katsh (2007) 100.

163 Schultz (2003a).

164 ICC Best Practices for Online Dispute Resolution in B2C and C2C transactions at 12; Katsh \& Rifkin (2001) 82.

165 Webb (2004) 133.

166 Rule (2002) 230.

167 Ibid 111.

168 Ibid 237.

169 Ibid 112.

170 McCorkle (2005) 166, 179.

171 Ibid 180.

172 Rule (2002) 56-57.

173 Ibid.

174 McCorkle (2005) 175.

175 GBDe Recommendations (2003) 60 and ICC Best Practices for Online Dispute Resolution in B2C and C2C Transactions at 11.

176 Gaitenby (2004).

177 Syme (2006) 348.

178 Hörnle (2003a) 9.

179 Rule (2002) 234.

180 Abernethy (2003) available at http://www.odr.info/unece2003 at 3.

181 Rule (2002) 243.

182 Bygrave (7 May 2002) 4. See also ch 5 of this book.

183 Perritt (2000a) 681.

184 Ibid.

185 http://www.adr.org.

186 Council Directive 2003/8/EC.

187 Duggan (2006) 51.

188 Edwards \& Wilson (2007) 5.

189 Thornburg (2001) 54. 
190 UDRP Policy para 4(k).

191 See ch 3.

192 Knudsen 'The Danish ADR System' paper presented at the Conference on ADR in Spain and the EU, Madrid (11-12 December 2006).

193 Ibid ECC Ireland 23.

194 Eisen (1998) 1354.

195 Syme (2006) 346; Katsh \& Rifkin (2001) 9.

196 Rule (2002) 246.

197 CEN/ISS Workshop Agreement on Standardization of Online Dispute Resolution Tools prCWA XXX (20 October 2009) available at http://www.cen.eu.

198 Katsh \& Rifkin (2001) 2.

199 Katsh \& Wing (2006) 27.

200 Ibid.

201 Communication from the Commission to the Council, European Parliament, the European Economic and Social Committee and the Committee of the Regions, i2010 - A European Information Society for growth and employment $\operatorname{COM}(2005) 229$ final at 3.

202 Rule (2002) 300.

203 Schultz, Kaufmann-Kohler, Langer \& Bonnet (2001).

204 Ponte \& Cavenagh (2005) 9.

205 Larson (2004) 131.

206 Hörnle (2003a).

207 Rabinovich-Einy (2006) 43.

208 Katsh \& Rifkin (2001) 93-117.

209 Katsh \& Wing (2006) 31; Gaitenby (2006) 372. Some scholars have more recently introduced the fifth party (the provider of the technology). See Lodder (2006) 143-55.

210 Katsh \& Rifkin (2001) 129.

211 Ibid 32. 


\title{
3 Consumer adjudicative processes supported by technology
}

\author{
Court processes and arbitration
}

ODR has the potential to fundamentally change the way litigators function and to become mainstream. ${ }^{1}$

The foundations of dispute resolution will be rocked by a combination of electronic disclosure, e-filing in the courts and online dispute resolution. ${ }^{2}$

\subsection{Introduction}

This chapter discusses how adjudicative dispute resolution processes are implementing technology, thus potentially allowing the resolution of online disputes. To that end, this chapter examines the effects of such procedures, eg mandatory use, binding decisions and so on. In addition, it assesses which adjudicative process, whether litigation or arbitration, is more suitable for dealing with consumer disputes arising out of e-commerce. Throughout this chapter, there is also an underlying discussion that considers how the law allows for the establishment of online adjudicative processes, and which circumstances contributed to their appearance, shortcomings and success.

This chapter is divided into two main parts: judicial and arbitral processes. The first part (3.2) considers judicial procedures supported by ICT. The first section comments on three domestic judicial procedures, namely the Irish small claims procedure, the English Money Claim Online and the Australian eCourt initiative. Thereafter, this section evaluates the regulation establishing a European small claims procedure, which is a judicial procedure implemented since January 2009 to deal with cross-border disputes of low value (below €2000) between parties situated in different Member States.

The second part of the chapter (3.3) deals with consumer arbitration and its compatibility with the use of ICT. First, this part examines the existing legal obstacles in the implementation of online arbitral procedures for consumer disputes. This section begins by considering the legality of pre-dispute arbitral clauses in two contrasting jurisdictions, the EU and the US, making a comparison between them. It then moves on to examine the enforceability of arbitral awards under the New York Convention. The second section examines the regulation of a national arbitration programme: the Spanish 
consumer arbitration boards, which specifically regulate online arbitration. The last and most extensive section evaluates international arbitration analysing, in detail, the online (non-binding) arbitration scheme for the resolution of domain name disputes (UDRP). This process has been involved in some controversy, with many commentators appealing for reform; despite this, it is a relatively fast and inexpensive procedure that deals efficiently with cybersquatting complaints. This section also discusses how the online arbitral procedure for domain names could be improved by reforming the existing process. Lastly, this section considers whether it would be possible to adapt the UDRP to resolve mainstream $\mathrm{B} 2 \mathrm{C}$ disputes arising out of e-commerce transactions.

\subsection{Online judicial processes}

\subsubsection{Domestic disputes: The incorporation of technology into the judicial process}

The use of technology in judicial processes is hoped to increase their access and effectiveness since parties involved in an online process are expected to save money and time. Courts are increasingly incorporating the use of ICT with features such as online case filing, case management and litigation support tools. ${ }^{3}$ The incorporation of ICT in the courts is generally referred to as e-Justice. ${ }^{4}$ Although these features do not qualify the traditional courts as ODR schemes per se, they form the first step towards the constitution of ODR, which combined with other applications for communications or decision-making will provide a true ODR system.

\subsubsection{Ireland: The online small claims court}

The online Small Claims Procedure (SCP) in Ireland has already been discussed in Chapter 1; thus, rather than set out its procedure again, this section will consider some of its consequences in practice. ${ }^{5}$

The Irish procedure allows consumers to lodge claims online and follow their cases through a web-based platform accessible using a PIN number. In the event that the defendant does not accept liability for the claim and decides to contest it, the parties will physically have to attend the hearing at the district court. Hence, the online process is only limited to certain aspects of the procedure.

Initially, the main hindrance with the SCP in Ireland was the lodging of the claims; in many cases claimants did not correctly include the name of the respondent, ie the name of the legal entity. ${ }^{6}$ According to the registrar of the Cork District Court, in 2007 there were over 100 claims made through the online service in court, of which half were dismissed because the claimant had failed to comply with some of the legal requirements. ${ }^{7}$ The reasons were mainly owing to defects of form, such as failing to write the legal 
name of the business, or defects of substance, that is when the claim fell outside the scope of the SCP, such as debts or private sales. ${ }^{8}$ It must be noted that when parties file their claims physically in the district court office, they are directly assisted by the registrar. Consequently, most of these offline claims are admitted.

\subsubsection{The UK: Money Claim Online and Possession Claim Online}

The online procedure can be used by consumers, businesses, government agencies and solicitors claiming debts in England and Wales. Computer requirements are very basic, such as an internet connection and Acrobat Reader. ${ }^{9}$ The claimant only needs to send the claim and the court in turn notifies the defendant. The defendant can enter a defence online and at every stage parties are encouraged to settle their dispute amicably. ${ }^{10}$ During the procedure parties can view the status of their claim, judgment or warrant. Parties may also pay their fees (which are lower than in the physical courts) to issue claims and warrants online by debit or credit card. The online procedure has been designed to be user friendly and it is supported by a customer help desk, which may be contacted by email or phone. ${ }^{11}$

Money Claim Online has handled over 200,000 claims and it is proving even more popular in recent times. The number of cases has increased significantly in recent years, passing from handling 300 new cases a day in 2006 to double this number in 2007. ${ }^{12}$ One of the reasons for such an increase appears to be that people are using the website to reclaim unauthorised overdraft bank charges, which are not reviewed by the Financial Ombudsman. This situation, however, illustrates how the use of online lodging may open a floodgate of cases slowing down the process of applications.

Similarly, Possession Claim Online (PCOL) was launched by Her Majesty's Courts Service in October 2006 to deal with claims of possession of residential property. ${ }^{13}$ The new service enables property owners, such as landlords, local authorities and mortgage lenders, to apply electronically for repossession when rent and mortgages are not paid. ${ }^{14}$ The PCOL allows parties to fill out their claims online, track their claims through the website and even to plea for warrants to be issued via the online service. ${ }^{15}$

Online processes were initially applied to simple legal matters such as debts and repossession claims. Nevertheless, distant communications are being increasingly included into the ordinary procedures. Thus, in the UK the use of telephone hearings is being introduced in the county courts, with the aim of making them the norm. However, telephone hearings will not be conducted where parties are without legal representation, where more than four parties apply for physical hearings or where the hearing could result in the final determination of the whole or part of the proceedings. This initiative follows the success of pilot schemes in Newcastle Combined Court Centre, and in Luton and Bedford county courts. ${ }^{16}$

More recently, in January 2010, a new Practice Direction complementing 
the CPR was issued to regulate an Electronic Working Scheme that is operational since April 2010. Under the new scheme it is possible to initiate claims online pursuant to Parts 7,8 and 20, and also arbitration claims and admiralty proceedings in the Admiralty and Commercial Court, the London Mercantile Court, the Technology and Construction Court, and in the Chancery Division of the High Court. ${ }^{17}$

\subsubsection{Australia: The eCourt initiative}

ODR technology can be useful not only to resolve those disputes that are impractical for the courts (eg e-commerce disputes) but also in the administration of public justice. As put by Clifford J of the Supreme Court of New South Wales, the 'use of technology to achieve necessary efficiencies in relation to litigation is not only highly desirable but sometimes absolutely essential'. ${ }^{18}$ With this purpose, the Federal Court of Australia has developed a pilot programme called eCourt that aims to take full advantage of ICT tools to resolve certain disputes, in particular demands on native title jurisdiction, where many parties are located far away. In 2004 the court implemented Casetrack, which is software that manages the court information. This in turn allows a number of ODR services.

First, case law is uploaded to the court website in real time and the e-search tool allows the parties to browse information on specific cases. The e-filing system permits the lodgement of applications, evidence and the payment of fees online. Under this new programme the court can give directions to the parties through the website forum (ie e-Court Forum), which the parties can access with a password. The forum is also used for mediation with court registrars playing the role of mediators. In addition, the forum may be employed for pre-trial matters, such as sending receipt of submissions, affidavits, hearings through video and telephone conferencing etc.

The advantage of these procedural features is that courts have the flexibility of using them whenever deemed necessary. For instance, according to the Leuven Report:

[T] he Conciliation, Trader and Tenancy Tribunal Act 2001 empowers the Tribunal largely to determine its own procedures, allowing it to be as flexible and informal as circumstances require, which may include lodging forms online and conducting hearings by telephone. ${ }^{19}$

In addition, the Electronic Transactions Act 2000 empowers the Attorney General to establish an electronic case management system that could enable documents to be served electronically, communication between the parties and the court to be in electronic form and the tracking of cases online etc. ${ }^{20}$

Online judicial processes are increasingly utilised in multiparty complex litigation. An example is the native title case of De Rose, which was an electronic trial from start to finish. ${ }^{21}$ This case, however, raised a number of 
issues with regard to security, costs and technical support. These issues convinced the court of the necessity of creating new guidelines and practice notes for the parties who wish to consider the use of electronic trials. ${ }^{22}$ Tamberlin discusses the three main criticisms of the e-Court initiative: ${ }^{23}$

(i) The limitation of access to justice; where most submissions are made online in writing may place a disadvantage on those with literacy or language difficulties. However, when parties are provided with legal assistance, written submissions should not present an imbalance of power between the parties.

(ii) The use of ICT tools often does not have the benefit of body language communications. Tamberlin maintains that ICT must be a complement to the procedure, using it only when it is beneficial.

(iii) Another criticism is the lack of publicity, but it is suggested that publicity can be respected by the use of the court registry. In other words, although the hearings may be conducted in private, the judgments of these cases could be uploaded onto the court website.

\subsubsection{Cross-border disputes: European small claims procedure}

This section considers the regulation establishing the European Small Claims Procedure (ESCP), which came into force in all Member States, with the exception of Denmark, in January 2009. ${ }^{24}$ With the objective of increasing consumer confidence and a truly integrated Common Market, the European Commission has produced a pan-European procedure to deal with low value disputes. The ESCP is predominantly a written procedure that deals with claims under $€ 2000$ in value arising in cross-border disputes within the EU. It provides enforcement of contested decisions in any of the Member States without the need of going through the mutual recognition of judgments. This section discusses the challenges posed by the new procedure and it suggests that the ESCP, in conjunction with ICT tools, has the potential to realise more efficient enforcement of consumers' rights. However, the optimal effectiveness of this procedure might be hindered by some of its restrictions, such as its exclusive competence for cross-border claims, its low economic limit and its lack of support of ADR and ODR.

\subsubsection{Genesis of ESCP}

The development of e-commerce and the increasing use of the EC rights of free movement of persons, goods and services had a knock-on effect in number of cross-border disputes within the EU. The Amsterdam Treaty empowered the Community to adopt measures in the field of judicial co-operation in civil matters with cross-border implications, insofar as this is necessary for the proper functioning of the internal market. ${ }^{25}$ The ESCP was first proposed in the Tampere European Council in October 1999, together 
with other two initiatives: the European Enforcement Order (EEO) and the European Order for Payment (EOP) ${ }^{26}$ One of the dangers of the ESCP is that large businesses and corporations may use this procedure mainly for the collection of small debts from consumers and small businesses. Hence, on the one hand the European Commission has opted for creating a specific process to deal with debts, the EOP. On the other hand, the EEO is a method of enforcing foreign judgments of uncontested claims in the EU and without the need of going through the recognition procedure set out in the Brussels Regulation.

The EOP is a fast written procedure that deals with uncontested debts. In the event that the defendant contests the claim it would automatically transfer the claim to the ordinary civil procedure. These two initiatives, unlike the ESCP, are restricted to pecuniary claims (without financial limits) and they are available for cross-border as well as domestic litigation.

\subsubsection{Main features of the ESCP}

\subsection{SCOPE OF THE ESCP}

The scope of the ESCP is all civil and commercial matters. This includes not just consumer disputes but a range of civil claims, such as personal injury compensation, disability discrimination and unequal access to services. There are a number of exceptions to the ESCP, given existing deep differences among Member States. Under the ESCP claims cannot exceed $€ 2000$ in value - excluding interest and legal costs. The UK Government and the European Economic and Social Committee (EESC), as well as many other organisations in the UK, have defined this threshold as an 'unrealistic low limit', taking into account the possibility of ending with 'disproportionate legal costs' for claims that are just above this monetary threshold. ${ }^{27}$

Increasing the monetary limit may bring a risk to the whole procedure, because the higher the monetary limit, the more complex and lengthier the procedure may become. For instance, in England where the economic limit is $£ 5000$, the average duration of the SCP is 53 weeks; while in Ireland where the economic limit is $€ 2000$, the average duration is between 8 and 12 weeks. $^{28}$ It has to be taken into account that this short average duration is probably a result of the high number of settlements thanks to the intervention of the court registrar (over 50 per cent). In any event, the statistics illustrate how low value claims should reflect in quicker judicial procedures. ${ }^{29}$

The ESCP has sought to insert a uniform threshold taking into account the diverse standard of living of the various Member States, which left the European Council with little choice but to compromise at the $€ 2000$ limit. This final figure, however, excludes many claims above this monetary limit, which find serious redress difficulties, particularly in those Member States where the standard of living is higher. An independent report made for the Commission considered the $€ 2000$ limit as too low a limit and one that may 
not be cost-efficient. ${ }^{30}$ For this reason, it is to be expected that the EU will increase the existing economic limit in forthcoming years.

\subsection{EXCLUSIVENESS FOR CROSS-BORDER DISPUTES}

The European Commission proposed that the ESCP should be applied in all Member States as an additional procedure for cross-border disputes as well as for domestic disputes. This issue was debated in the European Council where most Member States proposed that the ESCP should be restricted to crossborder disputes. ${ }^{31}$ The UK Government expressed its opposition to the use of the ESCP in domestic disputes, based on Article 65 of the EC Treaty (now Article 81 TFEU), which limits the Community participation in cross-border issues, and consequently on the principles of subsidiarity and proportionality. ${ }^{32}$ Finally, the European Parliament introduced an amendment whereby the ESCP would only be applied to cross-border cases. ${ }^{33} \mathrm{~A}$ cross-border dispute is understood to be one

... [i]n which at least one of the parties is domiciled or habitually resident in a Member State other than the Member State of the court or tribunal seised. ${ }^{34}$

A major danger of this restriction is that often claims do not appear to have a cross-border element until the enforcement phase. In these cases it would be possible to use the EOP when dealing with uncontested monetary claims. In the rest of the cases the enforcement procedure will have to follow the exequatur procedure or declaration of enforceability, which would require a second judgment by the court of the Member State of enforcement, frustrating one of the main advantages of the proposed ESCP. In order to prevent that, it will be necessary to have a provision by which judges could change from the domestic procedure to the ESCP. However, this should only be allowed in exceptional circumstances without jeopardising the legal certainty of the procedures.

The use of the ESCP, as an optional procedure for domestic disputes, would make individuals feel equally protected with a familiar legal procedure regardless of the Member States of action and it will also remove the national limitations of domestic procedures. ${ }^{35}$ As previously mentioned, the SCP in Ireland is exclusively used for consumers in a limited number of situations. ${ }^{36}$ In Spain the upper limit of a small claim is €900; above this limit legal representation is obligatory. ${ }^{37}$ Many Member States do not have a domestic SCP at all and they could benefit from its use. It is therefore recommended that Member States use the ESCP to resolve domestic disputes. Furthermore, the use of this cross-border procedure for resolving domestic disputes would be particularly necessary in those Member States who do not have their own national procedure for resolving small value claims (ie a SCP). ${ }^{38}$ This might take a step towards a legal uniformity and the objective of obtaining a single and coherent area of justice within the EU. 


\subsection{LEGAL REPRESENTATION}

Litigants are not obliged to be represented by lawyers either during the ESCP or during their appeals. ${ }^{39}$ However, parties will be compensated for the costs of legal representation when the judges consider these costs necessary and proportionate to the value of the claim. ${ }^{40}$ Furthermore, it is understood that litigants can be represented or assisted by someone who is not necessarily a lawyer by training. ${ }^{41}$ It is regrettable that a specific provision has not been included allowing consumers to be represented by consumer associations and professional associations to represent their members. This is common in ADR processes but not in litigation, where national procedural rules may prohibit it.

\subsubsection{Procedure}

\subsection{SUBMISSION OF THE CLAIM}

The procedure commences when the claimant submits a claim to the competent court, which will forward it to the defendant for a response within 14 days. There are no provisions on how legally unrepresented claimants should be advised on which is the competent forum to hear their cases. The ESCP does not include forum selection or choice of law provisions so it will be necessary to refer to the Brussels Regulation and to the Rome Regulation. ${ }^{42}$ In e-commerce, when a consumer buys an item online, if the site targets the consumer's location, eg using the consumer's language and currency, then the court of the consumer's domicile is competent to hear the case. ${ }^{43}$

Litigants are able to draw up their claims without making any legal reference by using a multilingual uncomplicated standard form (Claim Form and an Answer Form) which uses a tick-box-approach insofar as possible. ${ }^{44}$ Although these forms are simple enough to fill in without the assistance of a lawyer, the ESCP provides that claimants must be supported with practical assistance to complete the form. The type of practical assistance required is unclear; it could be a written guideline or help from a court official or civil servant in a similar way to the Irish small claims. ${ }^{45}$ In addition, when parties are unrepresented the judge must assist them with procedural matters. ${ }^{46}$

The defendant may make a counterclaim in his or her response. If the amount of the counterclaim is above the limit of the procedure and it derives from the same legal relationship, then both the claim and counterclaim are excluded from the ESCP. ${ }^{47}$ This event could lead to the possibility that defendants acting in bad faith could frustrate the efficiency of the ESCP by making frivolous counterclaims over the $€ 2000$ threshold.

\subsection{WRITTEN PROCEDURE}

Following the civil law tradition the procedure is designed to be carried out fully in writing. This is due to practical reasons in order to reduce costs and 
speed up the procedure. An oral hearing can exceptionally be held when the court considers this necessary; the regulation of the oral hearing is left to the Member States. Parties tend not to apply for an oral hearing given that generally it is not a pleasant experience to go to court. Despite this, if both parties request an oral hearing the court may refuse such request when it appears that an oral hearing is not necessary for a fair resolution. ${ }^{48}$ The interpretation of this provision should therefore be treated with extreme caution by the court if there is no intention to threaten the adversarial principle and the right to a fair trial ${ }^{49}$ this may even raise constitutional issues in some Member States, particularly in those that follow the common law tradition. Nevertheless, the EU has formerly stated that oral hearings are not always necessary for resolving consumer disputes. ${ }^{50}$

\subsection{LANGUAGE}

A challenge that faces the ESCP is the translation of documents. This is of particular importance because it affects the length and cost of the proceedings. It is the role of the standard claims with multi-choice options and ICT tools to deliver a workable scheme. There has been debate on which language the forms should be completed. On the one hand, it was argued that it should be in the language of the claimant, thus facilitating claimants' access to the ESCP. On the other hand, it was also argued that the language of the whole procedure should be that of the court where the case is being presented. The European Parliament opted for the latter argument by deciding that parties must submit their forms in any of the languages admitted by the court. In addition, the translation of additional documents can only be requested when such translations are necessary for obtaining a judgment. It appears reasonable that the parties must pay their own costs of the translation of documents as long as the judge has the discretion to impose legal costs when necessary.

\subsection{COSTS}

Currently, the procedural rules with respect to reimbursement of costs differ significantly among those Member States with a SCP. The Commission proposal on the ESCP decided that the unsuccessful party must pay the costs of proceedings but excluded the payment of lawyers' fees by an unrepresented natural person. ${ }^{51}$ The European Parliament deleted this exclusion on the grounds that the successful party should not be disadvantaged from taking legal representation. Ireland proposed in the Council Group to amend the Commission proposal to ensure that the ESCP is cost-effective by stating that legal fees must be proportional to the value of the claim. ${ }^{52}$ Parties should be informed at the start of the proceedings about the system of costs and the reimbursement. Both measures have been incorporated into the text by the European Parliament's amendments. ${ }^{53}$ However, it would be desirable to establish a limit to the reimbursement of costs, eg 20 per cent of the claim 
value, with an exception for frivolous claims. Furthermore, the application of these provisions may hinder the cost-efficiency of the ESCP, particularly when using the present monetary limit of $€ 2000$ where translations and experts' reports may be required.

\subsection{ENFORCEABILITY}

Probably the main advantage of the ESCP is that it allows the enforcement of a judgment in any Member State (with the exception of Denmark) without the need of obtaining the mutual recognition of judgments (exequatur). The ESCP is carried out without condition of a security by filling in a form making the enforcement considerably faster and less expensive. A significant exception to this rule is judgments from uncontested claims, ie those default judgments where the defendant has not participated during the process. The peril of this exception is that defendants who are aware of this may refuse to participate in the procedure in order to hinder the enforcement of the judicial decision that will follow the recognition procedure.

\subsection{JUDICIAL REVIEW}

International law does not consider the right of appeal in civil procedure as a fundamental right but as a matter to be determined by the national legislature. Consequently, there is a significant diversity on this matter under national laws. As a result, the ESCP leaves it up to Member States to decide whether an appeal is available and communicates it to the Commission. ${ }^{54}$ As noted by the House of Lords, 'the absence of a common rule on appeals is disappointing' because it does not conform with the intention of unifying the resolution of small claims with cross-border elements. ${ }^{55}$

\subsubsection{ICT in the ESCP}

The use of the internet and ICT tools reduce barriers to access to justice by simplifying court formalities, lowering costs, increasing international cooperation and promoting the use of major languages. ${ }^{56}$ Another major advantage of the internet and ICT is that it provides information in a fast and centralised way, which is useful in a judicial procedure with an international dimension. ${ }^{57}$ In this regard the European Parliament has introduced informative web links for parties involved in the ESCP. ${ }^{58}$ The claim and answer forms are available on the internet, a requirement which further facilitates access to the ESCP. However, the regulation leaves it up to the Member States to decide to provide the use of online lodging of claims, the use of e-mail for interrogating witnesses or to admit experts' opinions etc.

The objective of the ESCP is the creation of a cost-efficient procedure applicable to small value claims in cross-border disputes. This objective can only be achieved by using a written procedure, assisted by electronic forms 
such as e-mails and video-conferencing, as foreseen by the proposed ESCP. Additionally, the ESCP enables the use of new technologies in transferring information and evidence between the courts of the different Member States. However, it is the Member States who decide, through their own regulations, which specific means of communication are acceptable in their courts. Given that the ESCP is a regulation and not a directive, it is arguable whether it leaves too many aspects to the discretion of Member States, which could call into question the legal certainty expected from a European regulation. This approach, on the one hand, risks the emergence of some degree of procedural disharmony within the EU. On the other hand, it seeks to comply with the principle of subsidiarity and to promote the use of ICT. Thus, it is expected that, in due course, electronic communications will reach every possible and reasonable aspect of the judicial procedure to assist in the resolution of online as well as offline disputes.

\subsubsection{ADR as a complement to ESCP}

The use of ADR can be particularly useful for some types of contractual relations, such as those where there is a cross-border element and where a longterm relationship exists between the parties. Non-adjudicative ADR is also effective in resolving those disputes where both parties are willing to reach an agreement. Clearly, ADR has some advantages when compared to litigation: it is more flexible, it has less jurisdictional problems, it can be more costeffective, etc. Furthermore, when two parties settle a dispute amongst themselves the result will be convenient for both of them; by contrast, when the dispute is resolved in court the award may not satisfy both parties to the same level. Nonetheless, the use of litigation is still necessary when one party refuses to negotiate a settlement, which leaves the courts as the only remaining opportunity to obtain redress. It must be also noted that unnecessary use of ADR could cause additional expense to the parties.

The regulation vaguely states that ' $[\mathrm{w}]$ henever appropriate, the court or tribunal shall seek to reach a settlement between the parties. ${ }^{59}$ This includes sending the parties to use ADR or ODR if appropriate. In these cases, it must be emphasised to the parties that these methods will reduce time spent in the resolution of the dispute, that any agreement reached will be voluntarily reached, and that if everything fails the parties still may use the ESCP. The English Small Claims Track has taken a more direct approach by stating in its leaflet that litigants should consider the use of ADR, to the extent that if it is refused unreasonably by one party the judge in his discretion may impose legal fees on that party whether or not he is successful in the proceedings. ${ }^{60}$ This situation creates a number of issues, however. First, it is questionable whether all cases are appropriate for ADR, eg a defendant may consider a claim to be frivolous. Secondly, a litigant may assist an ADR programme without being co-operative. It is arguable how the judge can weigh the co-operation of the parties without being informed by the neutral third 
party (who has the duty of confidentiality) and without colouring the judge's thinking on the case. These and other related issues will be examined in the next chapter of this book.

According to Wissler there are three types of disputes that are more likely to settle in mediation, with the consequent mutual satisfaction of both parties. First, these are disputes where the defendant admits partial or total liability. Secondly, they are those disputes where parties seek resolution rather than self-recognition, ie public recognition of being right. Lastly, certain types of disputes are more likely to be resolved in mediation, eg disputes related to the payment of goods or services. ${ }^{61}$

The use of ADR must be complemented by ICT in order to deal effectively with disputes arising from e-commerce. At present, ODR has proven to be an effective tool for resolving small value claims amongst consumers. Accordingly, the use of ADR and ODR can complement the ESCP. Colin Rule suggested that ODR services for consumers should be the substitute for the offline small claims court. ${ }^{62}$ If this is done appropriately, for example by informing the parties and by means of imposing legal fees on a party if participation in ODR or ADR is unreasonably refused, it may encourage litigants to settle their disputes in a faster and more efficient way. In addition, the majority of $\mathrm{B} 2 \mathrm{C}$ online disputes will allow consumers to initiate the ESCP in their own jurisdictions. This situation may encourage online businesses to press for consensual ODR avoiding the need of going to court.

\subsubsection{Assessment}

In evaluating the current national SCPs it can be concluded that SCPs are a suitable mechanism for resolving local disputes, which in some jurisdictions, such as Ireland, part of the proceedings are available at the click of a mouse. National procedures, however, often have very limited scope; for instance, the Irish procedure is only available to consumers in a very limited number of disputes and the Spanish procedure has a low monetary limit (€900). Nevertheless, national procedures are about to be complemented by an ESCP which deals with many types of cross-border disputes. The proposed ESCP is a written procedure that offers European consumers with cross-border disputes a new option for access to justice. It is suggested that the ESCP - if assisted with ICT tools - has the potential to increase effectiveness in the enforcement of consumers' rights across the European Union. However, some issues will need to be carefully addressed when adopting online court procedures. Above all, it must be ensured that technology does not operate as a barrier to access to justice. If these issues are properly dealt with, the use of ICT would bring significant benefits to courts and litigants.

It must be noted that the potential of the ESCP may be limited by its own restrictions. Those restrictions are mainly the exclusive application of the ESCP to cross-border disputes and contested claims, its low monetary threshold and the lack of adequate provisions supporting ADR and ODR. The use 
of the ESCP as an optional procedure for domestic disputes would provide a useful instrument in those Member States which lack their own small claims procedures and it would also remove national limitations where they already exist. Furthermore, the regulation is far from exhaustive and this could lead to different practices in the Member States. The inclusion of the recognition procedure for uncontested claims will stop those who attempt to delay the enforcement of decisions. In addition, the current economic limits may need to be raised given that this procedure may not be the best option for the lowest monetary claims. ODR methods, such as online negotiation and online mediation, have proven to be a more cost efficient and faster solution for such claims as well as many others such as those arising from the internet or involving one party outside the EU. ${ }^{63}$ This section concludes that the use of consensual ODR is a necessary complement to the ESCP and the existing national procedures. To that end, it is regrettable that clear provisions referring to and encouraging the use of ADR and ODR have not been included in the regulation for an ESCP. Despite this, since consumers' jurisdictions will apply in most online B2C disputes, online businesses may prefer and encourage consumers to use consensual ODR.

An effective implementation of the ESCP may in turn increase consumers' confidence in buying goods in other Member States and thus promote the development of a truly integrated European market. The ESCP is the first step towards a unified European procedural law and its success will determine an expanded implementation to higher claims and in other new areas outside civil and commercial law. In this regard, the implementation of the ESCP and the Rome (I) Regulation are expected to increase consumers' access to justice. The ESCP may consequently increase businesses' interest in using postdispute ODR arbitral clauses in order to avoid the risk of legal actions in all of the EU Member States.

\subsection{Online arbitration}

\subsubsection{Introduction}

Arbitration is increasingly being chosen as a method for the resolution of international disputes for various reasons. Arbitration limits appeals and is hence faster than litigation. Whereas judges are legally appointed and might lack expertise regarding matters of conflict, arbitrators can be selected by the parties from a pool of experts. ${ }^{64}$ Other features are the confidentiality of the process and the freedom of the parties to choose particular substantive and procedural rules. According to Ponte and Cavenagh, arbitration may be preferred when dealing with one-off transactions between strangers who are not concerned with maintaining professional or personal relationships and when parties are not willing to compromise over a disagreement and they need a quick, cost-effective decision. ${ }^{65}$ Businesses also choose arbitration because arbitral awards can be easily executed in over 150 countries signatories to the 
New York Convention of 1958, and in other jurisdictions through bilateral agreements or regional conventions, such as the European Convention on International Commercial Arbitration of 1961.

If a national court recognises an agreement to arbitrate as valid under national law, it will stay litigation pending the arbitration. According to Stipanowich, the law of arbitration has the role of 'regulating the interface between the private forum of arbitration and the courts, with primary emphasis on the judicial enforcement of agreements to arbitrate and of the resulting arbitral awards'. ${ }^{66}$ However, national laws rarely impose any restrictions on the qualifications required of arbitrators, nor on the procedures to be followed, as long as it is a fair process that complies with minimum due process requirements. ${ }^{67}$ This nonetheless may be understood in different ways across the world, particularly when power imbalance affects the autonomy of the parties.

Traditional arbitration resolves disputes by delivering a decision that will be binding, that is, enforceable by the public authorities in the same manner as a judgment. Non-binding arbitration as used with domain names seems to be a preferred method when using online arbitration, because it avoids the legal obstacles that will be discussed below. Online arbitration brings the convenience of the internet to the dispute resolution process. Moreover, it requires neither much training nor much ODR sophistication because proceedings are mostly written. ${ }^{68}$ Thus, to use arbitration for dispute resolution there is seldom a need for more than e-mail and secure communications. ${ }^{69}$ The majority of legal studies on online arbitration agree that the existing law and arbitral principles do not prevent arbitration from taking place online. ${ }^{70}$ Currently, most arbitration providers have introduced some ODR tools into the arbitration process, eg allowing the parties to download claim forms, the submission of documents through standard e-mail or secure web interface and so on. ${ }^{71}$ Entities such as the National Mediation Board handle approximately 10 per cent of their arbitration cases online. ${ }^{72}$ Examples of other well established online arbitration providers are the American Arbitration Association (AAA), the Better Business Bureau (BBB), the National Arbitration Forum (NAF), the World Intellectual Property Organization (WIPO) Arbitration and Mediation Centre and the Judicial Arbitration and Mediation Services (JAMS). ${ }^{73}$

\subsubsection{Obstacles to the online arbitral process}

\subsubsection{Agreement to arbitrate: $U S$ and EU approaches}

\subsection{ARBITRATION AGREEMENTS IN THE EU}

Businesses may introduce an arbitration clause when contracting with consumers. The contractual clause will require the parties to resolve all disputes by a particular arbitration process. However, within the EU, consumers 
have the right to go to court and this right is often considered as a right which cannot be waived. In this regard, the EU has issued a number of laws ensuring that consumers cannot be excluded from seeking judicial redress, ie consumers can only agree to arbitration once a dispute has arisen and not before. However:

- Article 6.1 of the European Convention of Human Rights (ECHR) states: 'In the determination of his civil rights and obligations [. . .], everyone is entitled to a fair and public hearing within a reasonable time by an independent and impartial tribunal established by law'. Notwithstanding, this right is not absolute and restrictions can be made if they pursue legitimate aims. An arbitration clause, therefore, if it has undeniable advantages for the individuals concerned as well as for the administration of justice, will not violate the ECHR. ${ }^{74}$

- Annex [q] of the Unfair Terms in Consumer Contracts Directive and Annex II paragraph [c] of the proposal for a Directive on Consumer Rights also challenge the validity of arbitration clauses. ${ }^{75}$ According to the directive a term is invalid if it excludes or hinders the consumer's right to take legal action or to exercise any other legal remedy, in particular 'terms requiring the consumer to take disputes exclusively to arbitration not covered by legal provision' ${ }^{76}$ This provision confines the validity of pre-dispute agreements to public arbitration schemes which are regulated by ad hoc statutory regulations. ${ }^{77}$

- Article 17.1 of the Brussels I Regulation states that the contractual exclusion of the courts in consumer disputes is void if this takes place before the dispute arises.

- The Council Resolution on a community-wide network of national bodies for the extra-judicial settlement of consumers' disputes provides that any out-of-court resolution of consumer disputes should be based on voluntary participation and should not prejudice any other means of judicial redress. $^{78}$

- Article 4 of the EC Recommendation on the principles applicable to the bodies responsible for out-of-court settlement of consumer disputes provides that consumers should not be bound by a pre-dispute arbitration clause. $^{79}$

It must be noted that all restrictions on mandatory pre-dispute arbitration clauses apply exclusively to consumer arbitration services; thus, in other civil law areas, such as landlord-tenant relations, the above restrictions do not apply.

The implementation of the Directive on Unfair Terms appears to vary across the EU. ${ }^{80}$ In France, article 2061 of the Civil Code only allows arbitration clauses in contracts concerning professional activities, ie not in consumers' contracts; but this article does not apply to international arbitration. ${ }^{81} \mathrm{~A}$ case on the legality of an international arbitration clause was discussed by the 
French courts in the Jaguar case. ${ }^{82}$ The first instance court stated the clause to be illegal, the Court of Appeal reversed that decision and the Supreme Court admitted the arbitrability of the dispute in the circumstances at hand (it was a transaction of high value and the consumer was not in a weaker position).

The England and Wales Arbitration Act 1996 and the Unfair Terms in Consumer Contracts Regulation 1999 allow pre-dispute consumer arbitration clauses only when the amount at stake is more than $£ 5000 .{ }^{83}$ Nevertheless, consumers may prove an arbitration clause as unfair, even when the amount of the claim is over $£ 5000$, using the tests set out in the directive and the regulation. In consumer disputes below the limit of the small claims court ( 5000 in England and Wales, $£ 750$ in Scotland, $£ 1000$ in Northern Ireland), such clauses are automatically not binding on the consumer. Accordingly, the Office of Fair Trading has consistently required businesses to delete predispute binding arbitration clauses below this economic threshold. ${ }^{84}$ This has influenced businesses and ODR providers to act accordingly; for instance, the Ford and ABTA Travel Association business members of the Chartered Institute of Arbitrators only use post-dispute agreements, which only are unilaterally binding on businesses. ${ }^{85}$ Under EU law, unlike under US law, in order to uphold arbitration clauses, it is not sufficient that the consumer is aware of the significance of such clauses; the proposed arbitration must be a suitable and fair process.

Overall there is still some legal uncertainty, which could be resolved by using arbitration that allows court appeals, unilateral binding arbitration, post-dispute arbitration agreements and public arbitration bodies or tribunals. The European Commission has listed on its website a database with the contact details of consumer arbitration bodies. The database includes the bodies that, according to the Member States, comply with the Recommendation $98 / 257 / \mathrm{CE}$, such as the Spanish arbitration boards, whose procedure is examined later in this chapter. ${ }^{86}$

\subsection{US ARBITRATION}

In the US, consumer arbitration clauses are used as a common solution to avoid conflicts of law. As a result, many US standard terms in electronic contracts often include arbitration clauses. There have been several attempts to shift arbitration online, but no mainstream consumer-specific arbitration tribunal has yet been introduced despite continuous interest from ADR and ODR providers.

The Federal Arbitration Act (FAA) considers arbitration clauses, even predispute binding agreements, as 'valid, irrevocable, and enforceable', without distinguishing between business contracts and consumer contracts. In this respect, several US Supreme Court cases have rejected challenges to predispute arbitration clauses in consumer contracts, eg Buckeye Check Cashing, Inc. $v$ Cardegna. ${ }^{87}$ In this case the court ruled that the arbitration clause of an alleged illegal and void contract was enforceable for two reasons. First, 
according to the court, the validity of the contract can only be decided by the arbitrator; and, secondly, because the validity of an arbitral clause is independent from the rest of the contract. ${ }^{88}$

In Allied-Bruce Terminix Cos. $v$ Dobson the US Supreme Court included consumers within the scope of the FAA, stating that '[the] Congress, when enacting [the FAA] had the needs of consumers, as well as others, in mind'. ${ }^{89}$ In this case the Supreme Court held that Alabama's statute prohibiting mandatory pre-dispute arbitration clauses was pre-empted by the FAA. ${ }^{90}$ In those cases where the FAA does not apply, state arbitration law governs. Moreover, under most state laws, consumer arbitration agreements are also enforceable. ${ }^{91}$

Pre-dispute arbitration, nonetheless, has certain restrictions. In a recent decision, Ross $v$ Bank of America, the Second Circuit Court held that the credit card industry had breached anti-trust laws by conspiring to limit consumers' dispute resolution choices through pre-dispute mandatory arbitration clauses. ${ }^{92}$ This decision can only be changed by the US Supreme Court, and it could be extended to other industries with similar practices, such as mobile phones, auto dealerships etc. Other exceptions to defeat the enforceability of agreements to arbitrate are based on general contract law defences, such as coercion, fraud, duress or unconscionability, although those defences are usually construed narrowly. ${ }^{93}$

Accordingly, only a clearly unfair arbitration agreement will be recognised as unenforceable by the courts. ${ }^{94}$ In Comb and Toher $v$ Paypal the judge found Paypal's arbitration clause unconscionable for consumers, holding that Santa Clara County in California was not a neutral forum. ${ }^{95}$ Another reason for unconscionability is concerned with the one-side nature of the contract and its oppressiveness, eg a clause restricting consumers' redress to arbitration while allowing the business to go to court. ${ }^{96}$ Reasons for unconscionability would also be the suppression of consumers' rights recognised by their legal forum and imposing excessive arbitration fees. ${ }^{97}$ In addition, US law found unconscionable clauses where there is a limit on damages, attorneys' fees or limitation period, where the arbitration clause surprised the consumers because it was buried in the contract, when the consumer cannot read English etc. ${ }^{98}$

Arbitration is generally faster than litigation because the arbitrator is often an expert on the subject matter, and procedural rules are simplified. This is, however, arguable. In Brower v Gateway, Inc. the New York Appellate Court held that a consumer clause referring disputes to the International Chamber of Commerce was unenforceable owing to the high cost of this procedure, ie US $\$ 4000 .{ }^{99}$ In fact the cost of many arbitration services often excludes low value claims; for instance, the International Chamber of Commerce has a minimum administrative fee of US $\$ 2500 .{ }^{100}$ Some arbitration services in the US, such as JAMS and NAF offer consumers the opportunity to opt out from their service when they prefer to pursue the matter in the small claims court, regardless of any contractual clause. ${ }^{101}$

In addition, some entities such as the AAA, NAF and JAMS have introduced reduced fees for small claims. In order to make arbitration more cost 
efficient class actions may be permitted. ${ }^{102}$ In Green Tree Financial Corp. $v$ Bazzle the US Supreme Court stated that unless class arbitration is excluded in the arbitral clause, the arbitrators, and not a court, will decide whether a class action is appropriate. ${ }^{103}$ Even though class arbitration can be contractually excluded, ${ }^{104}$ it must be taken into account that its exclusion might be considered unconscionable. ${ }^{105}$ This will be decided by the court on ad hoc basis. ${ }^{106}$ It appears advisable to enact legislation on this matter to ensure that restrictions to class actions are not allowed. ${ }^{107}$

\subsection{COMPARING THE EU AND THE US APPROACHES}

Albeit, in both jurisdictions the courts police the fairness of consumer arbitration agreements on a case-by-case basis, the legal approach taken in consumer contracts in the EU differs from that taken in the US. The US courts generally uphold pre-dispute arbitration clauses unless it can be shown that the arbitration agreement does not comply with fundamental fairness or is found to be oppressive or highly unreasonable. ${ }^{108}$ In fact, unlike the EU, the Federal Arbitration Act in the US is often interpreted in a manner in which doubts about arbitrability are often resolved in favour of arbitration. ${ }^{109}$ Drahozal and Friel observed that particular legal circumstances, such as the greater availability of civil jury trials, class actions and punitive damages in the US give their businesses more incentives to oppose regulation that excludes pre-dispute agreements. ${ }^{110}$ However, they suggested that currently in the US lobbying from consumer groups and trial lawyers is increasing the demand for restrictions in arbitration clauses, which may result in a greater convergence with EU regulation.

In the EU, as a rule, pre-dispute agreements are considered unfair and void. However, some commentators have argued that EU law would be compatible with an arbitration clause that mandates all disputes to be resolved through a procedure which is proven to be fair and easily accessible for consumers. ${ }^{111}$ Online arbitration could fulfil these requirements. Under the current wording of the proposal for a Directive on Consumer Rights such interpretation is no longer possible, unless it is statutory arbitration. ${ }^{12}$ In the next few years we might see contractual clauses referring to mandatory ODR providers; nonetheless, it will be first and foremost necessary to ensure that these providers comply with minimum due process standards set by a legal framework. ${ }^{113}$ In the mean time it appears that this is not so easily achieved and, as a result, online businesses frequently include different dispute resolution clauses depending on the consumer's jurisdiction.

\subsubsection{Enforcement of arbitral awards: The New York Convention}

When one party refuses to comply with an arbitral award, there may be difficulties in enforcing the award. For this reason consumer arbitration is currently working mainly at domestic level as enforcement is easier and less 
costly than at international level, particularly when small amounts of money are at stake. At international level the two most relevant set of rules in relation to arbitration are 'pre-internet age': the UNCITRAL Model Law on International Commercial Arbitration 1985 and the New York Convention on the Recognition and Enforcement of Foreign Arbitral Awards 1958.

Katsh and Rifkin consider that the New York Convention appears to validate online arbitration provided that it complies with certain rules related to the agreement to arbitrate, the process of arbitration and the arbitral award. ${ }^{114}$ First, the contractual agreement to validate must be in writing; under most national legislations, electronic writing is considered equivalent to traditional writing. Secondly, the process of arbitration must comply with the express approval of the parties using electronic forms. In addition, the methods used must be secure, confidential and comply with basic due process principles. ${ }^{115}$ Ultimately, in order to enforce an arbitral decision in the courts, the majority of experts recommend printing a copy and having it signed by the arbitrators. ${ }^{116}$ In fact, most laws require an original written (or duly certified copy thereof) and signed award. ${ }^{117}$

Under the New York Convention a court may refuse to enforce an arbitral award when the award is contrary to the public policy of the country. ${ }^{118}$ Some countries may consider B2C arbitration as non-arbitrable subject matters and, in this sense, contrary to public policy. ${ }^{119}$ This last exception has been criticised for being too general in scope and should be interpreted in a narrow sense. ${ }^{120}$ The New York Convention was created with B2B cases in mind; thus, a clear distinction between B2B and B2C arbitration would be more appropriate.

In 2007 UNCITRAL adopted the Convention on the Use of Electronic Communications in International Contracts, which would reform the New York Convention. The new Convention will no longer allow a narrow interpretation of the written requirement, by permitting ODR methods. ${ }^{121}$ To date, online arbitration awards have not been fully tested in the courts but what could be expected is that the courts will review online awards using similar standards applied to offline arbitration. ${ }^{122}$

By contrast, non-binding arbitration seeks neither recognition of its agreements nor fixed standards of due process. However, these systems face an obvious challenge: compliance with decisions. Self-enforcement mechanisms and incentives, such as reputation systems, blacklists and escrows, are used to persuade parties to comply. ${ }^{123}$

\subsubsection{Domestic arbitral procedures: The Spanish Consumer Arbitration Boards}

The Spanish Act on the Services of the Information Society opens the possibility of using consumer arbitration and other ADR methods, either offline or online. ${ }^{124}$ However, Spanish law consents only to the use of online consumer arbitration under the national regulation. ${ }^{125}$ The formalism of the small 
claims procedure in Spain has probably influenced the design of an institutionalised consumer arbitration system to address consumer disputes. A recent regulation (Real Decreto 231/2008) incorporates online consumer arbitration. ${ }^{126}$ The new online procedure is promoted by the government and it is expected to take place online, from start to finish. ${ }^{127}$ The new law regulates all the necessary aspects for the functioning of the online service, such as the determination of the competent Arbitration Board, the place of arbitration, the use of electronic signatures and electronic notifications. At the time of writing there were no publications on the implementation and performance of the online process.

The Spanish Consumer Arbitration Boards (Juntas Arbitrales de Consumo) provide a voluntary procedure characterised for being quick (a maximum of four months), confidential, free, flexible (there is no economic limit and parties choose if they want the arbitration to be based on law or equity), as well as binding. ${ }^{128}$ Consumer arbitration cannot be used in those cases where there is intoxication, injury, death or reasons to believe that there is a crime involved in the dispute. The Spanish Consumer Protection Act considers a clause that refers consumers to arbitration different to the Public Consumer Arbitration Scheme to be illegal, unless the arbitration institution had been created by law for a specific sector. ${ }^{129}$ This excludes not only private arbitration but also any international arbitration. ${ }^{130}$

The Spanish Consumer Arbitration Scheme is exclusively applicable to B2C transactions. Only consumers can initiate the procedure by making a claim at the Arbitration Board that is the closest to the consumer's place of residence. In order to use consumer arbitration, both parties must agree to participate in the arbitration after the dispute arises. Also, Spanish businesses may already be voluntarily registered in the Consumer Arbitration Scheme. The adherence of the business is registered in a public list and businesses must display the official trustmark, which is also available electronically. In cases involving registered businesses it will only be required that the consumer accepts arbitration after the dispute arises. In this sense there is a pre-dispute arbitration clause which is binding on the business, but not on the consumer. ${ }^{131}$

Once the application is submitted by the consumer, it will be forwarded to the business which can accept it or reject it (only if it is not already registered) in writing (also using electronic devices, if they are available) within 15 days. If an agreement to use arbitration is reached, one or three arbitrators will be appointed, depending on the value and complexity of the dispute. ${ }^{132}$ One arbitrator will be appointed by the Arbitral Board, except when the parties agree to the appointment of a particular arbitrator, when the dispute is not complex and the value of the dispute is below $€ 300 .{ }^{133}$ Disputes over this economic threshold will be dealt with by three arbitrators. ${ }^{134}$ The chairman is appointed from a pool of arbitrators with a law degree by the Arbitral Board, except when the parties agree to a different arbitrator. The other two arbitrators do not need to be legally qualified. They are appointed as follows: one by consumer associations and the other by business associations. However, 
arbitrators will not defend the interests of the party who chooses them; on the contrary, they must be impartial while reaching a fair outcome.

Under the new regulation, mediation is introduced as a prior step to take before continuing to arbitration. ${ }^{135}$ Parties participate in mediation except if one of them is expressly opposed to it. ${ }^{136}$ If the mediation fails, the arbitrators listen to the parties at the hearing where parties present the evidence themselves. Hearings are private and the parties may participate with or without legal representation, but the parties bear their own costs, unless the Arbitral Board decides to appoint an impartial expert; in this event, the board would pay the expert's fees.

The arbitral process may take place with an oral hearing or by submitting documents; however, in most cases it is carried out orally because the meeting may assist the parties in achieving a settlement. In the event that an agreement cannot be reached during the hearing, the arbitrators will resolve the dispute based on equity, although exceptionally the parties may decide to seek an arbitral award based on law. Decisions are binding and enforceable but may be appealed in the Provincial Court (Audiencia Provincial) on a number of grounds, such as violation of due process rules.

\subsubsection{The UDRP: An international adjudicative process similar to arbitration}

\subsubsection{Background of the UDRP}

Domain names are an easy-to-remember translation of Internet Protocol (IP) addresses, which identify websites that are physically located in computers hosted by Internet Service Providers (ISPs). ${ }^{137}$ There are two types of domain names: generic top level domain names (gTLDs) and country code top level domain names (ccTLDs). On the one hand, ccTLDs correspond with a location in a particular country, such as .ie in Ireland or .uk in the UK; national authorities control ccTLDs applying their own domestic regulations. On the other hand, gTLDs are regulated by the Internet Corporation of Assigned Names and Numbers (ICANN). Some of these gTLDs do not have any restrictions on their registration, such as .com, .net, .org, .info. By contrast, others need certain requirements for their use, such as .edu (related to education) or .biz (related to business). There are many political concerns about the creation of new gTLDs. For instance, ICANN refused a proposal for the creation of a new gTLD .xxx for pornographic websites on the grounds that it was unworkable and would lead to ICANN being dragged into content regulation, which is outside its remit. ${ }^{138}$ Another major reason is that existing domain name holders, especially trade mark owners, are concerned that new gTLDs would depreciate the value of their domain names and could contribute towards increased confusion among their customers. More recently, ICANN has proposed allowing anyone to create any gTLD on the payment of a fee of US $\$ 185,000 .^{139}$ 
The existence of domains without specific requirements for registration has led to a policy of 'first come, first served'. This has created many disputes with trade mark owners owing to the fact that, since the early 1990s, many speculators registered domain names in order to resell them for a much higher price to trade mark owners and new businesses. Problems arose with trade mark owners because of their entitlements to IP rights, leading them to believe that they had been taken advantage of financially by this new practice of 'cybersquatting'. Currently, in most cases anyone who wishes to register a domain which is trade-marked for the first time can do so; any objections from trade mark owners will be dealt with at a later stage. However, more recently, when new gTLDs have been launched, trade mark owners were given priority rights for a certain period of time to register their brands. However, the cost of registering domain names during this so-called 'sunrise' period tends to be significantly higher than the cost of registration during the subsequent 'land rush' period (first come, first served), although it is still cheaper than the costs of disputing ownership of the domain name in the courts.

In 1998 the US Government ordered the World Intellectual Property Organization (WIPO) to undertake an extensive international consultation process in order to design an efficient online procedure - quickly and costeffectively - to stop the most outrageous trade mark violations. ${ }^{140}$ WIPO opted to recommend the use of a mandatory administrative procedure limited to fight cybersquatting, which was universally condemned throughout the consultation process. The WIPO proposal was the blueprint for the Uniform Domain Name Dispute Resolution Policy (UDRP) implemented by ICANN on 1 December 1999. The implementation of UDRP has a retrospective application and is hence applicable to all domains, including those registered before the UDRP came into effect. ${ }^{141}$ However, this provision was limited by a US court which held that the UDRP binds only those domain name registrants who had entered into the registration agreement with the UDRP clause. ${ }^{142}$

The creation of the UDRP had a dual purpose: first, to deal efficiently with the most blatant violations of trade mark law (cybersquatting); and, secondly, it was created to protect the registry (ICANN) and the registrars from trade mark litigation. ${ }^{143}$ The UDRP is legally a mandatory administrative procedure that resembles a document-only arbitration. However, it does not follow the arbitration laws; panels are unaccountable and decisions are not legally binding, allowing parties to initiate a legal action any time during the UDRP procedure. Parties adhere to the UDRP through a clause in their contract, which is formed between the registry (ICANN) and the registrar (ISP) and between the registrar and the registrant (domain name holder). ${ }^{144}$ The contractual clause states that certain trade mark disputes (cybersquatting disputes) will be resolved by one of the ICANN's approved dispute resolution providers. Currently, there are four approved providers:

1 World Intellectual Property Organization (WIPO) Arbitration and Mediation Centre ${ }^{145}$ 
2 National Arbitration Forum (NAF) ${ }^{146}$

3 Asian Domain Name Dispute Resolution Centre (ADNRC) $)^{147}$

4 Czech Arbitration Court (CAC). ${ }^{148}$

The CAC is the newest UDRP service provider. In its application the CAC made a number of innovative suggestions with the aim of delivering a fairer process, such as allowing class complaints ${ }^{149}$ and the right to refuse complaints from parties found guilty of three or more offences of 'reverse domain name hijacking'. In addition, it has also proposed the use of a 'quasi-appeal mechanism' against UDRP decisions made by single panels. ${ }^{150}$ These initiatives reflect the need for reform within the UDRP. Most commentators, however, rightly consider that all the CAC's proposals are inconsistent with the existing UDRP Rules and Policy, which do not contemplate such possibilities. ${ }^{151}$ More recently, the CAC has proposed more conservative proposals, namely: a simplified way of sending signed hard copies of complaints and responses to the provider; and the service of delivery of signed hard copies. ${ }^{152}$ WIPO has also made similar proposals, from which the paperless and fully online procedure has been recently accepted by ICANN and its use became mandatory for all UDRP providers from March 2010. ${ }^{153}$

In the ODR context, the most important initiative of the CAC is the service that, for the first time, provides a full online UDRP process, using a unique 'chess card' (ie a coded card) to authenticate the parties and their submitted documents. The new online process completed a pilot period and was approved by the ICANN on 21 May 2009. A few months later, on 30 October 2009, the ICANN board amended the UDRP rules to allow a paperless procedure. The new fully online WIPO service commenced on 14 December $2009 .^{154}$

The UDRP is divided into two main parts, namely the policy and the rules. The policy section deals with the substantive law, including the grounds for filing a complaint, defences, remedies etc. The rules deal with the procedural provisions such as communications, time limits, appointment of panels etc. Dispute resolution providers have also included a third set of rules (Supplemental Rules), which contain procedural details that are exclusively applicable to the specific dispute resolution provider.

The UDRP has created a form of global trade mark law which mimics the minimum standards existing in national trade mark laws and co-existing with the national laws. ${ }^{155}$ According to David Post, the UDRP can be regarded as an independent legal system, because despite its private lawmaking origin, it complies with three main features of a legal system: it has an independent regulation, an autonomous procedure and it issues enforceable decisions. ${ }^{156}$ In Post's view the missing element of this private lawmaking is the democratic legitimacy. He proposes the use of juries in the UDRP proceedings to democratise the 'aristocratic management of cyberspace'. ${ }^{157}$ However, it is suggested that the democratisation of ICANN law should come not only from those who apply the UDRP (dispute resolution 
providers and panellists) but also from those who create the policy and the rules (ICANN and WIPO). A more democratic composition in ICANN would therefore contribute to strengthening the legitimacy of the UDRP.

\subsubsection{The UDRP procedure}

The procedure can be divided into five stages:

1 the submission of the complaint

2 the response

3 the appointment of the panel

4 the delivery of the decision and

5 the enforcement of the decision.

\subsection{SUBMISSION OF THE COMPLAINT}

The procedure commences with the submission of the complaint together with the appropriate fee paid to any of the ICANN approved dispute resolution providers. The complaint does not have to follow a particular model, although it is possible to download a standard claim form from any of the providers. ${ }^{158}$ As from 1 March 2010 the complaint must be submitted electronically. ${ }^{159}$

The complainant must give evidence proving that the respondent's registration violates its trade mark rights in three respects. First, the registered domain name must be identical or confusingly similar to a trade mark or service mark in which the complainant has rights. Secondly, the registrant has no rights or legitimate interests in respect of the domain name. Thirdly, the domain name has been registered by the respondent and is being used in bad faith. ${ }^{160}$

In addition, the complainant must state the remedy sought which may be either the cancellation or the transfer of the disputed domain. Once the dispute resolution provider has checked that the complaint complies with the UDRP rules, it has three days to forward it to the registrar (ISP) and to the registrant (domain name holder). The registrar, although not a party to this procedure, must co-operate with the dispute resolution provider by three means: sharing all information that may be required; not allowing the transfer of the domain name to a third party until a decision is reached; and enforcing the decision.

One particular concern is the burden of proof. Under the UDRP, the onus of the burden of proof is on the compainant; however, in certain circumstances, for instance when the complainant does not have access to the relevant information, the panel may shift the onus onto the respondent. ${ }^{161}$ As a result, it is not always clear where the burden of proof lies. This will ultimately be determined at the sole discretion of the panel. ${ }^{162}$ It is arguable whether this discretion, without any regulatory restrictions, might violate the respondent's rights. 


\subsection{RESPONSE}

The registrant is generally informed by e-mail and has the obligation under the registration contract to answer the complaint. ${ }^{163}$ The respondent has 20 days from when the complaint was sent to produce an answer. ${ }^{164}$ To that end, the respondent may complete a standard answer obtainable from the dispute resolution provider. If he fails to respond, it will not result directly in a decision in favour of the complainant, who will still have to show evidence to support his claim; this is done without prejudice to the negative inferences that the lack of response may imply to the panel. If the answer is submitted late the panel will continue with the procedure using the belated information at its discretion. In addition, panellists may decide at their discretion to accept unsolicited supplemental filings from either party, bearing in mind the other party's rights. Currently, NAF is the only dispute resolution provider that has distinguished itself from its competitors by specifically regulating in its supplementary rules the possibility of applying for a time extension to submit the response, and even allowing new submissions after the response, prior to the payment of a fee. ${ }^{165}$ This evidences the consequences of dealing with for-profit dispute resolution providers.

\subsection{APPOINTMENT OF THE PANEL}

Panels may be composed of one or three members, although single-member panels are more common. ${ }^{166}$ The dispute resolution provider appoints the single member panels. ${ }^{167}$ This competence and lack of transparency has created much criticism, from accusing the panel of forum shopping to using a biased procedure financially supported by trade mark owners. The two first major studies reporting grounds of bias to the UDRP were the statistical analyses of Mueller and Geist. ${ }^{168}$ These reports raised significant concerns about the impartiality and independence of the UDRP proceedings.

When a party requests a three member panel, each party may select one panellist by proposing three candidates from the provider's roster. The third panellist will be appointed by the provider from a list of five candidates proposed by the provider to the parties, where parties can again express their preferences. ${ }^{169}$ Appointed panellists must be independent and unbiased, which obliges them to disclose any circumstance that may affect this condition. Unfortunately, the UDRP does not provide the grounds for disqualification and there is not a procedure whereby the parties may recuse either the appointment of panels or the dispute resolution providers. This aspect is also worthwhile considering when reviewing the UDRP.

\subsection{DELIVERY OF THE DECISION}

Decisions are issued between 40 and 50 days from the submission of the complaint, which must be within 14 days after the appointment of the 
panel. ${ }^{170}$ If one of the parties decides to proceed, the panel has the discretion to decide whether or not to continue with the procedure. ${ }^{171}$ Parties may also reach an agreement before a decision is attained, automatically terminating the proceedings. ${ }^{172} \mathrm{~A}$ reform in the UDRP proceedings might allow UDRP providers to be complemented with consensual ODR processes, such as assisted negotiation and online mediation, provided the parties voluntarily agree to their use. ${ }^{173}$ This has been successfully used by Nominet, the national ODR provider for the uk ccTLDs, which employs mediation prior to the issue of the decision. ${ }^{174}$

The administrative proceeding may conclude by reaching one of three possible decisions: first, the panel may decide to transfer the domain name to the complainant; secondly, it may order the cancellation (or modification) of the domain name; and, thirdly, it may deny the complaint. In this last case, the panel may find that the complaint was submitted in bad faith with the deliberate purpose of acquiring a domain name to which the claimant has no right. This is called 'reverse domain name hijacking' (RDNH) and the panel will state this, if proved. In practice, it appears that most panels are reluctant in upholding RDNH claims because the UDRP does not provide appropriate grounds on which to do so. ${ }^{175}$ In this regard, it has been argued that the lack of uniformity of decisions and the low cost of the UDRP proceedings may encourage frivolous complaints hiding the RDNH. ${ }^{176}$ The current sanction (the RDNH statement) is insufficient to discourage abuses. An additional criticism of the UDRP is that in spite of being designed to deal exclusively with clear cases of cybersquatting, some decisions are related to other issues not expressly included within the UDRP's scope, such as common law trade marks, ${ }^{177}$ and its application to famous personal names ${ }^{178}$ and geographical names. ${ }^{179}$ The UDRP needs to clarify these issues, which have provoked conflicting interpretations among different panels.

The UDRP has developed a transparent dispute resolution procedure where UDRP decisions are published online in their entirety by the providers, unless under very exceptional circumstances the panel decides otherwise. ${ }^{180}$ However, complainants' and respondents' submissions are not published. Arguably, such publications (respecting personal and financial data) might increase transparency and would further inform future litigants, particularly weaker parties who are often respondents.

\subsection{ENFORCEMENT}

Registrars are compelled to enforce UDRP decisions, which in cases of cancellation or transfer will take place 10 days after the decisions have been published. All that is needed to enforce the outcome of a decision is for ICANN to change an entry in its master database. There is only one exception to this rule; if a legal proceeding is initiated by the respondent enforcement will not occur until the judicial proceeding concludes. ${ }^{181}$ The jurisdiction competent to hear the case will be the 'mutual jurisdiction' to which the complainant 
had originally agreed when filing the complaint. The UDRP rules states that the mutual jurisdiction is either that of the registrar or the registrant. ${ }^{182}$ The registrar's jurisdiction is the domicile of the principal office, and the domain holder's jurisdiction is the domicile stated in the 'WHOIS' database. In practice, however, court actions are extremely rare, unless the case is related to a number of issues. ${ }^{183}$ This may be owing to a number of reasons, such as the high cost of litigation, low chances of redress for cybersquatters, or because the 10 day period to bring a court action may be too short to prepare a demand. Thus, as a matter of fact the vast majority of UDRP decisions are final. ${ }^{184}$ Nevertheless, the UDRP should extend the existing time limits. It is suggested that the 10 day limit may be far too short, and what seems to be the same rule for both parties certainly favours the complainant because the latter would not have changed his status quo, neither the lack of domain name, nor the type of claim where he is still the claimant. ${ }^{185}$

\subsubsection{Grounds for the cancellation or transfer of domain names}

The grounds that a complainant must prove to succeed can be seen in the light of published decisions, which allow an analysis of the interpretation of the UDRP. This analysis will focus on the WIPO Arbitration and Mediation Centre (WIPO) decisions since it is the main provider of the UDPR having administrated over 16,000 disputes. WIPO has published a report with the consensual views of panels on selected issues. ${ }^{186}$ The evaluation often shows a lack of unanimous consensus in the interpretation of the UDRP, which may be for a number of reasons, such as the lack of an appellate review and panels composed by members from a multitude of jurisdictions and informed by different legal traditions.

This analysis is divided into the three circumstances that the complainant must prove to the panel: (1) similarity of the domain name to the trade or service mark; (2) lack of rights or legitimate interest in the registered domain name; and (3) bad faith in the registration and use of the domain name.

\subsection{DOMAIN NAME IDENTICAL OR CONFUSINGLY SIMILAR TO THE TRADE MARK OR SERVICE MARK}

The UDRP does not offer any guidance in these circumstances and, as a result, there are divergent opinions over the concept of 'confusingly similar'. Within WIPO there is a consensus that the content of a website is only relevant if the disputed domain is confusingly similar to a trade mark or a trade name. ${ }^{187}$ It is generally agreed that geographic indications are not regarded as trade marks under the UDRP. ${ }^{188}$ In addition, there is a consensus that trade marks rights are protected without prejudice to their location. However, those trade marks that have automatic registration procedures - ie US state registration as opposed to US federal registration - may have fewer protections. ${ }^{189}$ 
It appears that a domain name partly translated into another language may be considered confusingly similar. ${ }^{190}$ It has been controversial whether a domain name composed of a trade mark and a negative term is confusingly similar to the trade mark, ie the so called 'sucks' cases: '[trade mark] sucks.com' or ' $\mathrm{f} * * \mathrm{k}$ [trade mark].com'. ${ }^{191}$ Panels have frequently found these registrations abusive for a number of reasons, including that the domain name may be confused with the trade mark for not being recognised as negative or because it might be seen by non-fluent English speakers who may be misled into thinking that the domain name holder is the trade mark owner etc. ${ }^{192}$ By contrast, there are an increasing number of new cases allowing parody and 'gripe' sites, holding that the likelihood of confusion between the trade mark and the domain name were not high since they had non-commercial purposes. $^{193}$

Donahey finds two different doctrinal approaches to ascertain whether a domain name is confusingly similar to a trade mark. ${ }^{194}$ On the one hand, part of the doctrine uses the objective test: if a trade mark is part of a domain name - regardless of added letters or words - the confusion exists. On the other hand, some panellists use a subjective test: actual likelihood of confusion between the trade mark and the domain name, eg 'typosquatting'. ${ }^{195}$ This second test seems to be the most sensible and fair because it analyses the specific circumstances and the intention of the user to confuse the domain name with the trade mark. Nevertheless, the problem with this test is that it often raises divergent opinions. ${ }^{196}$ Donahey proposes the use of the objective test since the subjective approach is already used during the evaluation of the next two circumstances. However, Donahey's objective approach must be qualified by the approach taken by most national courts in considering whether a reasonable consumer or internet user would believe that the trade mark owner has sponsored the domain name. ${ }^{197}$

\subsection{DOMAIN NAME HOLDER LACKING RIGHTS OR A LEGITIMATE INTEREST IN THE REGISTERED DOMAIN NAME}

The most common defence for the registrant is to show evidence that there is a legitimate interest in the use of the domain name; in order to do so, the UDRP provides three grounds that prove rights or a legitimate interest for the current domain name holder:

(i) before any notice to you of the dispute, your use of, or demonstrable preparations to use, the domain name or a name corresponding to the domain name in connection with a bona fide offering of goods or services; or

(ii) you (as an individual, business, or other organisation) have been commonly known by the domain name, even if you have acquired no trade mark or service mark rights; or

(iii) you are making a legitimate non commercial or fair use of the 
domain name, without intent for commercial gain to misleadingly divert consumers or to tarnish the trade mark or service mark at issue. ${ }^{198}$

These three grounds are not exhaustive; registrants can put forward other scenarios that may prove 'rights or legitimate interests in respect of the domain name'. In practice, however, it seems that respondents have been unsuccessful in finding new circumstances. ${ }^{199}$

It has been very controversial whether the use of domain names for criticising trade marks is a legitimate use or, by contrast, tarnishes the trade marks. Panels have expressed different views. On the one hand, it has been decided that the right to criticise does not include the right to register a domain confusingly similar to a trade mark. On the other hand, it has also been decided that since the domain name is merely an internet address, different from a trade mark, the use of free speech without a commercial gain is legitimate, even when it tarnishes or dilutes a trade mark. ${ }^{200}$ This last approach has been more prevalent among US panellists, referring to the First Amendment of the US Constitution. ${ }^{201}$ Donahey states that mixed websites, often with criticism and minimum commercial activities, eg the use of Google ads, may strip away registrant protection in 'making a legitimate non-commercial or fair use of the domain name' ${ }^{202}$ However, solicitations of donations and advertisements for another criticism website have not been considered as commercial use. ${ }^{203}$

Notwithstanding, when the domain name lures internet users who are looking for the trademark to its own site, then regardless of the legitimacy of its critics, it will be considered contrary to the UDRP. ${ }^{204}$ Overall, it is not clear whether the use of a domain name to criticise a trade mark will be permited under the UDRP, unless a clear non-commercial intention is shown. Furthermore, when dealing with freedom of speech issues panels seem to be at least cautious, transferring only those where there are patent intentions of extortion or blackmail from registrants. ${ }^{205}$

Another type of controversial domains are fan sites that are active but do not pursue a commercial interest. In some cases panellists found that there is a legitimate interest in their use, even when using the complainant's trade mark; in other cases panellists stated that respondents were misrepresenting themselves by pretending to be the official website. ${ }^{206}$ Nevertheless, in a number of cases UDRP panels have held that personal names can be protected when they are being used as a common law trade mark. ${ }^{207}$

It has also been much debated whether authorised distributors, licensees, franchisees and resellers have legitimacy in using the trade mark in their domain name. On these issues the cases differ significantly. The majority of cases allow the use of the disputed domain when the registrant - mainly or exclusively - deals with trade mark products. ${ }^{208}$ 


\subsection{COMPLAINANTS MUST PROVE THAT THERE IS BAD FAITH IN THE} REGISTRATION AND IN THE USE OF THE DISPUTED DOMAIN NAME

The UDRP does not define the meaning of bad faith but it sets a number of non-exhaustive circumstances that if found by the panel will be sufficient to prove bad faith in the use and registration of the disputed domain name:

(i) circumstances indicating that you have registered or you have acquired the domain name primarily for the purpose of selling, renting, or otherwise transferring the domain name registration to the complainant who is the owner of the trade mark or service mark or to a competitor of that complainant, for valuable consideration in excess of your documented out-of-pocket costs directly related to the domain name; or

(ii) you have registered the domain name in order to prevent the owner of the trade mark or service mark from reflecting the mark in a corresponding domain name, provided that you have engaged in a pattern of such conduct; or

(iii) you have registered the domain name primarily for the purpose of disrupting the business of a competitor; or

(iv) by using the domain name, you have intentionally attempted to attract, for commercial gain, internet users to your web site or other online location, by creating a likelihood of confusion with the complainant's mark as to the source, sponsorship, affiliation, or endorsement of your web site or location or of a product or service on your web site or location. ${ }^{209}$

Several of these factors indicating bad faith overlap with the first two elements. The burden of proof is on the complainant, although some panels have shifted the onus to the respondent. ${ }^{210}$ When the registration of a domain name is established before the trade mark right, it will be considered as prima facie evidence of good faith. Under these circumstances the complainant may prove otherwise, for instance in the expectation of a merger between two companies proved bad faith registration. ${ }^{211}$ In the case of an inactive website, it does not usually prove lack of bad faith 'use', or the existence of bad faith, but it can be counted as a factor to determine bad faith. ${ }^{212}$ Other factors can be the resemblance to a well-known trade mark, having former abusive registrations, the use of a false identity during the registration, lack of response to the complaint etc. ${ }^{213}$

WIPO has noted that cybersquatting is growing rapidly through the use of 'domain parking sites' on which pay-per-click links are listed. ${ }^{214}$ Bulk domain names are registered, taking advantage of the five day grace period (free of charge), which is re-registered automatically under a different registrant. It was also found that the failure to conduct prior checks for third party rights in certain circumstances would represent bad faith under the UDRP. ${ }^{215}$ 
In other cases it may suffice as evidence of an offer to sell the domain name when there is a clear intention of extortion. ${ }^{216}$ The majority of panels admit the offer to sell from the respondent as a proof of bad faith, yet a minority considers that the mere offering, without more, does not indicate circumstances suggesting the respondent 'registered the domain name primarily for the purpose of selling' it. ${ }^{217}$

\subsubsection{Assessment}

\subsection{UDRP ACCUSATIONS OF BIAS}

The UDRP has been accused of forum shopping and of using a bias procedure financially supported by trade mark owners. The two first major studies reporting grounds of bias to the UDRP were the statistical analyses of Mueller and Geist. ${ }^{218}$ These reports raised significant concerns about the impartiality and independence of the UDRP proceedings. They will now be discussed in the light of the published rebuttals.

Biased ODR providers: Mueller's analysis Mueller's study was the first statistical study to raise concerns about forum shopping by the two main dispute resolution providers. The study criticises WIPO and NAF for being biased in favour of claimants. Mueller's principal contention is that WIPO and NAF have obtained the majority of the market share (61 per cent and 31 per cent respectively) by deciding more often in favour of trade mark interests (complainants win 82 per cent with WIPO and 81 per cent with NAF). ${ }^{219}$ This market share is contrasted with the now out of business eResolution, which despite charging cheaper fees, obtained a smaller market share ( 7 per cent) because it resolved disputes in a less complainant friendly way (complainants won in 51 per cent of cases). These circumstances have not changed in recent years. $^{220}$

The above findings may explain why the Canadian company eResolution went bankrupt after only two years in business. Its former president, Karim Benyekhlef, stated that the lower complainant win rate with eResolution diverted many cases to other dispute resolution providers who were more complainant friendly. ${ }^{221}$ Benyekhlef argued that this situation was so obvious that even the Canadian Government selected the more expensive and foreign WIPO rather than the national and cheaper service of eResolution in order to assure a more convenient outcome. ${ }^{222}$ Froomkin has suggested that the bias goes further than mere forum shopping because the future of dispute resolution providers and the income of the panellists depend mainly on the complainants' lawyers' views of which dispute resolution provider would benefit them most. ${ }^{223}$

Mueller's statistical analysis has received much criticism. One of the most contentious critiques was from the International Trade Mark Association (INTA), which declared that the study undermines the UDRP's achievement 
in creating a cost-effective procedure to combat cybersquatting. ${ }^{224}$ INTA argues that the selection of dispute resolution providers is not based mainly on their decisions (favouring claimants) but rather on their international reputation. ${ }^{225}$ It also reports that Mueller's presumption that a non-biased procedure would have a 50/50 result is mistaken since the UDRP was designed for cases involving abuse. ${ }^{226}$ Finally, it is stressed that respondents can always seek redress through the courts, but as Mueller rightly noted this is often a useless resource for respondents with inferior economic means.

Mueller proposes that in order to avoid the existing forum shopping, registrars, instead of claimants, should be responsible for selecting the dispute resolution provider, owing to the fact that registrars' incentives are more balanced than litigants' incentives. It is arguable whether registrars would be as effective as complainants in maintaining competent fees among all the providers, because registrars could also be biased; for example, a registrar may attempt to attract cybersquatters by selecting the most expensive dispute resolution providers or the most respondent friendly provider.

Biased appointment of panellists: Geist's analysis Geist found that a handful of panellists have resolved a significant number of those cases with a very high complainant success rate. ${ }^{227}$ INTA justified this finding by stating that panellists have busy schedules, making it difficult to ensure panellists have an even case load. Geist proposes the use of a minimum and maximum case load system for each panellist in order to avoid case allocation to complainant friendly panellists. ${ }^{228}$ Geist's report found that in single panel cases (appointed by the provider) complainants win more often than in three member panel cases (appointed equally by the parties' preferences). In those cases where respondents voluntarily pay part of the fees (for a three member panel) it may be because they have adequate economic means and a stronger case. Geist argues that this is also due to respondents with a stronger desire to avoid potentially biased panellists. ${ }^{229}$ In order to change this situation, he proposes compulsory three member panels for all contested (as opposed to default) decisions, which must be paid only by the complainant.

Geist indicated that there are fewer default cases in three member panels than in the single panels. ${ }^{230}$ Thus, the different rate of complainants' chances of being successful may not stem exclusively from biased single member panels but also from a higher number of default cases in single panels. ${ }^{231}$ This becomes clearer when taking into account that complainant success expectations in default cases was 94 per cent. ${ }^{232}$

It could be argued that before changing to compulsory three member panels, and consequently increasing considerably the price of the UDRP, it would be necessary to prove that single member panels are biased with something more than merely comparing the results of decisions. INTA rightly stated that statistical analysis in dispute resolution cannot evaluate fairness, indicating that bias can only be asserted by the merits of the cases decided 
by the panellists. ${ }^{233}$ An appellate review may be more appropriate to monitor unjust decisions.

It has been suggested that it may not be an intentional or direct bias but that it may be an indirect bias; from reading the publicly available CVs of panellists it appears that most of them are practising intellectual property lawyers. ${ }^{234}$ Froomkin suggests that UDRP providers' lists should also include people from other legal backgrounds, such as civil liberty lawyers. ${ }^{235}$ Furthermore, in order to provide independent panellists it would be necessary for the UDRP rules explicitly to prevent panellists from representing other parties in UDRP proceedings. ${ }^{236}$

Default cases Geist reported that 54 per cent of all UDRP cases were default cases and that a large majority of these decisions were in favour of claimants (94 per cent). ${ }^{237}$ It is not surprising that there is a high rate of successful default claims since when the defendant does not respond panels find in favour of the complainant because of the presumption afforded to complainant's factual allegations'. ${ }^{238}$ As for the lack of responses there may be many possible reasons for this high rate of default cases. On the one hand, trade mark and UDRP advocates assert that a significant group of cybersquatters do not participate in the procedure because they can foresee very little chance of succeeding and thus decide not to waste their time in defending themselves. On the other hand, it can be argued that a procedure managed by trade mark lawyers with a high complainant success rate may intimidate domain name holders - who may not be fully aware of their rights - from participating. According to Froomkin, the main reason for high default rates may be that the time limit of 20 days for respondents is too short a time to give the respondent a fair chance of preparing a proper defence. ${ }^{239}$

It is interesting to note that Nominet, the UK body in charge of internet domains, has amended its policy to allow the delivery of summary awards with a reduced fee for default cases. ${ }^{240}$ A similar initiative has recently been proposed by WIPO. ${ }^{241}$ Under Nominet proceedings when a case is being disputed by the domain name holder, parties are allocated to a mediation process which takes place over the phone and generally lasts for two weeks. ${ }^{242}$

\subsection{OTHER PROCEDURAL SHORTCOMINGS}

Language issues The language of the proceedings must be the one used in the registration contract, unless the parties agree a different language. ${ }^{243}$ However, the panel may change the language taking into account relevant circumstances, such as the nationality of the parties, the language of the documentation etc. ${ }^{244}$ Panels may also require parties to translate the documents that are not in the language of the procedure.

The UDRP has not been officially translated from English into any other language and all the existing unofficial translations have been done by 
dispute resolution providers and registrars. This lack of official translation has been denounced for violating many national laws that require that all information forming part of a consumer contract must be translated into the consumer's local language in order to be valid. ${ }^{245}$ Consumer law thus requires ICANN to carry out official translations of the UDRP policy and rules.

Costs issues For trade mark owners the UDRP has been a great success because they do not have to rely on multi-jurisdictional litigation, thus reducing costs in terms of time and money. This has also been achieved given the simplicity of the proceedings where each party only makes a single written submission on which the panel delivers its decision.

The complainant always pays the fee unless the complainant applies for one panellist and the defendant applies for three; in these circumstances the parties split the fee. This fee varies according to the number of domain names involved, the dispute resolution provider and the number of panellists involved. In very exceptional circumstances, the panel in its discretion may require hearings, including teleconference, video conference and internet conference; in such cases the parties will have to cover their expenses over and above the regular fee. ${ }^{246}$

In addition, the various dispute resolution providers have set competitive fees in order to attract complainants. This cannot be confused with forum shopping, as the latter is understood as unfair competition where there is a bias to attract claimants to the detriment of defendants' rights. This raises questions as to why one of the most expensive dispute resolution providers (WIPO) has the biggest share in the dispute resolution market. It may be for two reasons. First, when all the legal costs of a UDRP action are taken into account, the fee difference among providers may not be very relevant. ${ }^{247}$ Secondly, Geist and Mueller maintain that the higher complainant friendly rates are a major aspect and the fee is an unimportant element among trade mark owners because they have economic power. ${ }^{248}$ Also, INTA has ensured that factors such as international reputation are very important in selecting providers.

Under the UDRP it is not possible to order financial compensation or to impose the payment of legal costs; to recover these, it would be necessary to claim through the courts. ${ }^{249}$ This issue was debated during the WIPO consultations but it was decided to exclude the allocation of legal costs in the UDRP because these legal costs could intimidate the registration of new domains. Furthermore, it would be difficult and expensive to recover small costs, particularly from registrants.

Time limits One of the main objectives of the UDRP was to accomplish an expedited procedure, whilst avoiding the potential problem that a fast procedure may overlook due process issues. In the UDRP this is noticeable through the imposition of strict word limits, only one plea being permitted, limiting evidence and hearings and establishing short time limits. These 
limits may be justified provided they are applied equally to both parties. Since the UDRP proceeding is not a judicial procedure but an administrative procedure where decisions are not legally enforceable by any court, the UDRP should not be expected to deliver the same legal standards as those expected in a judicial system. Nonetheless, the time limitation has been strongly criticised for favouring the complainant rather than the respondent because complainants have no time limit for initiating a UDRP complaint. ${ }^{250}$ As mentioned above, Froomkin proposes that the period for responding should be at least 60 days, and that this period should only commence once the complaint has been received by the registrant. ${ }^{251}$ However, the increased response time should not apply to default claims where the respondent does not participate; otherwise, it may delay the process unnecessarily.

In relation to the enforcement of decisions the same reasoning should be applied: the 10 day limit may be far too short for contested claims, and despite there being apparently the same rule for both parties, it certainly favours the complainant because the latter would have not changed his status quo - neither the lack of domain name that the complainant claims, nor the type of claim where he is still the claimant. ${ }^{252}$ The UDRP attempted to balance this by favouring respondents with mutual jurisdictions, either the respondents' or the registrars' jurisdiction. ${ }^{253}$ Despite this, the present time limits are too short for preparing a legal action.

\section{Need for legal advice for respondents It may be possible that a certain number of} registrants may not defend their domain in their best interests, or even not defend it at all if they are not familiar with the procedure. Even though the UDRP proceeding is rather simple for a lawyer, it may appear confusing for registrants without legal training. This may be particularly burdensome for respondents who are not companies but individuals who may not easily find legal advice on the UDRP procedure.

The legitimacy of the UDRP has been questioned given the existing imbalance of power between the parties in the UDRP procedure, which is noticeable from the initial contract entered into by the registrant. ${ }^{254}$ This imbalance is apparent throughout the proceeding; where there are a high number of default cases, respondents tend not to be represented and the time limits are particularly short for them. It does not appear that, in 20 days and even if promptly notified, respondents will have sufficient time to draft legal responses (ie of up to 5000 words with WIPO) effectively proving a legitimate interest and good faith in their domain names. Moreover, if it is assumed that complainants have no time restrictions and more economic power, it might be expected that their arguments will be better prepared than those of respondents, which creates a new imbalance in the UDRP procedure. Thornburg has stated that ' $[t]$ hese power disparities also illustrate that even technologically accessible processes may not function equitably unless the system provides some kind of representative for the weaker party'. ${ }^{25}$ She proposes the assistance of an ombudsperson who, as an expert, could advise the weaker party. ${ }^{256}$ 
In order to balance the power between the parties, registrants could be offered some type of free and accessible legal advice. This legal advice could be offered by ICANN or the providers. If dispute resolution providers prefer not to supply this service in order to avoid accusations of bias in favour of respondents, they should at least refer respondents to institutions that can offer this type of service. Experts could provide some type of personalised information about previous cases, assist in finding panellists, ${ }^{257}$ answer respondents' enquiries and explain their entitlements. The aim is not to help cybersquatters but, on the contrary, to assist those registrants who have a lawful right to retain their domain names.

\subsection{LACK OF UNIFORMITY}

Abuse of the UDRP The UDRP regulates a very specific type of violation of trade mark rights related to cases of abusive registrations. These cases are purported to be very easy to prove in a fast cost-effective written proceeding where certain procedural guarantees are excluded ie hearings, evidence etc. It has been argued that some UDRP proceedings have illegitimately assumed the role of the courts, thereby violating the procedural guarantees that can only be provided by the courts. ${ }^{258}$ Froomkin observed that several panels formed by trade mark lawyers have transferred domain names based on grounds which were completely outside the scope of the UDRP. ${ }^{259}$ In this respect Hedley pointed out that when registrants clearly breach trade mark laws some panels (formed by IP lawyers) will find it very difficult to recognise in them a legitimate interest or good faith in doing so. ${ }^{260}$ This misappropriation is favoured by the high level of freedom given to panellists who can decide many issues at their own discretion. This creates two main problems: First, panellists do not use their discretion in the same way and consequently decisions can be inconsistent. Secondly, as a result of the first reason, there is a lack of legal certainty.

The lack of uniformity of decisions and the low cost of the UDRP proceedings may encourage frivolous complaints hiding RDNH intentions. ${ }^{261} \mathrm{~A}$ mere RDNH statement might not be enough to discourage claimants from abusing the UDRP. WIPO seems to be responsible for this situation. Froomkin has observed: 'As WIPO's prime concern was the protection of trade marks, not protection against trade marks abuse, it made no recommendation to address this problem'. ${ }^{262}$ In order to stop this it has been suggested that frivolous complaints should be penalised by the imposition of a fine in the event that a panel finds RDNH, whereby the claimant would have to pay financial compensation to the respondent. ${ }^{263}$ It could, however, be asked why the trade mark owner should compensate the registrant for an attempt to RDNH while the cybersquatter is not held responsible for extortion. The answer is clear: the cybersquatter, unlike the trade mark owner accused of $\mathrm{RDNH}$, does not abuse the UDRP procedure in order to hijack a domain name. 
The role of precedent The UDRP, like arbitration, is informed by the adversarial principle, but it does not follow a strict doctrine of precedent. ${ }^{264}$ Panels nonetheless consider former decisions on similar facts in order to preserve predictability and fairness. Thus, the persuasive nature of former decisions is unquestionable, in particular when such decisions concern registrants who already have a record of abusive registrations. Despite this, it is not surprising that the lack of a strict doctrine of precedent, plus the lack of an appeal review contribute to the creation of contradictory decisions and subsequent confusion. It has been suggested that the use of more effective and organised search engines will assure that parties and panellists will not miss reference to significant cases. ${ }^{265}$ To date, domain name providers have compiled their own decisions but without including the decisions of other providers.

An undeniable achievement of the UDRP is its transparency, which is manifested from the policy and rules, easily accessible online, to all decisions that are reasoned and published online. Transparent systems have many benefits because they promote accountability and remain open to criticism on how to improve them. However, transparency may have opposite consequences: in an effective procedure it promotes confidence but in an unfair procedure it produces the opposite effect to legal certainty, creating confusion and unpredictability.

\subsection{APPROACHES FOR INCREASING UNIFORMITY}

Panellists from different countries with diverse legal values have produced inconsistent interpretations of the UDRP. ${ }^{266}$ Since the UDRP does not fall within the concept of arbitration and it is not subject to its laws, there is no possibility of judicial review or appeals. Only the courts can reverse a UDRP decision but even judicial review cannot be considered a means of unifying the interpretation of the UDRP because cases are treated ex novo disregarding UDRP decisions; furthermore, courts apply national trade mark laws and not the UDRP. ${ }^{267}$ A welcome development in WIPO is the recent admission of cases involving multiple complainants with one respondent holding a number of disputed domain names. ${ }^{268}$

A more uniform approach in the interpretation of the UDRP could raise legal certainty and greater predictability of outcome. This could be achieved by writing guidelines, reforming the UDRP and creating an appellate review, as follows:

(i) Creating new guidelines can be useful in inspiring uniformity but it may not be enough to persuade those minority views with strong arguments, as often seen in the three member panels. ${ }^{269}$ Additionally, the existing public guidelines are directed to the parties and not to panellists. It would be more persuasive if they were official guidelines, ie approved by ICANN.

(ii) Reforming the UDRP to clarify those aspects that have caused different 
interpretation among the panellists: clarifying the discharge of the claimants' burden of proof; to spell out the meaning of 'tarnish' in relation to parody sites; ${ }^{270}$ defining trade mark and common law trade mark; regulating the $\mathrm{RDNH}$; grounds for recusal of panellists and dispute resolution providers; banning complainants from using the UDRP more than once against the same domains etc. In addition, the UDRP proceedings should support the use of technology and consensual procedures such as negotiation and mediation provided the parties voluntarily agree their use.

(iii) An appellate review would be the best option in order to create precedents and legal certainty. The aim of an appellate review is to correct bad decisions and give uniformity and fairness to what is fast becoming the 'law' of ICANN. The downside of an appellate review is that it might benefit more trade mark owners, leaving registrants exposed to two administrative procedures to defend their domains. It has been also argued that an appeal review will increase costs and will delay the whole procedure. Yet, the desire for minimum costs and speed should not outweigh the fairness and predictability that should emanate from an appeal process. ${ }^{271}$ Furthermore, appellate reviews have been implemented successfully by national laws to resolve ccTLD disputes, such as in the case of Nominet in the UK.

\subsection{APPLYING UDRP TO CONSUMER DISPUTES}

The UDRP proceeding is the most famous online 'arbitration' process. It is not then surprising that the UDRP has been suggested as a model for other consumer complaints in e-commerce. ${ }^{272}$ There is, however, some scepticism about the application of this model, ${ }^{273}$ where the availability of several ODR providers would give businesses and consumers the choice of which provider to choose and would encourage future ODR development through competition and profit initiative. The UDRP somehow displays the promise and the perils of privatised law and ODR. ${ }^{274}$ The main promise is to provide an affordable and transparent procedure that would be self-enforceable. The main peril is to create an inefficient procedure designed and funded exclusively by businesses for their sole benefit.

Donahey has drafted an adaptation of the UDRP in order to address three types of online consumer complaints related to goods and services: (a) that do not comply with the description; or (b) that they were delivered late; or (c) that were not delivered at all. In this proposal sellers would fund this system by a small fee payable on each transaction and in turn they would display a trustmark. ${ }^{275}$ Donahey proposes that in order to assure prompt enforcement, each online seller would be required to maintain a monetary deposit from which any decision will be satisfied. ${ }^{276}$

According to him, a successful complainant must prove one of the following circumstances: (a) the seller misrepresented himself or the quality or 
condition of the goods or services received; (b) the goods or services were not delivered in the reasonable time expected; (c) they were never delivered. And sellers must prove one of the following: (a) there was no misrepresentation; (b) the consumer refused to accept the delivery; (c) the consumer did not pay.

The proposed rules are very similar to the UDRP Rules, differing only in two significant issues: (i) the consumer has the opportunity to meet the assertions of the seller after the latter has answered the complaint; and (ii) all decisions are issued by a majority of a three member panel, which is appointed one for each party and the third member by the ODR provider. In addition, one of the most significant and positive aspects of the UDRP is that it allows the disputants to initiate de novo legal actions in court. This rule could be applied to online consumer arbitration, at least for a period of time, until online consumer arbitration has won wider acceptance. ${ }^{277}$

A challenge in transposing the UDRP to mainstream B2C is that the resolution of most of these disputes may not be cost-effective, except for high value transactions (eg new cars), particularly if they are linked to specific markets (eg car dealerships). Since the UDRP is still quite legalistic, a transposition of this process to $\mathrm{B} 2 \mathrm{C}$ would require legal representation. For low value disputes other methods, such as the highly automatic procedures and more inquisitorial procedures, may be more appropriate. Also the intervention of a single panellist may be a more cost-effective option. Perhaps, three member panels could be retained for an appellate review. In addition, it must be noted that many types of consumer complaints may be difficult to prove in a written only procedure. This could be avoided to some extent by the use of consensual ODR methods, such as negotiation and mediation tools as used by Nominet, which can be very effective when appropriate incentives are used to attract businesses' participation.

\subsubsection{Evaluation}

ICANN, together with the UDRP, has succeeded in developing a transparent global ODR procedure based on contract law that allows trade mark owners to fight cybersquatting efficiently. This is a positive accomplishment for the development of e-commerce because it favours consumers' confidence in the internet by reducing the number of fraudulent registered domain names. This success, particularly among trade mark owners, has been attained by creating a cost-effective procedure which has compulsory participation built in and a self-enforcement mechanism.

The UDRP, however, has been harshly criticised for the use of proceedings that are seen in favour of complainants, further damaging the legitimacy of ICANN. The main reason for this appears to be that interests of all parties are not equally represented within the law maker (ICANN and WIPO) and those who apply this law (UDRP dispute resolution service providers and panellists). Since the creation of the UDRP up to the time of writing the UDRP has not shown any intentions of reform despite all the existing critics. After a 
decade of experience, it appears clear that the UDRP needs to be reviewed if it aims to provide, not only an efficient but a fair procedure.

This section has suggested that the UDRP should take steps towards the following changes. First of all, the UDRP needs to clarify those issues which have provoked dissented interpretations, eg burden of proof, parody websites and the meaning of common law trade mark. Secondly, there is an imperative need for designing an effective appeal system to contribute to legal certainty; otherwise, it will be more the rule of the individual panellist rather than the application of a 'uniform' policy. Thirdly, respondents need more assistance and guidelines; accordingly they should be provided with free advice on their rights. Fourthly, a more effective RDNH control should be put in place. Fifthly, time limits need to be extended. Sixthly, the UDRP should mandate transparent non-biased selection of single panellists, including the grounds on which panels and dispute resolution providers can be recused. It should expressly exclude panellists from representing other parties and complainants from using the UDRP more than once on the same domains. Finally, UDRP proceedings should support the use of technology and consensual procedures, such as negotiation and mediation, whenever parties voluntarily agree to its use. ${ }^{278}$

\subsection{Conclusion}

The greatest advantage of adjudicative procedures is that decisions are reached regardless of the parties' ability to attain an agreement. When the dispute concerns a violation of the law, the more appropriate tool will often be an adjudicative procedure because the aggrieved party does not need to conciliate. In most cases, however, consumers cannot access traditional forms of dispute resolution given the disproportionate cost of these procedures in relation to the amount in dispute, particularly in cross-border disputes. This chapter has argued that the assistance of ICT reduces the time and cost associated with the resolution of consumer disputes, thereby improving the effectiveness and accessibility of dispute resolution mechanisms. In the next few years the development of ICT and the access to ICT within society is expected to continue to increase, which in turn would augment the need for workable adjudicative ODR models. This chapter has focused on the potential of two processes in resolving consumer disputes online: the ESCP and the UDRP.

Within the EU much is expected of the ESCP, which in order to deliver a cost-effective process will need to rely on ICT support. Public courts have the tools to deliver a workable dispute resolution system for consumers because they can deliver trust and due process guarantees. ${ }^{279}$

This will be a significant challenge, because unlike the UDRP - an ODR system which deals with specific complaints - the ESCP deals with more complex disputes that require not only parties who are comfortable with the online environment, but also powerful and effective ODR resources (the 


\section{Online Dispute Resolution for Consumers in the European Union}

fourth party). It is anticipated that the ESCP may be a successful tool in dealing with EU cross-border disputes within a certain economic range, eg between $€ 500$ and $€ 2000$. It will be particularly useful for dealing with disputes where parties cannot reach consensus through any other ODR method, especially when disparity of power exists between the parties.

This chapter has pointed out some criticisms as possible constraints that could hinder the full potential of the ESCP. First, it has recommended that the ESCP should be applied to domestic disputes, at least when the parties or the Member States agree to it. Furthermore, the economic limit should be increased, because the ESCP may not be cost-effective for all claims below $€ 2000$ when expert reports, translations and legal fees may be paid by one of the parties. A significant challenge for the success of the ESCP is that judges may be compelled to dismiss many claims related to $\mathrm{B} 2 \mathrm{C}$ transactions owing to the lack of proper evidence and other substantive or procedural defects. This will be a challenge for many claimants, particularly those who lack legal representation. Hence, this chapter has suggested that low value disputes should first explore more informal procedures, ie the use of consensual ODR and automated processes. The success of consensual and automated processes will depend on the type of dispute and the capability of the third (and fourth) neutral parties in evaluating the cases.

The ESCP has an obvious limitation: it can only be applied to disputes arising from within the EU. Arbitration can be more effective than litigation when dealing with cross-border disputes because arbitral awards overcome jurisdictional problems more easily. However, B2C arbitration needs to incorporate tools that guarantee fairness and compliance with due process principles. It also needs to incorporate post-dispute agreements and effective enforcement mechanisms, or non-binding arbitration with self-enforcement mechanisms akin to the UDRP. Disputes outside the competence of the ESCP can be suitable candidates for arbitration, as can disputes above the ESCP economic limit because in these cases cross-border litigation may still not be cost-effective. Arbitration is viewed as a voluntary adjudicative procedure but different approaches are taken around the world. In the US the use of arbitration is compulsory when it is not unconscionable for consumers. In the EU the voluntary standard is higher; consumers' approval to participate in arbitration is only valid when given after the dispute has arisen. Hence, consumer arbitration should be promoted, particularly for specific disputes, eg domain names, but it cannot offer a higher burden to consumers, ie it cannot be more expensive than litigation or the small claims procedure. The UDRP has shown how non-binding arbitration can be effective without the courts' assistance, with its own system of enforcement. Perhaps, this mechanism illustrates how online arbitration will develop in the future.

This chapter has provided some examples of how ICT is an important element to improve efficiency and access to justice in adjudicative processes. Both the ESCP and the UDRP were designed by public authorities in order to resolve special types of disputes which could not be resolved by traditional 
means based on offline mechanisms with jurisdictional difficulties. In order to create cost-effective legal processes to resolve low cost disputes, adjudicative methods will need to be assisted by ICT. It is too early to consider the success of the ESCP but it does provide consumers with a new tool to overcome disputes in the internal market. It is hoped that the ESCP will contribute in assuring consumers that it is possible to participate in the EU market with confidence, with the backing of effective and fair redress mechanisms.

In the case of the UDRP, ICANN also sought to provide a mechanism that could resolve, in a cost-effective manner, disputes relating to cybersquatting, without being sued by trade mark owners for allowing registration of domain names that violate national trade mark laws. The UDRP, as well as other arbitration programmes, such as the Spanish Arbitration Boards, have proven that in order to promote the regular use of online arbitration, it is necessary to obtain a commitment from businesses to use ODR prior to the dispute arising.

However, the resolution of disputes (particularly those where one of the parties is outside the EU) through adjudicative procedures would need similar laws and expectations. This is not always possible or achievable in a multicultural society. Adjudication may not be the best solution for all types of internet disputes, even for those arising out of e-commerce; in fact, the search for a settlement could allow parties to save time, money and personal/business relationships. The next chapter examines the use of online consensual methods and their potential for settling consumer disputes.

\section{Notes}

1 Richard Susskind, IT Adviser to the Lord Chief Justice, Fifth Annual Forum on Online Dispute Resolution, Liverpool (19-20 April 2007).

2 Susskind (24 January 2006).

3 Oskamp, Lodder \& Apistola (eds) (2004).

4 Poblet \& Casanovas (8 June 2007b) 57.

5 Chapter 1.2.2. See http://www.smallclaims.ie.

6 The author has carried out two interviews in the Cork Small Claims Court. The first interview took place on 26 May 2006 and the second on 5 December 2007.

7 This admissibility rate is a common rate for dispute resolution services open to consumers and non-business parties. See Traesch \& Ferrali (8 June 2007) 44.

8 Author's interview with Leonard McCarthy, registrar of the Cork District Court (5 December 2007).

9 For more information see http://www.moneyclaim.gov.uk/csmco/guidelines_ system.jsp.

10 Reiling (2006) 194.

11 The customer helpdesk can be contacted for support between $9.00 \mathrm{am}$ to $5.00 \mathrm{pm}$, Monday to Friday on Tel: 0845601 5935, Fax: 0845601 5889, E-mail: customerservice.mcol@hmcourts-service.gsi.gov.uk.

12 BBC News 'Bank Claims Deluge Legal Service' (8 June 2007) available at http:// news.bbc.co.uk/2/hi/business/6733361.stm.

$13 \mathrm{http} / / / \mathrm{www}$. possessionclaim.gov.uk/pcol/.

14 HMCS News Release 'Possession Claim Launched' (30 October 2006) available at http://www.hmcourts-service.gov.uk. 
15 Civil Procedure Rules r 55.10.A and Practice Direction - Possession Claims Online.

16 HMCS News Release 'Telephone Hearings Will Lead to Speedier Justice in County Courts' (30 March 2006) available at http://www.hmcourts-services. gov.uk.

17 Practice Direction 5C-Electronic Scheme. 51st Update January 2010.

18 Einstein J, 'Technology in the Court Room 2001: Friend or Foe?' available at http://www.lawlink.nsw.gov.au/lawlink/supreme_court/ll_sc.nsf/pages/SCO_ speech_einstein_201101; see also Webb (2007) 73.

19 New South Wales Conciliation, Trader and Tenancy Tribunal Act 2001; European Commission, Health and Consumer Protection Directorate-General Directorate B Consumer Affairs prepared by The Study Centre for Consumer Law, Centre for European Economic Law Katholieke Universiteit Leuven, Belgium 'An analysis and evaluation of alternative means of consumer redress other than redress through ordinary judicial proceedings' (17 January 2007) 249 (Leuven Report).

20 Electronic Transactions Act of New South Wales 2000 and Courts Legislation Miscellaneous Amendments 2002. See Webb (2007) 73-74.

21 De Rose $v$ State of South Australia [2003] FCAFC 286.

22 Current guidelines are available at http://www.fedcourt.gov.au/how/practice_ notes_cj17.htm.

23 Tamberlin J, Third Annual Forum on Online Dispute Resolution, Melbourne (July 2004).

24 Regulation (EC) 861/2007 of the European Parliament and of the Council of 11 July 2007 establishing a European Small Claims Procedure [2007] OJ L199/1. Some of the ideas expressed in this section were previously published in Cortés (2008a) 83-97.

25 ECT arts 61(c) and 65 introduced by the Amsterdam Treaty in 1999.

26 Regulation 805/2004 creating a European Enforcement Order for uncontested claim. Regulation (EC) 1896/2006 creating a European order for payment procedure.

27 Government Response to the Constitutional Affairs Select Committee's Report, 'The Courts: small claims' (February 2006) §§ 23-24. Opinion of the European Economic and Social Committee on the Proposal for a Regulation of the European Parliament and of the Council establishing a European Small Claims Procedure (COM(2005) 87 final 2005/0020 (COD)) para 6.1.1.

28 Leuven Report (17 January 2007) 215.

29 See Small Claims 2006 Report avaialable at http://www.courts.ie. See also European Consumer Centre Ireland Report 'The Development of Alternative Dispute Resolution (ADR) in Ireland, An Analysis of Complaints, Best Practices and Future Recommendations' (May 2008).

30 Leuven Report (17 January 2007) 209-210.

31 House of Lords, European Union Committee: European Small Claims Procedure, 23rd Report of Sessions 2005-06 para 78.

32 Ibid para 6.

33 Article 1.1 as amended by the European Parliament Opinion of 24 October 2006.

34 Ibid art 3.2.

35 This view is supported by the EC Commission and the Leuven Report (17 January 2007) 229.

36 See ch 1.

37 Article 31.2.1.

38 According to the Leuven Report there are five Member States which do not have either a SCP in strict sense nor simplifications on the ordinary civil procedure for small claims. See Leuven Report (17 January 2007) 197.

39 Articles 10, 17. 
40 Ibid art 14.

41 Ibid art 10.

42 Council Regulation 44/2001 (Brussels I) on jurisdiction and the recognition and enforcement of judgments in civil and commercial matters. Regulation 593/2008 (Rome I) on the law applicable to contractual obligations.

43 See ch 1.3.

44 Standard forms A and C as amended by the European Parliament.

45 Recital 12.b as amended by the European Parliament.

46 Preamble para 2.1.2, art 9 and recitals 11, 16.

47 Ibid art 4.6.

48 The refusal must be reasoned in writing: art 5.1.

49 ECHR art 6.

50 Recommendation 98/257/EC.

51 Ibid art 16.

52 See discussions at the JHA meeting (June 2006).

53 Article 14.1 and recital 4 as amended by the European Parliament.

54 Ibid art 17.

55 The House of Lords supported this view. See House of Lords 23rd Report of Sessions 2005-06 para 181.

56 Rabinovich-Einy (2003/04) 17.

57 Ibid.

58 Standard form A.

59 Article 12.3.

60 HMCS leaflet EX301'Making a Claim-Some Questions to Ask Yourself at 1 See Burchell v Bullard [2005] EWCA Civ 358 and Halsey v Milton Keynes General NHS Trust [2004] 1 WLR 3002.

61 Wissler (1995) 332-34.

62 Rule (2002) 120.

63 Hill (2008) 377-78.

64 Byrne \& Horton (2007).

65 Ponte \& Cavenagh (2005) 86.

66 Stipanowich 'The Arbitration Penumbra: Arbitration Law and the Rapidly Changing Landscape of Dispute Resolution' Legal Studies Working Paper Series, Paper Number 2008/1 at 5 available at http://ssrn.com/abstract $=1007490$.

67 CEN/ISS Workshop Agreement on Standardization of Online Dispute Resolution Tools prCWA XXX (20 October 2009).

68 Lodder, Gerard \& Vreeswijk (2004) 23.

69 United Nations Conference of Trade and Development, E-Commerce and Development Report 2003 ch 7 'Online Dispute Resolution: E-Commerce and Beyond' 179.

70 Hill (1999); Wahab (2004) 123; Vreeswijk \& Lodder (2004); Katsh \& Rifkin (2001) 138; Kierkegaard (2004) 180; Schultz (2002).

71 Ponte \& Cavenagh (2005) 84.

72 Krause (October 2007).

73 For more information visit their websites: AAA http://www.adr.org/; BBB http:// www.bbb.org/; NAF http://www.arb-forum.com/; WIPO http://www.wipo.int/ amc/en/index.html and JAMS http://www.jamsadr.com/.

74 Deweer v Belgium (27 February 1980) ECtHR Series A nr 35 para 49; Leuven Report (17 January 2007) 120.

75 Council Directive 93/13/ECC [1993] OJ L095 (21 April 1993).

76 Proposal for a Directive on Consumer Rights COM(2008) 614/3.

77 Friel (2000) 294 ff; Hörnle (2009); Picardi v Cuniberti [2002] EWHC 2923 (QB) para 102.

78 [2000] OJ C 155 (6 June 2000). 
79 Recommendation 98/257/EC.

80 Kaufmann-Kohler \& Schultz (2004) 204-205.

81 Leuven Report (17 January 2007) 120.

82 Sté V 2000 and Sté XJ 220 Ltd c M Meglio and M Renault Rev. Arb. 1997 p. 537 and Cass Civ Ire (21 May 1997).

83 Arbitration Act 1996 s 91; Bates (2004) 841.

84 Office of Fair Trading 'Unfair Contract Terms Bulletin' (August 2000) 29. See also Matthews (2005) 5.

85 Chartered Institute of Arbitrators 'Rules of Independent Arbitration Scheme for the Travel Industry' art 1.8 (1994).

86 See the approved ADR bodies available at http:/ec.europa.eu/consumers/ redress/out_of_court/adrdb_en.htm.

87546 US 440 (2006).

88 Alderman 'The Future of Consumer Law in the United States - Hello Arbitration, Bye-bye Courts, So-long Consumer Protection' University of Houston Law Center No 2008-A-09 at 9.

89 Allied-Bruce Terminix Cos. v Dobson 513 US (1995) 277.

90 Sternlight (1996) 637.

91 Omni Tech Corp. v MPC Solutions Sales, LLC 432 F.3D 797, 799 (7th Cir. 2005).

92 Ross $v$ Bank of America F.3d. 2008 WL 1836640 (Cir.2d. NY).

93 Thornburg (2006) 312.

94 Allied-Bruce Terminix Cos. v Dobson 513 US (1995) 265.

95 Comb and Toher v Paypal, Inc. (US District Court, ND Cal, San José Div 30 August 2002).

96 Iberia Credit Bureau v Cingular Wireless LLC, Sprint Spectrum Company, Centennial Wireless 379 F3d 159, 168169 (5th Cir. 2004).

97 Hörnle (2002).

98 Leuven Report (17 January 2007); US National Report 3-4.

99 Brower $v$ Gateaway 2000 Inc 676 NYS 2d 569, 572 (1998).

100 Statutes of the International Court of Arbitration art IV. See also 'Guidelines for Arbitrating Small Claims under the ICC Rules of Arbitration' available at http://www.iccwbo.org/court/english/arbitration/pdf_documents/small_ claims.pdf.

101 Leuven Report (17 January 2007); US National Report 21.

102 Sternlight \& Jensen (2004) 75.

103 Green Tree Financial Corp. v Bazzle 123 S Ct 2402 (2003).

104 Alderman 'The Future of Consumer Law in the United States - Hello Arbitration, Bye-bye Courts, So-long Consumer Protection' University of Houston Law Center No 2008-A-09 at 13.

$105 \mathrm{Ibid}$; Dale $v$ Comcast US Court of Appeals for the 11th Circuit 498 F3d 1216 (2007).

106 Examples where class arbitration was not recognised: Champ v Trading Co. $55 \mathrm{~F}$ 3rd 269, 275-77 (7th Cir. 1995); Radolf v Green Tree Financial Corp. 991 F Supp. 1410 (MD Ala. 1997).

107 Hamilton (2006) 693.

108 Ponte \& Cavenagh (2005) 95.

109 Advanced Bodycare Solutions, LLC v Thione International, Inc. No 07-12309 (11th Cir. 21 April 2008).

110 Drahozal \& Friel (2002) 357.

111 Kaufmann-Kholer \& Schultz (2004) 208. See also Hörnle (2009).

112 Annex II para (c).

113 See ch 5 of this book.

114 Katsh \& Rifkin (2001) 139.

115 New York Convention art V(1)(b); Schultz (2002) 119-29. 
116 Katsh \& Rifkin (2001); Wahab (2004); Kierkegaard (2004) 180; Schultz (2002); Hill (2008) 199.

117 eg English Arbitration Act 1996 s 52(1); New York Convention 1958 art IV.

118 Article 5.2.

119 Schultz (2002).

120 Kierkegaard (2004) 180. See United Nations Convention on the Use of Electronic Communications in International Contracts (2007). See also UNCITRAL 39th session revision to article 7 of the Model Law on Arbitration and the recommendation on article II and VII of the New York Convention.

121 Gillieron (2008) 322.

122 Ponte \& Cavenagh (2005) 97.

123 See ch 2.

124 Ley de Servicios de la Sociedad de la Información 34/2002 art 32 and para 2 of disp. adic. 3 .

125 Ley 60/2003 of Arbitration of 23 December.

126 RD 231/2008 arts 51-55.

127 Ibid art 51.

128 Ibid art 1.

129 Ley 7/1998, LGDCU disp. adic. 1.26.

130 Gonzalo Quiroga (2003) 120.

131 Ley 44/2006 of 29 December 2006 on Consumer Protection art 31.4.

132 RD 231/2008 art 18.

133 Ibid art 19.

134 Ibid art 20.

135 Ibid art 38.

136 Ibid.

137 An IP address is a string of numbers, eg '192.0.34.163', which is translated by ICANN to the correspondent domain name, eg 'www.icann.org'. An early version of this section has been previously published in Cortés (2008b) 133-39 and Cortés (2008c) 349-59.

138 'Board Rejects .XXX Domain Application' (30 March 2007) available at http:// www.icann.org/announcements/announcement-30mar07.htm.

139 ICANN 'New gTLD Program, Explanatory Memorandum, Cost Considerations of the New gTLD Program' (24 October 2008) available at http://www. icann.org/en/topics/new-gtlds/cost-considerations-23oct08-en.pdf.

140 See the US Department of Commerce 'White Section' (5 June 1998) available at http://www.icann.org/general/white-section-05jun98.htm.

141 UDRP Policy para 4(a).

142 Parisi v NetLearning, Inc. 139 F. Supp. 2d 745 (2001).

143 Hedley (2006) 177.

144 UDRP Policy para 1.

145 WIPO was approved by ICANN on 1 December 1999. It is based in Geneva, Switzerland. See http://www.wipo.int/amc/en/domains/.

146 NAF was approved by ICANN on 23 December 1999. It is based in Minneapolis, Minnesota. See http://domains.adrforum.com/.

147 ADNDRC was approved by ICANN on 28 February 2002. It has two offices in Beijing and Hong Kong. See http://www.adndrc.org/adndrc/index.html.

148 CAC was approved by ICANN on 23 January 2008. See http://www.adr.eu/.

149 This is already admitted by some UDRP providers. See National Dial a Word Registry Pty Ltd and Others $v 13000$ Directory Pty Ltd WIPO/D 2008-0020.

150 ICANN Press Release 'ICANN Opens Public Comments on Revised Proposal from the Czech Arbitration Court (CAC) to Become a UDRP Provider' (12 November 2007) available at http://www.icann.org/announcements/ announcement-2-12nov07.htm. 
151 WIPO 'Comments on the CAC Application to Become a UDRP Provider' (29 November 2007). See also Michael 'Pledge Public Comments on the CAC Application to a UDRP Provider' (25 June 2007).

152 http://www.icann.org/en/announcements/announcement-22jul08-en.htm.

153 'WIPO Launches Paperless UDRP Proceedings' PR/2009/624 (11 December 2009) available at http://www.wipo.int/pressroom/en/articles/2009/article_ 0057.html. ICANN 'Announcement Regarding Implementation of Modification to Implementation Rules for Uniform Domain Name Dispute Resolution Policy' (7 December 2009) available at http://www.icann.org/en/announcements/ announcement-07dec09-en.htm.

$154 \mathrm{Ibid}$. See also UDRP Rules applicable since 1 March 2010 available at http:// www.icann.org/en/dndr/udrp/uniform-rules.htm.

155 Eg American Anti-Cybersquatting Consumer Protection Act, Pub. L. No $106-43 \$ \$ 3$ (a) (2), 5, 113 Stat, 218, 220 (1999).

156 Post 'Juries and the New Common Law of Cyberspace' (September 2000) available at http://www.temple.edu/lawschool/dpost/Juries.html.

157 Ibid.

$158 \mathrm{Eg}$ WIPO's model complaint available at http:/www.wipo.int/export/sites/ www/amc/en/docs/complaint-udrp.doc.

159 Previously hard copy submissions were permitted because when the UDRP was originally designed in 1999 many countries did not have appropriate legislation equating electronic and hard-copy communications.

160 UDRP Policy para 4(a).

161 UDRP Policy para 4(a); Sormac BV v Domains by Proxy, Inc. and James McCrory D2007-1338 denied; Playboy Enterprises International, Inc. v Joao Melancia D2006-1106 transfer.

162 Hedley (2006) 185.

163 UDRP Rules para 12.

164 Ibid paras 4(c), 5(a).

165 Ibid para 10(c); NAF Supplemental Rule 6(a).

166 Geist found in a case study of 4000 claims that 89.6 per cent of the cases were resolved by single member panels. See Geist (2002) 922.

167 UDRP Rules para 6.

168 Mueller (2002); Geist (2002) 903. See also rebuttal from Branthover (2002) (INTA).

169 UDRP Rules para 6(e).

170 Ibid paras 15(b), 16(a).

171 Ibid para 18(a).

172 Ibid para 17(a).

173 WIPO has reached a high number of settlements in 2006 with ccTLDs: 121 settlements from a total of 446 cases. See WIPO Press Release (2007) 'Cybersquatting Remains On The Rise With Further Risk To Trademarks From New Registration Practices' PR/479/2007; Patrikios (2008) 66-76.

174 http://www.nominet.org.uk/disputes/drs/mediation/.

175 Strick.com NAF 94801.

176 Proto Software, Inc. $v$ Vertical Axis Inc/PROTO.COM D2006-0905 denied; Jazeera Space Channel TV Station v AJ Publishing D2005-0309 denied; Dreamgirls.com v Dreamgirls Entertainment D2006-0609 denied.

177 Wal-Mart Stores, Inc. and Mrs Helen Walton v Bestinfo/David Webb WIPO/D20050086 transfer. Benyekhlef \& Gélinas (2005) 112; Froomkin (2002) 699.

178 Eg Julia Fiona Roberts $v$ Russell Boyd WIPO/D2000-0210 transfer. The name of Julia Roberts was identified as a common law trade mark.

$179 \mathrm{Eg}$ Excelentísimo Ayuntamiento de Barcelona v Barcelona.com, Inc. WIPO/D20000505 transfer. 
180 UDRP Rules para 16(b). The WIPO website provides a search engine to find cases easily: http://www.wipo.int/amc/en/domains/search/index.html.

181 UDRP Policy para 4(k).

182 UDRP Rules para 3(b), (xiii).

$183 \mathrm{Eg}$ ozu.com. This Spanish case, in addition to the use of domain names (ozu.com), was related to other issues, namely software ownership and competition law. See Vizcaya Provincial Appellate Court judgment dated 5 January 2001 (Aranzadi Data Base reference: AC 2000/68).

184 Kesan \& Gallo (2005) 304.

185 Thornburg (2002) 191; Froomkin (2002) 652.

186 WIPO 'Overview of WIPO Panel Views on Selected UDRP Questions' available at http://www.wipo.int/amc/en/domains/search/overview/index.html.

187 Arthur Guinness Son E Co. (Dublin) Limited v Dejan Macesic WIPO/D2000-1698 transfer; and ATET Corp. v Amjad Kausar WIPO/D2003-0327 transfer.

188 Gobierno de Asturias v Diego Miras Silva D2007-1392 denied; See generally Bently \& Sherman (2006) 901.

189 PC Mall, Inc. v Pygmy Computer Systems, Inc. WIPO/D2004-0437 transfer.

190 Consorzio del Prosciutto de Parma v Mattew Gasse, Hanslmeier Fleischwarenfabrik WIPO/D2003-0474. See also Bently \& Sherman (2006) 901.

191 Société Air France v Virtual Dates, Inc. D2005-0168 transfer; America Online, Inc. v Johuanthan Investments, Inc. WIPO D2001-0918. See also Burshtein (2007) 54.

192 Vivendi Universal D2001-1121.

193 Lockheed Martin Corporation v Dan Parisi WIPO/D2000-1015 denied. See Schwartz (2006) 95; Burshtein (2007) 54.

194 Donahey (2002) 10.

195 Amazon.com, Inc. $v$ Steven Newman alkla Jill Wasserstein alkla Pluto Newman, D2006-0517 transfer.

196 Bloomberg LP v Secaucus Group NAF/FA97077 transfer. See also Donahey (2002) 7-9.

197 Schwartz (2006) 91-92 referring to Bally's Total Fitness v Faber 29 F. Supp. 2d 1161 (C.D. Cal. 1998) and Lucent Technologies, Inc. v Lucentsucks.com 95 F. Supp. 2d 528 (E.D. Va. 2000).

198 UDRP Policy para 4(c).

199 Hedley (2006) 185.

200 View 1: The Royal Bank of Scotland Group v Personal and Pedro Lopez WIPO/ D2003-0166 transfer; View 2: Bridgestone Firestone v Jack Myers WIPO/D20000190 denied. The number of cases following the View 1 is nearly twice as many as the number following View 2.

201 Joseph Dello Russo MD v Michelle Guillaumin D2006-1627 transfer and denied. See also Schwartz (2006) 109-120; Burshtein 61.

202 UDRP Policy para 4(c)(iii). See Daniel J. Quirk v Michael J. Maccini NAF/ FA94964; Donahey (2002) 14.

203 See Ladner $v$ Wetmore NAF FA 305190. See also Burshtein (2007) 61.

204 Justice for Children v R Neetso / Robert W. O'Steen WIPO D2004-0175.

205 Hedley (2006) 184.

206 View 1: Chivas USA Enterprises, LLC, et al v Cesar Carbajal D2006-0551 denied; View 2: David Gilmour Music Limited v Ermanno Cenicolla WIPO/D2000-1459 transfer.

207 Tom Cruise v Network Operations Center/Alberta Hot Rods D2006-0560 transfer; Julia Fiona Roberts $v$ Russell Boyd WIPO/D2000-0210 transfer; and Dr Michael Crichton $v$ In Stealth Mode WIPO/D2002-0874 transfer.

208 Jerome Stevens Pharmaceuticals, Inc. $v$ Watson Pharmaceuticals D2004-1029 denied; Control Techniques Limited $v$ Lektronix Ltd D2006-1052 transfer.

209 UDRP Policy para 4(b). 
210 Sormac BV v Domains by Proxy, Inc. and James McCrory D2007-1338 denied; Playboy Enterprises International, Inc. v Joao Melancia D2006-1106 transfer.

211 Optimum Digital Enterprises v Intership Limited WIPO/D2001-0074.

212 Telstra Corporation Limited v Nuclear Marshmallows WIPO/D2000-0003.

213 Playboy Enterprises International, Inc. v Joao Melancia D2006-1106 transfer.

214 WIPO Press Release 'Cybersquatting Remains on the Rise with Further Risk to Trademarks from New Registration Practices’ (2007) PR/479/2007.

215 Mobile Communications Services, Inc. $v$ WebReg RN WIPO/D2005-1304.

216 CBS Broadcasting, Inc. v Gaddoor Saidi WIPO/D2000-0243.

217 LifePlan v Life Plan clo Relational Dynamics, Inc. NAF/FA0005000094826.

218 Mueller (2002); Geist (2002) 903.

219 Mueller (2002) 16.

220 WIPO has revealed that in 200684 per cent of cases were in favour of complainants. See WIPO Press Release PR/479/2007.

221 Bonisteel 'Arbitration Firm Quits Domain Name Business' Newsbytes (3 December 2001).

222 Ibid.

223 Froomkin (2002) 690.

224 INTA (2002).

225 Ibid 4.

226 Ibid 6.

227 The most notorious example found by Geist was with the six busiest panellists with NAF, who had resolved 1379 cases corresponding to 56.4 per cent of all NAF single member panel cases. In these cases the complainant winning rate was 95.1 per cent. See Geist 'Fundamentally Fair.com? An Update on Bias Allegations and the ICANN UDRP' (2002) 6 available at http://aix1.uottawa.ca/ geist/geistudrp.pdf.

228 Ibid 29.

229 Ibid 20.

230 Ibid 7.

231 Donahey (2001) 937.

232 Geist 'Update' (2002) 7.

233 INTA (2002) 6.

234 Froomkin (2002) 674.

235 Ibid.

236 Thornburg (2006) 313.

237 Geist 'Update' (2002) 7.

238 Schwartz (2006) 99.

239 Froomkin (2002) 674.

240 http://www.nominet.org.uk/disputes/drs/help/.

241 WIPO Press Release 'WIPO Marks 10th Anniversary of UDRP' (12 October 2009) PR/2009/613.

242 http://www.nominet.org.uk/disputes/drs/mediation/.

243 UDRP Rules para 11(a).

244 Ibid para 11(b); L'Oréal SA v Munbyunja WIPO/D2003-0585 transfer.

245 Froomkin (2002) 707.

246 UDRP Rules para 13.

247 Geist (2002) 907.

248 Ibid 904; Mueller (2002) 15.

249 US Anticybersquatting Consumer Protection Act (ACPA) Pub. L. No 106-43 para 3(a)(2), 5, 113 Stat. 218, 220 (1999) and Lanham Act s 43(d), 15 USC para 1125(d) (2000).

250 Froomkin (2002) 675.

251 Ibid 702. 
252 Thornburg (2006) 191; Froomkin (2002) 652.

253 See 'mutual' jurisdiction at UDRP Rules paras 1, 3(b)(xiii).

254 Froomkin (2002) 712-13.

255 Thornburg (2006) 191.

256 Ibid.

257 Froomkin (2002) 704.

258 Dinwoodie (2006) 214.

259 Froomkin (2002) 654.

260 Hedley (2006) 182.

261 Proto Software, Inc. $v$ Vertical Axis Inc/PROTO.COM D2006-0905 denied.

262 Froomkin (2002) 649.

263 Ibid 693.

264 His Holiness Phakchok Rinpoche v Kim Joe D2006-0328 transfer.

265 Rule (2002) 207.

266 Donahey (2002) 3.

267 Ponte \& Cavenagh (2005) 141. Thornburg (2006) 47.

268 National Dial a Word Registry Pty Ltd and Others $v 13000$ Directory Pty Ltd WIPO/D 2008-0020.

269 See UDRP Opinion Guide from Harvard University; WIPO Guide to UDRP; Overview of WIPO of Panel Views on Selected UDRP Questions.

270 UDRP Policy para 4(c).

271 Kesan \& Gallo maintain that procedural duration is the main indicator to measure the efficiency of the UDRP system. Kesan \& Gallo (2005) 343.

272 Donahey (2003) 475.

273 Rule (2002) 292; Hörnle (2009).

274 Thornburg (2006).

275 Donahey proposes that the system be known as the Online Consumer Dispute Resolution Policy (OCDRP); Donahey (2002) 4.

276 Ibid.

277 Perritt (2000a) 683.

278 WIPO has reached a high number of settlements in 2006 with ccTLDs: 121 settlements from a total of 446 cases. See 'Cybersquatting Remains on the Rise with Further Risk to Trademarks from New Registration Practices' Geneva (12 March 2007).

279 Schultz (2004) 71. 


\section{Online mediation \\ for consumers}

The way forward

Mediation is a good thing because it helps to engender settlement and only a fool does not want to settle. ${ }^{1}$

\subsection{Introduction}

Mediation is the fastest growing dispute resolution method. ${ }^{2}$ It represents an alternative to the 'win-lose' adjudicative processes. Mediation also offers a particular benefit for litigants: it permits parties to resolve cross-border disputes, circumventing many complex legal issues such as the conflict of laws. The expansion of mediation is being supported by an increasing number of judicial referrals, legislative efforts to encourage its use, and in some countries, such as the UK and the US, it has even been a priority for governments. ${ }^{3}$ This has impacted on mediation services. An example of this is the Chartered Institute of Arbitrators, where 84 per cent of all its services with consumers (between 2001 and 2006) concerned arbitration, yet it is expected that by 2010 consumer mediation will have taken the lead, reducing accordingly the ratio for arbitration down to 20 per cent. ${ }^{4}$

Mediation is predominantly carried out on a face-to-face basis, but there is an increasing interest in complementing mediation with ICT. Despite the fact that online mediation is still in its infancy, some commentators have expressed scepticism about its effective implementation. ${ }^{5}$ However, the prospects of ODR seem optimistic; as new generations are increasingly interacting online, they will in all likelihood embrace ODR technology. ${ }^{6}$

The aim of this chapter is to examine, from an EU perspective, the current legal context of mediation in order to evaluate if the present rules and practices allow the use of consumer online mediation. The use of online mediation is only possible if there is a need for it, technology permits it and the law allows it. ${ }^{7}$ This chapter also evaluates the extent to which parties should be encouraged or even compelled to use online mediation in the resolution of their disputes.

This chapter is divided into four parts. The first part of this chapter (4.2) analyses the transition from traditional mediation to online mediation. It 
starts by defining the different stages of the mediation procedure and the major types of mediation schools. The dynamics of computer mediated communications are also reviewed by the illustration of two ODR service providers: SmartSettle and SquareTrade. Then, it moves to evaluate the benefits and limitations of online mediation, and the appropriate cases for this dispute resolution method. Lastly, this part considers several approaches used to build trust amongst the users of online mediation.

Since mediation is mostly an unregulated field, self-regulatory initiatives and industry practices have special importance in determining the procedural requirements. The second part of the chapter (4.3) commences by looking at how online mediation can balance certain paradoxical aspects, namely procedural flexibility and legal certainty, on the one hand, and confidentiality and transparency, on the other hand. The next section examines the need of ensuring impartiality, fairness and the protection of the weaker party. Additionally, the mediators' status is surveyed from different ODR providers and countries in order to assess the minimum requirements for online mediators. Finally, as mediation is conducted on a case-by-case basis, there is the danger that similar disputes will be handled differently or that errors will go unrecognised, thus this section also considers the accountability of mediators.

The third part of the chapter (4.4) contemplates the interaction between the courts and the mediation procedure. To that end, the purpose of regulating mediation is first discussed. Subsequently, this part focuses on three regulatory aspects of mediation: the enforceability of mediation clauses; the enforcement of mediated agreements; and the suspension of limitation periods. The examination will focus on the Directive on Mediation.

The fourth part (4.5) considers the efforts of the judiciary and the government at the domestic level to promote the use of mediation. First, it takes an overview of mediation in the EU. Secondly, it discusses the rule of costs in England and Wales, which encourages parties to engage in mediation by directing litigants to participate in mediation and relayinging the payment of legal costs onto the party who has unreasonably refused to engage in mediation. The legal authority in this area, the Halsey ruling, is evaluated in order to address its validity with the benefit of hindsight.

\subsection{From offline mediation to online mediation}

\subsubsection{The difference between online and offline mediation}

Online mediation is generally considered as a broad concept, which includes everything from automated blind-bidding procedures and e-mediators to online mediation platforms with a human facilitator and case management programmes. ${ }^{8}$ In online mediation the role of the mediator remains the same but the selection of techniques differs. ODR platforms are designed to facilitate negotiation among their users by encouraging the discovery of positive common points that may result in agreements. In fact, the flexibility afforded 
by the mediation procedure makes it particularly appropriate for being conducted primarily online. Thus, online mediation is any dispute resolution process that is directed by a neutral third party (generally a human mediator), which does not impose the form of resolution but assists the parties in resolving their dispute by communicating largely through the internet.

Online mediation is often carried out through written exchanges, which lack the main factors of offline mediation, ie the face-to-face communications. However, like offline mediation, the efficiency of online mediation depends to a large extent on the skill of the mediator and the parties' will to resolve their disputes. In addition, an important component is added in online mediation, the ODR software or fourth party, which may assist in delivering a smooth mediation or, if badly designed, may hinder the mediation process.

\subsubsection{Types of mediation}

Mediation can be employed in a variety of settings, including court-annexed or private, offline or online. The majority of mediations, however, follow a similar procedural structure. Ponte and Cavenagh differentiate five stages in a mediation process: ${ }^{9}$

1 the initial statement of the mediator describing the process and the role of the parties and the mediator;

2 the parties' opening statements describing the facts, the issues requiring resolution and the desired outcomes;

3 the mediator assists the parties in articulating their cases, summarises positions and sometimes may even suggest outcome approaches;

4 at some point, in most mediations, the mediator will hold one or more caucuses with the parties to address those issues which are not suitable for open discussion, such as strengths and weaknesses of the parties' positions etc;

5 the parties draw the agreement or memorandum of understanding with the assistance of the mediator.

The role of the mediator is to open the eyes of the parties to the merits of the opponent's case, the issues involved, the risk and costs of litigation and the attractions of a settlement. ${ }^{10}$ There are several approaches by which mediation can be conducted. There are, nonetheless, two main schools of practice, as follows.

\subsubsection{Problem solving approach}

In this type of mediation the neutral third party is often highly directive in his attempt to reach this goal, focusing on areas of consensus and 'resolvable' issues, while avoiding areas of disagreement where consensus is less likely. ${ }^{11}$ The role of the mediator may vary from merely assisting the parties to 
communicate (facilitative role) to being interventionist (or evaluative role). In the latter case, according to Gibbons and others, the mediator may 'give advice, make assessments, state opinions - including opinions on the likely court outcome, propose a fair or workable resolution to an issue or the dispute, or press the parties to accept a particular resolution'. ${ }^{12}$

\subsubsection{Transformative approach}

Gibbons and others observe that the transformative approach 'does not seek the resolution of the immediate problem, but rather, seeks the empowerment and mutual recognitions of the parties involved', ${ }^{13}$ for empowerment and recognition is understood to 'strengthen one's capacity to analyse situations and make effective decisions while strengthening one's capacity to see and consider the perspective of others' ${ }^{14}$ Therefore, it is not settlement driven but rather based on supporting the parties through their own decision-making process by giving them the tools to define their own issues and reach their own agreements. ${ }^{15}$

Parties in a B2C dispute may take different approaches. For instance a large corporation, which deals with many disputes, would want to resolve disputes as efficiently as possible. By contrast, consumers may take disputes at a more personal level, frequently expecting not just a quick and inexpensive resolution but also some additional recognition. ${ }^{16}$ In those cases where consumers feel that they have been wronged or cheated, they will seek a sincere apology; thus a transformative approach in such event may be more effective. ${ }^{17}$

The role of the mediators is to identify at the beginning of the mediation which approach is the most appropriate for the type of dispute at stake. When there is an imbalance of power between the parties (B2C) it appears that some type of direction may be adequate but the situation may be different in other cases (B2B or C2C). In the context of mainstream e-commerce disputes, the mediators tend to use an evaluative approach, focusing on uncovering the source of the problem and identifying conditions using fair standards under which agreements could be completed, rather than in finding creative solutions using brainstorming techniques that require more time and a higher cost. ${ }^{18}$

\subsubsection{Two ODR examples: SmartSettle and SquareTrade}

\subsubsection{Complex mediation: SmartSettle}

SmartSettle is a privately owned company established in Canada offering ODR services. It provides an online negotiation tool based on algorithm analyses that assist parties to resolve complex disputes. This ODR service supports face-to-face mediation and online mediation sessions. ${ }^{19}$ SmartSettle acts as a mediator between the parties assisting them in the resolution of their 
conflicts. It first requires the parties to identify the issues in dispute and to rank them in terms of priority by giving a nominal value to the different issues. Then, the algorithm analysis suggests various proposals to help the parties reach the most efficient resolution. SmartSettle applies some techniques from game theory with the aim of producing an optimum outcome. SmartSettle uses a six-step process where parties, with the help of an independent facilitator, express the value of their preferences. ${ }^{20}$ The six steps are:

1 Preparation: the ODR process is explained and parties agree to follow SmartSettle guidelines.

2 Qualify interests: parties identify the issues of the dispute.

3 Quantity satisfaction: parties' demands and their value are rated by both parties.

4 Establish equity: the software makes settlement packages based on parties' preferences.

5 Maximise benefits: the software keeps proposing new improved settlements even over the initial minimum acceptable by the parties.

6 Secure commitment: parties sign the framework for agreement.

SmartSettle has been referred to as the bridge between online mediation and software assistance because it is able to facilitate multi-party negotiation cases with any number of quantitative or qualitative issues. ${ }^{21}$ However, this method may be too complicated and time consuming for the majority of B2C disputes, being more cost-efficient when resolving complex and high value disputes (B2B). SmartSettle, on the one hand, has a great potential since it delivers mathematically optimal solutions to the dispute but, on the other hand, this ODR platform may initially be technically difficult to use. For this reason SmartSettle advises disputants to work with a human mediator who administers the programme. Therefore, this is not an insuperable obstacle. Indeed, it is believed that in the near future, once this type of technology becomes user friendly it will revolutionise the ODR market ${ }^{22}$ as it could then be applied to mainstream consumer disputes.

\subsubsection{Simple mediation: SquareTrade}

To date SquareTrade has been the leading online mediation provider for B2C disputes. It assisted eBay users to resolve their disputes. However, owing to changes in the eBay feedback system in May 2008, SquareTrade decided to stop resolving eBay feedback disputes from June $2008 .{ }^{23}$ It appears that the remaining ODR services provided by SquareTrade have been taken over by eBay, PayPal and their dispute resolution new partners, eg NetNeutral for eBay Motors. ${ }^{24}$ This section will still examine SquareTrade as it operated successfully for a number of years providing online mediation services.

SquareTrade resolved small value disputes using a process in which a mediator assisted disputants through asynchronous e-mail and web communications 
with the parties. SquareTrade employed around 200 mediators from over 15 different countries. ${ }^{25}$ The online mediator had a similar role to the offline mediator: he managed the process, uncovered the parties' underlying interests and led them toward a mutually acceptable resolution. ${ }^{26}$ Once the disputants reached an agreement, the mediator drafted the memorandum of understanding and both parties clicked 'I accept'. ${ }^{27}$

SquareTrade ODR software was designed to resolve disputes arising out of online transactions, particularly feedback disputes from eBay; thus, it was designed ad hoc to deal with specific types of disputes. The advantage of eBay disputes is that the vast majority of disputes arise over a limited number of issues, eg the item bought on eBay arrived late, or it did not fit the description, and so on. An additional advantage is that eBay disputants have the inherent incentives that encourage them to resolve their dispute as quickly as possible, in that the buyer wants economic compensation and the seller wants positive feedback. Furthermore, the majority of eBay disputes are niche disputes, ie they could not be resolved offline.

It is, however, necessary to be aware of the limitations of SquareTrade. Its main limitation was that SquareTrade relied on written communications that were conducted with each party separately. SquareTrade did not use video communications, which could bring another dimension to online mediation. SquareTrade used a fairly limited vocabulary and resolved a fairly limited range of disputes. Despite this, some credit should be given to SquareTrade, which claimed a success rate of 80 per cent in online mediation with the average dispute resolved in two weeks. SquareTrade mediation was available in five languages and it resolved over 2 million disputes with parties situated in over 120 different countries. ${ }^{28}$ It is arguable whether SquareTrade relied on sophisticated ODR software or not. But what is beyond doubt is that SquareTrade software used a precedent system that recognised patterns. This assisted parties in resolving their disputes on the internet without imposing a settlement against the will of one of the parties. ${ }^{29}$

\subsubsection{Benefits and limitations in using online mediation}

Online mediation enhances some of the benefits and difficulties of traditional mediation. As with traditional mediation, online mediation allows the mediator to adapt the process in order to address the particular needs of the disputants.

The benefits of online mediation include the following:

- Online mediation is less costly, particularly when compared to the cost of resolving a case in an offline setting. ${ }^{30}$ The benefit of saving travelling expenses opens the use of online mediation for e-commerce and low value disputes, which simply do not have an alternative option. Accordingly, online mediation has the potential for increasing access to justice for many disputants. 
- Internet communication increases the number of mediators available for each dispute since within the internet there are no geographical limits. In addition, it respects the anonymity of the parties, which is part of the culture of the internet.

- Mediation processes are flexible and user-friendly. Individuals are encouraged to resolve disputes themselves without recourse to lawyers. ${ }^{31}$ Flexibility is increased when using technology, because there is a vast array of communication methods. Moreover, asynchronous communications allow parties to participate in mediation at more convenient times. Also, parties can work on their best communication, avoiding the immediate, and often worst, responses that can take place in face-to-face mediation.

- Online mediation is time efficient: mediation usually takes place immediately after the dispute arises, while litigation may take place months or even years after the event, when the circumstances of the parties may have changed. If online facilities are used, whether in total replacement of face-to-face meetings or preparatory to such meetings, mediation can commence immediately. This can be very advantageous if damage is continuing or if a solution is urgently required. As a matter of fact, disputes are frequently settled on the day of mediation or shortly thereafter. ${ }^{32}$

- In online mediation there is less perception of bias. A mediator from the International Chamber of Commerce (ICC) stated that during mediations he does not take notes for three reasons: first, to show that he is listening; secondly, to give the impression that he is not paying more attention to one of the parties; and, thirdly, so that the parties would perceive the mediation as confidential. ${ }^{33}$ There is no need for doing this in an online setting. Moreover, when dealing with cross-border disputes only a consensual process may offer the parties a truly neutral forum, free of any suggestion of bias by local laws. ${ }^{34}$

- It is a voluntary process, which allows for additional and more formal dispute resolution mechanisms. If mediation fails, each party will still have gained some significant expertise in how to deal with the dispute, because usually the numbers of issues to be contested are narrowed down. Furthermore, after mediation parties have a more accurate understanding of the facts and evidence, becoming better equipped to engage in an adversarial process.

- When parties control the resolution of the dispute, they are generally more willing to comply with the agreed outcome than with an imperative decision provided by an adjudicative body. In fact, mediation agreements are voluntarily enforced in the majority of cases, while judgments are not.

- Mediation facilitates settlements without damaging relationships. It seeks win-win solutions, where all disputants are satisfied with the outcome. There is a wider range of settlement options, ie not just monetary compensation, whereas an adversarial procedure is generally restricted to solutions fixed by the relevant law. Mediation does not have these 
restrictions, focusing more on the pragmatic aspects of commercial life, the speedy and low-cost solutions that are most attractive to both of the parties. Since mediators do not focus on legal entitlements but on amicable solutions, they take more of a 'business' approach rather than a 'legal' approach.

The limitations of online mediation include the following:

- Online mediation might be effective only with a limited range of disputes. $^{35}$ The efficacy of online mediation may be constrained by limited amounts of time and economic resources. For transactions involving goods of small value, even online mediation might be too costly.

- Online mediation is often conducted through text rather than orally. This introduces a new challenge: the parties' lack of body language and physical interaction, ${ }^{36}$ which creates barriers for an open dialogue. This challenge may nevertheless be mitigated to a certain extent with the use of ICT tools that replicate face-to-face interactions, such as videoconferencing.

- Voluntariness can be an advantage but also a disadvantage. Among the main reasons why online mediation is not used is the lack of consent of at least one party. Online B2C disputes often involve one-off transactions, which hinders the interest in reaching an amicable agreement.

- There can be some technological problems, which are amplified when disputants come from countries with different levels of technological skills. ${ }^{37}$ However, it has been observed by online mediators that 'communication barriers posed by technological problems, computer illiteracy, or poor writing skills were insurmountable barriers in only a relatively small minority of cases'. ${ }^{38}$ But when these problems appear they cannot be ignored and must be dealt with fairly, even cancelling the online mediation whenever deemed appropriate by the mediator.

- When adjudicative methods treat similar cases alike (stare decisis) they then provide with a high degree of legal certainty which will ultimately prevent future disputes. ${ }^{39}$ This feature is not present in mediation.

- When mediation is used there is not a decision from a competent body setting out the parties' rights. ${ }^{40}$ However, the assumption that there is one single fair result of every dispute, which only an adjudicative body can deliver. is not always correct. ${ }^{41}$

- There is no possibility of appeal. It is only possible to strike out a mediated agreement in court if it is proven that such agreement was created under fraud, duress or some other legal defence under contract law.

\subsubsection{Appropriate cases for online mediation}

In order to assess the type of cases that would be suitable for online mediation it is simpler to start by referring to those which are unsuitable for online 


\section{2}

mediation. These are cases involving criminal matters (at least when the victim so decides), disputes where an important legal precedent is sought or where there is a matter of policy which needs to be addressed. In addition, a major difficulty is to mediate with someone who does not want to be in the mediation process. ${ }^{42}$ Online mediation is more appropriate when the disparity of power between the parties is not great, ie B2B, C2C, B2C (with small and medium sized enterprises (SMEs)). By contrast, online mediation is the best method of resolving those disputes where parties 'want' to resolve the dispute but the parties are unable or reluctant to meet the other party, as in many cases involving e-commerce disputes.

Mediation is well established with insurance disputes, construction disputes, employment disputes, personal injury claims, medical negligence claims and family disputes. Furthermore, mediation is now expanding to new fields, such as financial services, competition disputes, small claims and e-commerce disputes. ${ }^{43}$ Conducting mediations wholly online provides the opportunity to extend the benefits of mediation to many disputes that otherwise would not be able to be resolved, particularly disputes between parties who are geographically distant and disputes where the value of the dispute is not sufficiently high to justify face-to-face meetings. For instance, under the Spanish Mediation Bill all disputes below $€ 300$ must take place online, except when online access is not available to one of the parties. ${ }^{44}$ Disputes where particular conduct may not reflect well on an individual or business may be better addressed through mediation - eg B2C - where the business wants to avoid publicity or where it involves sensitive material. In those cases where there is a potential ongoing business or personal relationship, a consensual method will offer a solution without disrupting a relationship. Mediation is appropriate when both parties actively sought an agreement through negotiations but they failed to find one. Mediation will be also appropriate to deal with those disputes where parties need an expeditious settlement since adjudicative procedures, in particular litigation, are generally slower in resolving disputes.

\subsubsection{Building trust in online mediation}

The first challenge when using mediation is to convince both parties to participate in the mediation process. It appears that parties' decision not to engage in mediation is generally a disbelief in a successful settlement, which may often be owing to the lack of understanding of mediation. In order to have effective mediation, parties must be well informed about what mediation has to offer. Once parties agree to engage in mediation, the next step is for the mediator and the ODR platform to encourage the parties to tackle the dispute appropriately. ${ }^{45}$ At the start of an online mediation process, parties often express a higher level of anger, their orientation is usually win-lose and they are anxious to have the mediator on their side to force the other party into action. ${ }^{46}$ Mediators start by establishing communication boundaries between the parties, for example, allowing communications through the mediator 
only, compelling parties to check their messages and respond to them within 24 hours, not allowing e-shouting (to write with capital letters) etc.

According to Rule, when communicating online it is easier to lie; hence, parties are more sceptical about facts, assertions and apologies. ${ }^{47}$ Mediators and technology also have an important role to play in order to compensate for this lack of trust. On the one hand, technology enables the parties to research online; verification of facts during the dispute resolution process can help to build confidence. On the other hand, the role of the mediator is to assist the parties to put aside their personal feelings and focus on problem solving. Fisher and Ury affirm that this is achieved through mutual understanding (without necessarily agreeing) of the point of view of each disputant and reflecting on possible solutions based on objective criteria, such as law, tradition, market value etc. ${ }^{48}$ Further, they maintain that in order to obtain a productive negotiation it is important to begin discussing the issues which both parties may agree upon, regardless of how meaningful they might be. ${ }^{49}$ Research regarding electronic communications during the resolution of disputes has shown that when there is some rapport established between the parties, they behaved more co-operatively and reached more efficient arrangements. ${ }^{50} \mathrm{~A}$ possible strategy would be to encourage and provide the text exchange of some personal information. Alternatively, this could be carried out at the initial stage of the mediation by video-conference or by telephone conference, where the mediator may briefly explain to the parties what mediation is about and request some basic neutral information from the parties with the aim of setting the parties in a positive and co-operative frame of mind.

When parties come from different backgrounds, as often happens in the online context, they may have different expectations when engaging in an ODR process. For instance, one party may enter into negotiation from a competitive perspective, while the other party may enter with a more collaborative approach. ${ }^{51}$ In these cases, if parties are not well guided, they will quickly become disappointed and may drop out of the discussion. It is not surprising then that empirical research has demonstrated that the two main factors in obtaining a settlement were the skill of the mediator and the attitude of the parties. ${ }^{52}$

\subsubsection{Dynamics of computer mediated communications}

Eisen observed that the online medium increases the chances of miscommunication, which makes it impractical for mediation. ${ }^{53}$ This is because online mediation does not allow face-to-face interactions in the same way as offline mediation. However, online mediation has the power of the fourth party which is manifested in the screen or interface which may be used in communicating with an equivalent meaning to verbal communication. For this reason Katsh and Rifkin affirm that a key aspect is the design of the ODR software that appears on the screen. ${ }^{54}$ The design of the screen can add authority, quality and trust to the online mediation process. Consequently, good use of the screen will 
enhance the chances for settlement and add value to the expertise of the mediator. ${ }^{55}$ By contrast, bad use of the screen will have the opposite effect.

Another peculiarity of online mediation is that it often relies on asynchronous communication, which introduces a cooling-off period where parties may think about how to resolve their dispute, which is a key aspect of mediation. In this regard, asynchronous communications may have a positive effect on the parties, avoiding the heat of face-to-face communications. ${ }^{56}$ It has been said that in online mediation the neutral third party has insufficient control over the parties since the mediator lacks physical presence. ${ }^{57}$ However, the mediator has a new set of tools, such as the opportunity to channel information and reframe communications. This is because computer mediated communications may censure inflammatory statements and facilitate caucusing in a more effective manner than is feasible with face-to-face communications. $^{58}$

In the offline world, resolving disputes where there are many individuals involved can be very complicated. ICT resources can be very helpful in organising information and giving the impression to all the individuals that they are offered a personal treatment (essential in mediation), by for example sending them personalised communications with little effort. Computer mediated communications allow parties to use many tools, such as track changes, which is particularly useful for written communications when drafting agreements. ${ }^{59}$

ODR software allows providers to improve their service by studying previous cases. For example, SquareTrade gathered a substantial database from all the procedures, which remained accessible to SquareTrade, the mediator and the parties for up to a year. ${ }^{60}$ These analyses were key factors for the company to improve its services. For instance, SquareTrade became aware that some of its website's content was unclear or complicated and caused users to drop out. ${ }^{61}$ It also discovered that some users expected the mediator to render binding decisions. Furthermore, throughout the free-text boxes SquareTrade noticed that they very frequently had feedback rating disputes, so they incorporated feedback disputes in their automatic negotiation stage. ${ }^{62}$

Mediators must consider the impact of the technology on the process. Technology is not neutral in the sense that when computer mediated technology is compared with face-to-face communications; the former emphasises some aspects of communications and minimises or eliminates others. ${ }^{63}$ The behaviour of the parties when interacting online follows specific patterns that can be identified (eg emoticons or use of capital letters) and analysed in order to create effective ODR technology to address consumer disputes. ${ }^{64}$

\subsection{Self-regulation and soft law: Procedural aspects of mediation}

Mediation is generally not a regulated field. The scarce existing regulation, such as the EC Directive on Mediation, also encourages self-regulatory 
measures. In addition, soft law initiatives give guidelines on self-regulation. In the EU the two most significant initiatives are the EC Recommendation 2001 and the 2004 European Code of Conduct for Mediators. These initiatives were developed by the European Commission setting out a number of principles to which individual mediators in civil, commercial and consumer matters can voluntarily decide to commit. Organisations providing mediation services can also make such a commitment, by asking mediators acting under the auspices of their organisation to respect these principles. ${ }^{65}$ Adherence to these principles is without prejudice to national legislation regulating individual professions, such as the rules of consumer associations or bar associations.

This part of the chapter examines the main self-regulatory procedural principles of online mediation. First, it balances necessary principles for effective online mediation: flexibility, legal certainty, confidentiality and transparency. Secondly, it examines the adequate approach to ensure impartiality, fairness and the protection of the weaker party. Thirdly, the mediator's status is surveyed from different ODR providers and countries. Lastly, this part considers the accountability of mediators.

\subsubsection{Flexibility, legal certainty, confidentiality and transparency}

One of the core features of mediation is the flexibility of the proceedings, which not only lowers costs for disputants in comparison with litigation but also has the potential to answer the emotional needs of disputants. Mediation does not need to rely on lawyers, giving parties greater control over the dispute and its resolution. As a result, mediation delivers agreements that are more satisfying and voluntarily enforceable. ${ }^{66}$ At the same time these selfregulatory principles may be complemented with regulation, such as the Mediation Directive, which ensures minimum compliance with due process (eg confidentiality) and legal certainty by guaranteeing the enforceability of mediated settlements. ${ }^{67}$

Another key feature is the principle of confidentiality, which encourages parties' honesty in expressing their arguments, assuring them that anything they say will not be published or used against them in a public judicial process. ${ }^{68}$ Nevertheless, in the e-commerce context parties may have fewer concerns with confidentiality issues. In consumer mediation, where there is an imbalance of power between the parties, the principle of confidentiality must be balanced with the principle of transparency in order to identify possible abuses from businesses, which generally are the stronger parties in the dispute. In this context, publicity is necessary to monitor the quality of mediation as well as to identify business malpractice. ${ }^{69}$ Publicity becomes more important when the ODR provider relies on public funding. ${ }^{70}$ By contrast, it has been suggested that the publication of agreements may not be practical because that would remove one of the main appealing factors of mediation. ${ }^{71}$ 
Further, it appears that confidentiality and flexibility of online mediation may hinder transparency. ${ }^{72}$ Hörnle suggested that there is a clear conflict of interest which the EU could alleviate by introducing minimum standards in this area. ${ }^{73}$ To some extent this has been already introduced with the Mediation Directive. During the mediation parties are encouraged to participate fully in what is considered a confidential procedure; thus, if that confidentiality is broken against the will of one of the parties, it may undermine the mediation. According to the UK Court of Appeal in Halsey $v$ Milton it is important that confidentiality of the process is respected, so that the court should not know and should not investigate why the process failed to result in an agreement. ${ }^{74}$

It is worth noting here that the confidentiality principle is not an absolute principle. Thus, mediators may testify in court when both parties require it in order to improve the court's ability to reach a fair decision. This view has been transposed in the EU by the EC Mediation Directive as an exception to confidentiality but only when the mediator and the parties agree to it. ${ }^{75}$ Otherwise, information about the mediation may not be given as evidence in a civil court proceeding unless it is judged necessary to implement or enforce a settlement or owing to reasons of public policy.

Finally, it must be noted that consumer disputes in e-commerce are generally monetary disputes over low value transactions. These disputes tend to be less emotionally charged and disputants tend to be relatively indifferent to confidentiality. ${ }^{76}$ Overall, confidentiality should be constrained in favour of transparency in B2C mediations. The publication of agreements, withholding the personal details of the parties whenever this is deemed necessary, may also help future participants to understand the functioning of mediation.

\subsubsection{Independence, fairness and protection of the weaker party}

Independence ensures that the appointment of the mediator is carried out in a transparent manner and guarantees that the mediator does not have a conflict of interest with the parties. ${ }^{77}$ To prevent a conflict of interest it must be taken into account that the mediator or ODR service provider does not depend financially on one of the parties in the dispute. It has been suggested that an independent body should supervise these essential requirements. ${ }^{78}$ This control is currently carried out exclusively through self-regulation.

Fairness comprises the obligation to provide information concerning the procedure and giving equal opportunity to the parties to put forward their case. Enforceability of mediated agreements poses no problem when the agreement satisfies both parties but it may create difficulties when mediation is perceived not to be fair or lacks compliance with due process issues. ${ }^{79}$ There is a disagreement among practitioners and scholars as to whether mediators should actively assist consumers to obtain a fair result ${ }^{80}$ and also whether mediators should be held liable for their decisions. In the response to the 
Green Paper, the majority view maintained that 'the third party could not be held responsible for ensuring that the agreement is balanced' ${ }^{81}$ However, this view should be limited to those cases where there is no serious misconduct by the mediator. Mediators should therefore have the duty of ensuring that the parties reach a decision voluntarily and that such decision is not manifestly unfair, particularly in B2C mediation where there is an imbalance of power between the parties. ${ }^{82}$

\subsubsection{The mediator's status}

The Green Paper on ADR opened a discussion about the need to regulate the training and liability of mediators. ${ }^{83}$ In particular, the Green Paper raised two important questions. First, should the EU create minimum standards on these issues? And, secondly, what degree of responsibility will be expected from neutral third parties? Ethical rules and minimum standards are certainly necessary to deliver fair mediation within the EU. However, it may be too early for developing binding regulations on these issues. The Green Paper enquired about the use of European or national certificates to ensure that mediators are competent. The responses proposed that 'Member States should be encouraged to set up a national professional body whose aim would be to draw up these ethical rules and monitor their implementation'. ${ }^{44}$ Arguably, this will be more effectively achieved if it is co-ordinated at the EU level, at least initially, to deal with cross-border disputes. This could be done by establishing a pan-European trustmark. ${ }^{85}$

The Mediation Directive does not establish a European accreditation body for third parties, but encourages compliance with the voluntary European Code of Conduct for mediators and the development of a system of certification for national bodies offering training courses in mediation. ${ }^{86}$ The use of quality and ethical standards will gain more importance as soon as online mediation service providers have succeeded in satisfying an actual need of offering ODR services to a significant number of consumers.

Liability of mediators is currently regulated under the civil liability law of the Member States. When mediators belong to a regulated authority (eg the legal bar) it might be easier to make them comply with professional standards. Problems may arise when third parties do not belong to professional bodies, especially in those Member States that do not have provisions relating to liability of mediators. In order to avoid this uncertainty, it has been suggested that each ODR provider should implement its own code of ethics, so that the location of the mediator in relation to the applicable code of ethics would no longer be an issue.

There are new challenges when resolving cross-border disputes and these difficulties derive from crossing cultures; thus, the design of ODR and the training of the mediators must accommodate different social, legal and cultural elements. ${ }^{87}$ Furthermore, ODR programmes require new skills to be mastered by professionals. Special training should be required for online 
mediators, eg for the use of the ODR software, relying on templates and precedents, interpreting texts rather than facial expressions, using caucus mediation and so on. ${ }^{88}$ At present, most ODR providers have their own internal training systems, although the intensity of these programmes varies. For instance, the Better Business Bureau (BBB) provides five days' training in basic mediation skills, with an emphasis on an interest-based model of mediation. SmartSettle's facilitators are attorneys which have received a special 20 hour online training course. ${ }^{89}$ The Mediation Room and the ADR Group provide a course of 10 hour distance training on online mediation. ${ }^{90}$ Although standardisation of minimum training for online mediators may not be appropriate at this early stage of development, a certain level of training and monitoring is essential to provide quality online mediation.

\subsubsection{Accountability}

Accountability in online mediation entails the monitoring of the mediator and the service provider by an authority which ensures that the ODR service is delivered in a fair and effective manner following the pre-established rules. It is not correct to dismiss accountability measures simply because mediation is voluntary and any resolution reached is acceptable to all parties. ${ }^{91}$ It is important to have accountability in order to avoid errors and ensure fairness in mediation where parties may have different levels of bargaining power. The role of the mediator is to change parties' perceptions of a dispute in order to facilitate the settlement. According to Rabinovich-Einy:

$[\mathrm{P}]$ rofessional mediators must be held accountable to parties, providers that rely on their services, relevant regulatory authorities, and the general public for the delivery of procedurally fair mediation services that meet accepted standards of mediation. A breach of these obligations should result in legal, disciplinary, monetary, or reputational consequences. ${ }^{92}$

There are a number of difficulties in attaining accountability of mediators supplying online services. First, it is difficult to evaluate the outcome of a mediation process which is driven by party satisfaction and allows for tradeoffs, such as those between legal remedies and apologies. ${ }^{93}$ Hence, it cannot always be expected that similar disputes will be resolved in similar ways. Secondly, it is difficult because the confidentiality of the proceedings encourages a case-by-case approach. This may cover problematic trends, particularly in offline mediations as they are based on oral discussions. By contrast, when using online mediation, it appears more convenient to require feedback from the parties and it is also possible to study the interactions of the parties with the ODR software. Thirdly, most online mediation providers only release partial data, when it is beneficial to them, such as resolution rates and party satisfaction surveys, both of which are of limited use in evaluating mediator performance. ${ }^{94}$ 


\subsection{Regulatory approach in the EU:}

\section{The Mediation Directive}

\subsubsection{The purpose of regulating mediation in the $E U$}

Since mediation is an informal process, it is necessary first of all to consider why and to what extent mediation needs to be regulated. In the field of dispute resolution, one of the functions of the law is to ensure compliance with the fundamental procedural principles, such as confidentiality, transparency, impartiality and fairness. In addition, regulation has the role of promoting and legitimising mediation, particularly when judicial enforcement of mediation clauses and settlements proves to be sporadic or elusive. ${ }^{95}$ Nonetheless, regulation may also have a negative effect on the flexibility of mediation, especially if it incorporates strict rules. Accordingly, any regulation on mediation needs to balance two aspects, namely due process and procedural flexibility. Within the EU there are a number of laws governing mediation and issues related to $\mathrm{B} 2 \mathrm{C}$ mediation, such as civil procedures and consumer protection laws. The EU has as an objective to harmonise, whenever necessary, the laws of the Member States in the area of dispute resolution with the purpose of improving competition within the internal market.

The Mediation Directive is applied in civil and commercial mediations where parties are domiciled in different Member States (with the exception of Denmark) ${ }^{96}$ For consumer mediation the directive refers to the principles set out in the EC Recommendation for consensual resolution of consumer disputes. ${ }^{97}$ The recommendation does not apply to pre-contractual negotiations, consumer complaint schemes or processes where the third party issues a decision, recommendation or evaluation, whether or not such outcome is legally binding. The Mediation Directive excludes from its application civil and commercial matters where parties do not have disposal of their rights under their national law, eg matters related to family law, employment law and other important public policy issues. ${ }^{98}$

Although the directive applies exclusively to cross-border agreements, its application is also recommended for domestic cases. ${ }^{99}$ In sensu stricto, the directive will not have a broad impact, since the majority of mediations presently deal with domestic disputes. It must be noted that the directive does ensure that online mediation may take place, although its application does not bind national mediation laws. In this regard, recital 9 of the directive encourages the use of ICT, stating that:

This Directive should not in any way prevent the use of modern communication technologies in the mediation process. ${ }^{100}$

The directive mandates Member States to introduce legal reform whenever necessary in order to implement a number of its provisions. The directive sets 
out when mediators can be called upon to give evidence to explain the basis of the parties' agreement. ${ }^{101}$ It reinforces the principle of confidentiality, the limits of which were not very clear in some Member States. ${ }^{102}$ The directive enables parties to obtain an agreement with similar status to that of a court judgment. ${ }^{103}$ Accordingly, accredited agreements will be recognised and enforced throughout the EU under the same conditions as those for court judgments and arbitral awards. This provision also ensures that the court will not consider a mediation agreement inadmissible as a confidential communication. It is expected that online agreements will have the same treatment, at least when they derive from bodies approved by the Member States. ${ }^{104}$ It is still unclear what procedural form this recognition will take, although it seems that judicial approval or notarial certification would be sufficient to allow such agreements to be enforceable in court or by another public body. ${ }^{105}$ The European Commission will make available information on the competent courts and authorities to enforce mediated agreements by November 2010. ${ }^{106}$

The Mediation Directive requires Member States to allow courts to recommend the use of mediation or to invite the parties to attend an information session on the use of mediation. ${ }^{107}$ Some commentators have observed that the directive does not go far enough, because it should be more explicit by giving national courts the duty to inform parties of the availability of mediation. ${ }^{108}$ It seems that the court's power to refer cases to mediation may be effective in convincing disputants that mediation will assist them in settling their dispute. ${ }^{109}$ However, more research is needed to evaluate whether the above statement is true and, if so, to what degree. ${ }^{110}$

A stable and predictable legal framework would contribute towards setting mediation on an equal footing with judicial proceedings. But to what extent does the Mediation Directive achieve this? The directive points out the advantages of using a means of resolving conflicts that is more economical and simpler than judicial or quasi-judicial remedies. The directive was created with the aim of promoting the use of mediation and of increasing legal certainty about the way courts in all EU Member States deal with issues arising out of mediation. There is a mandate in the directive which requires Member States to 'ensure that information is available to citizens, in particular on internet sites, on how to contact mediators and organisations providing mediation services'. ${ }^{111}$ This information should contain data on the experience of mediators; this would make it easier for parties to choose their mediator, eg similar to the way this is done by the UDRP approved dispute resolution service providers. Research found that when parties select the mediator, they are more likely to settle than when the mediator is selected otherwise. $^{112}$

Additionally, it is argued that the obligation to inform should be extended to legal practitioners and it should also be imposed on the law societies. This is particularly necessary in those Member States that face a crisis in their judicial systems. ${ }^{113}$ Awareness could also be raised through different channels 
such as universities and European bodies, eg the European Judicial Network, Eurochambers and the European Consumer Centres. ${ }^{114}$

\subsubsection{Mandatory mediation}

Mediation is a consensual process whereby the parties voluntarily agree to participate. However, mediation may also take place when so ordered by a court or when parties introduce a clause in their contract agreeing to use mediation. Thus, contracts may include an ODR clause which requires parties to attempt to settle their disputes arising out of the contract. The purpose of such a clause would be to increase the chances of settling a dispute before the parties resort to adjudicative methods.

It must be noted that in the EU a contractual clause cannot oust the jurisdiction of the court by inserting a consensual clause but, in certain circumstances, particularly in B2B disputes with detailed mediation clauses, the court may stay proceedings to allow parties to honour their agreement to mediate. ${ }^{115}$ In any event, a party's right to seek injunctive or declaratory relief and to avoid the prescription of a cause of action is always preserved.

The legal force of these clauses and whether such agreement or court mandate could be enforced against the will of one of the parties is debatable. ${ }^{116}$ In general terms, mandatory mediation is considered less problematic than mandatory arbitration given the fact that access to the courts is only temporarily suspended and that parties cannot be forced into an agreement. ${ }^{117}$ For this reason mandatory mediation would not contradict Article 6 of the European Convention on Human Rights (ECHR) or Article 47 of the Charter of Fundamental Rights of the European Union (ie the right to a fair trial). In fact, the directive opted for allowing mandatory mediation, although Member States may restrict its use. ${ }^{118}$ Consequently, the directive requires Member States to grant parties the possibility of initiating judicial proceedings or arbitration in relation to their dispute by the expiry of limitation or prescription periods during the mediation process. ${ }^{119}$

Even though in theory when a mediation clause is mandatory a party can be obliged to start the mediation procedure, thus far in practice this has not been very common, as mediation in those circumstances may encounter difficulties in succeeding, given the unwillingness of one of the parties. ${ }^{120}$ Despite this, a number of Member States, including Spain and Italy, are currently implementing in their national law mandatory mediation. ${ }^{121}$ In addition the directive states that the court may invite the parties to use mediation or, whenever it is available, to attend an information session on the use of mediation. ${ }^{122}$ In these scenarios consumers should only be obliged to participate when the session is free of charge. The American Arbitration Association (AAA) states that the courts should only be allowed to impose mandatory mediation when the cost of mediation is publicly funded and the mediation is of high quality. ${ }^{123}$

In England the Court of Appeal in Halsey stated that 'forcing people to go 
to mediation before a trial is a recipe for a mediation disaster'. ${ }^{124}$ This statement has not yet been fully explored. Katz observed that the approach to mediation should be process-orientated, rather than a means of ensuring a settlement. ${ }^{125}$ According to Katz, "[n]othing about ADR requires that the parties be willing or eager to settle. The process is designed to facilitate settlement precisely when disagreement is strongest' ${ }^{126}$ Furthermore, research has shown that when parties are informed in court that they have the option of using mediation, they often decide to opt out. ${ }^{127}$ However, when parties are compelled to use mediation, the results are not dissimilar to those who engage in mediation voluntarily. ${ }^{128}$

In some cases the refusal to participate in mediation could be interpreted as a violation of the obligation of good faith. ${ }^{129}$ However, if it is clear that negotiation would be useless, would the denial of access to the courts be unfair? This control could only be examined on a case-by-case analysis, either by the courts or by a public supervisory body. ${ }^{130}$ A pilot project on mediation for small claims in the English courts demonstrated that the administrative costs of letting parties litigate on whether or not it is appropriate to mediate was not cost-effective. ${ }^{131}$ It appears to be more cost-effective to have an ex post analysis, deciding on the appropriateness of mediation when determining the costs. ${ }^{132}$

The European Parliament has pronounced in favour of the legality of mandatory mediation clauses, but only when the appointed ADR bodies have been approved by the Commission. ${ }^{133}$ On the other hand, the Commission decided not to require Member States to allow mandatory mediation for the following reasons. First, it considered that validating mandatory mediation clauses could create disparities with the constitutions of some Member States. Furthermore, it was argued that in the light the Unfair Contract Terms Directive 1993 and of Article 6 of the ECHR, a mandatory mediation clause could deprive consumers of their right to go to court. This approach is contentious. As explained above, mediation clauses do not deny access to courts but only a temporary delay, which would probably be a short one when using ODR schemes. ${ }^{134}$ Moreover, in most cases mandatory mediation allows parties to initiate parallel legal proceedings at any stage. ${ }^{135}$

The Commission maintained in 2003 that mediation was not sufficiently developed at the time as to make its use compulsory. ${ }^{136}$ There are a number of issues related to mandatory mediation that remain to be explored. According to Jeff Rifleman:

$[\mathrm{M}]$ andatory mediation as opposed to traditional voluntary mediation raises additional ethical concerns including good faith participation, privacy and confidentiality, and enforceability of any attained agreements, and presents perhaps the ultimate question - do the benefits of mandatory mediation outweigh the costs? ${ }^{137}$

A mediation clause should not be enforced when mediation might be a burden to consumer access to justice. To date, the legality of mandatory consensual 
ODR clauses in B2C contracts has not been fully tested in the courts since analogies with ADR may not be valid. ${ }^{138}$ These clauses should be enforceable provided they do not reduce the capacity of the consumer to access justice by introducing new barriers, ie unreasonable costs, geographic barriers and linguistic limitations. ${ }^{139}$ Therefore, mandatory mediation should not create new barriers to consumer redress, eg it should not be more expensive than the small claims procedure or exclude consumers from taking class actions ${ }^{140}$ since this might be considered unfair under the forthcoming Directive on Consumer Rights.

As a matter of policy, legal harmonisation should recognise the enforceability of mediation clauses provided that the clauses are drafted in good faith and they do not obstruct later access to courts. ${ }^{141}$ It is regrettable that the Mediation Directive did not take the opportunity to clarify what constitutes equitable mandatory clauses in consumer contracts. ${ }^{142}$

\subsubsection{Enforcement of settlements}

It is expected that when parties reach a voluntary settlement they will be willing to comply with its terms. But what happens when someone is acting in bad faith or simply refuses to comply with the settlement? In order to make a private agreement enforceable it may be necessary to go to court. When dealing with cross-border disputes this is not always an easy option, as there may be high costs, delays and possibly a number of jurisdictions and laws that are potentially applicable.

The location of online mediation is legally significant because its jurisdiction will determine which laws will govern the mediation, the existence or not of professional standards, immunity or limited liability of mediators, the level of confidentiality of the mediation, whether the mediator has the capacity to assess the party's chance of success should the case proceed to litigation etc. ${ }^{143}$ This is decided, as in arbitral procedures, based on the place where the consumer is based, or where the mediator receives and sends communications. ${ }^{144}$ In order to avoid these legal uncertainties it would be advisable to enter into an agreement at the start of the procedure establishing the competent court and law for the enforcement of the decision. Thus, parties and the mediator must select a jurisdiction whose laws best support the mediation process.

Article 6 of the directive states that upon request of the parties, settlement agreements must be confirmed by a public authority and enforced across the EU. ${ }^{145}$ The directive does not provide an enforcement procedure, leaving the Member States to decide on procedural matters. ${ }^{146}$ The Green Paper suggested that courts, public notaries or even Chambers of Commerce, can undertake this role. ${ }^{147}$ Hence, in order to seek an effective enforcement mechanism, it would be necessary to refer to the civil procedural laws of the Member States, which will determine whether a judicial act or an administrative act will suffice to make the agreement enforceable. ${ }^{148}$ According to the 
Spanish Mediation Bill, when a mediated agreement has been reached with the assistance of an accredited mediator, such agreement will be directly enforceable in court and will have the status of res judicata. ${ }^{149}$ The use of a simplified enforcement procedure would make more effective the use of mediation, especially for small claims and consumer cases. ${ }^{150}$

It is expected that national courts will enforce online agreements drafted by ODR providers that have been approved by the Member States. ${ }^{151}$ Mediation agreements should be assimilated, under certain conditions, with other documents liable to a swift enforcement, which could benefit from the simplified exequatur mechanism provided by the Brussels I Regulation, ie with the same enforceability qualities as those given to arbitral awards. ${ }^{152}$

\subsubsection{Suspension of limitation periods}

The Green Paper considered whether the limitation period for initiating a court action should be suspended whilst the parties attempt to resolve their disputes by mediation. The current situation varies among Member States. Hörnle has put forward arguments in favour and against the suspension of limitation periods. With regard to the arguments against, she first argued that mediation sessions are short and that parties are permitted to initiate legal proceedings at the same time as they negotiate. ${ }^{153}$ The situation is however different when the national law requires the parties to attempt mediation prior to the commencement of a legal action, such as the case of Spain for monetary claims (excluding consumer claims) where under the Mediation Bill time limits are suspended. ${ }^{154}$ By contrast, she argued in support for the suspension of limitation periods by noting that the suspension would encourage the use of mediation, and that in some countries the period of time for commencing legal proceedings can be very short. This view also protects those unaware of the limitation periods for commencing legal proceedings, thereby protecting the weaker party, ie the consumer. ${ }^{155}$

Most respondents to the Green Paper considered the suspension of the limitation periods essential with a view to encouraging the use of mediation. Conversely, other respondents stated that regulation on this point is not justified. ${ }^{156}$ The directive requires Member States to ensure that parties who choose mediation are not prevented from initiating judicial proceedings or arbitration in relation to their dispute by the expiry of limitation or prescription periods during the mediation process. ${ }^{157}$ In order to implement this provision it will be necessary to amend the national procedural rules of some Member States. Hence, this provision requires the suspension of limitation periods during the mediation, thus ensuring that parties will not be prevented from going to court as a result of the time spent in mediation. 


\subsection{Regulatory approach at the domestic level, particularly in England and Wales}

\subsubsection{Mediation under national law}

Mediation is encouraged in many different ways in each jurisdiction; for instance, mediation may be recommended during an arbitral procedure. In Spain, the institutionalised consumer arbitration programme has a mediation stage before the oral hearing of the arbitration. ${ }^{158}$ However, mediation, including the online process, only takes place with a professional mediator, who must be a different person than the arbitrator, when the parties have voluntarily agreed to it (ie it is non-mandatory). Accordingly, if one of the parties refuses to participate, the arbitral tribunal will not impose a sanction. However, once an agreement is reached it will have the force of an arbitral award. The agreement is legally binding and the courts cannot review it provided there is no legal flaw in it or a violation of the due process principles.

Mediation referrals may also come from the courts. In Portugal, magistrates' courts encourage parties during the pre-trial stage to use in-court mediation when they consider it appropriate. ${ }^{159}$ Also, in Germany the courts recommend the use of mediation and judges take the role of mediators. In England and Wales, where family disputes benefit from public funding, parties are requested to attend a compulsory information session on mediation.

Private or public initiatives may promote the use of online mediation. In France, Mediateur du Net has settled more than 4000 B2C disputes between September 2004 and December 2006. ${ }^{160}$ Despite the fact that a French statute explicitly included mandatory clauses in the indicative list of abusive consumer clauses, ${ }^{161}$ the French Supreme Court has enforced contractual mediation clauses, provided they do not impede a contracting party from bringing an action before the courts when mediation fails. ${ }^{162}$

This tendency, although not uniform, may also be appreciated in the US. ${ }^{163}$ In the recent case of Advanced Bodycare $v$ Thione, the 11th Circuit held that a mediation clause (as well as a clause that requires the parties to mediate 'or' arbitrate) does not fall within the meaning of the Federal Arbitration Act and, therefore, the court cannot stay litigation and compel the parties to mediate. ${ }^{164}$ However, according to McLean and Wilson, this case would not apply to Med-Arb clauses, ie where mediation is a precondition to the arbitration process. ${ }^{165}$

The debate in the US has been focused on good faith mediation. Its critics, on the one hand, argue that the good faith requirement leads to coerced settlements and it places at risk the principle of confidentiality in mediation. On the other hand, its advocates argue that the good faith requirement is necessary for obtaining effective mediation where parties may not abuse its process. ${ }^{166}$ Lande observes that claims for costs or other relief have been based on failure to attend mediation sessions, failure to send a representative with 
settlement authority and failure to participate substantively in the mediation. ${ }^{167}$ Similarly, in England and Wales the Civil Procedural Rules (CPRs) and a number of court rulings have opened the debate on how mediation should be encouraged.

The CPRs in England and Wales give powers to the courts to encourage litigants to use mediation. ${ }^{168}$ This trend has also been noted in other common law jurisdictions; for instance, section 651(b) of the US Alternative Dispute Resolution Act of 1998 requires federal district courts to recommend to litigants in civil litigation that they consider the use of ADR, subject to some restrictions, such as where the discussion on the merits includes constitutional rights. ${ }^{169}$

There are other measures that encourage the use of mediation. For instance, in England and Wales Part 36 of the CPRs provides that one party may make an offer to settle with cost consequences; thus, if the offer of settlement is refused, and if the judgment is not better than the offer to settle, then the judge will be informed at the time of determining the costs about the previous offer and will impose all the legal costs on the party who refused the earlier offer to settle. ${ }^{170}$ Ireland applies a similar rule through lodgments in court under Order 22 of the Superior Court Rules. ${ }^{171}$ Also, in the US this practice is effected through a procedure known as an offer of judgment, which is regulated under Rule 68 of the Federal Rules of Civil Procedure. Comparable rules have been adopted by most states in the US. These rules, however, are rarely applied in arbitration and are unknown in continental Europe where Member States seem less keen to encourage settlements amongst litigants.

\subsubsection{The approach to mandatory mediation in England and Wales}

In England there have been cases where courts have enforced a mediation agreement, even against the will of one of the parties. This occurred in Cable \& Wireless v IBM United Kingdom, where the court decided to stay proceedings until the parties had referred all their disputes to the CEDR mediation procedure. ${ }^{172}$ In this case, the High Court held that had the clause only provided vaguely for an attempt in good faith to resolve any dispute by mediation, it would have been unenforceable. It must be noted that this case was B2B and it would be unlikely to apply to B2C; however, it evidences punctual support by the court in using mediation. Currently, these practices are not common since more often than not judges do not stay proceedings in order to enforce mediation agreements. ${ }^{173}$ In such event, it is more likely that at the end of the litigation the court would impose the legal costs on the party who had unreasonably refused to mediate. ${ }^{174}$ This in itself is also rare.

In some cases, it would seem justified for the court to press in favour of mediation, taking into account the cost of litigation. For instance, in Egan $v$ 
Motor Services (Bath) Ltd the Court of Appeal dealt with a consumer claim where the claimant was unsatisfied with his new car and the defendant car dealer refused to refund the full price of the car. ${ }^{175}$ The parties fought the case through litigation and spent a disproportionate amount in legal costs. In his ruling, Ward LJ delivered the following comments:

What I have found profoundly unsatisfactory, and made my views clear in the course of argument, is the fact that the parties have between them spent in the region of $£ 100,000$ arguing over a claim which is worth about $£ 6,000$. In the florid language of the argument, I regarded them, one or other, if not both, of them, as completely cuckoo to have engaged in such expensive litigation with so little at stake [. . .] This case cries out for mediation. ${ }^{176}$

Under the law in England and Wales costs 'follow the event', ie the loser pays the winner's legal costs, which often makes the losing party's detriment 'immeasurably greater than the benefit of winning'. ${ }^{177}$ Disproportionate legal costs are not unusual, particularly when claims are appealed and conditional fees are involved. A grossly disproportionate case was Campbell v MGN Ltd, where the House of Lords ordered the Daily Mirror newspaper to pay $£ 3500$ in damages to Naomi Campbell for the publication of pictures of her leaving a rehabilitation centre (ie this violated her right to privacy) and over $£ 1$ million in legal costs. ${ }^{178}$ The disproportionality between legal costs and amounts in dispute invites English mediators to encourage parties to be co-operative during the mediation process; thus, many mediators strategically commence the first meeting considering the amount of money that disputants have already spent on the dispute and the amount of money they would have to spend if the dispute escalated to be resolved in the courts. ${ }^{179}$

The CPRs, similar to the Mediation Directive, state that the court has the role of 'encouraging the parties to use an alternative dispute resolution procedure if the court considers that appropriate'. ${ }^{180}$ It is not clear in which circumstances the courts would require the parties to participate in mediation but it appears that the chances of success and a cost analysis will be key elements for a court's decision. ${ }^{181}$ The CEDR has gone so far as to suggest that parties should not be allowed to proceed to trial, save in exceptional circumstances, without having previously attempted mediation. ${ }^{182}$ Furthermore, the CEDR has observed that mediation is underused and that courts should make more use of the pre-action protocol requiring litigants to attempt mediation.

The CPRs provide that a party who refuses to consider whether a case is suitable for mediation may be at risk of having to pay the legal costs of the other party, particularly where the court has made an order requiring the parties to consider mediation. ${ }^{183}$ In several judgments the English courts have recommended legal practitioners to consider mediation. In Burchell v Bullard, Ward LJ stated: 
[t] he court has given its stamp of approval to mediation, and it is now the legal profession which must become fully aware of and acknowledge its value. The profession can no longer with impunity shrug aside reasonable requests to mediate. ${ }^{184}$

Obviously, mediation may not be appropriate for all cases. The most authoritative precedent guidance on when it is unreasonable to refuse to mediate is Halsey $v$ Milton Keynes General NHS Trust. ${ }^{185}$ In this case the claim arose from the allegedly negligent treatment of a hospital patient, who might have died because the tube from which he was being fed was incorrectly fitted and instead of going to his stomach it directed food to his left lung. The claimant proposed mediation a number of times but the defendant refused it on the grounds that there was no negligence in this case since it claimed that the food got into the lung when the patient inhaled his own vomit. The court assessed whether this refusal to mediate was or was not unreasonable. In the end, the Court of Appeal dismissed the case, finding the refusal to mediate reasonable. The Halsey ruling set a non-exhaustive checklist for deciding when the refusal to mediate is unreasonable: ${ }^{186}$

- The nature of the dispute and its inherent suitability for mediation. For instance, a reasonable refusal would be in a dispute where the parties want the court to set a binding precedent on a point of law. However, in the view of the Court of Appeal, most cases are not by their very nature unsuitable for mediation.

- The merits of the case and the parties' reasonable belief that they have a strong case.

- Whether other settlement methods have previously been made but rejected.

- Whether the cost of mediation would be disproportionately high. This is a factor of particular importance where there is little money at stake. Hence, unless mediation is publicly funded, it would be difficult to find an affordable mediation service that would be cheaper than the Small Claims Court.

- Whether the mediation will result in an unacceptable delay to the trial. This would be in the event when the mediation is suggested just before the hearing or when an injunction is required. ${ }^{187}$

- Whether mediation would have reasonable prospects of success. This is an important factor, but not the only one to be taken into account.

It must be noted that this is not a numerus clausus list. In Halsey, and in subsequent cases such as $P 4$ Limited $v$ United Integrated Solutions plc, an important factor in considering the refusal as reasonable or not was the fact that the request for mediation seemed more tactical than a genuine desire to resolve the dispute in question. ${ }^{188}$

The Court of Appeal in Halsey stated that 'the court's role is to encourage, 
no to compel [mediation]. The form of encouragement may be robust' ${ }^{189}$ The Court of Appeal created two new rules with regards to mediation:

(i) The court held that if a litigant is ordered to proceed to mediation against his will, this would be regarded as an unacceptable constraint on the right of access to the courts and, therefore, a breach of Article 6 of the European Convention on Human Rights, which protects the right to a fair and public hearing within a reasonable time by an independent and impartial tribunal established by law.

(ii) The court stated that a litigant who seeks the imposition of costs on his opponent on the ground that the latter refused to give mediation a chance has the burden of proving that the refusal was unreasonable.

In relation to the first rule, as argued above, it seems that requiring parties to go to mediation could barely, if at all, delay litigation. Hence, to consider mandatory mediation as a restriction to the right of access to justice, ie as an infringement of human rights, is mistaken. ${ }^{190}$ According to Lightman LJ:

In respect of Article 6, the reasons are twofold. First, the Court of Appeal appears to have confused an order for mediation with an order for arbitration or some other order that places a permanent stay on proceedings [. . . S Secondly, the appeal court appears to have been unaware that ordering parties to proceed to mediation regardless of their wishes happens elsewhere. ${ }^{191}$

Indeed, Article 5 of the Mediation Directive and more recently the European Court of Justice allow for the use of mandatory mediation provided it does not deny the parties access to the court after an unsuccessful mediation. ${ }^{192}$ Also in England this happens when parties pursuant to a divorce with public funding are required to participate in an information session on mediation. ${ }^{193}$ In addition, the county courts in England carried out pilot projects whereby disputes were automatically sent to mediation. However, it has been argued that the Automatic Referral to Mediation project failed largely as a result of the Halsey decision. ${ }^{194}$

In Halsey, the Court of Appeal relied on the decision of the European Court of Human Rights (ECtHR) in Deweer $v$ Belgium. ${ }^{195}$ In this case a Belgian butcher was facing criminal prosecution for over-charging for pork. The Belgian authorities threatened a provisional closure of his premises until the conclusion of the criminal proceedings unless the butcher agreed to a financial settlement. The butcher agreed but brought a successful legal action in the ECtHR for violation of his Article 6 rights. The ruling of the ECtHR acknowledged that waiving the right to a fair trial may be compatible with Article 6 but it warned that caution was required when that right is waived in proceedings substituting the court, ie in arbitration proceedings. ${ }^{196}$ It seems that an arbitration agreement or a coerced settlement may violate Article 6 
but not mandatory mediation. According to Lord Phillips, President of the UK Supreme Court, this could only happen in extreme cases, such as finding a party in contempt for not following a court order to participate in mediation or striking down a legal action for not having recourse to mediation. ${ }^{197}$ The same could not be applied by a mere sanction of facing legal costs. Clarke MR observed that 'there may well be grounds for suggesting that Halsey was wrong on the Article 6. ${ }^{198}$ Equally, Lord Phillips stated that there is a need for 'legislation to alter the effect of the decision in Halsey'. ${ }^{199}$

After Halsey there have been subsequent court interpretations considering mandatory mediation as contrary to Article 6, eg Hickman v Blake Lapthorn. ${ }^{200}$ Notwithstanding, according to Clarke MR and Phillips LJ the comments in Halsey on mandatory mediation were obiter dicta since the question before the court was not whether mandatory mediation is appropriate, but whether costs could be imposed on a successful litigant for refusing to engage in mediation. ${ }^{201}$ Hence, it appears that the English courts still retain the power of compelling parties to participate in mediation.

With regard to the second issue ruled in Halsey, the onus of proof of reasonableness, the Court of Appeal held that it rests on the party seeking legal costs relief. Lightman LJ strongly disagreed with this view. According to him, the onus imposed a hurdle in access to justice; thus, he exhorts the judiciary to reverse the current burden of proof.

While the benefits of mediation may be apparent, it is necessary to explore how to balance the costs of those who do not reach a settlement in mediation with those who do. ${ }^{202}$ In fact, many complain about the costs of unsuccessful mediation. Clarke MR proposes a general principle whereby the costs of mediation will be treated as ordinary costs and thus the party with the stronger case who succeeds in court will be protected against the costs of a failed mediation. ${ }^{203}$

According to Genn and others, 'Facilitation and encouragement together with selective and appropriate pressure are likely to be more effective and possibly more efficient than blanket coercion to mediate'. ${ }^{204}$ Perhaps less effort should be put into pressuring unwilling parties to mediate and more into identifying which cases are suitable for mediation and how to encourage parties to use mediation. Therefore, in certain circumstances the judiciary should compel parties to participate in mediation, although some limits and opt outs must be established, particularly when dealing with low value disputes and amongst parties with unequal bargaining power. In these cases, as well as when mediation becomes mandatory, it is generally understood that regulation is needed to set boundaries, legal standards and a public monitoring system. ${ }^{205}$

In general terms, mediation should not be mandatory unless the refusal of mediation by one of the parties would cause a barrier to access to justice for the other party, who could not afford the risks and costs of cross-border litigation. In other cases the reasonableness of refusing mediation in civil and commercial cases may be examined ex post, ie the judge must take the 
refusal of mediation into account when deciding where to allocate legal costs. Moreover, the parties and the judge should consider the use of mediation, not just at early stages of proceedings, since this may not be the best time for using it, but also at later stages of proceedings. ${ }^{206}$ This is because lawyers are often apprehensive about showing weakness by proposing or accepting mediation at an early stage of the legal proceedings. Also, disputants are frequently hostile to the idea of compromise, particularly in the early stages of litigation. ${ }^{207}$ This occurs despite the fact that over 90 per cent of civil cases are settled by agreement between the disputants, ${ }^{208}$ although these agreements rarely occur at an early stage of the litigation process, when mediation may be more useful.

\subsubsection{The way forward}

In the context of this book, it is important to question whether these judgments could be applied to online mediation. It may be that, one day, when consumers initiate cross-border legal actions in their domicile, under the Brussels Regulation, e-businesses could require a temporary stay of the proceedings while attempting online negotiation or online mediation. There will be greater possibilities of staying proceedings when there is an existing contractual clause or when the judge advises the use of online mediation. In any event, the referral to online mediation should only be ordered when mediators are accredited by their national authorities and when the referral does not create new barriers to consumers' access to justice, eg increasing consumer costs of redress. In March 2010 the European Court of Justice issued a preliminary ruling which established that when mediation is only available online and it is a prerequisite for the admissibility before the courts of actions, it may hinder the right to effective judicial protection. ${ }^{209}$

While commentators argue that associating mediation with compulsion could erode the legitimacy of mediation, ${ }^{210}$ the use of mandatory mediation may contribute to changing the perception of people who may then consider it as a legitimate process, equal to a court process. ${ }^{211}$ It is necessary for disputants to be aware of the existence of mediation; furthermore, if mediation is effective it would need to be accompanied by legal and practical incentives. On balance, it must be noted that mediation is an interest based dispute resolution rather than right based orientated; this allows parties to reach original solutions outside of legal provisions but it also raises issues when applied to B2C in relation to imbalance of power and accountability.

For online mediation to succeed it would also need to be supported by the judiciary. The Ministry of Justice for England and Wales has run a pilot project using The Mediation Room.com as a platform for online mediation for cases awaiting final hearing from the Small Claims Court. ${ }^{212}$ ODR can be used to carry out the mediation entirely online or as an extra support tool for court mediators where the parties may clarify or narrow issues before or after the mediation. 
There is a need to stress that there is a difference between, on the one hand, compelling or robustly encouraging parties to go to mediation and, on the other hand, requiring their continued attendance or requiring them to settle. ${ }^{213}$ Moreover, when parties withdraw from mediation the confidentiality of the process does not allow them to inform the judge about their discussions. ${ }^{214}$

When considering online mediation as a mandatory step, it is important to question whether consumers would settle for less than their entitlements and whether the use of litigation is economically accessible for both parties. It is necessary to develop policies that set the appropriate balance between selfdetermination and persuasion for attending mediation. When dealing with mandatory or persuasive online mediation it must be ensured that ODR providers comply with legal minimum standards. For instance, parties may receive some pressure from the mediator to settle their disputes. ${ }^{215}$ This does not justify reaching a settlement through coercion or to allow the misrepresentation of mediators by making parties believe that the judge wants a settlement, to the extent that if one party refuses to reach a settlement, the judge will be inclined to rule against the other party. ${ }^{216}$ This should be avoided by informing the parties that they cannot be coerced to settle, and that if this occurs, they may report such coercion to the relevant authority. ${ }^{217}$ Irrespective of whether the mediation is carried out online or offline the mediator's code of ethics must expressly forbid not only duress but also more informal pressures.

\subsection{Conclusion}

Online mediation has the potential to increase access to justice because it bypasses conflicts of law, it is cheaper, quicker and less stressful than litigation and it does not remove the right to go to court as a last resort. Online mediation seems particularly suitable for resolving B2C disputes between consumers and SMEs where there is a genuine dispute and the power imbalance is not insuperable. Some commentators remain sceptical about the potential of online mediation but, as a matter of fact, mediation providers are increasingly moving part of the mediation process to the online realm. ${ }^{218}$ This trend is not likely to diminish; on the contrary, as the increase of e-commerce and cross-border disputes continues, the use of online mediation will undoubtedly grow.

This begs the following question, if online mediation is so beneficial, why is it not more extensively used? The answer is probably that the main challenge to mediation is attracting disputants. Before online mediation can gain credibility, offline mediation must be better understood and valued by the public. ${ }^{219}$ Indeed, the best indicator for success is the parties' willingness to enter into mediation and the provision of well-trained mediators. Persuasive incentives may come from self-regulation, for instance trustmarks and feedback reviews, or from regulations, such as imposing legal costs. 
Mediation systems are still in their early years in the EU; however, they project a promising future. To date governments have taken a hands-off approach in order to promote the development and flexibility of mediation. Nevertheless, on the one hand an effective regulation at the regional level might harmonise national laws allowing and promoting the use of online mediation. On the other hand, there is a concern that any attempt to regulate mediation could stifle its development. The purpose of the Mediation Directive has been to promote mediation and ensure the enforcement of settlements.

This chapter has focused on the incentives that can be taken to encourage parties to mediate those disputes that are better solved through online mediation. The following incentives are suggested, as follows.

First, the many benefits of online mediation to resolve online $\mathrm{B} 2 \mathrm{C}$ disputes are strong arguments for legitimating mandatory mediation within clear limits. This can be achieved through legislation, court rules and contractual agreements. In this way mediation would truly become part of the litigation system. However, if courts and lawyers are going to recommend the use of mediation, it will first be necessary to raise awareness and increase education about mediation. The same applies to online mediation. When court attendance is not practical for the parties, eg for e-commerce disputes, online mediation could be imposed as a preliminary and mandatory step. It is unlikely that mandatory mediation violates the fundamental right to access to a court. Voluntariness is an important aspect of mediation but it should not be used as a veto for a dispute resolution process which is unknown by many. The Halsey ruling is an attempt to draw the line on what is a reasonable request to mediate but it has attracted too many criticisms and it is expected that, in due course, it will be overruled with a new precedent or legislation. A European legal framework could establish clear limits for mandatory mediation, especially to mediate B2C disputes. For instance, parties might only be compelled to participate in one information session, which must be free of cost for the consumer. Also consumers might be allowed to opt out when a small claim procedure is available to them.

Secondly, legal standards for online mediation are needed. To that effect the existing directive should be complemented with the 2001 EC Recommendation, which should be mandatory and supplemented with additional provisions for online mediation. Furthermore, an accreditation EC body should monitor compliance of these legal principles by those ODR providers who are eligible for mandatory mediation. This can be delegated at a national level. Courts should also contribute to this monitoring.

Thirdly, the courts and governments should encourage parties to use mediation. Hence, mediation should become an integral part of litigation and not just an ancillary element to it. In other words, it should be available for everyone contemplating litigation. ${ }^{220}$ Accordingly, disputants must be well informed about the different dispute resolution methods. The rules of courts could follow the English example, allowing for a stay of legal proceedings and 
imposing legal costs when a party unreasonably refuses to participate in mediation. However, the imposition of legal costs must be approached with caution. In relation to ODR, we are still at an early stage but it appears that, given the imbalance of power between consumers and businesses, it would be more likely that businesses would be ordered to bear the legal costs for unreasonable refusal rather than consumers. Katsh observed that when mediation emerged in the late 1970s, its growth was accelerated by the recommendation of its use by judges as well as its use in the courts. He suggested that ODR may expect to follow a similar path in the near future. ${ }^{221}$

Fourthly, enforcement of mediated settlements must be ensured when using mandatory mediation in order to avoid bad faith participation; this could happen where one of the parties attends mediation with the intention of not complying with a settlement, or attends only in order to obtain information for use at the litigation stage. Under the Mediation Directive, all Member States must ensure that cross-border agreements are directly enforceable. It is expected that online agreements will receive the same treatment, at least when they derive from bodies approved by the Member States. It is still unclear what procedural form this recognition will take, although it has been suggested that mediation agreements could be granted the same enforceability as that given to arbitral awards.

This chapter has shown that the law in the EU certainly allows for the use of online mediation. But allowance is not the same as ensuring its use under national law, or promoting its use by introducing it as a valuable extension to adjudicative dispute resolution methods, saving time and costs. Greater research is needed to examine how the law can successfully promote online mediation. In the next chapter I will explore a possible strategy for the EU to promote ODR in a more effective manner.

\section{Notes}

1 Clarke MR 'Mediation - An Integral Part of Our Litigation Culture' Littleton Chambers Annual Mediation Evening, Gray's Inn (8 June 2009).

2 An earlier version of some of the ideas expressed in this section were previously published in Cortés (2008d) 1-41.

3 Green Paper on Alternative Dispute Resolution in Civil and Commercial Law (2002) 196 final at 22. For the US see 'Two More States Enact New Uniform Mediation Act' (3 February 2005) available at http://www.nccusl.org/nccusl/ DesktopModules/NewsDisplay.aspx? ItemID $=129$.

4 Hunt 'Consumer ADR in the UK' conference on Consumer ADR in Spain and the EC, delivered in Madrid 11-12 December 2006 (on file with author).

5 Eisen (1998) 1305.

6 Larson (2006) 629.

7 Gibbons, Kennedy \& Gibbs (2002) 27.

8 Nadja (2006) 245.

9 Ponte \& Cavenagh (2004).

10 Lightman J 'Mediation: An Approximation to Justice' SJ Berwin LLP (28 June 2007) 4 . 
11 Burgess 'Transformative Mediation' available at http://www.colorado.edu/ conflict/transform/tmall.html.

12 Gibbons, Kennedy \& Gibbs (2002) 55.

13 Ibid.

14 Ibid 59.

15 Ibid 55.

16 Schultz (August 2003) 10.

17 Raines (2005) 441.

18 Rabinovich-Einy (2006) 258.

19 Conley Tyler \& McPherson (2006) 1.

20 http://www.smartsettle.com.

21 Gibbons, Kennedy \& Gibbs (2002) 66.

22 Rule (2002) 59.

23 SquareTrade 'ODR Is No Longer Offered by SquareTrade' available at http:// www.squaretrade.com/pages/odr-discontinued.

24 http://www.netneutrals.com.

25 Rabinovich-Einy (2006) 258.

26 Ibid 259.

27 Raines (2005) 440.

28 http://www.squaretrade.com/pages/about-us (last accessed 1 May 2008).

29 Dyson 'Do You See a Pattern?' (28 August 2006) available at http://www. squaretrade.com/pages/about-us-news? vhostid $=$ daffy\&stmp=squaretrade $\&$ cntid $=$ 3 ja18a4y81.

30 In civil procedures it is estimated that up to 50 per cent of the amount in dispute will go on costs in legal fees, the courts and administrative costs. See Caffey (2005) 3 .

31 Getz (December 2007) 18.

32 South (2004) 5.

33 de Choiseul 'Alternative Methods of Dispute Resolution' Lecture at the Intensive Program: General Problems of Transnational Law and its Implications for the Companies in International Trade, Deusto University (19 September 2007).

34 Katz (1988) 581.

35 Goodman (2003) 4.

36 Evans, Wettman, Shadoff \& Birdwell (2006) 424-25.

37 Nadja (2006) 245.

38 Raines (2006) 367.

39 Michaelson \& Maples (13 May 2005) 725.

40 Clarke MR 'The Future of Mediation' Civil Mediation Council National Conference, Birmingham (8 May 2008) 6.

41 Phillips LJ (31 March 2008) 15.

42 Prince (2007a) 84.

43 Wood (2007) 313.

44 Article 29 of the Spanish Mediation Bill (19 February 2010).

45 Rule (2006) 255.

46 Raines (2006) 360.

47 Rule (2006) 83.

48 Fisher, Ury \& Patton (1991) 89.

49 Ibid 79; Anonymous authors (1990) 1092.

50 Braeutigam (2006) 101.

51 Femenia 'ODR and the Global Management of Customers' Complaints: How Can ODR Techniques be Responsive to Different Social and Cultural Environments?' paper presented at the Joint Conference of the OECD, HCOPIL, ICC, The Hague, Holland (12 December 2000). 
52 Genn et al 'Twisting Arms: Courts Referred and Court Linked Mediation Under Judicial Pressure' Ministry of Justice Research Series 1/07 (May 2007) iii.

53 Eisen (1998) 1305.

54 Katsh \& Rifkin (2001) 137.

55 Rudolph Cole (2006) 198.

56 Rule (2006) 66.

57 Eisen (1998) 1305.

58 Poblet \& Casanovas (2007a) 150.

59 Rule (2006) 260.

60 Rabinovich-Einy (2006) 270. See also SquareTrade submission comments to the Federal Trade Commission (19 April 2000) (on file with author).

61 Rabinovich-Einy (2006) 270.

62 Ibid.

63 Gibbons, Kennedy \& Gibbs (2002) 68.

64 Poblet \& Casanovas (2007a) 152.

65 Jacobs (2006).

66 Rabinovich-Einy (2006).

67 Mediation Directive 2008/52/EC art 9.

68 Ibid art 7.

69 Hörnle (2003a) 5 and ODR Workshop; Ponte (2002) 477.

70 Edwards \& Wilson (2007) 328.

71 Ibid.

72 Rabinovich-Einy (2006) 256.

73 Hörnle (2003a) 4.

74 Halsey v Milton Keynes General NHS Trust [2004] EWCA Civ 576 at para 14.

75 Directive 2008/52/EC art 7.

76 Rabinovich-Einy (2006) 276.

77 Szöke (2006) 15(2) 134.

78 Kaufmann-Kohler \& Schultz (November 2004) 131; Hörnle (2003a) BILETA. See also ch 2.3.1 of this book.

79 Haloush (2007) 82-83.

80 Gibbons (2006) 353.

81 Summary of Responses to the Green Paper on Alternative Dispute Resolution in Civil and Commercial Law (31 January 2003) 7.

82 Rudolph Cole (2006) 195.

83 Green Paper (2002) paras 88-94.

84 Ibid.

85 See ch 5 of this book.

86 Mediation Directive 2008/52/EC art 4.

87 Nadja (2006) 243.

88 Rule (2006) 258.

89 http://www.smartsettle.com/training.

90 http://v2.theclaimroom.com/index.lxp?host $=245$.

91 Rabinovich-Einy (2006) 261-62.

92 Ibid.

93 Ibid 266.

94 Ibid 267.

95 Katz (1988) 577.

96 Mediation Directive 2008/52/EC art 1.

97 Commission Recommendation 2001/310/EC 4 April 2001 on the Principles for Out of Court Bodies Involved in the Consensual Resolution of Consensual Disputes COM(2001) 161 final.

98 Mediation Directive 2008/52/EC Recital 10, art 1.

99 Ibid Recital 8, art 2. 
100 Ibid Recital 9.

101 Ibid art 7.

102 Bowman v Fels [2005] EWCA Civ 226; Aird and Aird v Prime Meridian Ltd [2006] EWCA (TCC) 2338, EWCA Civ 1866.

103 Mediation Directive 2008/52/EC art 7.

104 See list at http://ec.europa.eu/consumers/redress/out_of_court/database/index_ en.htm.

105 Europa Press Release IP/08/628 'A Boost for Mediation in Civil and Commercial Matters: European Parliament Endorses New Rules' (23 April 2008).

106 Mediation Directive 2008/52/EC arts 10, 12.

107 Ibid art 5.2.

108 Chambre de Commerce et d'Industrie de Paris, Response to the Proposal for a Directive of the European Parliament and of the Council on Certain Aspects of Mediation in Civil and Commercial Matters (22 October 2004).

109 Keet \& Salomone (2001) 57.

110 Campbell \& Opie 'Mandatory Mediation' (2002) available at http://www. findlaw.com.au/article/6190.htm.

111 Mediation Directive 2008/52/EC art 9.

112 Prince (2007a) 87.

113 Sternlight (2006) 569.

114 Summary of Responses to the Green Paper (31 January 2003) 2.

115 Mediation Directive 2008/52/EC art 5.2. See also the interpretation of the English court in Cable E Wireless plc v IBM [2002] EWCH Ch 2059 and Halseyv Milton Keynes General NHS Trust [2004] EWCA Civ 576.

116 Stipanowich (2007) 427.

117 European Commission, SANCO, The Study Centre for Consumer Law, Centre for European Economic Law Katholieke Universiteit Leuven, Belgium 'An Analysis and Evaluation of Alternative Means of Consumer Redress other than Redress through Ordinary Judicial Proceedings' Leuven, (January 2007) 117.

118 Mediation Directive 2008/52/EC art 5.2.

119 Ibid art 8.

120 Leuven Report (January 2007) 122.

121 Spanish Mediation Bill (19 February 2010) and Italian Mediation Bill (4 March 2010).

122 Mediation Directive 2008/52/EC art 5.1.

123 American Arbitration Association (2007) Consumer Due Process Protocol.

124 [2004] EWCA Civ 576 at para 10; Sander et al (1996) 885.

125 Katz (1988) 584.

126 Ibid.

127 Macfarlane 'Court-Based Mediation for Civil Cases: An Evaluation of the Ontario Court (General Division) ADR Centre' Ministry of the Attorney General (November 1995) 8.

128 Genn et al (2007) iii. Other empirical studies reached the conclusion that the difference between mandatory and voluntary mediation is not significant. Prince (2007a) 86; McEwen \& Maiman (1981) 252. See also Anonymous (1990) 1094.

129 Green Paper (2002) para 65.

130 Ibid.

131 Wood (2007).

132 See English Small Claims Track Leaflet EX301.

133 OJ C146 (17 May 2001) 94(4b).

134 Hörnle (2003a).

135 Ibid. 
136 Summary of Responses to the Green Paper (31 January 2003).

137 Rifleman 'Mandatory Mediation, Implications and Challenges' (2005) available at http://adrr.com/adr9/jeff.htm.

138 Cases C-240/98 to C-244/98 Océano Grupo Editorial SA and Salvat Editores SAv Rocio Murciano Quintero [2000] ECR I-4941 (27 June 2000); Kaufmann-Kohler \& Schultz (November 2004) 204.

139 Ponte \& Cavenagh (2004) 157; Kaufmann-Kohler \& Schultz (November 2004) 100.

140 Thornburg (2006) 303.

141 Hörnle (2003a).

142 Edwards \& Wilson (2007) 328.

143 Gibbons, Kennedy \& Gibbs (2002).

144 Wahab (2004a) 163.

145 Mediation Directive 2008/52/EC art 6.

146 Rome Convention on the Law Applicable to Contractual Obligations [1980] OJ L266.

147 Green Paper (2002) para 85.

148 Mediation Directive 2008/52/EC art 9. The Member States have the obligation to communicate the relevant procedure to enforce a mediated agreement by 21 November 2010. See Mediation Directive 2008/52/EC art 12.

149 Article 28 of the Spanish Mediation Bill (19 February 2010).

150 Hörnle (2003a).

151 Provided they operate within the EU and they are publicised by the EU Commission at http://ec.europa.eu/consumers/redress/out_of_court/adrdb_en.htm.

152 Responses to the Green Paper (31 January 2003) 6.

153 Hörnle (2003a) 3.

154 Article 4 of the Spanish Mediation Bill.

155 Ibid.

156 Summary of responses to the Green Paper (31 January 2003).

157 Mediation Directive 2008/52/EC art 8.1.

158 RD 231/2008 art 51.

159 Paterson (2007) 27.

160 http://www.mediateurdunet.fr.

161 Loi $^{\circ}$ 2005-67 of 28 January 2005, J.C.P. G 2005, act. 92. q); Leuven Report (January 2007).

162 Leuven Report (January 2007); Chambre de Commerce et d'Industrie de Paris, Response to the Proposal for a Directive of the European Parliament and of the Council on Certain Aspects of Mediation in Civil and Commercial Matters (22 October 2004).

163 AMF, Inc. v Brunswick Corp. 621 F. Supp. 456 (S.D.N.Y. 1985); Stipanowich (2007) 430.

164 Advanced Bodycare Solutions, LLC v Thione International, Inc. No 07-12309 (11th Cir. 21 April 2008).

165 McLean \& Wilson 'Putting the Horse before the Cart: Compelling Mediation in the Context of Med-Arb Agreements' (2008) available at: http://works. bepress.com/sean_patrick_wilson/1.

166 Lande (2002) 69.

167 Ibid 82-84.

168 Particularly the introduction of CPR $\mathrm{r} 44.3$ and the decision of Dunnett $v$ Railtrack plc [2002] 2 All ER 850. See also Roberts \& Palmer (2005) 359.

169 Alternative Dispute Resolution Act of 1998, Pub. L. No 105-315, 112 Stat. 2993 (1998).

170 Part 36.12(2) (2006 Amendment). See also Multiplex Constructions (UK) Ltd v Cleveland Bridge UK Ltd and Another (No 7) [2008] EWHC 2280. 
171 Rules of the Superior Courts Order 22; Harrison v Ennis [1967] IR 286 at 291; Superwood Holdings plc v Alliance (unreported, SC 12 April 2002).

172 Cable E Wireless v IBM United Kingdom Ltd [2002] EWHC 2059 (Comm Ct).

173 Paysner \& Seneviratne 'The Management of Civil Cases: The Courts and the Post-Woolf Landscape' Department of Constitutional Affairs UK (2005).

174 CPR rr 26(4), 44(5) (26 April 1999); Burchell v Bullard [2005] EWCA Civ 358.

175 [2007] EWCA Civ 1002.

176 Ibid para 53.

177 Phillips LJ (31 March 2008) 2. At the time of writing legal costs in civil litigation are under review. See Preliminary Report by Jackson LJ 'Review of Civil Litigation Costs' (8 May 2009).

178 [2005] UKHL 61 on appeal from [2002] EWCA Civ 1373; Mosley v News Group Newspaper Limited [2008] EWHC 1777 (QB). R (Cowel) v Plymouth City Council [2001] EWCA (Civ) 1935, [2002] 1 WLR 803.

179 Wood (2007).

180 CPR r $1.4(2)(\mathrm{e})$.

181 Campbell \& Opie (2002).

182 Mackie (July 2009) 'The Cost Crisis - Mediation as a Solution?' CEDR's Submission to the Jackson Inquiry into Legal Costs available at http:// www.cedr.com/index.php?location=library/articles/20090721_264.htm.

183 CPR r 44.3(2); Dunnett v Railtrack [2002] 2 All ER 850; Halsey v Milton [2004] EWCA Civ 576 at para 33.

184 [2005] EWCA Civ 358 at para 53; Hurst v Leeming [2004] EWCA Civ 576 at para 11.

185 [2004] EWCA Civ 576.

186 Ibid paras $26 \mathrm{ff}$.

187 Henderson 'Unsettling Questions, Refusing to Mediate Can Be a Dangerous and Expensive Option' (6 June 2008) New Law Journal 810.

188 Cooke 'The overriding objective and the Halsey guidelines: a cautionary tale' Newsletter, Mediation, International Bar Association Legal Practice Division (July 2007) 21; Rowallan Group Ltd v Edgehill Portfolio No 1 [2007] EWCA Ch 32 and Palfrey $v$ Wilson [2007] EWCA Civ 94.

189 [2004] EWCA Civ 576 para 11 (Dyson LJ).

190 Wood (2007) 313; See also Anonymous (1990) 1094.

191 Lightman LJ 'Breaking Down the Barriers' Times Online (31 July 2007) available at http://business.timesonline.co.uk/tol/business/law/article2166092.

192 Alassini and Others $v$ Telecom Italia C-317/08 (18 March 2010) para. 67.

193 Family Proceedings Rules 1991 and Family Act 1996 r 2.61E.

194 Genn (2007).

195 Deweer v Belgium (1980) 2 EHRR 439.

196 Clarke (2008) 6.

197 Phillips LJ (31 March 2008) 13.

198 Clarke (2008) 16.

199 Phillips LJ (31 March 2008) 15.

200 Hickman v Blake Lapthorn [2006] EWHC (QB) 12.

201 Phillips LJ (31 March 2008) 12 and Clarke (2008) 6.

202 Rifleman (2005).

203 Clarke (2008) 21.

204 Genn et al (2007) v.

205 Wood (2007).

206 Genn 'Court Based ADR Initiatives for Non Family Civil Disputes: The Commercial Court and the Court of Appeal' (2002) London, Lord Chancellor's Department.

207 Ibid. 
208 Phillips LJ (31 March 2008) 2.

209 Alassini and Others $v$ Telecom Italia C-317/08 (18 March 2010) para. 67.

210 Leuven (January 2007) 170.

211 Anonymous (1990) 1093.

212 See the platform available at http://v2.theclaimroom.com/index.lxp?host=294.

213 Allen 'Whither Halsey or Will Halsey Wither? A Passage from India' CEDR (May 2008).

214 Ibid.

215 Fiss (1983) 1075.

216 McEwen \& Maiman (1981) 237.

217 See Anonymous (1990).

218 Raines (2005) 450.

219 Ponte (2001) 91.

220 Clarke (2009) 2-3 making a reference to Rozenberg 'Dame Hazel Genn Warns of Downgrading of Civil Justice' The Law Society Gazette (16 December 2008).

211 Katsh 'Cyberweek Proceedings' (2007) available at http://www.odr.info/ cyberweek2007/. 


\title{
5 A legal framework to develop consumer ODR in the EU
}

\author{
A proposal
}

Whether many disputes will be resolved online is not a matter of 'If, but of 'When' and 'How'. The question of exactly when is not of great importance; time will tell. The question of 'How' is what we should focus on. ${ }^{1}$

\subsection{Introduction}

The development of sustainable e-commerce requires ODR, given the limitations of traditional court based dispute settlement mechanisms for resolving online disputes. In the last few years there have been significant efforts to encourage the use of ODR as a viable alternative to resolve consumer disputes, in particular disputes arising from use of the internet. However, the development of ODR to date seems to be quite modest; even publicly funded and free of charge services, such as ECODIR, have failed to attract participants. There is clearly a significant gap between the potential for ODR and its actual use. ${ }^{2}$

This final chapter examines what legislative role the EU should take in order further to develop ODR. This chapter suggests that appropriate legal provisions establishing minimum legal standards for ODR providers will provide the required confidence in attracting ODR users. It is advocated that if EU law ensures that private ODR providers are fair and efficient, then ODR can compete even outside e-commerce on an equal footing with a government-sponsored judicial system. Some writers challenge this assumption by arguing that the role of law is not to impose legal standards but only to allow enough room for ODR to develop from the industry. ${ }^{3}$ However, the limits of the industry creating ODR standards and the difficulties for ODR providers to enter into the market support the argument in favour of developing public ODR standards.

The aim of this chapter is to evaluate the critical question of this book: whether a legal framework is needed to enhance consumer ODR. The chapter explores the efficiency and sufficiency of the existing regulatory mechanisms and the need for developing a European legal framework in the field of ODR in order to promote the use of fair and effective ODR systems. It seems obvious that there is a need to regulate consumer ODR, either through the 
use of government regulation or industry self-regulation. Presently, the regulatory strategy is principally being developed through self-regulatory rather than governmental intervention. However, self-regulation is market orientated, fulfils private interests and is fragmented. ${ }^{4}$ This chapter considers what type of European initiative could contribute to the development of the ODR market, thus preventing inconsistent standards and regulations arising within the EU. Even though self-regulation for ODR will be criticised in this chapter, it is apparent that legislation alone cannot fully regulate ODR. Therefore, a legal framework in this field must give due consideration to the need for appropriate legal structures and the importance of allowing party autonomy and flexibility.

This chapter assesses those questions concerning ODR regulation from a European perspective, in particular mandatory ODR clauses in electronic contracts and the enforceability of binding awards reached through ODR processes, which can only be answered through legislation and cannot be left to self-regulation. ${ }^{5}$ This chapter proposes the classification of ODR into two categories: non-accredited and accredited ODR. On the one hand, nonaccredited ODR will include the existing ODR providers that are developed by the industry without the support or restrictions of regulation. The use of accredited ODR, on the other hand, will refer to a new proposed category of ODR providers that comply with the legal standards set by the EU. The latter providers will display a pan-European trustmark assuring compliance with the substantive law and procedural standards. In addition, the use of accredited ODR will be mandatory and their decisions will be enforceable, if necessary, by the courts of law.

\subsection{The need for a regulatory balance in the field of ODR}

\subsubsection{Increasing access to justice through ODR}

The previous chapter argued that if the legislature and judiciary were more proactive in encouraging disputants to use ADR and ODR, its use would be more extensive. As reviewed above, to date their efforts have been limited. For instance, only in a handful of cases have English judges imposed legal costs on the party who unreasonably refused to engage in ADR. On the surface, the main reason for this is that courts are very cautious in denying access to a legal procedure, particularly to consumers, taking into account Article 6 of the ECHR and consumer protection laws. It is also possible to argue that disputants may waive their rights to a fair trial only when the ODR process is supported by minimum procedural guarantees or it is subject to review in a body that grants compliance with the due process requirements expected under Article 6 of the ECHR. ${ }^{6}$

This is, to some extent, due to the fact that there are no accredited ADR or ODR mechanisms that provide disputants with similar rights and guarantees as those provided by the judicial system. This can only be changed by 
amending the existing laws, thus requiring parties to participate in accredited ADR and ODR when disputes are suitable for it, and provided there is no violation of the right to access justice, ie the parties are forced to participate in a procedure without due process guarantees or even in a more expensive or less effective redress mechanism.

It is necessary to revise the concept of access to justice and 'alternative' dispute resolution methods. Increasingly, commentators and governments are considering the new concept of 'appropriate' dispute resolution methods.' Access to justice, as mentioned above, should not be considered as the existing concept of the right to participate in an adversarial legal procedure in the public courts, but instead as the right to obtain redress through the most appropriate dispute resolution mechanism, which with many disputes, particularly those arising out of electronic transactions, may well be ODR. ${ }^{8}$ If ODR is used effectively, it may increase access to justice, making it possible for consumers and businesses who previously could not take adequate legal action to resolve their disputes.

The use of ODR is especially needed for the resolution of $\mathrm{B} 2 \mathrm{C}$ and crossborder disputes where face-to-face meetings are not feasible. It is believed that ODR is particularly useful where the bargaining power of the parties is not too disproportionate. According to Abernethy, ODR and trustmarks have a great potential to boost e-commerce where there is a perception that SMEs and private sellers cannot provide the same level of dispute resolution services as large online businesses. ${ }^{9}$ If these disputes are fairly resolved by outsourced and reputable ODR services, consumers' confidence in SMEs will increase, resulting in a more sustainable and competitive e-market.

\subsubsection{Failed expectations in ODR}

In spite of all the potential, to date ODR has not achieved a widespread market implementation, save in certain notable exceptions such as CyberSettle and ICANN's UDRP dispute resolution providers. ${ }^{10}$ Indeed, many ODR operators established in the last few years have ceased providing their services, although some still continue under a different trade name, eg WeCanSettle changed first to The Claim Room and is now called The Mediation Room. Throughout this book and elsewhere the reasons that have contributed to the failure of many ODR programmes have been discussed. ${ }^{11}$ Amongst the reasons stated, it has been argued that the development of ODR has been slowed by the challenge in designing software such that it is 'complex, time consuming and costly. ${ }^{12}$ Also, the lack of enforceable mechanisms has decreased the level of trust by disputants in ODR schemes. Consumer services present further obstacles, including the lack of independent ODR providers funded by business parties, inequality of bargaining power between the parties and linguistic barriers. ${ }^{13}$ Moreover, there is a lack of confidence in the technology itself and in the law that governs it. ${ }^{14}$ It has been suggested that to a large extent these difficulties could be reduced by appropriate technological 
developments and legal changes. This chapter focuses on the second element, examining what aspects need to be regulated in order to provide awareness and induce trust in the use of ODR.

\subsubsection{Creating a balance between regulation and self-regulation}

The legal maturity of ODR depends on a balance between regulation and selfregulation. In other words, there is a need for legal certainty, quality and impartiality on the one hand; and there is a need for flexibility and innovation on the other hand. ${ }^{15}$ Accordingly, a legal framework for ODR may encourage the appearance of quality ODR services as well as the creation of awareness and the increment of trust amongst consumers. However, if a regulation is too intrusive, it may hinder the progress of the ODR industry because the law in this area could be technologically exclusive and could rapidly become outdated. ${ }^{16}$

Hence, equilibrium between self-regulation and regulation seems to be the key approach. Governments should carry out this role by implementing industry best practices that take into consideration market and social policies. ${ }^{17}$ Some aspects such as the type of technology utilised and service charges should be left open to self-regulation if it is not to curtail the growth of the ODR industry, since it is plain that the law is very slow in responding to these issues. A regulatory legitimisation for ODR is also necessary because consumers and businesses alike would only use ODR schemes if they comply with accepted socio-legal standards. Furthermore, the establishment of a framework with legal standards in the ODR field for B2C disputes will increase legal certainty, thereby facilitating the expansion of proficient and fair ODR methods.

\subsubsection{Risks of self-regulation}

\subsubsection{The rise of lex informatica}

A similar challenge to that faced today by disputes arising out of e-commerce occurred in the Middle Ages. The Law Merchant reflected a move away from jurisdictional law towards a dispute resolution process that applied universally; it was designed to meet the needs and interests of the individuals who used it. ${ }^{18}$ It appeared in the Middle Ages to cover international trade given the lack of international private law. This so-called lex mercatoria (or leges mercatorum) did not depend on national laws but on the usages and customs of international trade, which applied their own laws in ad hoc courts. As a result, to this day customs and traditional practices represent an important source in international law, ${ }^{19}$ being employed by international arbitration tribunals and public courts.

Cyberspace now faces a similar situation where new regulations are being developed without the assistance of governments and parliaments. Selfregulation, understood as market regulation, may take different forms; for 
instance, the online community is developing its own social norms in order to co-exist in harmony, eg net-etiquette or the law of eBay. Some authors argue that e-commerce has its own customs and usages which must shape the regulation of ODR, and if ODR is left to the industry to develop, ODR providers will compete with one another to supply consumers with efficient services. ${ }^{20}$

Take for example UDRP ODR providers; the law of ICANN is developing as a legal body on domain names separate from the law of any country or any international treaty. To some extent the UDRP (self-regulation) is contributing to harmonise the laws (regulation) regarding domain names. UDRP panellists add to this process through their decisions and by referring to previous decisions. It can be argued that, in the same manner that common law was created from the rulings of the courts, ODR may develop its own rules and legal precedents by delivering decisions. A similar path is taken by eBay, which implements its own rules through its own consumer satisfaction services or even using external dispute resolution mechanisms. ${ }^{21}$

These self-regulatory initiatives have created rules and standards that will apply everywhere regardless of the jurisdictional issues. These emerging self-regulations form part of a new independent legal system (lex informatica) because they are considered as 'an autonomous transnational legal system with its own sources, rules, and dispute resolution methods'.$^{22}$ Calliess argues that the harmonisation and growth of ODR will come neither with international treaties nor with self-regulation but with the use of competitive dispute resolution services that create their own norms, which Calliess refers to as a 'competitive legal pluralism'. ${ }^{23}$ This type of market regulation is necessary because it contributes to legal harmonisation and it accelerates the globalisation and development of ODR.

\subsubsection{The limits of self-regulation}

Self-regulation is thus necessary to develop a regulatory system. Indeed, creating new rules or transplanting offline rules to the online world without taking into account industry and social practices cannot prove effective. ${ }^{24}$ The flexibility of self-regulation is needed to allow the industry to adapt quickly to technological and market changes. However, when there is inequality of bargaining power, such as in the case of $\mathrm{B} 2 \mathrm{C}$ disputes, a balance should be reached between two aspects: fairness and effectiveness. This is not always an easy task and it may require some type of trade-off. ${ }^{25}$ In this regard, there is a clear clash between fairness, ie procedural quality to attain just decisions and access to justice, ie cost-effective dispute resolution systems. ${ }^{26}$

Corporations generally defend market self-regulatory approaches, arguing that the market will be able to create effective ODR services and that regulation would be too slow to match the growth of technology. These liberal ideas maintain that 'by the time any law promoting or regulating ODR came into effect, the e-commerce environment and technology would likely have changed so much that the law would be irrelevant at best or an obstacle to 
progress at worst'. ${ }^{27}$ By contrast, consumers' advocates have argued that if left to self-regulation, the playing field will be seriously biased in favour of corporations since they often pay the bills for ODR services, use them repeatedly and choose the providers. ${ }^{28}$ It is reasonable to fear that, if allowed, some corporations could make ODR mandatory, thereby excluding consumers' right to access court and consumer class actions. ${ }^{29}$ This is particularly alarming when there are concerns over the lack of impartiality and independence of extrajudicial dispute resolution providers. Consumers' representatives also warn that ODR providers could require fees from consumers in order to discourage them from using ODR, although businesses' representatives justified these charges as a means to discourage frivolous claims. ${ }^{30}$

\subsubsection{The need for government intervention to set boundaries}

The lack of regulation may create difficulties for consumers in finding quality ODR services. ${ }^{31}$ Arguably, self-regulation in the ODR field may be regarded as a biased type of regulation if it is designed by only some of the stakeholders (businesses). Teitz observes that 'the regulation of legal services, including dispute resolution, need not be delegated wholly to the professional organizations that incorporate a degree of self-interest ${ }^{\prime 2}{ }^{32}$ Without public control selfregulatory functions may be subjugated to industry demands. Governments therefore have the role of verifying the soundness of self-regulatory rules. ${ }^{33}$

Many commentators particularly from the US have expressed greater trust in industry and in a competitive market in order to establish ODR standards, even for tackling B2C disputes. According to Pearlstein:

[in the same manner that] consumer organizations can help balance deceptive retailer behavior, and unions can help balance overbearing employers, emergence of privately ordered dispute resolution will doubtless be accompanied by privately created protections. And the market itself can help promote fairness and weed out those who attempt to take advantage. ${ }^{34}$

Other authors are more sceptical about the suitability of the market alone for developing ODR. Thornburg warns about the perils of self-regulation, stating that 'faster is not always better. Cheap is not always fair or accurate. Market power is not always used to achieve the public good. And the power to make the rules is often the power to win the game'. ${ }^{35}$ Market abuses can only be controlled by public laws. Katsh correctly observes that ' $\mathrm{t}] \mathrm{he}$ emergence of some standards overseen by the state is still quite conceivable'. ${ }^{36}$ Consumers International has also highlighted the need for developing international legal standards in the field of B2C ODR. ${ }^{37}$ It proposed the creation of a universal third party accreditation system, the monitoring of providers and the publication of ODR decisions.

Given the current standstill of ODR, the adoption of a self-regulatory 
approach is increasingly being questioned by some commentators who suggest that ODR needs to be regulated. In this regard, Morek notes that the ODR market is different:

[t] he hands-off approach ... could be effective if the market had just emerged and many new players were appearing. For a developed market, this approach could be effective if clients derived benefits from real competition between businesses. However, this is not the ODR market of today. This is a market of insufficient information and limited client choice. ODR providers experience difficulties getting new cases. ${ }^{38}$

According to Edwards, extrajudicial ODR carries serious public policy concerns because it represents a form of private justice outside the sphere of public law. ${ }^{39}$ Furthermore, Trans Atlantic Consumer Dialogue (TACD) does not believe that the voluntarily-led market alone is sufficient to address the problems arising from e-commerce. ${ }^{40}$ TACD urges the EU and the US to ensure that private dispute resolution services meet certain standards set by governments. ${ }^{41}$ It appears plain that ODR is not a typical service and certain procedural aspects need to be regulated in order to deliver fair resolutions and increase trust amongst potential users. ${ }^{42}$

\subsubsection{The objective of regulating $O D R$}

Schultz observes that it is a misconception that the internet developed without regulation and that because ODR takes place on the internet then ODR does not need regulation in order to function appropriately. ${ }^{43}$ The internet depends mainly on self-regulation but, following the bursting of the dot-com bubble at the dawn of the new millennium, governments have started seeking greater control over the internet in an effort to uphold their national laws and priorities. ${ }^{44}$ This is increasingly happening in other spheres related to e-commerce, including online gambling, taxation, privacy, child protection, pornography, money laundering and terrorism. ${ }^{45}$

Regulation, in my view, must as a minimum allow the use of ODR but it should go further and encourage the use of quality ODR by giving incentives to appropriate disputants and providing suitable enforcement mechanisms. However, it has been observed that if ODR is regulated by national laws it may only benefit national ODR providers and users while at the same time creating obstacles for foreign providers and users. ${ }^{46}$ The ideal approach is to co-regulate between governments, pursuing common standards but leaving the implementation of some of these standards to the national authorities. The EU works in this manner through directives (establishing and cosupervising common goals but letting Member States decide how to achieve the goals) and regulations (establishing legal provisions common for all Member States that are believed to be necessary for the development of the internal market). 
Regulation and self-regulation have the same objective in creating norms and standards for ODR, ie ensuring fairness, increasing trust, providing legal certainty etc. The mechanisms for enforcing these standards, however, vary. Regulation, on the one hand, corrects non-compliance through public entities which are accountable. In addition, these public entities are often trusted and they can use public enforcement resources, ie the courts. Selfregulation, on the other hand, leaves it to the market to correct the breach of standards but without political accountability.

Currently, self-regulation and government intervention have different weights, depending on the jurisdiction. For instance, self-regulation is shaping ODR in the US and the EU, although there have been some regulatory initiatives promoting ADR and ODR in the EU, such as the Mediation Directive, which do not have a counterpart in the US. ${ }^{47}$ It is a question of time before governments and courts in both countries develop a set of bottom-line principles. According to Schultz, '[t] he best regulation for ODR is, in my view, minimal regulation which is strictly and publicly enforced; it provides for trust and at the same time it leaves room for development'. ${ }^{48}$

\subsubsection{International initiatives}

There is currently no general legal framework for ADR at either the international or regional, or even national level. The creation of a general legal framework on ADR might be a positive step forward; this is particularly urgent in less developed countries, where the use of ADR may have very little public support. ${ }^{49}$ The same legal lacuna appears in the ODR field where there is no clear uniform regulation. ${ }^{50}$ There are, however, numerous specific initiatives from private industry and there is a tendency to proceed towards increased regulation and institutionalisation. In a report from the OECD it was stated that:

Despite the diversity of mechanisms and legal cultures that exist in Member countries, a consensus exists on the need for common principles setting out the main characteristics of effective consumer dispute resolution and redress systems. ${ }^{51}$

So why do we need legal standards for ODR? According to Rule, a need for ODR standards is based on six factors: ${ }^{52}$

(i) There is a clear need for redress in B2C transactions in order to boost e-commerce, particularly, cross-border trade.

(ii) It is difficult for consumers to get information about ODR.

(iii) The existing legal infrastructure is not completely well adapted to deal with B2C transactions.

(iv) ODR is often related to legal rights, ie right to trial and due process.

(v) There is an imbalance of power between consumers and businesses. 
(vi) There is a potential for abuse of ODR by stronger parties in the dispute, ie businesses.

According to Kaufmann-Kohler and Schultz, the main ODR stakeholders (ie governments, business organisations, consumer organisations and institutions of dispute resolution) want to promote ODR, but they have different views on what the objectives of ODR should be. ${ }^{53}$ They argue that governments want to increase consumer access to justice by providing ODR, thus decreasing court congestion and contributing a boost to e-commerce. Business organisations are interested in developing ODR to resolve disputes quickly, increase confidence and, consequently, to augment revenues. Consumer organisations want to achieve consumer redress, particularly for those disputes that cannot be resolved through another dispute resolution method. Lastly, dispute resolution providers would like to offer cutting edge ODR services in order to compete against other providers. As a result, all of the above stakeholders contribute to the development of ODR policy, based on their own priorities.

During the past decade a number of recommendations and guidelines were issued with the objective of promoting ADR and ODR participation. Governments overall have largely come out in favour of ODR in the B2C context and they have recognised that ODR should be the default means of redress for $\mathrm{B} 2 \mathrm{C}$ disputes arising out of e-commerce. Among the existing initiatives from international governmental bodies the most influential is the OECD's Guidelines for Consumer Protection in the Context of Electronic Commerce and the subsequent report on Consumer Dispute Resolution in the Global Market Place. ${ }^{54}$ These guidelines were complemented in July 2007 by a recommendation on B2C dispute resolution. ${ }^{55}$ The OECD has consistently encouraged the promotion of ODR, and it has suggested that the main obstacle for the development of ODR is national differences in existing legal frameworks on ADR, such as differences as to the validity of ADR clauses, enforceability of settlements, procedural principles and so on. ${ }^{56}$ The United Nations Commission on International Trade Law (UNCITRAL) is also working on uniform legal provisions for ADR in commercial matters and it is recently considering the development of ODR standards for the resolution of $\mathrm{B} 2 \mathrm{~B}$ and $\mathrm{B} 2 \mathrm{C}$ e-commerce disputes. ${ }^{57}$

In addition, business organisations have taken initiatives in this area with the aim of promoting e-commerce and shielding themselves from liability and court procedures. ${ }^{58}$ The most relevant initiatives were issued by the Alliance for Global Business, ${ }^{59}$ the Global Business Dialogue on Electronic Commerce $^{60}$ and the International Chamber of Commerce. ${ }^{61}$ Consumer organisations have also contributed to the development of ODR policies, notably the Trans-Atlantic Consumer Dialogue, ${ }^{62}$ Consumers International ${ }^{63}$ and the International Consumer Protection and Enforcement Network. ${ }^{64}$ Finally, dispute resolution providers have contributed to the development of ODR standards, eg the American Bar Association Taskforce on E-Commerce and ADR Recommended Best Practices for ODR Providers. ${ }^{65}$ This chapter 
does not intend to discuss these initiatives since they have already been discussed elsewhere ${ }^{66}$ moreover, the majority of these provisions are reflected in the EC recommendations, which are examined below in this chapter.

\subsubsection{Regional regulatory initiatives}

At a regional level the EU has produced a number of legal instruments harmonising ADR/ODR and highlighting their potential for resolving consumer disputes. The legal basis rests on Article 81 of the Treaty on the Functioning of the European Union (TFEU, which replaces Article 65(a) of the EC Treaty) that states that ADR procedures must be effective and developed. It also states that Member States have the obligation to co-operate in judicial matters, ie in the enforcement of ADR decisions within the EC. ${ }^{67}$

The first major initiative to improve consumer access to justice came in November 1993 with the Green Paper which surveyed national measures, addressed the particular problems of cross-border disputes and suggested a number of strategies for improving dispute resolution in the internal market. ${ }^{68}$ Thereafter, the 1996 Action Plan on consumer access to justice and the settlement of consumer disputes in the internal market stated the intention to establish minimum criteria applicable to the handling of cross-border disputes and the networking of out of court procedures. ${ }^{69}$ There are also a number of directives that encourage the use of ADR for resolving consumer disputes. $^{70}$ With the introduction of the E-Commerce Directive, the EU acknowledged the growth of ADR and ODR, giving indications to the Member States to support their use for the resolution of consumer disputes. Article 17 of the directive states that:

[Member States must ensure that their national] . . legislation does not hamper the use of out-of-court schemes, available under national law, for dispute settlement, including appropriate electronic means [. . .] Member States shall encourage bodies responsible for the out-of-court settlement of, in particular, consumer disputes to operate in a way which provides adequate procedural guarantees for the parties concerned. [Emphasis added]

This paragraph begs the following question: what are those 'adequate procedural guarantees' referred to in the directive? It could be suggested that the directive requires the development of due process standards for ODR. In the EU the closest measures to those standards are two non-binding recommendations issued by the European Commission with the intention of guiding industry and governments in creating harmonised rules for ADR and ODR. ${ }^{71}$ First, the EC 1998 Recommendation sets out a body of principles for the correct use of adjudicative processes where a neutral third party makes a decision, evaluation or recommendation to resolve consumer disputes. This recommendation includes those ODR providers who issue decisions that are not binding or are only binding as a contract and not as 
an arbitral award. Secondly, the EC 2001 Recommendation was issued to set minimum legal standards on consensual processes dealing with consumer disputes, where the neutral third party does not venture a decision, evaluation or recommendation. ${ }^{72}$ This recommendation has been complemented by additional initiatives. Of particular significance is the Green Paper of 19 April 2002 that opened a broad discussion on consensual ADR and ODR in civil and commercial matters. ${ }^{73}$ This document has been the basis for consultation on the main issues related to consensual ADR and ODR in order to establish common standards within the EU, thus promoting the development of a uniform legislation by all Member States. In the Green Paper the Commission referred to the development of ADR and ODR as a 'political priority'. ${ }^{74}$ The result of this consultation formed the blueprint for the Mediation Directive. ${ }^{75}$

Currently, under EU law, provisions referring to ADR also include ODR; this questions the fitness of the law, particularly when these standards were developed by using existing ADR law and practices without offering a thorough and interdisciplinary study on the special nature of ODR. ${ }^{76}$ Moreover, the EU initiatives are in their majority soft laws which complement neutral third parties' professional codes of conduct and the internal rules of ODR providers. In summary, the existing regulation on ODR has similar problems to the self-regulatory approach: it is scattered, patchy, non-binding and sets confusing procedural standards that apply to ODR as well as ADR. ${ }^{77}$ The next section argues that these problems may be addressed by drafting a regulation in the specific field of ODR.

\subsection{Proposal for a regulation in the field of ODR}

\subsubsection{The purpose of regulating ODR at the $\mathrm{EU}$ level}

Member States may enter into negotiations with each other with a view to securing the simplification of formalities governing the reciprocal recognition of extra-judicial processes, including ODR. ${ }^{78}$ In fact, Article 81 of the TFEU states that:

The Union shall develop judicial cooperation in civil matters having cross-border implications, based on the principle of mutual recognition of judgments and of decisions in extrajudicial cases. Such cooperation may include the adoption of measures for the approximation of the laws and regulations of the Member States. ${ }^{79}$

Accordingly, the European Parliament and Council must introduce regulatory measures not only to ensure the mutual recognition of ODR decisions but also to achieve a greater co-operation with the cross-border service of documents and to promote 'the development of alternative methods of dispute settlement'. ${ }^{80}$ 
The need for uniform legal standards is not new. Back in 2003 the European Parliament's Committee on Legal Affairs and Internal Markets acknowledged the importance of flexibility in ADR but recognised that 'there is a need for coherence, common procedural guarantees and common quality standards in order to protect consumers and avoid a proliferation of differing systems as between the Member States ${ }^{81}$ Nevertheless, legal provisions should not be too detailed since this could constrain the functioning of ODR providers. These principles, in my view, should only be binding on those providers who rely on public accreditation. The committee also recommended the issuing of soft laws, including the issuance of guidelines and codes of conduct, and through the promotion of best practice'. ${ }^{82}$

According to Stipanowich, "the very notion of a "law of ADR", however well-intended, strikes some as oxymoronic. When it comes to ADR, the implementing law is not an end in itself, but only a means to be prudently employed within the narrow bounds of necessity'. ${ }^{33}$ According to him, any type of broad regulation in the field of ADR presents a great challenge to legislators who face this task, because of the large degree of flexibility and the range of ADR processes. ${ }^{84}$ The same of course would apply in ODR schemes.

For this reason, he argues, legislatures have focused on specific process taxonomies, particularly with arbitration and mediation. He proposes for the US the compilation of principles in the form of restatements, setting legal principles to identify and promote the most effective legal standards in three different forms of dispute resolution, namely binding arbitration, mediation and non-binding third party decision-making. In his view this should 'include grounds for and scope of enforcement, judicial appointment of interveners, immunity of interveners, confidentiality, the legal effect of awards or other "results" of procedures, and grounds for judicial review or vacatur, if any". 85

The situation in the EU is quite different, particularly when dealing with $\mathrm{B} 2 \mathrm{C}$ disputes. In the EU there is a greater integration than in the US in terms of consumer protection. As a matter of fact the European Commission is keen to encourage the use of ADR methods and monitor their compliance with the existing recommendations. ${ }^{86}$ However, it is here proposed that the European Commission should take a step forward by developing a regulation with legal standards for extra-judicial ODR. The existing procedural standards (eg Recommendations 1998/257/EC and 2001/310/EC and the Mediation Directive) as well as industry initiatives in the field of ODR could form the blueprint for this proposal. An EC legal instrument could require accredited ODR bodies to comply with the existing consumer law and the established procedural requirements. If this is carried out appropriately, it will assist consumers in identifying reliable ODR providers, it will encourage the use of ODR methods and it will assist in the enforcement of decisions from accredited ODR bodies. A legal framework on ODR should be technologically neutral at the same time as being broad enough in order to survive technological changes. This is not an easy challenge because if the law is too broad and imprecise it may not fulfil its regulatory role. ${ }^{87}$ 
A European regulation seems to be the best approach to ensure a uniform compliance with minimum standards across the EU. The regulation must be drafted as far as possible with the consensus amongst all the stakeholders, in particular businesses and consumers. Before the creation of this regulation it might be advisable to issue a green paper to open an interdisciplinary discussion with the main stakeholders, primarily involving the participation of consumer associations, chambers of commerce and dispute resolution service providers. The Green Paper should be a follow-up to the one issued in 2002 but it should be more extensive and it should differentiate between ODR and ADR, as well as between consensual and binding adjudicative processes.

Some Member States have already introduced regulations which constrain the development of ODR by regulating ADR and introducing consumer protection policies based on the minimum standards approach taken by the EU. As a result, there are divergent positions within the EU. ${ }^{88}$ The regulation should therefore contribute towards restricting a regulatory spiral from the Member States that could prematurely over-regulate or restrict the use of ODR.

\subsubsection{The need to increase awareness of $O D R$}

A challenge faced by consumers is to identify ODR providers. The European Commission has built a database with the links of the national ADR and ODR providers that comply with the two recommendations mentioned above.$^{89}$ It is worth reiterating that all the approved services are ADR institutions and only a number of them also provide ODR services. ${ }^{90}$ However, a recent independent report for the EU has noted that not all the approved national ADR and ODR services comply with the recommendations. ${ }^{91}$ This shows that monitoring and regulating minimum standards are essential tools to ensure that ODR complies with due process principles. Currently, there is no body charged with the responsibility of assuring compliance. This could be done at the national level by the European Consumer Centres (ECCs) and Eurochambers, with the co-ordination of a single European entity, such as the European Commission or the European Judicial Network (EJN). The same strategy could take place through equivalent bodies in other regions. For example the Better Business Bureau (BBB) could play a similar role in the US, while the International Consumer Advisory Network (ICA-Net) could provide such a role in Asia and the Pacific Region.

The parties, businesses and consumer representatives, or other independent institutions, including online market places, government agencies and trustmark providers, may refer cases to accredited ODR providers. In addition intermediaries, such as lawyers, consumer organisations and chambers of commerce, may influence the type of dispute resolution sought by the parties. ${ }^{92}$ When the referral is done through the website the main method used is the affiliation to trustmarks. ${ }^{93}$ However, the proliferation of trustmarks has unfortunately introduced some confusion. The EU has the necessary resources 
to set up a public trustmark, thus ensuring the recognition and uniformity of a pan-European trustmark.

\subsubsection{The aim of accreditation}

Most commentators agree that trust is an essential ingredient for the development of ODR. Part of this trust enhancement would come by creating perceptions of reliability through accrediting ODR providers and practitioners. ${ }^{94}$ With regard to the accreditation of practitioners, neutral third parties should meet 'certain levels of education, training, or performance'. ${ }^{95}$ Currently, in the EU there are many different standards and codes of conduct in the field of ADR, which are also applied in ODR, eg the European Code of Conduct for Mediation. However, none of them is compulsory or ensures compliance. According to Conley Tyler and Bornstein's research, '[m]ost ODR sites have formal policies and procedures, including dispute management protocols, standards of conduct, codes of practice, and explicit policies on privacy'. ${ }^{96}$ Furthermore, ODR service providers apply the 'more favourable rights' provision when dealing with B2C disputes. For instance, the Chartered Institute of Arbitrators has a provision whereby B2C disputes resolved using online arbitration will apply the set of rules (applicable law or code of conduct) that is the most favourable to the consumer. ${ }^{97}$

Conley Tyler and Bornstein observe that, on the one hand, there are several factors in favour of accrediting ODR neutrals, such as increasing credibility of services, ensuring consumer protection, obtaining similar level of skills among neutrals and so on. ${ }^{98}$ On the other hand, they observe that there are also issues against accreditation, such as imposing education over natural skills and experience, inhibiting the development of innovative programmes, and legal or practical difficulties in accrediting at a cross-border level. ${ }^{99}$

There are two ways of accrediting neutrals, either through an ODR service provider, or through an external accrediting agency. The two options are valid provided there is always an external control, such as an agency accrediting ODR service providers. ${ }^{100}$ It appears that for most ADR providers it would be feasible to add ODR services and to give the initial neutral training at a low cost. ${ }^{101}$ What is less clear is whether an ADR provider will go online to resolve $\mathrm{B} 2 \mathrm{C}$ disputes without previously being assured of strong connections with e-commerce stakeholders.

With regard to the accreditation of ODR providers, consumers need to be informed when entering into a dispute about which ODR provider will be more suitable for resolving their disputes. ${ }^{102}$ Schultz proposes a regulatory framework establishing an accreditation service by a trusted public institution. In addition, according to him, this public institution could offer access to accredited providers; thus, if a provider does not comply with the regulatory requirements, it will be removed from the list of service providers, which would reduce the ODR's chances of referrals. ${ }^{103}$ He observes that ' $[\mathrm{a}] \mathrm{n}$ accreditation system induces trust because it provides an assessment of the 
providers'. ${ }^{104}$ The accreditation institution could grant a trustmark to ODR providers that comply with procedural and substantive rules, such as due process principles and consumer protection laws. The procedural aspects could be set in the proposed regulation based on the EC Recommendations, the Mediation Directive and industry best practices, while substantive issues are being codified in the forthcoming Directive on Consumer Rights. ${ }^{105}$

As stated above, this is currently being effected in an informal manner by the European Commission, which publishes a list of those providers that have been approved by the Member States. However, the existing structure is rather limited, since providers have to comply only with unsupervised recommendations and do not display a trustmark.

Bordone has adapted Sander's initiative of a multi-door court house. ${ }^{106} \mathrm{He}$ has proposed the creation of a gateway entry point with experts who would help disputants assess the nature of a dispute and would recommend a menu of possible ODR options. ${ }^{107} \mathrm{He}$ suggests building a strong feedback and evaluation system to assess areas of weakness where further changes are necessary. Schultz also proposes the use of clearing houses, which would control access to ODR providers. ${ }^{108}$ Therefore, in addition to offering a trustmark, it would be the portal to such providers. Moreover, clearing houses can help the claimant to choose the most appropriate provider and assist consumers filling in the forms. ${ }^{109}$ Although, there have been previous failed attempts, a successful initiative would be worth pursuing. ${ }^{110}$

According to Schultz, a clearing house ought to have a reputation system built in, where ODR users rate their satisfaction with each of the ODR providers. ${ }^{111}$ However, it can be argued that this suggestion may not be effective when using adjudicative procedures, owing to the fact that unsuccessful parties will rarely give positive feedback. In adjudicative methods, fairness and trust may be assured by the publication of decisions. By contrast, when using consensual methods or highly automated procedures, feedback may be essential in increasing effectiveness in the system.

\subsubsection{The Internet Ombudsman}

Once cross-border B2C disputes arise in the EU, consumers will first attempt to resolve them directly with the business. If unsuccessful, consumers may approach the European Consumer Centre (ECC) in their country, which will try to resolve their disputes by advising them of their rights and then trying to resolve their disputes by contacting the businesses (with the assistance, if necessary, of the national ECC where businesses reside). The ECC has proven to be quite efficient, with a rate of 70 per cent of resolved cases, ${ }^{112}$ although the number of complaints is proportionately small when compared with the size of the internal market. ${ }^{113}$ However, in the remaining 30 per cent it is very difficult to persuade businesses to use ODR, ${ }^{114}$ especially when it is recommended by the ECC, an entity that represents consumers' interests. The only alternative left is to seek a resolution in the court, which when dealing with 
cross-border disputes is not always a feasible option. Part of the efforts of the ECC is to find a suitable ODR service that could be used as an additional filter before recourse to the court, because the majority of disputants with cross-border disputes will not be able to access the courts. In this context The Internet Ombudsman (TIO) pilot project was born.

In Ireland and the UK, the national ECCs have started to work as clearing houses for B2C disputes between UK web traders and Irish consumers, and vice versa. ${ }^{115}$ The ECC recommended the use of ODR once the ECC failed in resolving the dispute on behalf of the consumer. TIO operated on a six month pilot phase with the ECC. It was a free ODR provider for B2C disputes, excluding airline travel disputes. TIO is powered by The Mediation Room and offers disputants online mediation. ${ }^{116}$ ECC (UK and Ireland) also assisted consumers with their technical and legal questions. If during the mediation process the parties did not succeed in reaching an agreement, a decision was taken through an adjudicatory process by an ombudsman who assessed the joint discussions, except those caucuses conducted in private areas (to which one of the parties did not have access). The decision was not binding on the consumer; however, it was binding on the business when the business had previously agreed to be bound by the decision.

The TIO procedure was operational from January to June 2008. Its main challenge was finding cases because businesses were reluctant to participate owing to a lack of trust in these new services. Graham Ross, CEO of TIO, stated that TIO approached businesses by informing them that ODR is cheaper than the Small Claims Court where, even if they win a case, businesses cannot recover most of their legal costs. ${ }^{117}$ However, in most cases businesses know that consumers will not take legal action if the value of the claim is small, bearing in mind the costs of the small claims track. In order to overcome this difficulty, it is necessary to devise a system where the use of independent ODR is mandatory.

\subsubsection{Proposal for a European trustmark}

Trust is essential for the development of ODR and e-commerce. ${ }^{118}$ Trustmarks were designed to boost consumer confidence but to date they have not achieved their expected potential. Existing ODR providers have a varying degree of reliance on trustmarks; for example, SmartSettle has no trustmark, CyberSettle has several and SquareTrade used to offer its own trustmark. The numerous existing trustmarks and the lack of a predominant marketing campaign have led to some confusion amongst consumers. ${ }^{119}$ Arguably, trustmarks need to be addressed at a national or regional level by public authorities in order to eradicate the existing confusion amongst internet users. Currently, the various trustmarks may even be giving the opposite signal, that of distrust, since there are too many trustmarks and too little knowledge of their existence and credibility. ${ }^{120}$ There is a need for uniformity that could then be used to accredit businesses and ODR providers alike. In 
my view, a pan-European trustmark, if complemented with public accreditation, will boost the development of ODR by increasing awareness, overcoming the deficiencies in self-regulation, providing uniform standards and ensuring quality ODR services.

This idea of a public trustmark is not new; for instance, the Spanish Government created a trustmark (Confianza En Linea) that is issued by the National Consumer Association. It assures impartiality and a complaint process free of cost. ${ }^{121}$ Public accreditation of ODR providers could then certify their compliance with standards of due process. At the EU level a supervisory body could monitor the compliance of certified ODR providers to ensure that they comply with a regulation. This would avoid potential providers certifying themselves unfairly in order to attract more users. ${ }^{122}$ It is suggested, as mentioned above, that there should be a division of extrajudicial ODR providers into accredited and non-accredited ODR providers, who would be distinguished by the inclusion or exclusion of a pan-European trustmark. This would allow for the establishment of private ODR providers.

The EU has actively encouraged the use of trustmarks since the 1999 eEurope initiative of the European Commission. ${ }^{123}$ The European Trustmark Requirements were set in 2000 with the e-confidence initiative. A number of trustmarks and international codes emerged from this initiative: GBDe guidelines, Eurolabel, Trusted Shops, Global Trustmark Alliance and WebTrader. Euro-Label, for instance, offers ODR to assist in the resolution of cross-border disputes. ${ }^{124}$ Euro-Label is currently run by six national registration offices in Austria, France, Italy, Germany, Poland and Spain. However, Euro-Label has not been able to achieve enough users to become recognised within the EU. A likely reason for this is that Euro-Label has received limited economic support from the EU. Public bodies, such as the ECC, could contribute in the promotion of the proposed pan-European trustmark and must absorb as many existing trustmarks as possible. This effort could also be carried out at an international level by reaching a compromise to overcome the failed attempt with the Global Trustmark Alliance (GTA).

According to the European Commission, in the creation of most of the existing trustmarks the involvement of consumers' input was minimal. ${ }^{125}$ Initially, the European Trustmark Requirements were to be to certify with a single European logo those providers as long as they complied with a European Code of Conduct. The view of the European Commission was that such a scheme would be backed financially by industry, but this was not achieved. ${ }^{126}$ The lack of success in achieving market implementation suggests that a regulatory initiative would be more successful. Public funding and control of the trustmark seems more appropriate. ${ }^{127}$ An obvious body to carry out this role is the ECC, which already links consumers with 400 ADR bodies across the EU. ${ }^{128}$

Thus, the European Trustmark Requirements could be the blueprint for the new pan-European Trustmark. Those online businesses and ODR providers that adhere to it will have to comply with EU legislation. Accredited online businesses will have the responsibility to provide online access to an 
in-house complaints system and information on a chosen accredited ODR. Accredited providers will then be able to deliver legally enforceable agreements that may rely on public enforcement. Therefore, the reference of a public pan-European system will flag accredited ODR providers that abide by pre-established legal standards.

\subsubsection{Mandatory ODR clauses}

There is a need to enhance the use of ODR for cross-border B2C disputes arising out of internet trading. A good way to increase its use would be through mandatory ODR clauses, which would need to be addressed in legislation. ${ }^{129}$ Currently, under EU law, parties in B2C disputes must agree on using ODR after the dispute has arisen, which is very difficult given the existing lack of trust between the parties once disputes have arisen. However, it has been argued that ODR is not sufficiently developed to be mandatory and that if imposed on consumers it might undermine their confidence. ${ }^{130}$ As a result, most mandatory ODR providers employing adjudicative methods have integrated self-enforcement mechanisms and allow parties to commence legal proceedings, eg through the UDRP.

In relation to consensual methods, the Directive on Mediation encourages the use of consensual ODR. As discussed in the previous chapter, an effective way of encouraging parties to consider the use of consensual ADR has been timidly adopted by the English civil procedure, which informs litigants that they should consider the use of ADR, to the extent that if its consideration is refused unreasonably by one party, the judge has discretion to impose legal fees on that party regardless of whether the party is successful in the legal proceedings. ${ }^{131}$ This situation raises a number of issues that were discussed in Chapter 4. The greatest difficulty, is to establish when mediation is appropriate. Research in this area would be relevant, particularly if it delivers some type of guidelines assisting the judiciary and the legislature in appropriately encouraging litigants to settle their disputes in a speedy and consensual manner.

With respect to adjudicative processes, such as arbitration, their use should be restricted when the purpose is to circumvent the enforcement of consumers' rights in the courts. ${ }^{132}$ Hence, if pre-dispute arbitration is allowed in consumer disputes, it ought to comply with consumer law.

Mandatory clauses must have limits, especially when businesses as repeated players have the advantages of selecting the ODR providers. In addition, it is not surprising that consumer advocates maintain that consumers should not be required to waive their legal rights or be restricted from resorting to other means of recourse if they are dissatisfied with an arbitral award. ${ }^{133}$ Although this might appear safer while ODR is developing, it has its own limitations, as many businesses will not be willing to engage in a process that may only delay a final resolution. In my view, decisions from accredited ODR providers should be enforceable but online appeals should also be allowed. If these 
providers comply with due process principles, why not treat them as such, ie akin to judicial decisions? This is something that would need support from the legislature. A regulation could establish the limits where consumers may have to waive their legal rights in accessing the courts, but only when the accredited ODR service facilitates parties' access to justice, in other words, when it is more cost-efficient for the parties to access an accredited ODR than the competent court.

There are a number of bills in the US legislature that aim to stop abuses of arbitration. The most notable ones are the Arbitration Fairness Act and the Fair Arbitration Act. Of these, the former requires agreements to arbitrate consumer and employment disputes to be entered after the dispute has arisen. ${ }^{134}$ In addition, the validity or enforceability of an agreement to arbitrate will be determined by the courts and not by an arbitrator. Conversely, the Fair Arbitration Act grants several specific due process rights to all consumers in arbitration proceedings. ${ }^{135}$ Under this bill, in order to be enforceable an arbitration clause must have a printed heading in bold capital letters entitled 'arbitration clause'. ${ }^{136}$ It must provide notice that consumers could opt for the small claims court procedure if the claim does not exceed US $\$ 50,000 .{ }^{137}$ The bill gives the consumer the right to have the arbitrator governed by the law that would apply under the conflict of laws principles applicable in the consumer's forum. ${ }^{138}$ This would avoid the evasion of judicial scrutiny and circumvent consumer protection statutes. Other rights provided by the Act include the right to be legally represented, the right to a fair hearing (even to conduct discovery) and the right to a written resolution. The bill also requires a timely arbitral award; to that end, where the defendant must file an answer within 30 days, the arbitrator must hold a hearing (using electronic means if deemed necessary) within 90 days, and where the final reasoned decision must be rendered within 30 days after the hearing. ${ }^{139}$ Some lessons could be learned from this bill and be applied in the EU law context to the proposal for a regulation in the field of ODR.

Consequently, as discussed in Chapter 3, some arbitration services in the US offer consumers the choice of opting out from arbitration when they prefer to pursue the matter in the small claims court, regardless of any contractual clause. ${ }^{140}$ Similarly, the England and Wales Arbitration Act 1996 and the Unfair Terms in Consumer Contracts Regulation 1999 also allow pre-dispute consumer arbitration clauses but only when the amount at stake is more than $£ 5000$, ie the economic threshold for the small claims track. ${ }^{141}$ The Office of Fair Trading has consistently required businesses to delete predispute binding arbitration clauses below this threshold. Accordingly, the Ford and ABTA business members of the Chartered Institute of Arbitrators only use post-dispute agreements for consumers and pre-dispute agreements for businesses. ${ }^{142}$

Overall, arbitration clauses should be enforceable provided they do not intend to reduce the capacity of the consumer to access to justice by introducing new barriers, such as unreasonable costs or geographic barriers. For 
instance, as suggested by the law in the US and in the UK, if an ODR clause mandates that parties participate in an ODR procedure that is more expensive than the small claims procedure, then that clause should be invalidated. Another limitation that must not be allowed is when the contractual clause impedes consumers from taking class actions, which might already be considered unfair under Directive 13/93. Therefore, clearer guidelines must be given to explain what constitutes equitable ODR clauses in consumer contracts, ${ }^{143}$ rather than having a blank ban on all clauses as it currently states in the proposed Directive on Consumer Rights. ${ }^{144}$

\subsubsection{Procedural legal standards for accredited $O D R$}

\subsubsection{Arbitration and other adjudicative processes}

The EC Directive on Electronic Commerce allows contracts to be concluded by electronic means. ${ }^{145}$ But does the directive include clauses that require the parties to engage in an ODR process when disputes arise out of their electronic contracts? As discussed in Chapter 3 it appears that there may be certain limits, particularly when using B2C online arbitration. Policy makers in the EU are cautious not to replicate the abusive arbitral clauses in the US, where statistics often show how consumer arbitration is not used for the benefit of consumers; on the contrary, the majority of cases are brought by businesses against consumers. ${ }^{146}$ It is not essential for governments to provide these arbitration services, but what is essential is that governments authorise and supervise these services. If the industry actively participates in the development of ODR, it will favour competition between ODR providers to supply cost-effective services. Thus, private (including for profit) ODR providers should be allowed, although minimum legal standards should be put in place when mandatory adjudicative processes are imposed on consumers.

It is necessary to open a debate in the EU on this matter in order to decide which aspects should be regulated and which aspects should be left unregulated. Certain procedural aspects can be left to the parties to decide but others need to be upheld by the law in order to ensure fair decisions. ${ }^{147}$ Naturally, binding arbitration processes would require more procedural guarantees, especially when an imbalance of bargaining power exists. In this context, online arbitration would need to be supervised either by governmental bodies or monitored by the courts.

The most relevant legal instrument at the EU level is the 1998 Recommendation, ${ }^{148}$ which identifies seven legal principles that must be followed in consumer adjudicative processes and in those dispute resolution processes where the neutral party plays an active role in making a decision or a recommendation. It has been proposed above that this recommendation be adapted to ODR and become binding in the form of a regulation for those ODR providers that are accredited with the pan-European trustmark. This does not mean that soft laws are unnecessary; on the contrary, this change should 
also be complemented by soft laws, both public and private. ${ }^{149}$ It is worth examining the seven principles stated in the Recommendation, and how they could be applied to ODR processes.

(i) The principle of independence for ODR arbitrators must be equivalent to the standard expected from offline neutral third parties; hence, they must not have either an interest in the dispute or a professional or personal connection with one of the parties. ODR providers must create a fair redress environment, unbiased towards any individual participant in the process. Software algorithms must similarly be designed to offer no systemic benefit to one party over another. In addition, the regulation herewith proposed must address liability of ODR neutral third parties and providers. A provision establishing immunity for arbitrators must require their impartiality and shield them from undue influence in making decisions but, unlike the neutral expert, the online arbitrator should be immune from legal actions for negligence.

(ii) The principle of transparency sets the information that parties have to be aware of when participating in arbitration, ie procedural and substantive provisions. This principle includes transparency with regard to funding systems, which should not create a bias in favour of any of the parties involved. Public funding and monitoring could ensure the delivery of a fair and effective ODR service for B2C disputes. Presently it is difficult to obtain accurate information about ODR providers and their source of funding. Although most providers disclose information on the services they offer, insufficient information is given on their governing structure, funding models, fees, officials, shareholders, users and results. Accredited ODR providers should increase accountability and trust by disclosing the above information, especially when allowing private (for profit) entities to carry out the arbitral processes. ${ }^{150}$

(iii) The adversarial principle guarantees that parties can present their arguments fairly in addition to the necessary experts' statements. In this regard, the arbitrator must employ special care so that disputants can use the available ODR technology competently. Another issue that needs to be dealt with is the allocation of the burden of proof. An obvious concern is the vulnerability of electronic documents when used as evidence. Electronic signatures and cryptography may assure authenticity, although often at a high cost. It is necessary to find equilibrium between security, as part of due process, and cost-efficiency.

(iv) The principle of effectiveness states that dispute resolution processes must be fast and cost-effective. Effectiveness must be balanced with the need for maintaining credibility in terms of accuracy of decisions and perceived justice. ${ }^{151}$ Many commentators and initiatives are in favour of delivering a service free of cost for consumers. Arguably, this does not have to be a requirement, but extra-judicial ODR should not be more costly than litigation when consumers are involved. The use of 
electronic communication services generally may reduce time and costs. Legal representation should not be required as it is hoped that these processes are consumer friendly. In practice, however, adjudicative processes involving substantial amounts of money may require legal representation.

(v) The principle of legality implies that adjudicative ODR must comply with the national law of the consumer's habitual residence. Despite this, arbitrators are presently not required to have any particular qualifications. Moreover, ODR does not need to be grounded exclusively on regulation but it could also rely on self-regulation, eg the law of eBay or the general customs of netiquette, which contributes to achieving consistent decisions across different jurisdictions.

(vi) The principle of liberty means that the consumer must agree to arbitration freely. This principle was previously discussed in relation to mandatory clauses. It must be emphasised that under this proposal for a regulation, the business could only include a mandatory clause for the use of accredited ODR services, which should be sufficiently highlighted so as to make the consumer aware of it before the contract is signed.

(vii) The principle of legal representation states that parties cannot be deprived of their right to be legally assisted; however, as mentioned above, parties should not be compelled to use legal representation. There should be a specific mandate for parties in ODR to disclose whether they are legally represented.

In addition, in the context of ODR an important principle is accessibility. The application of this principle is twofold: on the one hand ODR must be easy to find and access but on the other hand ODR must be accessible in the sense that it addresses cultural and language barriers. Furthermore, when possible, ODR systems should strive to become media neutral in order to encourage the widest access. ${ }^{152}$

\subsubsection{Mediation and consensual processes}

The Mediation Directive introduces some legal standards, such as confidentiality, and it encourages Member States and mediation providers to develop mediation training and the dissemination of effective mediation practices. ${ }^{153}$ The directive states that $\mathrm{B} 2 \mathrm{C}$ mediations should take into account the four principles enunciated in the 2001 Recommendation (impartiality, transparency, effectiveness and fairness). Thus those ODR providers that comply with the above principles as well as with some complementary best practices could be accredited by an officially recognised monitoring entity. In addition:

(i) The principle of impartiality requires mediators not to have a conflict of interest with either party. This principle is complemented by the principle of transparency since impartiality can only be assured by requiring mediators to disclose the relevant information that may affect their 
independence and impartiality. Also, the parties must be allowed to recuse mediators if there is (or if it is perceived that there is) a conflict of interest. This would be compatible with the immunity of mediators, which should be considered separately from the immunity of arbitrators. ${ }^{154}$

(ii) The principle of transparency states that consumers must be informed in simple terms about the mediation process. Essential information would be the cost of the online mediation, the time involved and the status of the settlement. It also recommends the publication of the performance of the mediation process, such as the number of agreed settlements, average time, compliance records, and so on. However, generally, given the confidential nature of most of these processes, ODR providers are reluctant to share these details, especially if this data may not create positive publicity.

(iii) The principle of effectiveness requires accessibility to the process, which includes offering electronic communications. In addition, it requires a cost-effective process, where costs are proportional to the dispute at stake. This can be difficult when disputes are of low value. Highly automated processes, brief intervention of mediators and the lack of legal representation may reduce costs. ODR must be easy to find and easy to use. In other words, there must be access to technology and appropriateness of ODR tools for the dispute at stake. There should be a requirement for mediators to guarantee that the use of technology does not inhibit one of the parties from participating correctly in ODR. ${ }^{155}$ These principles must be monitored by the mediators and ODR providers in each case. The pan-European trustmark provider must ultimately monitor compliance with the above principles. Furthermore, parties must be provided with a mechanism to voice any complaints in this respect.

According to Menkel-Meadow, efficiency is one of the driving concerns for encouraging the use of ADR in the US. ${ }^{156}$ The same can be said in the EU where it is common knowledge that the majority of civil trials terminate in settlement. This argument contributes to justify use of mandatory online mediation. Yet, the law must protect parties from coercion in settling disputes. One challenge will be to identify duress or undue influence in an online mediation process that may be protected with a confidentiality agreement. It will be the responsibility of the courts to balance these two aspects, unnecessary publicity and illegitimate coercion, taking into account when dealing with $\mathrm{B} 2 \mathrm{C}$ disputes the disparity in bargaining power between the two parties. ${ }^{157}$

(iv) The principle of fairness states that parties must be aware that they have the right to withdraw at any stage of the process and the choice as to whether or not to agree to a suggested solution. It also states that parties should be allowed a reasonable period of time to consider any suggested solution before an agreement is entered into. This approach may not be the most desirable because, as mentioned in Chapter 4, it is often the momentum of the mediation that helps parties to reach a compromise. ${ }^{158}$ 
The standards of mediators today depend mainly on self-regulation and soft laws. Some commentators have observed that it is vitally important to set liability standards applicable to all ODR neutral third parties, because at present any individual or business may offer ODR services without compliance with any minimum training or experience. ${ }^{159}$ According to Gibbons a code of conduct specifically on ODR is necessary to legitimate ODR and to satisfy potential sceptical ODR users. ${ }^{160}$

A first step in this direction was taken with the European Code of Conduct on mediation. This is just a soft law initiative; the European Commission does not expressly acknowledge that those who claim to comply with the Code of Conduct necessarily do so. The Commission has put together a list of those organisations and mediators who are signatories to this code but disclaims any verification of compliance. ${ }^{161}$ Under the current circumstances, the code may have the opposite effect by misleading users to trust mediators and service providers who claim compliance with the European Code of Conduct but who may not in fact so comply. An accreditation body, such as the European Judicial Network (EJN) or ECC and Eurochambers, should monitor, either themselves or through the Member States, compliance with the European Code of Conduct.

\subsubsection{Enforcement of ODR decisions}

Arbitral awards with cross-border implications are normally easier to enforce than judicial awards, owing to the existing international treaties. ${ }^{162}$ These conventions require an original or an authenticated copy of the award, the agreement to arbitrate and the necessary translations. ${ }^{163}$ The voluntary nature of consensual ODR is not expected to present many problems at the enforcement stage. Nevertheless, what cannot be ignored is the failure of the parties to comply with the results of an ODR decision. Without voluntary compliance, the parties can generally only enforce an ODR outcome by going to court. ${ }^{164}$ This would bring a set of legal and economic obstacles, particularly when dealing with cross-border disputes where offline enforcement will defeat the purpose of ODR. For this reason, most commentators argue that one of the greatest shortcomings of ODR is the lack of enforcement mechanisms. ${ }^{165}$ As a consequence, to date ODR providers rely mostly on self-enforcement mechanisms such as trustmarks, black lists, technological enforcements, deposits and so on.

It has been suggested that self-enforcement mechanisms should be complemented with a public enforcement safety net that would grant the enforcement of ODR outcomes in the national courts of the signatory countries. This is particularly important for adjudicative processes because parties will not participate unless they are assured that the awards will be legally enforceable. ${ }^{166}$ The international community is taking steps towards this. With regard to arbitration, UNCITRAL has adopted a draft convention that would reform the 1958 New York Convention. ${ }^{167}$ The new convention will 
no longer permit a narrow interpretation of the written requirement of arbitral awards, allowing online arbitration. UNCITRAL also issued a recommendation proposing that the New York Convention should incorporate the changes introduced by its Model Law in electronic signatures and electronic communications for international contracts. ${ }^{168}$

With regard to mediation in the EU, the Mediation Directive requires that by 2011 all Member States must ensure that mediated agreements, including those reached through ODR, are confirmed by the public authorities and enforced across the EU, provided that such agreements are not contrary to the law in the enforcing Member State. ${ }^{169}$ However, judicial enforcement of online mediated decisions may be problematic if procedural compliance is not clear. Hence, it is necessary to develop legal standards for ODR providers, ie accredited ODR.

Hörnle observes that 'extra-judicial ODR, like ADR, can only operate if supported by a court system with the power to enforce settlements and with the power to counteract deliberate wrongdoing such as fraud'. ${ }^{170}$ It is often assumed that courts are not likely to be the primary entities to resolve most online disputes because courts are too slow and expensive. However, courts can contribute towards the increase of trust and the legitimation of ODR. Even if the courts resolve only a small number of disputes, they will provide rules that create legal certainty, which an extra-judicial ODR cannot provide. ${ }^{171}$ Schultz suggests that online appeal processes could be run by public entities in order to control unsatisfactory decisions from private ODR providers. ${ }^{172}$ Public cybercourts are also the best forum to ensure compliance with Article 6 of the ECHR by exercising a supervisory and enforcement function. ${ }^{173}$

Online appeals for adjudicative decisions could provide a second layer of online proceedings that will improve the quality of decisions without removing the benefits of ODR. ${ }^{174}$ This mechanism will encourage transparency and uniformity amongst accredited ODR providers in implementing procedural and substantive legal provisions. Online appeal processes have already been proposed for the UDRP, but these proposals faced criticisms based on perceived delays, expenses, ease of abuse and lack of finality. But more importantly, an appeal process would insert trust in accredited ODR, thus increasing predictability and uniformity, which in turn would contribute towards creating a common law for e-commerce - the so-called lex informatica.

Within the EU, national courts could carry out this review through a system akin to the European Small Claims Procedure (ESCP). ${ }^{175}$ In order to avoid frivolous claims, the ESCP has a provision that gives the judge a discretion to impose legal costs. A judge may impose the costs, including reasonable and proportional legal fees, on the claimant in those cases where the claimant fails to improve on the result given by the accredited ODR provider. It would be advisable to establish a database where national courts of each Member State could publish these judgments. This database could be constructed from the previous work done by the Consumer Affairs Directorate and its European Database with Case Law Concerning Unfair Contract 
Terms ('CLAB database'), which stopped being updated in 2001. This work could be carried out by the European Commission in conjunction with the ECC-Net and would contribute to the education of consumers as well as promote legal certainty. It is to be expected that the courts will provide higher due process guarantees than private ODR providers and will deliver legal precedents while interpreting consumer law, thereby contributing towards the harmonisation and development of ODR legal standards.

\subsection{Conclusion}

ODR has been under-used in spite of its potential for resolving B2C disputes. The European legislature should take steps towards encouraging parties to use ODR on a widespread basis; however, in order to ensure fair and efficient ODR it will first be necessary to create public legal standards. The unequal bargaining position of disputants creates a requirement for legal provisions to uphold quality ODR processes that prevent weaker parties from being abused.

Regulation is not the only or best means of addressing every problem in ODR but it is a necessary tool without which ODR could not be efficiently and fairly developed. This chapter contends that part of the lack of success of ODR stems from a significant legal lacuna, which means that ODR as a result suffers from a lack of legal certainty and public confidence. It appears unrealistic to close the gap between the need for effective dispute resolution mechanisms for online consumers and their actual use without introducing a legal framework in the field of ODR.

The current self-regulatory approach has been unsuccessful. The market cannot be left as the sole regulator of a fair ODR system. The lack of uniform legal standards leaves ODR users and providers with little guidance. Thus, a legal framework will boost the legitimacy of ODR by providing appropriate information, awareness and trust. It is this author's contention that the development of ODR depends on creating legal standards that will serve as a badge to enforce ODR agreements. If ODR is to be effective within the EU, it will be worth reconsidering the use of mandatory ODR clauses and enforceable ODR decisions of accredited ODR providers. In order to allow this in a just manner, what is required is the regulation of procedural standards for ODR. These standards must take the form of a regulation that is based on the existing Mediation Directive, EC Recommendations and best practices that incorporate the special features of ODR, such as equal access to technology and secure communications. In addition, the regulation should create a pan-European trustmark programme, which will accredit those ODR providers who comply with the regulation and whose decisions are legally enforceable.

The number of ODR providers will increase over time. On the one hand, this will clearly stand to benefit consumers by having greater access to justice; on the other hand it poses the problem of forum shopping where 
businesses may seek the ODR provider that will benefit them the most. Mandatory ODR must be exclusively used to resolve in a fair manner those disputes that are suitable for it. The control of suitability must be carried out through legislation and court supervision. Legislative inactivity with the existing legal uncertainty of ODR legal standards will reflect the failure of courts to articulate clear and harmonised approaches to ODR. The role of the courts is not to legislate or make policy but to enforce the existing law.

It is argued that a regulation in the field of ODR would continue to allow the development of private and public ODR initiatives that rely on selfregulation, but if ODR is to attain a wider market implementation, special tools are needed. However, those tools should only be given to accredited ODR providers who comply with legal standards while resolving disputes that constrain the development of e-commerce.

Before this proposed regulation is designed, it would be advisable to issue a broad consultation through a Green Paper discussing the following proposals. First, accredited ODR providers should be obliged to comply with minimum legal standards, ie procedural and substantive provisions. Secondly, a panEuropean trustmark will accredit ODR providers and online businesses who voluntarily decide to join the proposed scheme. Thirdly, an EU institution will be appointed to monitor the compliance of accredited ODR providers with the regulatory standards. A major role could be played by ECC-Net, the European Commission, Eurochambers and the EJN. Fourthly, pre-dispute contractual clauses will be legally binding only when they refer to accredited ODR providers. Fifthly, settlements from accredited ODR providers will be enforced directly by the courts, following the modus operandi set out in the Mediation Directive.

Finally, adjudicative decisions of accredited ODR providers could be appealed in an online judicial process, such as the ESCP. This will increase public trust in accredited ODR providers. In this manner, online decisions will not be fully binding, but the use of ODR may be mandatory. A process similar to the ESCP appears to be the most suitable judicial process for national courts to deal with ODR appeals, particularly those with crossborder claims. As a result, the ESCP will press for the creation of a uniform interpretation of consumer protection policies through the publication of the appeals in a freely accessible database. Accredited and non-accredited ODR providers will render decisions based on a combination of customary law, equity, consumer law and legal precedents. Precedents will not be binding but will be persuasive in a similar manner to that taken in civil law traditions.

\section{Notes}

1 Lodder (2006) 153.

2 Schultz (2004) 71. 
3 Pearlstein (2007) 739.

4 Ponte \& Cavenagh (2005) 138; Hill (2008) 318.

5 Centre for European Economic Law Katholieke Universiteit Leuven, Belgium 'An Analysis and Evaluation of Alternative Means of Consumer Redress other than Redress through Ordinary Judicial Proceedings' Leuven (17 January 2007) 89 (Leuven Report); see also OECD Recommendation on Consumer Dispute Resolution and Redress (July 2007).

6 Schiavetta (2004).

7 Taylor (2006) 215.

8 Rule (2002) 98. Cf. Genn (2010) 69.

9 Abernethy 'Building Large-Scale Online Dispute Resolution and Trustmark Systems' Proceedings of the UNECE Forum on ODR 2003 available at http:// www.odr.info/unece2003.

10 Conley Tyler \& Bretherton 'Seventy-six and Counting: An Analysis of ODR Sites' (2003) Report of Research Conducted for the Department of Justice, Victoria, Australia.

11 Schultz (2004) 75; interview with B Hutchinson in Kaufmann-Kohler \& Schultz (2004) Annex.

12 Katsh (2007) 105-106.

13 Hörnle (2002).

14 Morek (2006) 176.

15 Ibid 167. See also American Bar Association (2002) 419; Zhao (2005) 197, 244; Schultz (2004) 106.

16 Gibbons (2006) 351.

17 Colón-Fung (2007) 243.

18 Bordone (1998) 200.

19 Zhao (2005) 237.

20 Calliess (2001); Nenstiel (2006) 320.

21 Katsh 'Adding Trust Systems to Transaction Systems: The Role of Online Dispute Resolution' First UN Economic Commission for Europe Forum on Online Dispute Resolution (June 2002) available at http://www.ombuds.org/un/ unece_june2002.doc.

22 Patrikios (2006) 274.

23 Calliess (2001) 26.

24 Zhao (2005) 52.

25 Rudolph Cole (2006) 204.

26 Zuckerman (2001) 11.

27 United Nations Conference on Trade and Development (UNCTAD) 'Online Dispute Resolution: E-Commerce and Beyond' in E-Commerce and Development Report (2003) 190.

28 Rule (2002) 31; Kaufmann-Kohler \& Schultz (2007).

29 UNCTAD (2003) 190.

30 Ibid.

31 Rudolph Cole (2006) 208.

32 Teitz (2001) 985.

33 Zhao (2005) 45.

34 Pearlstein (2007) 790.

35 Thornburg (2006) 303.

36 Katsh (2007) 103.

37 Consumers International 'Disputes in Cyberspace 2001: Update of Online Dispute Resolution for Consumers in Cross-Border Disputes' (2001a) available at http:// www.consumersinternational.org/Publications/.

38 Morek (2006) 185; UNCTAD (2003) 193.

39 Edwards (2007). 
40 Trans Atlantic Consumer Dialogue Report submitted to the presidents of the US and the EU (12 May 2006).

41 Thornburg (2006) 328-29.

42 Morek (2006) 185-86; Kaufmann-Kohler \& Schultz (2004) 237.

43 Schultz (2003a) 1.

44 Ponte \& Cavenagh (2005) 137.

45 Morek (2006) 165.

46 Ponte \& Cavenagh (2005) 137.

47 The most similar law in the US is the Uniform Mediation Act 2001. At the time of writing the Uniform Law has been adopted by only 10 states of the federation.

48 Schultz (2004) 106.

49 UNCTAD (2003) 193.

50 Ponte \& Cavenagh (2005) 136.

51 OECD Recommendation on Consumer Dispute Resolution and Redress (12 July 2007). The Recommendation specifically states its application to ODR at 10.

52 Rule (2002) 270.

53 Kaufmann-Kohler \& Schultz (2007) 90.

549 December 1999, 4 July 2002 and 11 April 2006. Committee on Consumer Policy 'Consumers in the Online Marketplace: The OECD Guidelines Three Years Later' OECD Publications (3 February 2003) DSTI/CP/(2002)4/Final available at http://www.oecd.org.

55 OECD Recommendation on Consumer Dispute Resolution and Redress (12 July 2007).

56 Kaufmann-Kohler \& Schultz (2007) 92-93.

57 eg UNCITRAL Model Law on International Commercial Conciliation (2005). See UNCITRAL, Note by the Secretariat: 'Possible future work on online dispute resolution in cross-border electronic commerce transactions' (23 April 2010).

58 Kaufmann-Kohler \& Schultz (2007) 104.

59 Alliance for Global Business 'A Global Action Plan for Electronic Business' (July 2002).

60 See for example the Global Business Dialogue on electronic commerce, Consumer Confidence Working Group 'Alternative Dispute Resolution - The Miami 2000 Recommendations and the Tokyo 2001 Recommendations'.

61 The International Chamber of Commerce Best Practices for ODR in B2C Disputes.

62 Global Business Dialogue on Electronic Commerce (GBDe) Recommendations on Alternative Dispute Resolution (September 2000).

63 Consumers International (2001a).

64 http://www.econsumer.gov/.

65 American Bar Association (ABA) Task Force on E-Commerce and ADR 'Addressing Disputes in Electronic Commerce: Final Report and Recommendations' (2002).

66 Davis (2002) 529; Ponte \& Cavenagh (2005) Appendix A examining the ABA Task Force initiative.

67 [2008] OJ C115/13.

68 Green Paper on Access of Consumers to Justice and the Settlement of Consumer Disputes in the Single Market ((COM(93) 576).

$69 \operatorname{COM}(96) 13$.

70 Directive 97/7/CE art 11; Directive 2002/65/CE art 14.

71 Recommendations 98/257/EC, 2001/310/EC.

72 List available at http://ec.europa.eu/consumers/redress/out_of_court/database/ index_en.htm. Similar, but less comprehensive lists have been developed by other organisations. See for example the list set out by the e-consumer initiative available at http://www.econsumer.gov/english/resolve/directory.shtm. 
73 Green Paper of 19 April 2002 on Alternative Dispute Resolution in Civil and Commercial Law, COM(2002) 196 final.

74 Green Paper (2002) 14-15.

75 Directive 2008/52/EC.

76 Farah (2005) 125.

77 Ponte (2002) 480.

78 An early version of the ideas expressed in this and the following sections have been published previously in Cortés (2008e) 221-37 and Cortés (2010) forthcoming.

79 TEC ex art 65(1).

80 TFEU art $81(2)(\mathrm{g})$.

81 Committee on Legal Affairs and Internal Market, European Parliament (Rapporteur, Diana Wallis) Report on the Commission Green Paper on Alternative Dispute Resolution in Civil and Commercial Law (21 February 2003) A5-0058/2003.

82 Ibid.

83 Stipanowich 'The Arbitration Penumbra: Arbitration Law and the Rapidly Changing Landscape of Dispute Resolution' Legal Studies Working Paper Series, Paper Number 2008/1 at 44; Nevada Law Journal (forthcoming) available at http://ssrn.com/abstract $=1007490$.

84 Ibid 47.

85 Ibid 53.

86 European Commission 'EU Consumer Policy Strategy 2007-2013' (COM(2007) 99 final) 11.

87 Morek (2006) 164.

88 Lázsló Szöke (2006) 129-42.

89 http://ec.europa.eu/consumers/redress/out_of_court/adrdb_en.htm.

90 See for example the ODR service of the Chartered Institute of Arbitrators ODR services for Trustmarks available at http://www.idrs.ltd.uk/trustmark/index.asp.

91 Leuven Report (17 January 2007) 11.

92 Ramsay (2006) 34.

93 http://www.truste.com and http://www.squaretrade.com.

94 Conley Tyler \& Bornstein (2006) 394.

95 Ibid 383.

96 Ibid.

97 Chartered Institute of Arbitrators 'Rules of Independent Arbitration Scheme for the Travel Industry' (1994) art 1.8.

98 Conley Tyler \& Bornstein (2006) 384.

99 Ibid.

100 Ibid 393.

101 Ibid.

102 Schultz (2003a) 4.

103 Schultz (2004) 94.

104 Schultz (2003a) 5.

105 Proposal for a Directive of the European Parliament and of the Council on Consumer Rights (COM(2008) 614 final).

106 Sander (1976) 111.

107 Bordone (1998) 199.

108 Schultz (2004) 97.

109 Schultz (2003a) 5.

110 UNCTAD (2003) 191.

111 Schultz (2003b).

112 Author's telephone interview with Susan Dowling from the ECC and Irish manager of the TIO (1 May 2008). 
113 European Consumer Centres Network Annual Report 2008 (August 2009).

114 Ibid.

115 European Consumer Centre Dublin press release (7 February 2008); Law Reform Commission (Ireland) Consultation Paper on Alternative Dispute Resolution (July 2008) 278-82.

116 http://www.theinternetroom.com.

117 E-mail from Graham Ross of 27 June 2008 (on file with author).

118 Mommers (2006) 182.

119 Shannon Martin (2002) 150; Gillieron (2008) 320.

120 Balboni (2009).

121 http://www.consumo-inc.es/Distintivo/queEs.htm.

122 Morek (2006) 169.

123 E-Europe: An information society for all, Communication on a Commission Initiative for the Special Council at Lisbon (23-24 March 2002).

124 http://www.euro-label.com.

125 Commission Staff Working Document 'Consumer Confidence in E-Commerce: Lessons Learned From the E-Confidence Initiative' (SEC(2004) 1390 final) 6.

126 Ibid 7.

127 CEN/ISS 'Workshop Agreement on Standardisation of Online Dispute Resolution Tools' (2009) 66.

128 Communication from the Commission on Cross-Border Businesses to Consumer e-Commerce in the EU (COM(2009) 557 final).

129 Consumers International (2001a) 26; Morek (2006) 186.

130 Kaufmann-Kohler \& Schultz (2007) 99.

131 HMCS leaflet EX301 'Making a claim - some questions to ask yourself at 1; Burchell v Bullard [2005] EWCA Civ 358; Halsey v Milton Keynes General NHS Trust [2004] 1 WLR 3002.

132 Alderman 'The Future of Consumer Law in the United States - Hello Arbitration, Bye-bye Courts, So-long Consumer Protection' University of Houston Law Center No 2008-A-09 at 10.

133 Kaufmann-Kohler \& Schultz (2007) 193.

134 Arbitration Fairness Act 2009 (HR 1020, status); Bill (Section 931, status).

135 Ibid Section 1135. The Fair Arbitration Act (FAA) 2007 is an amendment to the Federal Arbitration Act 1925.

136 FAA Section $17(\mathrm{a})$.

137 Senate Floor Statement of Senator Sessions, Fair Arbitration Act of 2007, Statements on Introduced Bills and Joint Resolutions.

138 FAA Section $17(\mathrm{~b}) 12$.

139 Ibid Section $17(\mathrm{~b}) 9$.

140 Leuven Report (17 January 2007); US National Report 21.

141 Ibid. For more information visit their websites: AAA http://www.adr.org/; NAF http://www.arb-forum.com/; and JAMS http://www.jamsadr.com/.

142 See ch 3.3 of this book.

143 Edwards \& Wilson (2007) 328.

144 Annex II.

145 Directive 2000/31/EC on Electronic Commerce art 9.1. See also Directive 1999/93/EC on Electronic Signatures.

146 Public Citizen 'The Arbitration Trap: How Credit Card Companies Ensnare Consumers' (September 2007) available at http://www.citizen.org. See also Sternlight (2007) 86.

147 Zuckerman (2001) 7.

148 Recommendation 98/257/CE of the Commission on the Principles Applicable to the Bodies Responsible for Out-of-Court Settlement of Consumer Disputes [1998] OJ L115. 
149 Kierkegaard (2004) 205.

150 American Bar Association Task Force on E-Commerce and ADR-Recommended Best Practices for ODR Service Providers (2002).

151 Hanycz (2008) 27(1) 102.

152 Advisory Committee of the International Centre for Technology and Dispute Resolution, Standards of Practice for Online Dispute Resolution (2009).

153 Directive 2008/52/EC arts 4, 7.

154 Cassondra (1997) 629.

155 Gibbons (2006) 356.

156 Menkel-Meadow (1990) 2.

157 Anonymous authors (1990) 1100.

158 Hörnle (2003) 27.

159 Katsh \& Rifkin (2001) 160; Rule (2002) 271; Morek (2006) 188; Ponte \& Cavenagh (2005) 145.

160 Gibbons (2006) 351.

161 http://ec.europa.eu/civiljustice/adr/adr_ec_code_conduct_en.htm.

162 The New York Convention on the Recognition and Enforcement of Foreign Awards of 1958 and the European Convention on International Commercial Arbitration of 1961.

163 New York Convention 1958 art 4; Schultz (2006).

164 Patrikios (2006) 282.

165 Colón-Fung (2007) 250.

166 Ibid.

167 UNCITRAL Convention on the Use of Electronic Communications in International Contracts (July 2005).

168 Recommendation regarding the interpretation of Article II, paragraph 2, and Article VII, paragraph 1, of the Convention on the Recognition and Enforcement of Foreign Arbitral Awards, done in New York (10 June 1958) adopted by the United Nations Commission on International Trade Law on 7 July 2006 at its 39th session.

169 Directive 2008/52/EC art 6.

170 Hörnle (2002).

171 Schultz (2004) 84.

172 Ibid.

173 Schiavetta (2004).

174 Schultz (2003a) 5.

175 Regulation 861/2007/EC of the European Parliament and of the Council of 11 July 2007 establishing a European Small Claims Procedure [2007] OJ L199/1. 


\section{Conclusion}

I see ODR as becoming the predominant form of dispute resolution in e-commerce. ${ }^{1}$

\section{Summary}

In this era of e-commerce, the consuequential litigation is often expensive, complicated and time-consuming. ${ }^{2}$ This book has examined online consumers' access to justice within the EU when it is coupled with ADR and ICT, thus lowering possible barriers facing consumers when enforcing their rights. In addition, this book has evaluated the development of ODR in resolving small value disputes arising out of e-commerce transactions and the need for designing a regulatory model in order to realise its full potential in resolving consumers' disputes in the EU. A number of suggestions have been posed with the objective of increasing the visibility of efficient and fair ODR providers for resolving B2C disputes. This book concludes by proposing a regulation in the field of ODR setting legal standards and limits to mandatory ODR. However, before such measure is effectively implemented, it would first require further research to outline clearly the various legal standards that certified ODR providers should comply with.

This proposal will benefit from an EU-wide consultation to all ODR stakeholders through a green paper. The blueprint of the new regulation will be mainly composed of the procedural provisions set in the two EC Recommendations (98/257/CE and 2001/310/EC), the Mediation Directive (2008/52/EC) and industry best practices. The regulation will create a panEuropean trustmark which will be granted to those ODR service providers who comply with its legal provisions. Compliance will be monitored by co-operation between national and regional authorities through the European Consumer Centres (ECC). The ECC and online business contracts would refer national and cross-border disputes to accredited ODR providers. The regulation will encourage the use of consensual ODR processes as a previous step to the adjudicative processes for all accredited ODR providers. On the one hand, settlements will be directly enforceable in the courts of all Member States by 
the application of the Mediation Directive. On the other hand, decisions emanating from adjudicative and accredited ODR bodies will also be directly enforceable in the courts through an expeditious online process. However, the latter decisions will not be immediately binding because they will be treated in the same manner as judicial decisions from a first instance court, ie decisions could still be reversed by the competent court. At the EU level, small value disputes, including domestic or national disputes could be appealed by consumers through the European Small Claims Procedure, which could follow some of the ODR procedural features of the Uniform Domain Names Dispute Resolution Policy, such as online submissions, written processes, standardised forms, publicity of decisions etc. Judicial review of ODR decisions will legitimate and monitor accredited ODR services and it will also contribute towards the establishment of uniform procedural and substantive legal standards in the field of ODR. In other words, the interpretation of the procedural and substantive provisions will be carried out by both ODR providers and the public courts. Therefore, this proposal suggests a two-step process, beginning with mandatory ODR where most disputes are expected to be resolved, preferably by using consensual processes and escalating, if necessary, to a judicial online process.

\section{Findings}

Chapter 1 considered consumer protection and access to justice from a European perspective. This chapter has shown that public enforcement mechanisms are not sufficient to enforce consumers' rights and thus alternative methods such as ODR are necessary to give appropriate access to justice for consumers. The chapter first considered the European consumer protection policy, analysing what rights are applicable to consumers when they participate in e-commerce. Consumers must be aware of the fact that they have more rights when buying online than when going to the local shops. Subsequently, this chapter analysed how consumers can enforce these rights in courts. Consumer accessibility to the courts was examined within the EU through the small claims procedures in Ireland, Spain and the UK, where consumers pursue damages individually, testing how successful these procedures were in resolving B2C disputes. Particular attention was given to those processes that were complemented with ICT, eg the Online Small Claims Procedure in Ireland, which naturally seemed more suitable for dealing with online disputes; yet, these processes may encounter difficulties in resolving crossborder disputes.

This chapter also addressed how conflicts of laws are resolved. The Brussels Regulation and the Rome Regulation were contrasted with US case law on consumer choice of law and forum selection. Generally, the tendency in the EU is to recognise consumers' habitual residence as the competent forum and consumers' domestic law as the applicable law (ie the country of destination approach), even when there is a contractual clause stating otherwise. 
Consequently, if businesses are being sued in the consumers' forum they may be inclined to use post-dispute ODR. Conversely, in the US, the approach is the opposite, where there is a preference to favour the country of origin approach and to uphold pre-dispute contractual clauses. Nevertheless, none of the above approaches seems to strike the right balance between the parties. Furthermore, in most cases recourse to the courts may neither be feasible nor desirable for one or both parties. Hence, public and private ODR initiatives may be a solution for many $\mathrm{B} 2 \mathrm{C}$ disputes.

Although it is often assumed that one of the major advantages of ODR is that it avoids jurisdictional issues, it must be noted that ODR cannot always rely on the co-operation of disputants; therefore, there is an urgent need to harmonise the law in relation to applicable law and forum. Consumer protection for e-commerce is meaningless unless effective enforcement mechanisms are provided. Finally, Chapter 1 discussed judicial enforcement of consumers' rights under EU legislation. It also looked at different options to enforce consumers' rights, individually and collectively, ie class actions and government intervention. The general conclusion of this chapter was that the existing mechanisms of the courts are not adequate to resolve the vast majority of civil (as opposed to criminal) B2C disputes arising from e-commerce; thus, in order to deliver adequate access to justice, new, effective and inexpensive mechanisms supported by information technology are clearly needed.

Chapter 2 considered ODR when used as a consumer redress strategy. This chapter was divided into two principal sections, of which the first section gave a general introduction to ODR and the second section evaluated the main challenges for the development of ODR. The first section started by defining ODR and related concepts, such as ADR and online ADR, and looked at the recent development of ODR. The main advantages and disadvantages of ODR for resolving consumer disputes were also discussed. The objective is to exploit the advantages and overcome the disadvantages with appropriate technological improvements and legal support. Although dispute avoidance mechanisms were not a major aspect of this research, various mechanisms were briefly examined, such as internal complaint procedures, escrows, online payment services, reputation systems and trustmarks. In conflict prevention, ODR offers added value to ADR as ODR technology could be used by online businesses to avoid complaints escalating to disputes.

Dispute avoidance includes consumer empowerment, which in the context of consumer protection is educating consumers about their rights, obligations, expectations and how to avoid disputes. It must provide mechanisms to ensure that online businesses recognise and comply with their obligations. Even when disputes arise, outsourced ODR providers should be used as the last resort to resolve those disputes which cannot be resolved at an early stage between the business and the consumer. This is well illustrated by eBay, whose in-house ODR process resolves more than 14 million disputes a year, while its previously preferred ODR provider, SquareTrade, resolved just over 
2 million disputes in its lifetime. ODR providers should assist online businesses in building effective internal complaint procedures, and disputes should only be outsourced to external ODR providers in the most difficult cases to ensure impartiality and create trust among the parties. In order to promote dispute avoidance within the EU, it is suggested that the proposed regulation in the field of ODR could mandate Member States to require that online businesses have effective internal redress mechanisms. This legal provision will also encourage online businesses to be attached to external ODR providers.

The focus of this book was on the major dispute resolution methods used to deal with consumer disputes. For ODR it was referred to more or less informal dispute resolution schemes that are provided by independent entities, rather than by one of the disputants. The most widespread ODR methods are automated negotiation, assisted negotiation, mediation, arbitration and small claims court procedures. Ultimately, this part looked at the most significant European initiatives to promote the use of consumer ODR, namely the Consumer Complaint Form, ECODIR and ECC-NET.

The second section of this chapter evaluated the challenges that hinder the growth of ODR. Existing surveys on ODR sites showed that many ODR providers have ceased operating, and many others have ceased updating their websites. Among the difficulties faced by the ODR industry in the B2C field, this chapter addressed how existing ODR projects are being funded and the risks to impartiality that these sources of funding may cause. This may be overcome using public funding, transparent private funding and appropriate monitoring. Another major identified challenge to the growth of ODR is attracting parties to utilise these services. It has been noted that two of the most successful ODR providers to date (UDRP providers and SquareTrade) appeared in a market where disputes were referred to them and where the market administrator (ICANN and eBay) wanted to avoid being sued by disputants, who in most cases could not access an offline dispute resolution mechanism for a reasonable cost. Also CyberSettle targeted specific markets, such as insurance companies and dispute suppliers, ie the City of New York and the American Arbitration Association. More research needs to be carried out on how to make ODR more appealing to consumers and businesses, encouraging them to resolve their disputes online in a fast, fair and efficient manner. It appears that public bodies, trustmarks and businesses and consumer intermediaries, such as the legal profession, consumer bodies and business associations could increase the awareness of ODR.

Due process requirements are at stake when a power imbalance exists with B2C disputants. In this regard, key procedural issues were discussed, including the need for impartiality, the selection of neutral third parties, legal representation and supervising ODR providers. However, disputants must accept the compromise that in order to develop a greater access to justice through ODR, it may be necessary to reduce some degree of procedural quality in exchange for faster, less expensive and more effective ODR processes. 
Judicial enforcement and self-enforcement mechanisms were also considered as an important element in the success of ODR services. Lastly, in the dispute resolution context, technology is not a neutral element because it can affect the way people interact. This chapter concluded by evaluating the role of technology in ODR processes by looking at the following matters: first, the strengths and weaknesses of the different ICT techniques; secondly, the security issues which are particularly relevant when large amounts of money are involved; and, thirdly, the potential of the fourth party in assisting individuals to resolve their disputes.

Chapter 3 dealt with consumer adjudicative procedures supported by ICT, ie online judicial processes and online arbitration. With regard to judicial processes this chapter examined some examples of how national judicial authorities are incorporating ICT into their processes, namely the Small Claims Court Online in Ireland, Money Claim Online in England and the eCourt initiative in Australia. The focus of this section, however, was on the Regulation Establishing a European Small Claims Procedure (ESCP). Some drawbacks were pointed out as possible constraints that could hinder its full potential. First, the ESCP excludes domestic disputes, even those that may require cross-border enforcement. In order to avoid this, judges should be given the discretion to switch from the domestic procedure to the ESCP when they deem it appropriate. Secondly, the economic limit may be too low as the ESCP may not be cost-effective for many claims below $€ 2000$, especially when translations and legal fees may end up being paid for by one of the parties. It has been suggested that a monetary threshold of $€ 5000$ would be more appropriate. For low value disputes, more informal processes, such as consensual ODR and automated processes should be robustly encouraged prior to turning to the ESCP.

It is regrettable that the ESCP Regulation missed the opportunity to include a provision that directly encourages the courts to search for a compromise between the parties whenever this is possible. The pilot project in Manchester and the registrar in Ireland have shown that an in-house civil servant, with the role of encouraging agreements between the parties before the hearing, is an effective strategy for resolving disputes without the need for the judge's intervention. A similar approach with the ESCP would be beneficial. The difficulties in dealing with possible language barriers must also be considered. This will be a significant challenge because, unlike the UDRP, an ODR system that deals with specific complaints, the ESCP deals with a variety of civil and commercial disputes. The best way of overcoming this difficulty is by devising ODR technology that exploits the use of a standardised process with agreed translations, creating a networking system among the European national courts.

The objective of the ESCP is the creation of a cost efficient judicial procedure applicable to small value claims in cross-border disputes. This objective can be best achieved by using a written procedure, assisted by electronic forms, such as e-mails and video-conferencing as foreseen by the ESCP. The 
regulation allows the use of new technologies in transferring information and evidence between the courts of the different Member States. Perhaps in time, within the EU, where we are concerned about the fairness of private procedures (eg restrictions in consumer arbitration) the ESCP may contribute to increasing trust in adjudicative ODR processes.

It is to be expected that, in due course, electronic communications will be utilised in every appropriate aspect of the judicial procedure to assist in the resolution of online as well as offline B2C disputes. During this evolutionary process it would be advisable neither to impose the use of technology nor to discourage it, taking into consideration all types of individuals and their needs. Users without internet access or with a limited knowledge of ICT should not be discriminated against by being forced into using unfamiliar electronic means. But neither should the law constrain those courts or litigants who feel confident in using ICT tools and could then benefit from them. Hence, it is regretted that the ESCP has missed the opportunity to introduce the use of ICT into the legal procedure in a way that makes it more efficient and accessible to the litigants. Its use should, however, be mandatory only for the courts and not for litigants without ICT skills, as it could create new barriers in access to justice.

With regard to online arbitration, this chapter first reviewed the regulation of arbitral procedures and what the legal implications of complementing arbitration with the use of ICT are. It appears that online arbitration is possible under the existing law but the lack of specific regulation and accreditation bodies creates some legal uncertainties, which are likely to be challenged in court when parties require the enforcement of online arbitral decisions. A national arbitration programme was also examined, namely the institutionalised Spanish arbitration system, which is currently moving towards the online sphere with the implementation of the new Regulation (RD 231/2008) that specifically regulates online arbitration. Lastly, but not least, this chapter assessed in detail ICANN's dispute resolution scheme: the UDRP.

The success of the UDRP in resolving domain name disputes through online 'arbitration' reveals possibilities for ODR to work through international organisations. International co-operation is not just useful but in many cases it is necessary. The UDRP is a good model for ODR providers who target $\mathrm{B} 2 \mathrm{C}$ disputes because, unlike traditional arbitration, it is not intended to supplant court proceedings but merely to afford an additional forum for dispute resolution, allowing parties to commence legal actions at any stage. The success of the UDRP rests on getting disputants to use the UDRP and its efficient self-enforcement mechanism. Parties do not sign an arbitration agreement; they submit to the procedure separately: complainants by filing their complaints and respondents by registering their domain names. Nonetheless, the UDRP is far from perfect. This section proposed a number of changes for the UDRP policy and rules in order to attain not only an efficient but also a fairer ODR process. To that end, it would be necessary to increase time limits and to clarify those issues which have provoked 
conflicting interpretations, such as the burden of proof, the use of parody websites and the meaning of the common law trade marks. In addition, it was suggested that greater 'uniformity' within the UDRP could be achieved by the inclusion of an appeal system. This chapter addressed how this scheme might be adapted to resolve consumer disputes arising from e-commerce. Finally, the chapter concluded by making some recommendations as to which ODR procedure, judicial or arbitral, is more suitable for each type of online consumer dispute, suggesting that the success of adjudicative ODR processes depends upon their self-enforcement mechanisms and mandatory participation.

Chapter 4 discussed online mediation for consumers. The potential for online mediation lies in the fact that it reduces barriers in accessing justice by avoiding conflicts of laws, thus reducing costs and time. In mediation both parties are often more satisfied with the outcome and consider the process fairer than adjudicative processes. This chapter examined how online mediation is presently used to resolve consumer disputes and what are the main hindrances to its expansion. It appeared that the main challenge to mediation is attracting users. Indeed, the best indicator for success is the parties' willingness to enter into mediation. SquareTrade and PayPal achieved this by using incentives in the form of trustmarks and managing eBay feedback reviews. This persuaded many eBay users to participate in the SquareTrade online mediation scheme. Furthermore, SquareTrade offered other incentives to its participants. First, it provided a fast and efficient ODR service, which resolved over 80 per cent of disputes in an average of two weeks. Secondly, its services were free (assisted negotiation) or of low costs (online mediation). Thirdly, parties could escalate to more formal dispute resolution services, ie starting with negotiation, moving to mediation, neutral third party evaluation (by the online mediator) and leaving open the option even to go to more formal dispute resolution services including, ultimately, the courts.

The use of offline mediation needs to be more widespread before online mediation can become of greater support. If mediation is to have a real impact in our society, education programmes and the promotion of its use need to be pursued as a matter of public policy. Consequently, mediation is being regulated at regional level and also promoted by national courts. The Directive on Mediation, which is due to be fully implemented by May 2011, assures the direct recognition and enforcement of cross-border settlements but not of mediation clauses. Mandatory mediation appears to be banned by the Unfair Contract Terms Directive, the ADR Recommendation and the Proposed Directive on Consumer Rights, as mandatory ADR is considered to be a procedure that denies or delays access to justice, currently understood as access to a legal procedure. However, does the same reasoning apply when access to the court is not economically feasible or simply less suitable?

In the UK, the Woolf reforms envisioned a new legal landscape where disputants would be encouraged to start a legal action only as a last resort, after using other, more appropriate means, ie ADR. This approach has not 
been fully implemented in the UK and it also remains a challenge in many other EU jurisdictions. ${ }^{3}$ Hence, in today's society the right to access to justice must be construed as the right to access the most appropriate dispute redress mechanism for each controversy. It is of paramount importance to persuade the legal profession of this interpretation. The English courts have an underused discretion to refer cases to ADR as well as imposing legal costs when a suitable ADR forum is unreasonably rejected by one of the parties. The same rules could allow judges to encourage the use of ODR.

It is suggested that mandatory online mediation and, more generally, consensual ODR methods, such as online conciliation, have the potential to increase consumer access to justice. This could be achieved with greater public awareness, increasing public funds, trained mediators and greater incentives for disputants to participate in online mediation. However, mandatory online mediation should have limits when employed for resolving B2C disputes. For instance, it should be free or provided at a low cost. Participants should be given the option to opt out after one meeting or information session, at least when a small claims process is available. Conversely, if clear limits are not defined, mandatory mediation could create new barriers for consumer redress by encouraging them to settle for less than that recognised by their legal rights. In order to avoid this, consumers should be empowered by being clearly informed that they cannot be pressured to settle, ie they still have the right to refuse an offer to settle. Finally, it was observed that the existing regulation in the EU allows for the use of online mediation, but this allowance is not the same as actively promoting its use. This led on to Chapter 5, which explored a possible strategy for the executive and legislature to promote ODR.

Chapter 5 evaluated the critical question of whether a legal framework is needed to enhance consumer ODR. This chapter proposed that a legal initiative within the EU is required in order to close the existing gap between the need for effective dispute resolution mechanisms for e-commerce and their actual use. At present, the regulatory strategy is being developed through self-regulation rather than legislative intervention. Yet some aspects, such as the enforceability of ODR clauses in electronic contracts and the enforceability of awards can only be achieved through legislation and cannot be left to self-regulatory initiatives. Therefore, it is necessary to establish clear legal standards in the ODR field.

In addition, Annex I of this book attempts to encapsulate some of the main ideas of this chapter in the form of a proposal for a regulation in the field of ODR. However, the writing of an optimal ODR regulatory framework is beyond the scope and ambition of this book, which has aimed to discuss the existing legal barriers, challenges and deficiencies that ODR faces in the EU. Hence, the blueprint contained in Annex I is simply a model upon which discussion could take place at EU level in order to evaluate the need for regulating and accrediting ODR services.

There is an increasing tendency towards private dispute resolution, mainly 
in those countries such as the US where pre-dispute mandatory arbitration is allowed under the national law. By contrast, the EU does not sanction that private dispute resolution systems should decrease the level of consumer protection in the internal market. Chapter 5 proposed a co-ordinated action within the EU to ensure that private ODR services meet the required legal standards. This chapter submits that a European legal initiative, particularly a regulation, would contribute towards developing the ODR market within the EU, stopping inconsistent standards and regulations within the EU and facilitating the expansion of the internal market. The regulation proposed would create a pan-European trustmark that would accredit those ODR providers and online businesses who meet the legal standards set out in the regulation. This strategy would ease the establishment of fair and efficient ODR services that comply with quality standards within the EU. Accredited ODR providers may be included in electronic contracts by online businesses as an initial mandatory dispute resolution stage, before going to court. Decisions and settlements reached through the accredited programmes would be enforced in the courts.

Given the cross-border nature of e-commerce, in order to develop an efficient ODR legal framework, it must be agreed at an international level with the collaboration of all the e-commerce stakeholders (governments, industry and the general public). It is only a matter of time before courts and legislatures will develop them. It will be, however, a step further to initiate the harmonisation of minimum legal standards for ODR within the EU. An EC regulation on minimum standards in the field of ODR will facilitate the EU to speak with one voice in the global debate on how to incorporate ODR into international law, wherein lies its greatest potential.

\section{Tiered ODR systems}

Certainly, there is not a single ODR method that could be suitable for all consumer disputes. ODR methods should be tailored to the problem, in particular when the ODR process is highly automated. Indeed, the success of automated processes depends on the nature of the dispute, the accuracy of the information provided and the capability of the software or the fourth party utilised in assessing the dispute.

Consensual processes avoid conflicts of laws, so parties can focus on their respective interests, rather than their rights under the law. The main challenge of these consensual processes is that both parties need to be motivated in resolving their dispute. Online mediation may be suitable in low context cultures, such as in e-commerce, if parties are motivated to resolve the dispute and when the imbalance of power between the parties is not too great, ie when consumers are dealing with small and medium sized enterprises. In other cases, adjudicative processes may be more apt for correcting possible abuses of power by online businesses.

Adjudicative procedures may also be useful methods for resolving online 
consumer disputes. Online arbitration has advantages: it is custom-built for the dispute at hand, it is conclusive and it may replace the jurisdiction of the courts. Online arbitration may be non-binding or appealable. The success of the UDRP providers derives from three aspects: (i) it deals only with blatant disputes, which are abusive registrations made in bad faith in order to take advantage of the reputation of existing trademarks; (ii) its referral is included through a mandatory contractual clause; and (iii) it has incorporated a self-enforcement mechanism. Online judicial processes are particularly appropriate for dealing with disputes where parties cannot reach consensus through any other ODR method, when a large disparity of bargaining power exists between the parties and when it is necessary to review decisions emanating from private ODR service providers.

Most online B2C disputes may be dealt with through a tiered system: the first step may be a company's internal customer service; the second step, consensual ODR: ie assisted negotiation, automated negotiation and online mediation; the third step, online arbitration; and the final step, an online judicial process. The final step should be reached by only a very small percentage of disputes. Multi-step dispute resolution processes should be considered as a matter of public policy and within the concept of proper access to justice. The law should therefore emphasise the parties' obligation to use consensual processes during the initial stage of their dispute in order to promote less formal, less costly and more efficient dispute resolution methods.

\section{Future dynamics and recommendations for ODR}

This book cannot reach final conclusions in the ODR field, a field which is constantly evolving. Instead, I will attempt to predict how ODR might develop in the EU over the next few years (let us say 10 to 15 years). There will be an increase in institutionalised ODR processes, such as the Spanish online arbitration systems, the Money Claim Online in England and Online Small Claim procedure in Ireland. The ESCP could become the first judicial procedure incorporating ODR technology to deal with cross-border claims within the EU. The ESCP, however, may not be the best scheme to deal with low value claims, since parties without legal representation may find difficulties in filing claims appropriately and bringing sufficient evidence forward. This is a challenge that judges and arbitrators will face that could potentially limit the effectiveness of the redress of consumer complaints by adjudicative processes. In the following years the resolution of disputes will be first attempted by consensual processes, regardless of the amounts of money involved. The ESCP, for instance, will incorporate in-house civil servants acting as online mediators to filter those disputes which may be ripe for compromise. When consensual processes were not attempted, the courts will start to consider systematically whether these disputes should be mediated. Hence, mediation will become part of the litigation system. Accordingly, legal professionals will advise on the appropriateness of each dispute resolution method. 
The future of ODR is undeniable. According to Katsh, ODR might not have taken over the world the first time around, but technology has reached the point where it simply does not make sense not to use the internet to handle disputes. ${ }^{4}$ There is a constant increase in the use of ADR, transnational e-commerce and online social networking. Evans et al observe that:

Many young people today keep in touch with one another through e-mail or instant messaging, rather than by telephone communications. It seems likely, therefore, that digital online communications systems will soon revolutionize the way people resolve their conflicts [...] The principal users of these futuristic ODR systems will likely be new generations of computer-literate youths. Operating beyond the constraints of either territorial or technical limits, these advanced ODR users could cross territorial, language, and cultural barriers. ${ }^{5}$

ODR might not always provide a perfect solution to resolve all $\mathrm{B} 2 \mathrm{C}$ disputes but it could certainly deliver a satisfactory resolution to many disputes, including those that arise out of the B2C sphere or even outside the commercial and online realm, such as citizen to government (C2G) disputes. The need for ODR increases when parties face certain circumstances; for instance, where parties have limited economic resources, where there is a vast geographic distance between the parties or where there is urgency in the resolution of disputes. It is also an ideal process for isolated B2C transactions where parties prefer less formal legal proceedings and are content to avoid face-to-face interactions.

This book suggests that the time is right to expand and regulate those ODR providers who are ready to provide fair and effective services. I believe that the ODR of the future will cater for specific disputes, will mainly be publicly operated and monitored, it will be compulsory, largely automated and it will be able to provide many of the functions of a human neutral party. Such a system would have to be supported by artificial intelligence. To date, a high level of automation has only been achieved with low comprehension that can only deliver information, eg SquareTrade assisted negotiation, or manage one single issue, eg CyberSettle blind bidding. Although ODR systems with a higher content of artificial intelligence already exist, eg SmartSettle, they have been proven not to be consumer-friendly as yet. Clearly, with the appropriate regulation it is merely a question of time before ODR services are improved, becoming the mainstream method for resolving online $\mathrm{B} 2 \mathrm{C}$ disputes.

\section{Notes}

1 Sir Brian Neill QC (former Lord Justice of Appeal and past President of the Civil Mediation Council) 5th International Forum on ODR, University of Liverpool (19-20 April 2007). 
224 Online Dispute Resolution for Consumers in the European Union

2 An early version of some of the ideas of this conclusion have been published in Cortés (2010).

3 Phillips LCJ (2008b) 5.49, 14.5.

4 Katsh \& Wing (2006) 26.

5 Evans, Wettman, Shadoff \& Birdwell (2006) 427. 


\section{Appendix}

\section{Proposal for a Regulation establishing an Accreditation Scheme for Online Dispute Resolution Services}

The following text is a blueprint that encapsulates some of the best practices while taking an EU perspective for the regulation and accreditation of online dispute resolution (ODR) service providers. It was suggested in Chapter 5 that, before this proposal is implemented, a green paper should be first issued with the objective of consulting the views of all stakeholders. The consultation shall enquire about the need for Community action in the accreditation of ODR service providers.

\section{Article 1}

\section{Objective}

The purpose of the Regulation is to accredit fair and efficient ODR service providers in order to promote the use of ODR for the resolution of all types of disputes, but in particular for the resolution of cross-border business to consumer (B2C) disputes arising out of e-commerce in the internal market. The accreditation of ODR service providers shall require that service providers comply and promote the application of the relevant consumer laws.

\section{Article 2}

\section{Definitions}

a) ODR service providers for the purpose of this Regulation shall be those whose processes take place mainly online with the use of ad hoc information and communication technology (ICT) tools.

b) Accredited ODR service providers shall be those ODR service providers who comply with this Regulation and that have been accredited by the EC Commission and the European Consumer Centre Network (ECC-Net). These providers shall display, if they decide to do so, a pan-European logo named EU-Confidence.

c) For an accredited ODR the process shall be considered as the entire course of the ODR proceeding, which shall be an online process from 


\section{Appendix}

the start to the end promoting, prior to the adjudicative resolution, a consensual agreement. This is without prejudice to the use off-line communications exceptionally whenever this is deemed necessary by the ODR service provider or the neutral third party.

d) For an ODR platform the website interface hosting the process shall be considered as that of an accredited ODR service provider.

\section{Article 3}

\section{Attentiveness}

Disputes shall be dealt within a reasonable time period reflecting the needs of e-commerce. Hereby, disputes shall be resolved as expeditiously as possible, and in any event disputes shall be resolved within two months after the commencement of the ODR process, unless all parties and the ODR service provider agree to an extension, which shall not be longer than an additional two months.

\section{Article 4}

\section{Language}

The language of the procedure shall be the same language of the transaction that originated the dispute. Parties may agree to a different language as long as this is accepted by the neutral third party and the accredited ODR service provider. Accredited service providers may however have a limited number of working languages. When their services are thus offered to an online business that makes transactions in more languages than those offered by the accredited ODR service provider, the trustmark logo must be accompanied by the expression of 'limited coverage'.

\section{Article 5}

\section{Submission to the online process}

a) If a consumer informs a business that is adhered to an accredited ODR provider that he or she rejects the remedy proposed by the company's internal customer complaints service and wishes to submit the dispute to the accredited ODR service provider, the business must co-operate fully in the proceedings and comply with the result, even when the decision may be appealable by the consumer.

b) Accredited ODR service providers shall admit collective claims. 


\section{Article 6}

\section{Claimants}

Consumers and businesses shall be able to initiate claims in online processes managed by accredited ODR service providers. But businesses shall not be able to lodge claims against consumers, only against other businesses.

\section{Article 7}

\section{Appeals}

a) Parties may appeal a decision from the accredited ODR service provider, except in B2C disputes where only consumer-claimants shall be permitted to appeal. The appeal shall be made to the competent court according to the Brussels (I) Regulation and the applicable law shall be that stated in accordance to the Rome (I) Regulation. ${ }^{1}$ When the appeal is $€ 5000$ or below and has cross-border elements, ie when one of the parties is located in a different Member State, the claim shall be processed according to the European Small Claims Procedure (ESCP). ${ }^{2}$

b) The ESCP is hereby amended, first, by increasing the economic limit from $€ 2000$ up to $€ 5000$ and, secondly, by removing the right of the claimant to request the legal costs for engaging in litigation when the award is not more favourable than the decision delivered by the accredited ODR service provider.

c) The European Commission will develop a pan-European website interface that will be used by all the national courts when resolving online appeals. The new interface shall allow litigants to participate in a fully online process obviating the need for travelling.

\section{Article 8}

\section{Binding nature of the ODR process}

Businesses shall not compel consumers to agree to the use of binding ODR processes prior to the materialisation of a dispute, except when the business has referred all unresolved complaints to an accredited ODR service provider. In the latter event, pre-dispute agreements shall be upheld if they were clearly disclosed before the transaction was completed. The final decision of the accredited ODR service provider shall be binding on both parties, except when one party appeals the decision.

\section{Article 9}

\section{Selection of neutral third parties and technology}

Accredited ODR service providers must be capable of selecting the appropriate neutral third party and adequate ICT tools for the resolution of each 
individual dispute, taking into account the scope and knowledge of the parties. The procedure of how neutral third parties are selected shall be transparent and shall be fully disclosed to the disputants.

\section{Article 10}

\section{Costs}

The costs of ODR services shall be kept as low as possible, particularly for consumers who must be able to access these services free of charge or at a low cost. In any event the cost of acceding to an accredited ODR service provider should be proportionate to the dispute and lower for both parties than an offline process. Accredited ODR service providers should be partly funded, whenever this is appropriate and possible, by public entities with the aim of enhancing consumer trust.

\section{Article 11}

\section{Neutral third parties}

a) Dispute resolution professionals shall have sufficient skills and training to fulfil their function, but they will not need to be licensed legal practitioners. However, accredited ODR service providers must take measures to ensure legal experts are available for consultation when specialised knowledge on the interpretation and application of laws and regulations is required in the process of providing ODR services.

b) Neutral third parties shall be independent, without any type of personal or professional relationship with any of the parties. Accordingly, accredited ODR service providers shall incorporate procedures for recusing providers and neutral third parties who are interested parties to a dispute or have any other causes which may harm the fair use of accredited ODR.

c) The neutral third party, whenever this is feasible, shall not be linked to successful case settlement or to a recommendation or decision in favour of any particular party. When dealing with repeated players accredited ODR service providers shall provide a mechanism to grant greater levels of transparency and impartiality, which may, for instance, allow an additional opportunity to recuse neutral third parties by nonrepeated-players.

d) Information about the credentials and experience of neutral third parties shall be made available to the parties. This information shall include the number of cases received and resolved (with anonymous caseload history when appropriate). 
Article 12

\section{Consensual processes and representation}

Accredited ODR bodies shall play an active role in encouraging the use of consensual methods for resolving disputes, thus reducing the need for legal representation. However, consensual processes should not be imposed against the will of the parties. Parties shall always retain their right to be represented or assisted by a third party at all stages of the procedure. Notwithstanding, whenever parties are legally represented they shall be asked to disclose their representation.

\section{Article 13}

\section{Accessibility}

a) The technology used by accredited ODR shall strive to keep user interfaces as simple and intuitive as possible. The European Commission and the ECC-Net shall provide some guidelines and criteria for ensuring accessibility.

b) Parties shall be able to download and print all the information contained in the ODR platform, including information related to their individual cases.

c) The ODR platform should be available to all parties in order to check their own case information 24 hours a day, with only the exception of scheduled downtime.

\section{Article 14}

\section{Notifications}

a) Accredited ODR service providers shall make available to the parties an appropriate and secure method for giving notifications. Without prejudice to the use other techniques that ensure the authenticity of the communications and the identity of the parties, the use of the electronic signature shall guarantee the communications and the identity of all parties.

b) Notifications shall be sent to the electronic destination chosen by the parties. They shall be considered to have legal effect the day after the party had accessed the notification. Nonetheless, if one party had not accessed the notification 10 days after the notification was sent, then the party shall be considered notified.

c) Accredited ODR processes shall encourage respectful online communications. 


\section{Article 15}

\section{Place of resolution}

The place where the ODR process occurs is where the physical ODR platform [or secretariat] is located. Hence, accredited ODR service providers shall disclose the physical location of their platforms, including the postal address and contact information, such as e-mail addresses of the ODR service providers and telephone numbers.

\section{Article 16}

\section{Privacy and confidentiality}

a) All the information contained and distributed shall observe all the data protection law and the confidentiality requirements established by European law.

b) The ODR platform shall maintain a high level of security, such as Secure Sockets Layer and cryptographic protocols, hence providing authentication procedures for access to cases files and other data.

\section{Article 17}

\section{User information}

The following information shall be clearly displayed by all accredited ODR service providers:

a) the identities and affiliations of the ODR service providers, their managers and interveners;

b) a description of the type of dispute which may be referred to as well as any existing restriction regarding territorial coverage and the effect of the decision;

c) whether the process is meant to be exclusively online, or both offline and online, and what it entails. Online processes shall disclose the system requirements (hardware and software) for using the ODR platform;

d) requirements that consumers must meet, such as the previous attempt to obtain redress through the business internal complaint system;

e) an explanation about what is a neutral mediator, arbitrator, neutral third party and other terms to which parties may be unfamiliar;

f) information about the credentials and experience of neutral third parties;

g) clear and unambiguous information about the processes involved and how users can best manage their cases;

h) information on time limitations and the suspension of prescription periods when applicable;

i) indication of fees and costs to be borne by the parties; 
j) where mediation and arbitration are offered, simple and clear information for parties about the differences between the services shall be available;

k) rules that serve as the basis for the decision, including legal provisions, considerations of equity and code of conduct;

1) the legal force of the decision taken, that is, whether and when an accredited ODR service provider would issue binding or non-binding outcomes;

m) whether the decisions are made publicly available;

n) when online arbitration is used, parties shall be informed how the arbitral award is delivered and how parties can enforce it;

o) parties are entitled to be informed of the decisions, its legal status, and the grounds of these within, unless otherwise agreed, two months after initiating the process.

\section{Article 18}

\section{Agreements and decisions}

a) Consumers shall be informed in clear and understandable language, before agreeing to a suggested settlement that they have the choice to agree or disagree with the suggested settlement.

b) Any decision or agreed settlement should be recorded on a durable medium.

\section{Article 19}

\section{Suspension of legal proceedings}

Where a lawsuit is pending between the parties to a civil dispute which may be settled by an accredited ODR service provider, the court in charge of the case, upon request of one of the parties, may decide that the legal proceeding shall be suspended for a period of not more than four months.

\section{Article 20}

\section{Submission of business reports}

a) Accredited ODR service providers shall prepare and submit to the ECCNet a business report, inventory list, balance sheet and expenditure statements for each business year within three months after the end of the business year.

b) The Business Report shall consist of information about the number and type of disputes being handled by the accredited ODR service provider, including the type of claims, any systematic problem arising from complaints, the number of disputes resulting in settlement or agreement and the average length of time for the resolution of disputes. 


\section{Article 21}

\section{Trustmark}

a) The EU-Confidence logo shall be given to all ODR service providers who are considered by the Commission and the ECC-Net to comply consistently with the present Regulation.

b) All online businesses that adhere to an accredited ODR body shall be permitted also to display the same logo as long as these businesses provide an internal complaint-handling system which is credible, works efficiently and is subject to independent monitoring or auditing by the ECC-Net.

\section{Article 22}

\section{Liability}

Accredited ODR providers shall be liable for damages caused to any person who relies on the trustmark as to the accuracy of the information therein represented; unless the ECC-Net recognises that the accredited ODR provider had not acted negligently. The European Commission and the ECC-Net shall issue guidelines regarding the limitation of liability for accredited ODR providers.

\section{Article 23}

\section{Feedback}

Accredited ODR service providers shall have a feedback system where users will post their satisfaction levels. Even though accredited ODR providers may decide on the publication of their feedback ratings, these shall form part of the annual report submitted to the ECC-Net.

\section{Article 24}

\section{Inspection}

If the ECC-Net considers that there is an accredited ODR body that does not comply with the Regulation, the ECC-Net shall remove the accreditation from the ODR service provider.

\section{Notes}

1 Regulation 593/2008 of the Parliament and the Council of 17 June 2008 on the Law Applicable to Contractual Obligations (Rome I) OJ L177 art 6; Regulation 44/2001 of 22 December on Jurisdiction and the Recognition and Enforcement of Judgments in Civil and Commercial Matters [2000] OJ L12 art 15.

2 Regulation (EC) 861/2007 of 11 July 2007 establishing a European Small Claims Procedure [2007] OJ L199/1. 


\section{References}

Abernethy, S. (2003) 'Building Large-Scale Online Dispute Resolution and Trustmark Systems' Proceedings of the UNECE Forum on ODR 2003 available at http://www.odr.info/unece2003.

Access to Justice Act 1999.

Ackerman, P. 'E-Commerce Law Update - UETA and UCITA' available at http:// www.peterackerman.com/article.html.

Advice Service Alliance (2007) 'Recent Developments in Alternative Dispute Resolution' (January 2007).

Alderman, R. (2007) 'The Future of Consumer Law in the United States - Hello Arbitration, Bye-bye Courts, So-long Consumer Protection' University of Houston Law Center No 2008-A-09.

Alfini, J. J. \& McCabe, C. G. (2001) 'Mediating in the Shadow of the Courts: A Survey of the Emerging Case Law' 54 Arkansas Law Review 171.

American Bar Association (2002) 'Addressing Disputes in Electronic Commerce: Final Recommendations and Report' 58 Business and Law 415.

American Bar Association Task Force on E-Commerce and ADR (2002) 'Recommended Best Practices for Online Dispute Resolution Service Providers'.

Andrews, S. (2005) 'OECD Workshop on Consumer Dispute Resolution and Redress in the Global Marketplace' Background Project (19 April 2005).

Anonymous authors (1990) 'Mandatory Mediation and Summary Jury Trial: Guidelines for Ensuring Fair and Effective Processes' 103 Harvard Law Review 1086.

Anonymous authors (2000) 'ADR, the Judiciary, and Justice: Coming to Terms with Alternatives' 113 Harvard Law Review 1851.

Arbitration Act 1954.

Arbitration Act 1996.

Arbitration Acts 1998.

Awoyemi, B. (2005) 'Zippo Is Dying, Should It Be Dead?: The Exercise of Personal Jurisdiction by U.S. Federal Courts Over Non-Domiciliary Defendants in Trademark Infringement Lawsuits Arising Out of Cyberspace' 9 Marquette Intellectual Property Law Review 62.

Bailey, C. \& Datnow, G. (2005) 'Mediation form the Advocate's Seat' New Law Journal (13 May 2005) 729.

Balboni, P. (2009) Trustmarks in E-Commerce: The Value of Web Seals and the Liability of Their Providers (The Hague: Information Technology and Law Series, Cambridge University Press). 
Baldwin, J. (1997) Small Claims in the County Courts in England and Wales (Oxford: Clarendon Press).

Baldwin, J. (2003) 'Is There a Limit to the Expansion of Small Claims' 56 Current Legal Problems 317.

Barbee, M. (2007) 'Reasons for the Rising Popularity of Mediation' Newsletter, Mediation, International Bar Association Legal Practice Division (July 2007).

Barnett, J. (2007) 'Showing Resolution' 104(13) Law Society Gazette 13.

Barrett, M. (2007) 'Domain Names, Trademarks and the First Amendment: Searching for Meaningful Boundaries’ 39 Connecticut Law Review 1033.

Barthel, T. (2008) 'Ethical Perspectives in Mediation' available at http://www. mediation.com.

Bates, D. (2004) 'A Consumer's Dream or Pandora's Box: Is Arbitration a Viable Option for Cross-Border Consumer Disputes' 27 Fordham International Law Journal 841.

Baumann, B. (2002) 'Electronic Dispute Resolution (EDR) and the Development of Internet Activities' 52 Syracuse Law Review 1227.

Bently, L. \& Sherman, B. (2006) 'The Impact of European Geographical Indications on National Rights in Member States' 96 Trademark Reporter 850.

Benyekhlef, K. \& Gélinas, F. (2005) 'Online Dispute Resolution' 10(2) Lex Electronica available at http://www.lex-electronica.org/articles/v10-2/Benyekhlef_ Gelinas.pdf.

Beses Miguel, M. D. (2004) 'Tutela Efectiva y Arbitraje de Consumo' 13 Revista Internauta de Práctica Jurídica.

BEUC Memorandum for the Finish Presidency (June 2006) BEUC/X/037/2006.

Blokland J. (2006) Opinion of the Committee of Civil Liberties, Justice and Home Affairs on the Draft Directive on Mediation (23 June 2006).

Bok, D. (1983) 'A Flawed System’ Harvard Magazine 38.

Bol, S. H. (2003) 'An Analysis of the Role of Different Players in E-Mediation: The (Legal) Implications' IAAIL Workshop Series - Second International Workshop 23 available at http://www.odrworkshop.info/papers2005/.

Bonnet, V., Boudaoud, K., Harms, J., Schultz, T., Kaufmann-Kholer, G. \& Langer, D. (2002) 'Electronic Communication Issues Related to Online Dispute Resolution Systems' Proc WWW2002 The Eleventh International World Wide Web Conference - Alternate Track CFP: Web Engineering, Honolulu, Hawaii Conference (7-11 May 2002).

Bonisteel, S. (2001) 'Arbitration Firm Quits Domain Name Business' Newsbytes News Network (3 December 2001) available at http://findarticles.com/p/articles/ mi_m0NEW/is_2001_Dec_3/ai_80510820.

Bordone, R. (1998) 'Electronic Online Dispute Resolution: A System Approach Potential, Problems, and a Proposal' 3 Harvard Negotiation Law Review 175.

Brady, A. (2008) 'Small Claims, Big Impact' Law Society Gazette (24 April 2008).

Braeutigam, A. M. (2006) 'What I Hear You Writing Is . . Issues in ODR: Building Trust and Rapport in the Text-Based Environment' 38 University of Toledo Law Review 101.

Brannan, J. et al. (1999) Civil Procedure Rules (London: Blackstone Press Ltd).

Branthover, N. (2002) 'UDRP - A Success Story: A Rebuttal to the Analysis and Conclusions of Professor Mueller in 'Rough Justice' INTA Internet Committee.

Brittol, D. \& McGonegal, S. (2007) The Digital Economy Fact Book (Washington: The Progress and Freedom Foundation, 9th edn). 
Burger, W. E. (1977) 'Our Vicious Spiral’ 49 Judges Journal 22.

Burk, D. (1997) 'Jurisdiction in a World without Borders' 1 Virginia Journal of Law and Technology 1.

Burshtein, S. (2007) 'Domain Names at the Intersections of Free Speech and TradeMark Law on the Internet' 56 University of New Brunswick Law Journal 47.

Bygrave, L. A. (2002) 'Online Dispute Resolution - What it Means for Consumers' Domain Name Systems and Internet Governance Conference, Sydney (7 May 2002).

Byrne, J. \& Horton, R. (2007) 'Arbitration, the Courts and Computers' 12(1) Tottels Communications Law 8.

Caffey, A. (2005) Stay Out of Court! The Small Business Guide to Preventing Disputes and Avoiding Lawsuit Hell (Canada: Entrepreneur Press).

Calliess, G.-P. (2001) 'Lex Mercatoria: A Reflexive Law Guide To an Autonomous Legal System' 2(17) German Law Journal.

Calliess, G.-P. (2006) 'Online Dispute Resolution: Consumer Redress in a Global Market Place' 7(8) German Law Journal 647.

Campbell, J. \& Opie, T. (2002) 'Mandatory Mediation' available at http:// www.findlaw.com.au/article/6190.htm.

Carbone, M. (2001) 'Enforcing Agreements Made at Mediation' (December 2001) available at http://www.mediate.com.

Carter, R. L. (2002) 'Oh, Ye of Little (Good) Faith: Questions, Concerns and Commentary on Efforts to Regulate Participant Conduct in Mediations' Journal of Dispute Resolution 367.

Cassondra, J. (1997) 'The Scope of Mediation Immunity' 12 Obio State Journal on Dispute Resolution 629.

CEN/ISS (2009) Workshop Agreement on Standardization of Online Dispute Resolution Tools prCWA XXX (20 October 2009).

Chambre de Commerce et d'Industrie de Paris (2004) Response to the Proposal for a Directive of the European Parliament and of the Council on Certain Aspects of Mediation in Civil and Commercial Matters (22 October 2004).

Charter of Fundamental Rights of the European Union (7 December 2000) [2000] OJ 2000/C (COM(2000)130).

Chartered Institute of Arbitrators (2005) Response to the Proposal for a Directive of the European Parliament and of the Council on certain Aspects of Mediation in Civil and Commercial Matters (8 November 2005).

Citizens' Advice Bureaux (2005) 'Establishing a European Small Claims Procedure' (7 October 2005) available at http://www.citizensadvice.org.uk.

Civil Jurisdiction and Judgments Act 1991.

Civil Procedure Rules 2001.

Clarke, A., MR (2008) 'The Future of Mediation' Second Civil Mediation Council National Conference, Birmingham (8 May 2008).

Clarke, A. MR, (2009) 'Mediation - An Integral Part of Our Litigation Culture' Littleton Chambers Annual Mediation Evening, Gray's Inn (8 June 2009).

Clark, E., Cho, E. \& Hoyle, A. (2003) 'Online Dispute Resolution: Present Realities, Pressing Problems and Future Prospects' 17 International Review of Law Computers and Technology 7.

Colón-Fung, I. (2007) 'Protecting the New Face of Entrepreneurship: Online Appropriate Dispute Resolution and International Consumer-to-Consumer Online Transactions' 12 Fordham Journal of Corporate and Financial Law 233. 
Communication of 15 April 1997 to the Parliament, the Council, the Economic and Social Committee and the Committee of the Regions: A European Initiative in Electronic Commerce (COM(1997) 157 final).

Communication of 30 March 1998 of the Commission on the Out-of-Court Settlement of Consumer Disputes (COM(1998) 198 final).

Communication of 4 April 2001 of the Commission on Widening Consumer Access to Alternative Dispute Resolution (COM(2001) 161 final).

Communication of 7 May 2002 from the Commission to the European Parliament on the Consumer Policy Strategy 2002-2006 (COM(2002) 208 final).

Communication of the Council on eEurope 2005: An Information Society for All $(\operatorname{COM}(2002) 263$ final).

Communication of the Commission on the Role of the eGovernment for Europe's Future, the Use of Information and Communication Technologies in Public Administrations Combined with Organisational Changes and New Skills (COM(2003) 567 final).

Communication of the Commission to the Council, European Parliament, the European Economic and Social Committee and the Committee of the Regions, i2010 - A European Information Society for Growth and Employment (COM(2005) 229 final).

Communication of the European Commission to the Council, European Parliament and the European Economic and Social Committee, EU Consumer Policy Strategy 2007-2013 (COM(2007) 99 final).

Communication from the Commission on Cross-Border Businesses to Consumer e-Commerce in the EU (COM(2009) 557 final).

Cona, F. A. (1997) 'Application of Online Systems in Alternative Dispute Resolution' 45 Buffalo Law Review 975.

Conley Tyler, M. (2006) 'Evaluating Recent Developments in Online Dispute Resolution' presentation on 22 March 2006 to the Fourth International Forum on ODR, Cairo.

Conley Tyler, M. \& Bornstein, J. (2006) 'Accreditation of On-line Dispute Resolution Practitioners' 23(3) Conflict Resolution Quarterly 383.

Conley Tyler, M. \& Bretherton, D. (2003) 'Seventy-six and Counting: An Analysis of ODR Sites' Report of Research Conducted for the Department of Justice, Victoria, Australia.

Conley Tyler, M. \& McPherson, M. (2006) 'Online Dispute Resolution and Family Disputes' 12(2) Journal of Family Studies 1.

Connolly, C. et al (2005) 'PKI Interoperability Models' Galexia Consulting available at http://www.galexia.com/public/research/articles/research_articles-art32.htm.

Consolidated Versions of the Treaty as Amended by the Treaty of Lisbon. Treaty on the Functioning of the European Union [2008] OJ C115/13.

Consumers International (2000) 'Disputes in Cyberspace, Online Dispute Resolution for Consumers in Cross-Border Disputes - an International Survey' (December 2000).

Consumers International (2001a) 'Disputes in Cyberspace 2001: Update of Online Dispute Resolution for Consumers in Cross-Border Disputes' (2001) available at http://www.consumersinternational.org/.

Consumers International (2001b) 'Online Dispute Resolution for Consumer in Cross-Border Disputes' (November 2001) available at http://www. consumersinternational.org. 
Consumer Protection Act 20/2007.

Consumer Privacy Guide (2001) 'What is TRUSTe and How Does it Work to Protect my Privacy' available at http://www.consumerprivacyguide.org/faq/ truste.shtml\#steps.

Consumer Strategy Group (2005) 'Make Consumers Count: A New Direction for Irish Consumers' (April 2005).

Convention on the Recognition and Enforcement of Foreign Arbitral Awards 1958.

Cooke, A. (2007) 'The Overriding Objective and the Halsey Guidelines: a Cautionary Tale' Newsletter, Mediation, International Bar Association Legal Practice Division, July 2007.

Cordera, M. (2001) 'E-Consumer Protection: A Comparative Analysis of EU and US Consumer Protection on the Internet' 27 Rutgers Computer and Technology Law Journal 231.

Corona Herrero, J. U. (2007) 'Una Nueva Administración: Modernidad y Tecnología' Administración y Nuevas Tecnologías, Diario LaLey (17 July 2007).

Cortés, J. P., (2008a) 'Does the Proposed European Procedure Enhance the Resolution of Small Claims?' 27(1) Civil Justice Quarterly 83-97.

Cortés, J. P., (2008b) 'The UDRP Reviewed: The Need for a 'Uniform' Policy' 14(6) Computer and Telecommunications Law Review 133-139.

Cortés, J. P., (2008c) 'An Analysis of the UDRP Experience: Is It Time for Reform?' 24(4) Computers Law and Security Report 349-359.

Cortés, J. P., (2008d) 'Can I Afford Not to Mediate? Mandatory Online Mediation for European Consumers: Legal Constraints and Policy Issues' 35(1) Rutgers Computer E Technology Law Journal 1-41.

Cortés, J. P., (2008e) 'Accredited Online Dispute Resolution Services: Creating European Legal Standards for Ensuring Fair and Effective Processes' 17(3) Information and Communications Technology Law 221-237.

Cortés, J. P., (2009) 'A European Perspective on Consumer Online Dispute Resolution' 15(4) Computer and Telecommunications Law Review 90-100.

Cortés, J. P., (2010) 'Developing Online Dispute Resolution for Consumers in the EU: A Proposal for the Regulation of Accredited Providers' 18 International Journal of Law and Information Technology forthcoming.

Courts Service News (2006) 'Online Small Claims is Here' 8(4) Courts Services (December 2006).

Craigforth (2006) 'Evaluation of the Small Claims Support Service Pilot at the Reading County Court' (DCA September 2006).

Craver, C. B. (2007) 'Conducting Electronic Negotiations' The Negotiator Magazine (June 2007).

Crawford, V. C. (2001) 'A Proposal to Use Alternative Dispute Resolution as a Foundation to Build an Independent Global Cyberlaw Jurisdiction Using Business to Consumer Transaction as a Model' 25 Hastings International and Comparative Law Review 383.

Davis, B. G. (2002) 'Building the Seamless Dispute Resolution Web: A Status Report on the American Bar Association Task Force on E-Commerce and Alternative Dispute Resolution' 8 Texas Wesleyan Law Review 529.

Davis, B. G. (2006) 'Symposium Enhancing Worldwide Understanding Through Online Dispute Resolution: Walking Along in the Mission' 38 University of Toledo Law Review 1. 
Deffains, B. \& Gabuthy, Y. (2005) 'Efficiency of Online Dispute Resolution: A Case of Study' 60 Communications and Strategies 205.

Department of Constitutional Affairs (UK) (2005) 'Partial Regulatory Impact Assessment on an EU Proposal for a Regulation creating a European Small Claims Procedure'.

Dickie, J. (1999) Internet and electronic commerce law in the European Union (Oxford: Hart Publications).

Dinwoodie, G. B. (2006) 'The International Intellectual Property Law System: New Actors, New Institutions, New Sources' 10 Marquette Intellectual Property Law Review 205.

Directive 1993/13/EC of 5 April on the Protection of Unfair Terms in Consumer Contracts [1993] OJ L95.

Directive 1997/7/EC of the Parliament and the Council of 20 May 1997 on the Protection of Consumers in Respect of Distance Contracts [1997] OJ L144.

Directive 1998/27/EC of 19 May on Injunctions for the Protection of Consumers' Interests [1998] OJ L166.

Directive 1998/84/EC on the Legal Protection of Electronic Pay Services Based on, or Consisting of, Conditional Access [1998] OJ L320.

Directive 1999/93/EC of the Parliament and the Council of 13 December 1999 on a Community Framework for Electronic Signatures [1999] OJ L13.

Directive 2000/31/EC of 8 June 2000 on Certain Legal Aspects of Information Society Services, in Particular Electronic Commerce, in the Internal Market [2000] OJ L178/1.

Directive 2002/65/EC of the Parliament and the Council of 23 September 2002 on Distance Marketing of Consumer Financial Services has Increased Consumers' Rights [2002] OJ L271/16.

Directive 2005/29/EC of the Parliament and Council of 11 May 2000 on Unfair Commercial Practices [2005] OJ L149/22.

Directive 2008/52/EC of the European Parliament and of the Council of 21 May 2008 on Certain Aspects of Mediation in Civil and Commercial Matters [2008] OJ L136/3.

District Court (Small Claims) Rules 1997.

District Court (Small Claims) (Amendment) Rules 1999.

District Court (Small Claims) (Amendment) Rules 2006.

Donahey, S. (2001) 'The UDRP - Fundamentally Fair, But Far From Perfect' 6 Electronic Commerce and Law Reports 937.

Donahey, S. (2002) 'Divergence in the UDRP and the Need for Appellate Review' 5 Journal of Internet Law 1.

Donahey, S. (2003) 'The UDRP Model Applied to Online Consumer Transactions' 20(5) Journal of International Arbitration 475.

Donnelly, M. \& White, F. (2005) 'The Distance Selling Directives - A Time for Review’ (2005) 56 Northern Ireland Law Quarterly 210.

Donnelly, M., White, F. \& Mulcahy, J. (2005) 'Consumers in the Electronic Marketplace: an examination of information based consumer protection in the context of distance selling over the Internet' University College Cork (December 2005).

Doyle, M., Ritters, K. \& Brooker, S. (2004) 'Seeking Resolution: The Availability and Usage of Consumer to Business Alternative Dispute Resolution in the United Kingdom' Department for Trade and Industry URN 03/1616 (January 2004).

Doyle, M. (2006) 'Evaluation of the Small Claims Mediation Service at Manchester 
County Court' (September 2006) available at http://www.dca.gov.uk/civil/adr/ index.htm.

Drahozal, C. \& Friel, R. (2002) 'Consumer Arbitration Clauses in the EU and the US' 28(2) North Carolina Journal of International Law and Commercial Regulation 357.

Duggan, A. (2006) 'Consumer Access to Justice in Common Law Countries: A Survey of the Issues from a Law and Economics Perspective' in Rickett, C. E. F. \& Telfer, T. G. W. (eds) International Perspectives on Consumers' Access to Justice (New York: Cambridge University Press).

E-Commerce Act 2000.

Edwards, S. (2007) 'Doing International Business Online for the Small and Medium Enterprise' in Kubota, T. Cyberlaw for Global E-Business: Finance, Payment, and Dispute Resolution (Hershey, PA: IGI Global).

Edwards, L. \& Theunissen, A. (2007) 'Creating Trust and Satisfaction Online: How Important Is ADR? The eBay Experience' 5 Web Journal of Current Legal Issues.

Edwards, L. \& Wilson, C. (2007) 'Redress and Alternative Dispute Resolution in EU Cross-Border E-Commerce Transactions' 21(3) International Review of Law, Computers and Technology 315.

Edwards, L. \& Wilson, C. (2007) 'Redress and Alternative Dispute Resolution in Cross-Border E-Commerce Transactions' DG Internal Policies of the Union, Policy Department Economic and Scientific Policy, Briefing Note (January 2007) (IP/A/ IMCO/IC/2006-206).

Eisen, J. (1998) 'Are We Ready for Mediation in Cyberspace' 4 Brigham Young University Law Review 1305.

Emos, W. \& Garoupa, N. (2006) 'US-Style Contingent Fees and UK-Style Conditional Fees: Agency Problems and Supply of Legal Services' 27(5) Managerial and Decision Economics 379.

Eurobarameter (2002) 'Public Opinion in Europe: Views on Business to Consumers Cross-Border Trade' (November 2002).

Eurobarameter (2004) 'Consumer Complaint Form. European Union Citizens and Access to Justice’ (October 2004).

Eurobarameter (2010) 'Attitudes Towards Cross-Border Sales and Consumers Protection’ (March 2010).

European Convention on Human Rights and Fundamental Freedoms 1950.

European Commission, SANCO, The Study Centre for Consumer Law, Centre for European Economic Law Katholieke Universiteit Leuven, Belgium, 'An Analysis and Evaluation of Alternative Means of Consumer Redress other than Redress through Ordinary Judicial Proceedings' Leuven (January 2007) (Leuven Report) available at http://ec.europa.eu/consumers/redress/reports_studies/index_ en.htm.

European Commission (Leuven Report) Irish National Report.

European Commission (Leuven Report) Spanish National Report.

European Commission (Leuven Report) United Kingdom National Report.

European Commission (Leuven Report) United States National Report.

European Consumer Centre Clearing House Dublin (2004) 'The Small Claims Court and its Use in Cross Border Dispute Resolution' (June 2004).

European Consumer Centre Ireland Report (2006) 'The European Marketplace: Consumer Complaints 2005, A Summary Analysis of Consumer Complaints Reported to the ECC-Net' (June 2006). 
European Consumer Centre Ireland Report (2008) 'The Development of Alternative Dispute Resolution (ADR) in Ireland, An Analysis of Complaints, Best Practices and Future Recommendations' (May 2008).

European Consumer Centres Network (2008) 'The European Online Marketplace, Consumer Complaints 2007' (May 2008).

European Consumer Centres Network (2009) 2008 Annual Report (August 2009).

Evans, F., Wettman, B., Shadoff, L. \& Birdwell, R. (2006) 'Proceeding: Enhancing Worldwide Understanding Through ODR: Designing Effective Protocols for Online Communications' 38 University of Toledo Law Review 423.

Fabri, M. \& Velicogna, M. (2007) 'Information and Communication Technology for Justice' Law and Society Conference, Berlin (July 2007).

Farah, Y. (2005) 'Critical Analysis of Online Dispute Resolutions: the Optimist, the Realist and the Bewildered' 11(4) Computer and Telecommunications Law Review 123.

Federal Rules of Civil Procedure 2007.

Federal Trade Commission and US Department of Commerce (2000) 'Summary of Public Workshop: Alternative Dispute Resolution for Consumers Transactions in the Borderless Online Marketplace' (November 2000).

Fisher, R., Ury, W. \& Patton, B. (1999) Getting to YES: Negotiating Agreement Without Giving In (London: Random House Business Books, 2nd edn).

Fiss, O. M. (1984) 'Against Settlement' 93 Yale Law Review 1073.

Folger, J. P. \& Baruch, B. A. (1996) 'Transformative Mediation and Third-Party Intervention: Ten Hallmarks of a Transformative Approach to Mediation' 13 Mediation Quarterly 236.

Froomkin, A. M. (2002) 'ICANN Uniform Dispute Resolution Policy, Causes and (Practical) Cures' 67 Brooklyn Law Review 690.

Gaitenby, A. (2004) 'Online Dispute Resolution' in The Internet Encyclopaedia (Wiley and Sons, Inc.).

Gaitenby, A. (2006) 'The Fourth Party Rises: Evolving Environments of Online Dispute Resolution' 38 University of Toledo Law Review 372.

García Álvaro, J. A. (2003) 'Online Dispute Resolution Uncharted Territory’ 7 The Vindobona Journal of International Commercial Law and Arbitration 175.

Gawith, D. (2006) 'Non Litigation-Based Redress for International Consumer Transactions Is Not Cost Effective - A Case for Reform?' 3 Macquarie Journal of Business and Law 115.

Gawith, D. (2007) 'Litigation for International Online Consumer Transactions Is Not Cost Effective - A Case for Reform?' 14(1) eLaw Journal 196.

Geist, M. (2002) 'Fair.com? An Examination of the Allegations of Systematic Unfairness in the ICANN UDRP' 27 Brooklyn Journal of International Law 903.

Gellman, R. (2000) 'Online Privacy Dispute Resolution: BBBOnline' 7 Privacy Law and Policy Reporter 145.

Genn, H. (2002) Court Based ADR Initiatives for Non Family Civil Disputes: The Commercial Court and the Court of Appeal (London: Lord Chancellor's Department).

Genn, H., Fenn, P., Mason, M. et al. (2007) 'Twisting Arms: Courts Referred and Court Linked Mediation under Judicial Pressure' Ministry of Justice Research Series 1/07 (May 2007).

Genn, H. (2010) Hamlyn Lectures 2008: Judging Civil Justice (Cambridge: Cambridge University Press).

German, P. (2006) 'Electronic litigation systems - a comparison of security issues 
between web-based litigation and traditional section based methods' 13(2) eLaw Journal Murdoch University 258.

Getz, C. (2007) 'Closing the Distance with Technology, Report on Phase I of the Technology-Assisted Family Mediation Project' British Columbia Mediator Roster Society (December 2007).

Gibbons, L. J. (2002) 'Creating a Market for Justice; a Market Incentive Solution to Regulating the Playing Field: Judicial Deference, Judicial Review, Due Process, and Fair Play in Online Consumer Arbitration' 23 Nortbwestern Journal of International Law and Business 1.

Gibbons, L. J. (2006) 'Online Dispute Resolution and the Need for More than Virtu(e)al Professionalism’ 38 University of Toledo Law Review 351.

Gibbons, L. J., Kennedy, R. \& Gibbs, J. M. (2002) 'Cyber-Mediation: ComputerMediated Communications Medium Massaging the Message' 27 New Mexico Law Review 27.

Gilles, L. (2006) 'Adapting International Private Law Rules for Electronic Consumer Contracts' in Rickett, C. E. F. \& Telfer, T. G. W. (eds) International Perspectives on Consumers' Access to Justice (New York: Cambridge University Press).

Gillieron, P. (2008) 'From Face-to-Face to Screen-to-Screen: Real Hope or Fallacy?' 23(2) Obio State Journal on Dispute Resolution 301.

Girot, C. (2001) User Protection in IT Contracts: A Comparative Study of the Protection of the User Against Defective Performance in Information Technology (The Hague: Kluwer Law International).

Global Business Dialogue on e-commerce, New York Recommendations 2003.

Goodman, J. (2003) 'The Pros and Cons of Online Dispute Resolution: An Assessment of Cyber-Mediation Websites' 4 Duke Law and Technology Review.

Goldsmith, J. (1998) 'Against Cyber-Anarchy' 65 University of Chicago Law Review 1221.

González Granada, P. (2007) 'Protección Judicial y Extrajudicial de Consumidores y Usuarios en el Ámbito del Comercio Electrónico’ Diario LaLey (12 June 2007) 1. Government Response (UK) (2006) to the Constitutional Affairs Select Committee's Report 'The Courts: Small Claims' (February 2006).

Gralf-Peter, C. (2003) 'Online Dispute Resolution: Consumer Redress in a Global Market Place’ 7 German Law Journal 651.

Graves, J. M. (2005) 'Party Autonomy in Choice of Commercial Law: The Failure of Revised U.C.C. 1-301 and a Proposal for Broader Reform' 36 Seton Hall Law Review 59.

Green Paper of the Commission of 16 November 1993 on Access of Consumers to Justice and the Settlement of Consumer Disputes in the Single Market (COM(1993) 576 final).

Green Paper of the Commission of 9 February 2000 on Legal Aid in Civil Matters: The Problems Confronting the Cross-Border Litigant (COM(2000) 51 final).

Green Paper of the Commission of 19 April 2002 on Alternative Dispute Resolution in Civil and Commercial Law (COM(2002) 196 final).

Green Paper on Alternative Dispute Resolution in Civil and Commercial Law, Summary of responses JAI/19/03 (31 January 2003).

Green Paper of the Commission of 20 December 2002 on the European Order for Payment Procedure and the Measures to Simplify and Speed up Small Claims Litigation (COM(2002) 746 final). 
Green Paper of the Commission of 8 February 2007 on the Review of the Consumer Acquis (COM(2006) 744 final).

Green Paper of the Commission of 27 November 2008 on Consumer Collective Redress (COM(2008) 794 final).

Haloush, H. (2007) 'Enforcement, Recognition, and Compliance with OADR Outcome(s)' 21 International Review of Law Computers and Technology 82.

Hamilton, J. W. (2006) 'Pre-Dispute Consumer Arbitration Clauses: Denying Access to Justice?' 51 McGill Law Journal 693.

Hampton, P. (2005) 'Reducing Administrative Burdens: Effective Inspection and Enforcement' (UK Treasury).

Hanycz, C. M. (2008) 'More Access to Less Justice: Efficiency, Proportionality and Costs in Canadian Civil Justice Reform’ 27(1) Civil Justice Quarterly 99.

Hartwig, H. (2005) 'Online Auctioning between Trade Mark and Consumer Protection' 27(9) European Intellectual Property Review 319.

Hawkins, E. (2006) 'General Jurisdiction and Internet Contacts: What Role, If Any, Should the Zippo Sliding Scale Test Play in the Analysis?' 74 Fordham Law Review 2371.

Hedley, S. (2006) The Law of E-Commerce and the Internet in the UK and Ireland (London: Cavendish).

Henderson, D. (2008) 'Unsettling Questions, Refusing to Mediate Can Be a Dangerous and Expensive Option' New Law Journal (6 June 2008) 810.

Hernández Fernández, A. (2003) 'Una Experiencia Paradigmática: El Arbitraje de Consumo On Line en el Marco del Sistema Español de Protección de los Consumidores' 2 Universidad de Valencia Revista de Derecho.

Heuvel, E. (2000) 'Online Dispute Resolution as a Solution to Cross-Border E-Disputes: An Introduction to ODR' available at http://www.oecd.org/dataoecd/ 63/57/1878940.pdf.

Hill, R. (1999) 'Online Arbitration: Issues and Solutions' 15(2) Arbitration International 199.

Hill, J. (2008) Cross-Border Consumer Contracts (Oxford: Oxford University Press).

Hörnle, J. (2002) 'Online Dispute Resolution in Business to Consumer E-Commerce Transactions' 7(2) Journal of Information, Law and Technology.

Hörnle, J. (2003a) 'Online Dispute Resolution: Emperor's New Clothes? 17(1) International Review of Law, Computers E Technology 27.

Hörnle, J. (2003b) ‘Alternative Dispute Resolution in the European Union' 5 Electronic Business Law 6.

Hörnle, J. (2004) 'Legal Briefing Paper: Online Dispute Resolution' JISC Legal Information 1.

Hörnle, J. (2007) 'Forcing Consumers to Stay Outside the Courtroom? Legal Controls on the Use of Arbitration Clause in the B2C e-Commerce Contracts' 5th ODR Forum, Liverpool (19 April 2007).

Hörnle, J. (2009) Cross-Border Internet Dispute Resolution (Cambridge: Cambridge University Press).

House of Lords (2005-06) 'European Union Committee: European Small Claims Procedure' (23rd Report of Sessions 2005-06) available at http://www.oecd.org/ document/51/0,2340,en_2649_201185_1824435_1_1_1_1,00.html.

Howells, G. \& Norhausen, A. (2004) 'Information Obligations in EC E-Commerce Law' in Nielsen, R., Sandfeld Jakobsen, S. \& Trzaskowski, J. (eds) EU Electronic Commerce Law (Copenhagen: Djøf Publishing). 
Huguet Tous, L. (2007) 'Pistoletazo de Salida para la Presentación Telemática de Escritos en los Órganos Judiciales' Administración y Nuevas Tecnologías, Diario LaLey (17 July 2007).

Hunt, G. (2006) 'Consumer ADR in the UK' Conference on Consumer ADR in Spain and the EU, Madrid (11-12 December 2006).

Hutchinson, B. (2006) 'ODR and the Future of ADR: Lessons Learnt from ECODIR', Conference on Consumer ADR in Spain and the EU, Madrid (11-12 December 2006).

Instituto Nacional de Consumo (2005) 'Memoria del Sistema Arbitral de Consumo' (April 2005).

International Chamber of Commerce (2002) 'Business-to-Consumer and Consumerto-Consumer Alternative Dispute Resolution (ADR) Inventory Project'.

International Chamber of Commerce (2003) 'Best practices for Online Dispute Resolution in B2C and C2C Transactions' (November 2003).

Internet Corporation for Assigned Names and Numbers (ICANN) Uniform Domain Names Policy (UDRP) 1999.

Iriarte Ahon, E. (2005) 'Regulación para Mundos Digitales: El Mundo Comunitario' 2(1) SCRIPT-ed A Journal of Law, Technology and Society 117.

Jackson, LJ (2009) Review of Civil Litigation Costs (8 May 2009).

Jackson, LJ (2009) Review of Civil Litigation Costs: Final Report (21 December 2009).

Jacobs, E. (2006) 'Mediation as Alternative Dispute Resolution in the European ICT-Sector' 11(2) Journal of Internet Banking and Commerce.

Jacobs, P. (2007) 'Mediation now and then, Michael P. Barbee' Newsletter Mediation, International Bar Association Legal Practice Division (July 2007).

Johnson, D. \& Post, D. (1996) 'Law and Borders: The Rise of Law in Cyberspace' 48 Stanford Law Review 1395.

Katsh, E. (2002) 'Online Dispute Resolution: The Next Phase' 7(2) Lex Electronica available at http://www.lex-electronica.org/articles/v7-2/katsh.htm.

Katsh, E. (2004) 'Bringing Online Dispute Resolution to Virtual Worlds: Creating Processes through Code' 49 New York Law School Law Review 271.

Katsh, E. (2007) 'Online Dispute Resolution: Some Implications for the Emergence of Law in Cyberspace' 21 International Review of Law Computers and Technology 97.

Katsh, E. \& Rifkin, J. (2001) Online Dispute Resolution: Resolving Conflicts in Cyberspace (San Francisco: Jossey-Bass).

Katsh, E. \& Wing, L. (2006) 'Ten Years of Online Dispute Resolution (ODR): Looking at the Past and Constructing the Future' 38 University of Toledo Law Review 26.

Katz, L. (1998) 'Enforcing an ADR Clause - Are Good Intentions All You Have' 26 American Business Law Journal 575.

Kaufmann-Kohler, G. \& Schultz, T. (2004) Online Dispute Resolution: Challenges for Contemporary Justice (The Hague: Kluwer Law International).

Keet, M. \& Salomone, T. B. (2001) 'From Litigation to Mediation: Using Advocacy Skills for Success in Mandatory or Court Connected Mediation' 64 Saskatchewan Law Review 57.

Kesan, J. (2003) 'Private Internet Governance' 35 Loyola University of Chicago Law Journal 87.

Kesan, J. \& Gallo, A. (2005) 'The Market for Private Dispute Resolution Services An Empirical Re-assessment of ICANN-UDRP Performance' 11 Michigan Telecommunications Technology Law Review 304. 
Kidd, D. L. \& Daughtrey, W. H. (2000) 'Adapting Contract Law to Accommodate Electronic Contracts: Overview and Suggestions' 26 Rutgers Computer and Technology Law Journal 215.

Kierkegaard, S. (2004) 'Online Alternative Dispute Resolution, Information Obligations in EC E-Commerce Law' in Nielsen, R., Sandfeld Jakobsen, S. \& Trzaskowski, J. (eds) EU Electronic Commerce Law (Copenhagen: Djøf Publishing).

King, I. (2004) 'Internationalising Internet Governance: Does ICANN Have a Role to Play?' 13(3) Information and Communications Technology Law 243.

Kirmayer, K. \& Wessel, J. (2007) 'An Offer One Can't Refuse: Mediate’ National Law Journal (18 October 2007).

Knudsen, P. F. (2006) 'The Danish ADR System' paper presented at the Conference on ADR in Spain and the EU, Madrid (11-12 December 2006).

Krajewska, A. (2007) 'Mediation in Poland: The Prospects' Law and Society Conference' Berlin (July 2007).

Kramer, X. (2006) 'Harmonisation of Procedures in Europe: The Proposal for a European Small Claims Procedure' 3-4 International Lis 109 available at SSRN website http://ssrn.com/abstract $=988539$.

Krause, J. (2007) 'Settling it on the Web. New Technology, Lower Costs Enable Growth of Online Dispute Resolution' American Bar Association Journal (October 2007).

Krause, W. (2001) 'An Overview of Online Alternative Dispute Resolution' 19(3) John Marshall Journal of Computer and Information Law 456.

Kubota, T. (2008) Cyberlaw for Global E-Business: Finance, Payment, and Dispute Resolution (New York: Information Science Reference).

Kuneva, M. (2007a) 'Commissioner for Consumer Protection, Consumer Strategy 2007-2013’ Brussels Press Conference (13 March 2007).

Kuneva, M. (2007b) Commissioner for Consumer Protection, Digital World Conference: 'Challenges and Opportunities in a Digitalised World' Berlin (15 March 2007).

Lande, J. (2002) 'Using Dispute System Design Methods to Promote Good-Faith Participation in Court-Connected Mediation Programs' 50 University College Los Angeles Law Review 69.

Larson, D. A. (2003) 'Online Dispute Resolution: Do You Know Where Your Children Are' 19 Negotiation Journal 199.

Larson, D. A. (2004) 'Online Dispute Resolution: Technology Takes a Place at the Table' 20(1) Negotiation Journal 131.

Larson, D. A. (2006) 'Technology Mediated Dispute Resolution (TMDR): A New Paradigm for ADR' 21(3) Obio State Journal on Dispute Resolution 629.

Law Gazette IT News (2007) 'Video Conferencing at Work' available at http:// www.lawgazette.co.uk/news/itnews.

Law Reform Commission (Ireland) (2008) Consultation Paper on Alternative Dispute Resolution (July 2008).

Lázsló Szöke, G. (2006) 'The Possibility of Online Mediation under the Hungarian Mediation Act in Comparison with a Number of International, Including European, Documents on Mediation' 15(2) Information and Communications Technology Law 129.

Leiss, M. E. \& Donohue, W. A. (2007) 'Removing Barriers to Conflict Resolution' paper presented to the Law and Society Conference, Berlin (July 2007).

Lester, T.P. (2003) 'Globalize Automatic Choice of Forum: Where Do Internet 
Consumers Sue?: Proposed Article 7 of the Hague Convention on International Jurisdiction and Foreign Judgments in Civil and Commercial Matters and its Possible Effects on e-Commerce' 9 New England Journal of International and Comparative Law 469.

Ley 26/1984 Consumer Protection Act.

Ley Organica 6/1985 of 1 July of the Judiciary.

Ley 26/1988 of 5 December of Arbitration.

Ley 38/1988 of 28 December of the Judicial Structure.

Ley 7/1998 of 13 April of General Conditions and Clauses for Consumer Contracts.

Ley $1 / 2000$ of 7 January of Civil Procedural Rules.

Ley $1 / 2002$ of 22 March of the Right to Association.

Ley 34/2002 of 11 July of Information Society Services and Electronic Commerce.

Ley 60/2003 of 23 December of Arbitration.

Lightman, J. (2003) 'The Civil Justice System and Legal Profession: The Challenges Ahead' 22 Civil Justice Quarterly 235.

Lightman, J. (2007) 'Breaking Down the Barriers' Times Online (31 July 2007) available at http://business.timesonline.co.uk/tol/business/law/article2166092.

Lightman, J. (2007) 'Mediation: An Approximation to Justice' SJ Berwin LLP (28 June 2007).

Ling, Y. Y. (2006) 'Domain Name Dispute Resolution within the Asian Region' 38 University of Toledo Law Review 403.

Lodder, A. (2006) 'The Third Party and Beyond, An Analysis of the Different Parties, in particular The Fifth, Involved in Online Dispute Resolution' 15(1) Information and Communications Technology Law 143.

Lodder, A. R. \& Vreeswijk, G. A. W. (2004) 'Online Arbitration Services at a Turning Point' ICC International Court of Arbitration Bulletin 21.

Lodder, A. R. \& Zeleznikow J. (2005) 'Developing an Online Dispute Resolution Environment: Dialogue Tools and Negotiation Support Systems in a Three-Step Model' 10 Harvard Negotiation Law Review 299.

Lord Chancellor's Department (2004) Judicial Statistics (Annual Report 2004).

Lugano Convention on Jurisdiction and Enforcement of Judgments in Civil and Commercial Matters (16 September1988) [1988] OJ L312/9.

Macfarlane, J. (1995) 'Court-Based Mediation for Civil Cases: An Evaluation of the Ontario Court, General Division ADR Centre' Ministry of the Attorney General (November 1995).

Mackie, K. (2005) 'Cross-Border Resolutions' 37 CEDR Resolutions 3.

Mackie, K. (2009) 'The Cost Crisis - Mediation as a Solution? CEDR's Submission to the Jackson Inquiry into Legal Costs' (July 2009).

Maher, D. (2002) 'The UDRP: The Globalization of Trade mark Rights' 33 ICC International Review of Intellectual Property and Copyright.

Manson, S. (2008) 'Electronic and Digital Signatures' in Rennie, M. International Computer and Internet Contracts and Law (London: Thomson Sweet and Maxwell).

Marder, N. (2006) 'CyberJuries: A New Role as Online Mock Juries' 38 University of Toledo Law Review 239.

Marín López, M. J. (2006) 'Presente y Futuro del Arbitraje de Consumo: 43 Cuestiones Controvertidas' 90 Revista de Derecho Privado 3.

Marín López, M. J. (2007) 'Medios Alternativos de Solución de Controversias' 11 Anuario de la Facultad de Derecho de la Universidad Autónoma de Madrid 123. 
Marín López, M. J. (2008) 'La Nueva Regulación del Arbitraje de Consumo: el Real Decreto 231/2008 de 15 de Febrero' Diario La Ley (17 March 2008).

Martin, M. S. (2002) 'Keep it Online: the Hague Convention and the Need for Online Alternative Dispute Resolution in International Business-to-Consumer e-Commerce' 20 Boston University International Law Journal 125.

Matthews, J. M. (2005) 'Consumer Arbitration: Is it Working Now and Will it Work in the Future?' 79 The Florida Bar Journal 1.

McArdle, D. (2006) 'Small Claims Court Goes Online' (5 December 2006) available at http://www.electricnews.net/story/show/9854919.

McCorkle, S. (2005) 'The Murky World of Mediation Ethics: Neutrality, Impartiality, and Conflict of Interest in State Codes of Conduct' 23(2) Conflict Resolution Quarterly 166.

McEwen, C. A. \& Maiman, R. J. (1981) 'Small Claims Mediation in Maine: An Empirical Assessment' 33 Maine Law Review 237.

McGuire, D. (2000) 'California Passes Sweeping Anti-Cybersquatting Law Government Activity’ Newsbytes News Network (23 August 2000).

McLean, D. J. \& Wilson, S.-M. (2008) 'Putting the Horse before the Cart: Compelling Mediation in the Context of Med-Arb Agreements' available at http://works. bepress.com/sean_patrick_wilson/1.

Menkel-Meadow, C. J. (1985) 'For and Against Settlement: Uses and Abuses of the Mandatory Settlement Conference’ 33 University College Los Angeles Law Review 485.

Michaelson, J. \& Maples, J. (2005) 'Taking clients to ADR' 155 New Law Journal 725.

Miller-Moore, D. (2006) 'ODR at the AAA: Online Dispute Resolution in Practice' 38 University of Toledo Law Review 395.

Mommers, L. (2006) 'Virtualization of Dispute Resolution. Establishing Trust by Recycling Reputation' 15(2) Information and Communications Technology Law 175.

Morek, R. (2006) 'The Regulatory Framework for Online Dispute Resolution: A Critical View' 38 University of Toledo Law Review 163.

Motion, P. (2005) 'Article 17 ECD: Encouragement of Alternative Dispute Resolution. On-line Dispute Resolution: A View from Scotland' in The New Legal Framework for E-Commerce in Europe (Oregon, Oxford and Portland).

Mueller, M. (2000) 'Rough Justice: An Analysis of ICANN's Uniform Dispute Resolution Policy' Syracuse University Convergence Centre available at http:// dcc.syr.edu/miscarticles/roughjustice.pdf.

Mueller, M. (2002) 'A New Profile of Domain Name Trademark Disputes under ICANN's UDRP' Syracuse University School of Information Studies.

Muñoz, R. (2007) 'El Gobierno rastrea 4,000 ordenadores privados para frenar el fraude en Internet' (12 February 2007) available at http://www.elpais.com.

Nadja, A. (2006) 'Fall 2005 Dispute Resolution Institute Symposium: Mobile Mediation: How Technology is Driving the Globalization of ADR' 27 Hamline Journal of Public Law and Policy 243.

Nadler, J. (2001) 'Electronic Mediated Dispute Resolution and E-Commerce' 17 Negotiation Journal 333.

National Arbitration Forum UDRP Supplemental Rules 1999.

National Audit Office (1996) Handling Small Claims in County Courts HCP 271 (London: HMSO).

National Audit Office (2003) Community Legal Service: The Introduction of Contracting HC 89 (London: HMSO).

Naylor, D. \& Ritter, C. (2005) 'French Judgment Condemning AOL Illustrates EU 
Consumer Protection Issues Facing U.S. Business Operating in Europe' 1(3) New York University Journal of Law and Business 887.

Nenstiel, A. (2006) 'Online Dispute Resolution: A Canada-United States Initiative' 32 Canada-United States Law Journal 313.

O’Brian, Jr. W. E. (2003) 'The Hague Convention on Jurisdiction and Judgments: The Way Forward' 66 Modern Law Review 491.

Opinion of the European Economic and Social Committee on the Proposal for a Regulation of the European Parliament and of the Council establishing a European Small Claims Procedure (COM(2005) 87 final - 2005/0020 (COD)).

OECD Guidelines for Consumer Protection in the Context of Electronic Commerce (December 1999).

OECD Guidelines for Protecting Consumers from Fraudulent and Deceptive Commercial Practices across Borders (2003).

OECD Recommendation on Consumer Dispute Resolution and Redress (12 July 2007).

OECD Workshop on Consumer Dispute Resolution and Redress in the Global Marketplace (19-20 April 2005).

Organisation for Economic Co-operation and Development Report (2006a) 'Consumer Dispute Resolution and Redress in the Global Marketplace' (11 April 2006).

Organisation for Economic Co-operation and Development (2006b) 'Best Practices for Consumer Policy: Report on the Effectiveness of Enforcement Regimes' (20 December 2006) available at http://www.oecd.org/dataoecd/26/61/36456184.pdf.

Orozco Pardo, G. \& Pérez-Serrabona González, J. (2007) ‘Estudio Critico y Propuestas de Reforma del Arbitraje de Consumo’ 5 Aranzadi Civil 3.

Oskamp, A., Lodder, A. \& Apistola, M. (eds) (2004) IT Support of the Judiciary (The Hague: Information Technology and Law Series 4).

Panama or Inter-American Convention on International Commercial Arbitration 1975.

Partington, M. (2004) 'Alternative Dispute Resolution: Recent Developments, Future Challenges' 23 Civil Justice Quarterly 99.

Paterson, L. (2007) 'Mediation Innovation' 52(11) Journal of the Law Society of Scotland 27.

Patrikios, A. (2006) 'Resolution of Cross-Border e-Business Disputes by Arbitration Tribunals on the Basis of Transnational Substantive Rules of Law and e-Business Usages: The Emergence of the Lex Informatica' 38 University of Toledo Law Review 271.

Patrikios, A. (2008) 'The Role of Transnational Online Arbitration in Regulating Cross-Border e-Business - Part I' 24 Computer Law and Security Report 66.

Paysner, J. \& Seneviratne, M. (2005) 'The Management of Civil Cases: The Courts and the Post-Woolf Landscape' Department of Constitutional Affairs UK.

Pearlstein, A. (2007) 'The Justice Bazaar: Dispute Resolution Through Emergent Private Ordering as a Superior Alternative to Authoritarian Court Bureaucracy' 22 Obio State Journal on Dispute Resolution 739.

Perritt, H. H. (2000a) 'Dispute Resolution in Cyberspace: Demands for New Forms of ADR' 15 Obio St. J. On Dispute Resolution 688.

Perritt, H. H. (2000b) 'The Internet is Changing the Public International Legal System' 88 Kentucky Law Journal 885.

Phillips LCJ (2008a) 'Alternative Dispute Resolution: An English View-Point' speech by Lord Chief Justice in England and Wales, India (29 March 2008). 
Phillips LCJ (2008b) Review of the Administration of Justice in the Courts (London, Judiciary of England and Wales, 31 March 2008).

Plains, W. (2006) 'The American Arbitration Association and CyberSettle Join Forces' CyberSettle press release (September 2006).

Plapinger, E. \& Menkel-Meadow, C. (1999) 'ADR Ethics: Model Rules Would Clarify Lawyer Conduct When Serving as a Neutral' (Summer 1999) Dispute Resolution Magazine 20.

Poblet, M. \& Casanovas, P. (2007a) 'Emotions in ODR' 21 International Review of Law Computers and Technology 145.

Poblet, M. \& Casanovas, P. (2007b) 'Towards a Convergence of the e-Justice and ODR Research Domains' in Lodder, A. R., Rule C. \& Zeleznikow J. (eds) Proceedings of 4th International ODR Workshop (Palo Alto, California) (8 June 2007) 57.

Poggi, C. T. (2000) 'Electronic Commerce Legislation: An Analysis of European and American Approaches to Contract Formation' 41 Virginia Journal of International Law 224.

Ponte, L. M. (2001) 'Throwing Bad Money After Bad: Can Online Dispute Resolution (ODR) Really Deliver the Goods for the Unhappy Internet Shopper?' 3 Tulane Journal of Technology and Intellectual Property 55.

Ponte, L. M. (2002) 'Boosting consumer confidence in e-business: recommendations for establishing fair and effective dispute resolution programs for B2C online transactions' 12 Albany Law Journal Science and Technology 441.

Ponte, L. M. \& Cavenagh T. D. (2005) Cyberjustice, Online Dispute Resolution for E-Commerce (New Jersey: Parson Prentice Hall).

Post, D. G. (2000) 'Juries and the New Common Law of Cyberspace' (September 2000) available at http://www.temple.edu/lawschool/dpost/Juries.html.

Preliminary Draft Convention on Jurisdiction and Foreign Judgments in Civil and Commercial Matters (Hague Convention) October 1999 and 2001.

Prince, S. (2007a) 'Mandatory Mediation: The Ontario Experience' 26(1) Civil Justice Quarterly 79.

Prince, S. (2007b) Institutionalising Mediation? An Evaluation of the Exeter Court Claims Mediation Pilot 5 Web Journal of Current Legal Issues.

Prince, S. \& Belcher, S. (2006) 'Small Claims Dispute Resolution Pilot Project at Exeter County Court' The UK Department of Constitutional Affairs, Research Series (September 2006).

Proposal for a Regulation on Consumer Protection Cooperation (COM(2003) 443 final).

Proposal for a Directive of the Parliament and of the Council on Certain Aspects of Mediation in Civil and Commercial Matters (COM(2004) 718 final).

Proposal for a Regulation of the European Parliament and of the Council establishing a European Small Claims Procedure (COM(2005) 87 final).

Proposal for a Regulation of the European Parliament and the Council on the Applicable Law to Contractual Obligations (Rome I) (COM(2005) 650 final).

Proposal for a Directive of the European Parliament and of the Council on Consumer Rights (COM(2008) 614 final).

Protopsaltou, D., Schultz, T. \& Magnenat-Thalmann, N. (2006) 'Taking the Fourth Party Further? Considering a Shared Virtual Workspace for Arbitration' 15(2) Information and Communications Technology Law 158.

Public Citizen (2002) 'The Cost of Arbitration' (May 2002) available at http:// www.citizen.org. 
Public Citizen (2007) 'The Arbitration Trap: How Credit Card Companies Ensnare Consumers' (September 2007) available at http://www.citizen.org.

Pupolizio, I. (2007) 'The Ideologies of Mediation between Theory and Practice' International Conference Law and Society in the 21st Century' Humboldt University, Berlin, Germany (25-28 July 2007).

Rabinovich-Einy, O. (2002) 'Going Public: Diminishing Privacy in Dispute Resolution' 7 Virginia Journal of Law and Technology 2.

Rabinovich-Einy, O. (2004) 'Balancing the Scales: The Ford-Firestone Case, the Internet, and the Future Dispute Resolution Landscape' 6 Yale Journal of Law and Technology 1.

Rabinovich-Einy, O. (2006) 'Technology's Impact: The Quest for a New Paradigm for Accountability in Mediation' 11 Harvard Negotiation Law Review 253.

Raghu, A. (2006) 'The Legal Challenges Facing Online Dispute Resolution: An Overview' Galexia Consulting.

Raines, S. S. (2005) 'Can Online Mediation Be Transformative? Tales from the Front' 22(4) Conflict Resolution Quarterly 437.

Raines, S. S. (2006) 'Mediating in Your Pajamas: The Benefits and Challenges for ODR Practitioners' 23(3) Conflict Resolution Quarterly 359.

Raines, S. S. \& Conley Tyler, M. (2006) 'From e-Bay to Eternity: Advances in Online Dispute Resolution' University of Melbourne Legal Studies Research Paper No 200 (5 April 2006).

Ramasastry, A. (2004) 'Technology, values, and the justice system: Government-tocitizen online dispute resolution: a preliminary inquiry' 79 Washington Law Review 164.

Ramsay, I. (2006) 'Consumer Redress and Access to Justice' in Rickett, C. E. F. \& Telfer, T. G. W. (eds) International Perspectives on Consumers' Access to Justice (New York: Cambridge University Press).

Real Decreto (Royal Decree, RD) 636/1993 of 3 May 1993 of the Consumer Arbitration System.

RD 231/2008 of 15 February of the Consumer Arbitration System.

Recommendation 98/257/CE of the Commission on the Principles Applicable to the Bodies Responsible for Out-of-Court Settlement of Consumer Disputes [1998] OJ L115.

Recommendation 2001/310/EC of 4 April 2001 on Principles of for Out-of-Court Bodies Involved in Consensual Resolution of Consumer Disputes [2001] OJ L109/56.

Recommendation of the Commission of 7 December 2001 on Principles for Using 'SOLVIT' - the Internal Market Problem Solving Network [2001] OJ L331.

Regulation 44/2001 of 22 December on Jurisdiction and the Recognition and Enforcement of Judgments in Civil and Commercial Matters [2000] OJ L12.

Regulation 733/2002 on the Implementation of the Internet Top Level Domain '.eu' [2002] OJ L113/1.

Regulation 874/2004 of the Commission Laying Down Public Policy Rules Concerning the Implementation and Functions of the Top Level Domain '.eu' and the Principles Governing Registration [2004] OJ L162.

Regulation 805/2004 of the Parliament and Council of 21 April 2004 creating a European Enforcement Order for Uncontested Claims [2004] OJ L143/15.

Regulation 861/2007/EC of the European Parliament and of the Council of 11 July 2007 establishing a European Small Claims Procedure [2007] OJ L199/1. 
Regulation 593/2008 of the Parliament and the Council of 17 June 2008 on the Law Applicable to Contractual Obligations (Rome I) [2008] OJ L177.

Reid, V. (2007) 'Small Claims, Big Questions' (March 2007) Legal Action Practice and Procedure 11.

Reidenberg, J. (2005) 'Symposium: Current Debates in the Conflict of Laws: Choice of Law and Jurisdiction on the Internet: Technology and Internet Jurisdiction' 153 University of Pennsylvania Law Review 1954.

Reiling, D. (2006) 'Doing Justice with Information Technology' 15(2) Information and Communications Technology Law 189.

Resolution of the Parliament of 15 July 1994 on Encouraging Recourse to Arbitration to Settle Legal Disputes [1994] OJ C205/519.

Resolution of the Council on looking into the future of Information Communication Technologies [2005] OJ C62/1.

Restatement (Second) of Conflicts of Law.

Rifleman, J. (2005) 'Mandatory Mediation, Implications and Challenges' (October 2005) available at http://adrr.com/adr9/jeff.htm.

Roberts, S. \& Palmer, M. (2005) Dispute Processes, ADR and the Primary Forms of Decision-Making (Cambridge: Cambridge University Press, 2nd edn).

Rodrigo, S. (2007) 'Controversial Introduction of the Mediation Regime in Argentina' Newsletter Mediation, International Bar Association Legal Practice Division (July 2007).

Rome Convention on the Law Applicable to Contractual Obligations [1980] OJ L266.

Ross, G. (2004) 'Online Dispute Resolution and Business' 8 Vindobona Journal of International Commercial Law and Arbitration 2.

Rudolph Cole, S. (2006) 'Online Mediation: Where We Have Been, Where We Are Now, And Where We Should Be' 38 University of Toledo Law Review 193.

Rule, C. (2002) Online Dispute Resolution for Businesses. B2B, E-Commerce, Consumer, Employment, Insurance, and Other Commercial Conflicts (San Francisco: Jossey Bass).

Rule, C. (2007) 'ODR in the Financial Sector' 5th ODR Forum, Liverpool (19 April 2007).

Rules of the Superior Courts (Commercial Proceedings) SI 2 (2004).

Sander, F. (1976) 'Varieties of Dispute Processing' The Pound Conference 70 Federal Rules Decisions 111.

Sander, F. et al. (1996) 'Judicial (Mis)Use of ADR? A Debate' 27 University of Toledo Law Review 885.

Schiavetta, S. (2004) 'The Relationship Between e-ADR and Article 6 of the European Convention of Human Rights Pursuant to the Case Law of the European Court of Human Rights' 1 Journal of Information, Law and Technology.

Schultz, T. (2002) 'Online Arbitration: Binding or Non-Binding' ADR Online Montbly UMASS.

Schultz, T. (2003a) 'An Essay on the Role of Government for ODR, Theoretical Considerations about the Future of ODR' ADR Online Montbly UMASS.

Schultz, T. (2003b) 'Connecting Complaint Filing Processes to Online Resolution Systems' 10 Commercial Law Practitioner 307.

Schultz, T. (2004) 'Does Online Dispute Resolution Need Governmental Intervention? The Case for Architectures of Control and Trust' 6 North Carolina Journal of Law and Technology 71.

Schultz, T. (2005) 'eBay: Un Système Juridique en Formation? 22 Revue du Droit des Technologies et de l'Information 27. 
Schultz, T., Kaufmann-Kohler, G., Langer, D. \& Bonnet, V. (2001) 'Online Dispute Resolution: The State of the Art and the Issues' University of Geneva.

Schuwartz, J. L. (2006) 'Making the Consumer Watchdog's Bark as Strong as its Gripe: Complaint Sites and the Changing Dynamic of the Fair Use Defence' 16 Albany Law Journal of Science and Technology 59.

Shannon Martin, M. (2002) 'Keep It Online: The Hague Convention and the Need for Online Alternative Dispute Resolution in International Business-To-Consumer E-Commerce' 20 Boston University International Law Journal 125.

Shah, A. (2004) 'Using ADR to Resolve Online Disputes' 10 Richmond Journal of Law and Technology 25.

Siburian, P. (2007) 'WTO's Online Dispute Settlement: Enriching Understanding on Rules and Procedures Governing Settlement of Disputes' available at http://ssrn.com.

Silver, C. (1996) 'Models of Quality for Third-Parties in Alternative Dispute Resolution' 12 Obio State Journal of Dispute Resolution 37.

South, J. (2004) 'One Size does not Fit All' 35 CEDR Resolutions 5.

Spanish Constitution 1978.

Spindler, G. \& Borner, F. (eds) (2002) E-Commerce Law in Europe and the USA (Berlin: Springer).

St Oren, J. (2003) 'International Jurisdiction over Consumer Contracts in E-Europe' 52 International Comparative Law Quarterly 665.

Stempel, J. W. (1996) 'Reflections on Judicial ADR and the Multi-Door Courthouse at Twenty: Fait Accompli, Failed Overture, or Fledgling Adulthood?' 11 Obio State Journal on Dispute Resolution 297.

Sternlight, J. (1996) 'Panacea or Corporate Tool?: Debunking the Supreme Court's Preference for Binding Arbitration' 74 Washington University Law Quarterly 637.

Sternlight, J. (2006) 'Is Alternative Dispute Resolution Consistent With the Rule of Law' 56 DePaul Law Review 569.

Sternlight, J. (2007) 'In Defense of Mandatory Arbitration (If Imposed on the Company)' 8 Nevada Law Journal 82.

Sternlight, J. \& Jensen, E. (2004) 'Using Economic Arbitration to Eliminate Consumer Class Actions: Efficient Business Practice or Unconscionable Abuse?' 67 Law and Contemporary Problems 75.

Stewart, K. \& Matthews, J. (2002) 'Online Arbitration of Cross-Border, Business to Consumer Disputes’ 56 University of Miami Law Review 1119.

Stipanowich, T. (2007) 'The Arbitration Penumbra: Arbitration Law and the Rapidly Changing Landscape of Dispute Resolution' 8 Nevada Law Journal 427.

Summary of Responses to the Green Paper on Alternative Dispute Resolution in Civil and Commercial Law (31 January 2003).

Susskind, R. (2007) 'ODR in Context' 5th ODR Forum, Liverpool (20 April 2007). Swire, P. P. (2005) 'Current Debates in the Conflict of Laws: Choice of Law and Jurisdiction on the Internet: Elephants and Mice revisited: Law and Choice of Law on the Internet' 153 University of Pennsylvania Law Review 1987.

Syme, D. (2006) 'Keeping Pace: On-line Technology and ADR Services' 23(3) Conflict Resolution Quarterly 348.

Tadic-Colic, L. (2005) 'International Arbitration: On-line Mediation: Evolution and Perspectives' 12 Croatian Arbitration Yearbook 251.

Tamberlin, B. (2004) 'Online Dispute Resolution and the Courts' United Nations Third Annual Forum on Online Dispute Resolution, Melbourne (July 2004). 
Tang, Z. (2007) 'An effective dispute resolution system for electronic consumer contracts' 23 Computer Law and Security Report 42.

The Economist (2006) 'March of the Robolawyers' (11 March 2006) 9.

Thiessen, E. \& Zeleznikow, J. (2004) 'Technical Aspects of ODR: Challenges and Opportunities' in Conley Tyler, M., Katsh E. \& Choi D. (eds) Proceedings of the Third Annual Forum on Online Dispute Resolution International Conflict Resolution Centre, University of Melbourne in collaboration with the United Nations Economic and Social Commission for Asia and the Pacific available at http://www.odr.info/ unforum2004/thiessen_zeleznikow.htm.

Teitz, L. E. (2001) 'Providing Legal Services for the Middle Class in Cyberspace: The Promise and the Challenge of Online Dispute Resolution' 70 Fordham Law Review 985.

Thompson, S. (1964) 'The Authority of Law' 75(1) Ethics 16.

Thornburg, E. (2002) 'Fast, Cheap, and Out of Control: Lessons from ICANN Dispute Resolution Process' 7 Journal of Small and Emerging Businesses Law 191.

Thornburg, E. (2006) 'Privatisation and Power: Dispute Resolution for the Internet' in Rickett, C. E. F. \& Telfer, T. G. W. (eds) International Perspectives on Consumers' Access to Justice (New York: Cambridge University Press).

Tilman, V. (2008) 'An Analysis of ODR Models and Providers' V0.1-14 March 2008 CEN WS/Stand-ODR.

Times Online (2007) 'EU Open to Consumer Class Actions' (13 March 2007).

Treaty of Maastricht establishing the European Community (7 February 1992) 1 (C 191).

Treaty of Amsterdam Amending the Treaty on European Union, the Treaties Establishing the European Communities and Related Acts (2 October 1997) OJ (C 340).

Treaty of Lisbon amending the Treaty on European Union and the Treaty establishing the European Community (13 December 2007) [2007] OJ C306/01.

Trzaskowski, J. (2006) 'Which Trustmarks Schemes Exist Today? Key Findings from a Report on European E-Commerce Trustmark Schemes' ECC-Net Conference, Trustmarks in the EU, Denmark (10 November 2006).

UDRP Rules 1999.

UNCITRAL, Note by the Secretariat: 'Possible Future Work on Online Dispute Resolution in Cross-Border Electronic Transactions' (23 April 2010).

Unfair Contract Terms Act 1977.

Unfair Contract Terms Regulation SI 1995/27.

Uniform Commercial Code 1999.

Uniform Computer Information Transactions Act 1999.

Uniform Electronic Transaction Act 1999.

United Nations (1999) Guidelines for Consumer Protection available at http:// www.unctad.org/en/docs/poditcclpm21.en.pdf.

United Nations Conference on Trade and Development (2003) 'Online Dispute Resolution: E-Commerce and Beyond' in E-Commerce and Development Report.

United Nations Convention on Contracts for the International Sale of Goods (CISG) Vienna 1980.

United Nations Convention on the Use of Electronic Communications in International Contracts of 23 November 2005.

Velicogna, M. (2007) 'Judicial Systems and ICT, What Can Be Learnt from Europe' 3(1) Utrecht Law Review 129. 
Vogenauer, S. \& Weatherill, S. (2005) 'The European Community's Competence for a Comprehensive Harmonization of Contract Law - an Empirical Analysis' 30 European Law Review 827.

Vreeswijk, G. A. W. \& Lodder, A. R. (2006) 'GearBi: Towards an Online Arbitration Environment Based on the Design Principles Simplicity, Awareness, Orientation, and Timeliness' 13 Artificial Intelligence and Law Journal 297.

Wallace, A. (2004) 'Australia' in Oskamp, A., Lodder, A. \& Apistola, M. (eds) IT Support of the Judiciary (The Hague: Information Technology and Law Series 4).

Wang, F. (2006) 'Domain Names Management and Legal Protection’ 26 International Journal of Information Management 116.

Wahab, M. (2004a) 'Globalisation and ODR: Dynamics of Change in E-Commerce Dispute Settlement' 12 International Journal of Law and Information Technology 123.

Wahab, M. (2004b) 'The Global Information Society and Online Dispute Resolution: A New Dawn for Dispute Resolution' 21(2) Journal of International Arbitration.

Wahab, M. (2006) 'Dispute Resolution and Information Technology at Crossroads: The Leading Edge' Working Paper available at http://www.cyberweek.internetbar. org/fall2006/DisputeResolutionandInformationTechnology.pdf.

Ware, R. (2006) 'The Use of Jurisdictional Arbitrage to Support the Strategic Interest of the Firm' 38 University of Toledo Law Review 307.

Ware, S. J. (1996) 'Arbitration and Unconscionability after Doctor's Associates, Inc. v. Casarotto’ 31 Wake Forest Law Review 1001.

Webb, L. (2004) 'International BBB Ratings á la eBay: A Proposal for an Improved Online Better Business Bureau to Facilitate International Business Transactions' 35 California Western International Law Journal 127.

Webb, T. (2007) 'Recent Development, Electronic Case Management in New South Wales, Australia' 16(1) Information and Communications Technology Law 73.

Weiss, R. (2006) 'Some Economic Musings on Cybersettle' 38 University of Toledo Law Review 89.

Winn, J. \& Webber, M. (2006) 'The Impact of EU Unfair Contract Terms Law on U.S. Busisness-to-Consumer Internet Merchants' 62 The Business Lawyer 1.

Witt, N. di (2001) 'Online International Arbitration: Nine Issues Crucial to its Success' 12 American Review of International Arbitration 441.

White, R. A. (1999) The English Legal System in Action (Oxford: Oxford University Press, 3rd edn).

Wissler, R. L. (1995) 'Mediation and Adjudication in the Small Claims Court: The Effects of Processes and Case Characteristics' 29(2) Law and Society Review 323.

Wood, W. (2007) 'Mediation: the Next Ten Years - the Master's Lecture of the Worshipful Company of Arbitrators' 73(3) Arbitration 313.

Woolf LJ (1995) Access to Justice: Interim Report to the Lord Chancellor on the Civil Justice System in England and Wales (London, Lord Chancellor's Department).

Woolf LJ (1996) Access to Justice: Final Report to the Lord Chancellor on the Civil Justice System in England and Wales (London, Lord Chancellor's Department).

Woolf LJ (2001) 'Emerging Findings' available at http://www.dca.gov.uk/civil/ emerge/emerge.htm.

Woolf LJ (2002) 'Further Findings' available at http://www.dca.gov.uk/civil/reform/ ffreform.htm.

Working Document of the Commission on the Creation of a European Extra-Judicial Network (SEC(2000) 405). 


\section{References}

Working Document of the Commission, Consumer Confidence in E-Commerce: Lessons Learned From the E-Confidence Initiative (SEC(2004) 1390 final).

World Intellectual Property Organisation (2001) 'Report of the Second World Intellectual Property Organisation Internet Domain Name Process' (September 2001) available at http://www.wipo.int/amc/en/processes/process $2 /$ report/html/ report.html.

World Intellectual Property Organisation (2005) 'Overview of WIPO Panel Views on Selected UDRP Questions' (February 2005).

World Intellectual Property Organisation (2009) 'WIPO Marks 10th Anniversary of UDRP' press release PR/2009/613 (12 October 2009).

World Intellectual Property Organisation UDRP Supplementary Rules 1999.

Zaremba, J. (2003) 'International Electronic Transaction Contracts between U.S. and EU Companies and Customers' 18 Connecticut Journal of International Law 479.

Zhao, Y. (2005) Dispute Resolution in Electronic Commerce (The Netherlands: Koninklijke Brill NV).

Zissu, J. (2004) 'Cybersettle RapidFunds System to Provide Attorney/Claimant Settlement Funds in Less Than 72 Hours' CyberSettle press release (18 October 2004).

Zondag, B. \& Lodder, A. (2007) 'Constructing Computer Assisted Dispute Resolution Systems by Developing a Generic Language to Analyse Information Exchange in Conflict Discourse' 21 International Review of Law Computers and Technology 191.

Zuckerman, A. (2001) Civil Justice in Crisis - Comparative Perspectives of Civil Procedure (Great Britain: Oxford University Press).

Zylstra, A. (2001) 'Privacy: The Road from Voluntary Mediation to Mandatory Good Faith Requirements: A Road Best Left Untraveled' 17 Journal of American Academy of Matrimonial Lawyers 69. 


\section{Index}

access to justice 9-44, 85, 103, 105-6, 161-2, 169-73, 213-22

online dispute resolution 181-3, 199 accreditation of ODR 173, 194-5, 225 ADR, see alternative dispute resolution Adjudication 94-135, 150-2, 195, 198, 200-2

costs of 1-5, 22-4, 56, 102, 127, 166-8

European small claims procedure, see European Small Claims Procedure

impartiality and independence in 76 , 79-81, 156-7, 200

judges 17-22, 57, 100-2, 104, $170-3$

transparency $78,130,201-2$

agreements to arbitrate 107-12

binding nature 107-12

law of 31

post-dispute 106, 109, 199, 215

pre-dispute 31, 107-12

Proposal 200-2

Spain 112-14

alternative dispute resolution 2-3, 7, 34, 51-4, 187-91

adverse costs 166-72

costs 56-7, 75-7

arbitration 110-11

mediation 149, 151, 161-3

negotiation 148

see also arbitration; mediation; online dispute resolution

waiver of right to access to court 106-14

American Arbitration Association 62, $82,107,110,161$

arbitration costs 82,110

American Bar Association 75-6, 189
Task Force on E-Commerce and ADR 76

appointments 53

Domain Name ODR 113, 116, 118, 125-6, 156

appeals 103, 109, 114, 130, 155, 205, 207,214

arbitration awards 106, 109, 114

Uniform Domain Name Dispute

Resolution Procedure 130-3

applicable law 25-8

arbitration 94-135

agreements to arbitrate 107-12

binding nature 107-12

bringing parties to arbitration 77-9, 107-12

comparative approach 111

European Union law 107-9

law of 107-12

post-dispute 112-14

pre-dispute 107-12

United States law 109-11

appeal rights 22-3, 36-7, 106

for arbitration awards 106, 109 , 114,130

applicable law 25-8

choice of law 25-8

asynchronous communications 56, 67, $85,148,150,154$

auctions 25, 61, 77

awards 20, 68-9, 106, 111-12

New York Convention on the

Recognition and Enforcement of

Foreign Arbitral Awards 111-12

clauses 107-14, 161-3

consumer arbitration 107-14

legal controls 107-12

mediation 161-3

mandatory laws 107-14 
online arbitration 106-35, 200

review 112

transparency versus confidentiality 78-9

United Kingdom 107-9

United States 109-11

artificial intelligence 84, 223

Asian Domain Name Dispute

Resolution Centre 116

assisted negotiation 67-8, 85-6

Australia, e-court initiative 97-8

automated negotiation 64-6, 86, 216

blind bidding, see blind bidding processes

negotiation assistance, see assisted negotiation

avoidance of disputes 59-64

awards 68-9, 106-7

appeals 111-12

defaults awards (UDRP) 125-6

fairness 79-80

international convention 111-12

judicial review 103, 130, 214

res judicata 37

awareness $73-5,77,86,160,173,184$, 193-4, 216, 220

\section{bargaining 17}

power $4,11,25,27,31$,

Better Business Bureau 62-4, 75, 107, 158,193

bias ODR 13, 58, 76, 78, 80, 82, 118, 124-9, 150, 186, 201

see impartiality and independence

binding ODR 227

blind bidding processes $64-6,145$, 223

Bordone, R.C. 195

bringing the parties to ODR 77-9

compulsory statutory arbitration $112-14$

contractually mandated schemes $106-12$

\section{Canada 147}

ODR in 147

chargebacks and payment service providers $60,69-70$

choice of law 25-8

clearing houses $74-5,86,195-6$ implementation of standards 195-6 codes of conduct 63, 72, 80, 204, 230

European 155, 194, 197, 205 communications $57-8,67,81,83-5$, 145,154

compulsory ODR 132, 134, 162, 165, 194,223

confidentiality 78-9, 155-6, 159, 163, $165,192,202-3$

conflict of laws 24-34

choice of law 24-8

European Union law 24-6

United States law 26-8

forum selection 28-34

European Union law 28-30, 30

United States law 30-2

Hague Conference 33

Conley-Tyler, M. 56, 77, 194

consumers 9-20

definition 10-11

legal controls on the use of arbitration 106-12

European Union 107-9, 111-12

United States 109-12

protection 9-17

e-commerce 12-17

European Union law 9-17

United States law 14-16

harmonization 16-17

unfair contract terms 107-12

contracts,

arbitration clauses 107-12

dispute resolution clauses 9-17

mediation clauses 161-3

costs $75-7$

allocation between parties 127

alternative dispute resolution 75-7

cybersquatting 114-33

Czech Arbitration Court 116

damages $63,69,110-11,167$

decisions $82-3,163$

inconsistency of 130-1

UDRP 118-20

default awards $34,36,86,103,125-6$, 128,189

delays $106,128,131,162-3,168,169$, 198, 205, 219

directives 9-17

Mediation Directive 159-64

disclosure 15-16, 78

disputes 2-3, 42-4, 51-2

domain name 114-35

disputes, see Uniform Domain Name

Dispute Resolution Procedure

Donahey, M.S. 121-2, 131 
due process $79-82$

arbitration 107-12

codes of conduct $63,72,80,204$, 230

disclosure 15-16, 78, 230

EU law 72, 80, 155, 157, 194, 197, 204, 230

fair hearing right 198

adjudicative processes $96,101-2$, 114, 199, 217

impartiality and independence 118 , 124, 186, 203

legal representation 17-20, 81-2, 100-1, 202, 228

right of appeal 36-7, 103, 103-31, 198, 205, 207

see also standards for ODR

selection of third neutral parties 118 , 157-8

eBay 61, 66-7, 72, 148-9, 216

PayPal system 3, 54, 60, 80, 110

effectiveness 185

Electronic Consumer Dispute

Resolution (ECODIR) 73-4

emoticoms 83, 154

enforcement 35-42, 82-3, 163-4, 204-6

administrative and public 35-42

class actions $37-8$

consumer organizations 38-9, 110, 110-11, 163, 186

European law 40-1

government agencies 39-40

international law 41-2

judicial 35-40

domestic judgments 36-7

foreign judgments 35-6

English law 20-2, 165-74

European Commission Recommendation 98/257EC 74, 108-9, 189,

201-2

European Commission Recommendation 01/310/EC 74, 155, 159, 173, 202-3

European Consumer Centre ECC-Net 7, 60-4, 72-4, 195-7, 213, 225

European Convention of Human Rights 108, 161-2, 168-9, 182, 205

European Small Claims Procedure 98-106

alternative dispute resolution 104-5

costs 102

cross-border disputes 98 enforceability 103

genesis 98-9

judicial review 103

language 102

legal representation 100-1

scope 99

written process $101-2$

European Union 1-3, 9-17, 24-44, 98-106, 159-61

arbitration rules 107-12

ODR initiatives $72-5$

evaluative mediation 147

evidence 19, 29, 57, 118

facilitative mediation 80,47

fair hearing 198

standards for ODR 199

Uniform Domain Dispute Resolution

Procedure 127, 129

fairness 79-82, 156-7

feedback 61-2, 64, 66-8, 79, 232

Fisher, R. 153

forum selection 28-35

fourth party 85

funding $75-7$

public $75-6$

private 76-7

Geist, M. 124-7

Germany 165, 197

government 42-4

human rights 108, 161-2

arbitration 108

European Convention of Human

Rights 108, 169-70

Human Rights Act 1996, 169-70

mediation 169-70

iCourthouse 72

immunity 201, 203

arbitrators 201

mediators 203

impartiality 75-6, 79-80, 124, 201-3, 216, 228

arbitrators 79-80, 201

appointments 118

disclosure 76

payment and 'repeat players' 76

appearance $75-6$

in adjudication 201

institutions 118

mediators 79-80, 202

providers 118 
Uniform Domain Name Dispute

Resolution Procedure 118, 124-6 allocation of panelists 124-6 complainant win rates $124-6$ inconsistency of decisions 129-31 independence see impartiality inquisitorial procedure $81-132$

International Chamber of Commerce Arbitration Rules 110

international conventions 33, 68-9, $111-12,168,204$

Internet 1-2, 25-6, 32, 34, 51, 55, 150, 195

Internet Corporation for Assigned

Names and Numbers 114-33

independence and impartiality 124-6

lack of appeal 130-1

language used 126-7

Uniform Domain Name Dispute

Resolution Procedure 114-33

Internet Ombudsman 195-6

Irish law 18-20

Small Claims Procedure 18-20, 23, 95-6

judges $17-22$

Jurisdiction see forum selection applicable law see applicable law

Katsh, E. 55, 61, 76-7, 85, 122, 153, $174,186,223$

language,

Uniform Domain Name Dispute Resolution Procedure 126-7 law,

applicable, see applicable law lex informatica, 184-5 205

lex mercatoria, 184

mandatory, see mandatory law

national legislation 18-22, 95-8, 164-6

arbitration, Spain 107-12

England 164-72

European Union 9-17, 106-12

United States 9-17, 106-12

litigation, see applicable law and forum selection

mandatory laws 12-17, 24-35

arbitration 107-12

mediation 159-64

med-arb 71, 80, 165 mediation $67-8,144-74$

advantages of 56-9

appropriate cases for 151-2

clauses 161-3

computer mediated communications 153-4

directive 159-61

disadvantages of 149-51

enforcement 163-4

clauses 161-4

agreements and settlements 163-4

limitation periods 164

mediators 157

accountability 158

offline 145-6

online 145-6

SmartSettle 147-8

SquareTrade 148-9

procedural requirements $154-8$

confidentiality $155-6$

fairness 155-6

flexibility 155-6

impartiality $156-7$

legal certainty 155-6

protection of the weaker party 156-7

transparency 155-6

regulation of 159-74

England and Wales 166-72

national law 164-74

online mediation 165

trust in 152-3

mock juries 72

model for ODR 191-207, 225-33

Mueller, M. 124-7

National Arbitration Forum 110, 115, 118,124

national legislation, see Ireland, Spain, United Kingdom and United States

negotiation, see automated negotiation, assisted negotiation and blind bidding

netiquette 202

non-binding forms of ODR 64-8

ODR,

advantages of 56-7

automated negotiation 64-6, 86, 216 assisted negotiation 67-8

SquareTrade 66-8

blind bidding 64-6

CyberSettle 64-6 
avoidance of disputes 59-64

consumer claim form $72-3$

escrows 60

internal complaints 59-60

shop assistance 60-1

trustmarks 62-4

chargebacks 69-70

costs $75-7$

definition 52-4

disadvantages 57-9

enforcement 82-3

forms of 64-72

history of 54-6

independence and impartiality $80-1$, 156

model for 225-64

online arbitration 68-70, 106-35

online mediation 66-8, 144-74

online negotiation 64-6

small claims courts $70-1,95-6$, 103-4

recommendations 200-4

regulation 181-91

transformative power 85,147

access to justice $85,105-6,161-3$, 169-73, 213-22, 229

dealing with negative emotions 147

oral hearing 101-2

outcomes 82-3

publishing $82-3$

party autonomy 181

PayPal 60

Post, D. 116

post-dispute agreement 109, 134, 198, 214

power imbalances $11,24,52,75,77,79$, $86,128,147,155,173,187$

pre-dispute agreement $107-12,161-3$

privacy $155-9,229$

procedure, see small claims

proportionality 23, 100, 167

publishing 82-3, 119

quality, see trustmarks

recommendations, see European

Commission Recommendations

referral systems $86,165,169,172,193$, 194, 222

refunds by payment service providers, credit-card chargeback $60,69-70$

PayPal 60 regulation 181-207

ODR 181-91

self-regulation 184-7

'repeat player' effect 198, 228

res judicata 37

resolution disputes see alternative methods and due process,

Rifkin, J. 55, 61, 76-7, 112, 153

risk of self-regulation 184-6

Rule, C. 51-2, 56, 60, 62, 70, 76, 79, $80,84,105,153,188$

seals see trustmarks

self-regulation see lex mercantoria and lex informatica

limits 185-6

size of claims,

small claims disputes 17-24, 98-106

small claims track 20-2

small claims,

English law 20-2

Irish law 18-20

Spanish law 22

SmartSettle 147-8

Spanish law,

arbitration 112-14

small claims procedure 22

SquareTrade 66-8

standards for ODR 181-207

technology

fourth party 85

role of $83-5$

The Internet Ombudsman 195-6

third parties $80-1$

time limits 164

translation 102, 126-7

transparency 78-9, 155-9

trust $77-9,152-3$

TrustE 62-4

trustmarks 62-4

proposal for a pan-European initiative 64

\section{UNCITRAL 188}

unconscionable contracts $31,110-11$, 134

unfair contract terms 13, 162, 219

Uniform Domain Names Dispute

Resolution Procedure 114-33

appointment of the panel 118

claim,

response 118

submission 117 
260 Index

decisions 118-19

default cases 126

enforcement 119-20

grounds for the cancellation and the transfer of the claim $120-4$

independence and impartiality $124-6$

allocation of panelists $125-6$

complainant win rates 124-6

language used 126-7

legal advice 128-9

United Kingdom, arbitration 107-12 consumer protection 9-17 small claims $20-2$
United States, arbitration 109-11 consumer protection 14-16

Ury, W. 153

video-conferencing 57-8, 103, 151, 153

Virtual Magistrate 54

voluntary arbitration 112-14

waiver of right to go to court 107-12, 161-3

witnesses 75, 103

Woolf Report 20, 23

World Intellectual Property Organization see Uniform Domain Name Dispute Resolution Procedure 